JOÃO PAULO PAES DE BARROS BOYADJIAN

\title{
A IMPORTÂNCIA DA ABORDAGEM DE GESTÃO DE PROJETOS VISANDO A IMPLEMENTAÇÃO DE ESTRATÉGIAS ORGANIZACIONAIS
}


JOÃO PAULO PAES DE BARROS BOYADJIAN

\title{
A IMPORTÂNCIA DA ABORDAGEM DE GESTÃO DE PROJETOS VISANDO A IMPLEMENTAÇÃO DE ESTRATÉGIAS ORGANIZACIONAIS
}

\author{
Dissertação apresentada à Escola \\ Politécnica da Universidade de São Paulo \\ para obtenção do título de Mestre em \\ Engenharia.
}

São Paulo 
JOÃO PAULO PAES DE BARROS BOYADJIAN

\title{
A IMPORTÂNCIA DA ABORDAGEM DE GESTÃO DE PROJETOS VISANDO A IMPLEMENTAÇÃO DE ESTRATÉGIAS ORGANIZACIONAIS
}

\author{
Dissertação apresentada à Escola \\ Politécnica da Universidade de São Paulo \\ para obtenção do título de Mestre em \\ Engenharia.
}

Área de Concentração:

Gerenciamento de Projetos

Orientador:

Prof. Dr. Oscar Brito Augusto

São Paulo

2008 


\section{DEDICATÓRIA}

Dedico este trabalho a minha família, a minha noiva e aos amigos que deram apoio em todos os momentos. 


\section{AGRADECIMENTOS}

A minha família e a minha noiva, Priscila Cintra Mil, que sempre me deram suporte, atenção e incentivo na continuação da pesquisa e que também tiveram paciência nestes momentos difíceis. Ao meu pai, por ter me introduzido no tema e apoiado o mestrado.

Ao meu orientador e professor, Oscar Brito Augusto, que com seus conhecimentos, dedicação, empenho e auxílio, me fez crescer na minha vida acadêmica e fez tornar possível a realização desta dissertação.

Aos meus amigos que estiveram presentes nos momentos difíceis da elaboração deste trabalho.

Aos colegas de trabalho da Watson Wyatt, especialmente ao Carlos Henrique Siqueira, local onde pude aprender e desenvolver diversos conceitos de Recursos Humanos que deram suporte ao modelo de implementação de estratégias. Carlos foi uma pessoa que sempre colaborou comigo independente do momento, me fez crescer muito como pessoa e como profissional. Além disso, permitiu conciliar o trabalho com o mestrado.

Ao amigo Frederico Faccioli pelas contribuições para a dissertação.

Ao departamento de Engenharia Naval da Escola Politécnica da Universidade de São Paulo e às pessoas que a representam, as quais tornaram possível a realização desta tarefa e o desenvolvimento acadêmico.

Às universidades americanas Harvard e New York Univerisity (Stern) que permitiram a pesquisa bibliográfica em suas instalações para que esta dissertação resultasse em um trabalho mais completo e atualizado. 
Aos professores Antonio Cesar Amaru Maximiano e Bernardo Andrade que contribuíram durante a qualificação e deram sugestões úteis para o instrumento de pesquisa.

Às mais de trinta empresas que foram pesquisadas. Sem elas, este trabalho não teria validade prática. Agradeço também às pessoas que entrevistei pela contribuição, atenção e explicações dadas ao presente trabalho. 


\section{EPÍGRAFE}

"A capacidade definitiva de um homem não está nos momentos de conforto e conveniência, mas nos períodos de desafios e controvérsias".

Martin Luther King 


\section{RESUMO}

Esta dissertação tem por objetivo principal identificar a importância do gerenciamento de projetos para o processo de implementação de estratégias. De forma mais específica, a dissertação investiga o grau de associação entre as diversas técnicas e práticas de gerenciamento de projetos, bem como de gestão estratégica para o processo de implementação de estratégias. Este trabalho é decorrente de um estudo bibliográfico inicial, por meio do qual se buscou a ampliação do conhecimento sobre o tema, seguida de uma pesquisa de campo. A pesquisa teve o caráter quantitativo-descritivo, visou à descrição do conjunto de dados e a determinação das relações relevantes entre as variáveis de interesse. Para tanto, foram definidas as variáveis independentes, dependentes e intervenientes da pesquisa, como sendo, respectivamente, a satisfação e o percentual de estratégias implementadas; as técnicas de gerenciamento estratégico e de projetos; e os níveis de maturidade. Utilizou-se uma amostragem não probabilística, selecionando a amostra por conveniência e julgamento. A amostra da pesquisa foi composta por executivos da área de gerenciamento de projetos $\mathrm{e}$ planejamento estratégico das 1.000 maiores empresas do Brasil. Para a coleta de dados lançou-se mão de três questionários que também serviram de guia para a entrevista com os executivos. A maioria das entrevistas foi conduzida pessoalmente e algumas, pela distância, foram feitas pelo telefone. $O$ tratamento dos dados foi feito com o uso de métodos estatísticos: análise descritiva, análise de correlação e regressão linear múltipla. A partir dos resultados da pesquisa pôde-se concluir que: 1) a maturidade não é a variável interveniente entre gerenciamento de projetos e sucesso na implementação de estratégias; 2) somente duas áreas do conhecimento tiveram alta correlação com implementação (escopo e aquisições); 3) foram apresentadas evidências positivas entre uma série de técnicas, conceitos e práticas de gestão estratégica e de projetos, com o sucesso na implementação de estratégias; 4) as empresas que possuíam satisfação com a implementação igual ou acima de 8 ou que conseguiram implementar mais do que $60 \%$ das estratégias possuíam níveis maiores de maturidade geral, principalmente, nas áreas de aquisições, custo e escopo. Cabe ressaltar que todas essas conclusões devem ficar restritas ao âmbito desta dissertação. Para pesquisas futuras recomenda-se: 1) a 
utilização de uma amostra maior e mais diversificada, o que permitiria obter uma estatística ainda mais rica e a comparação entre os diversos setores da economia ou focar apenas dentro de um setor; 2) a segmentação das empresas por porte; 3) a intensificação de estudos em outras áreas importantes, como recursos humanos e comunicação; e, 4) a coleta e análise de opiniões de funcionários táticos e operacionais, comparando os resultados. Por fim, o atual cenário brasileiro favorece a realização de estudos nesta temática, atendendo às necessidades de pesquisadores que se interessam pelo assunto.

Palavras-chave: Estratégia organizacional (implementação). planejamento estratégico. administração de projetos (implementação), 


\section{ABSTRACT}

This thesis aims to identify the main importance of project management for the process of strategy implementation. More specifically, the dissertation investigates the degree of association between the various techniques and practices of project management and strategic management to the process of implementing strategies. This work is due to an initial study literature, through which it sought the expansion of knowledge on the subject, followed by a field research. The research had the character quantitative-descriptive with the objective to describe the data set and determine relations between the relevant variables of interest. In such a way, some independent, dependent and intervenient variables of the research were defined, as, respectively, satisfaction and the percentage of strategies implemented the project management and strategic management techniques ment and strategic projects and the maturity levels. There was a non-probability sampling, selecting the sample with convenience and judgement. The survey sample was composed of executives from the area of project management and strategic planning of the 1,000 largest companies in Brazil. For data collection three questionnaires were used that also served as a guide for the executive interviews. Most of the interviews were conducted personally and some were made by telephone, because of the distance. Data analysis was done with the use of statistical methods like: descriptive analysis, correlation and multiple linear regression analysis. From the research it's possible to conclude that: 1) the maturity is not the variable actor (intervenient) between project management and strategy implementation success, 2) only two knowledge areas had high correlation with implementation (scope and acquisitions); 3) the analysis showed that there are some positive evidence between the strategy implementation success and a variety of techniques, concepts and practice of strategic management and projects, 4) companies with strategy implementation satisfaction equal or above 8 or who managed to implement more than $60 \%$ of the strategies, had greater levels of maturity general, particularly in the procurement, cost and scope areas. It is important to emphasizing that all of these conclusions should be restricted to the scope of this dissertation. For future research it is recommended: 1) the use of a larger and more diverse sample may give a richer statistical comparison between industries or it's possible to focus in only one sector, 2) it's possible to compare the survey results by 
company's size, 3) intensify studies in other important areas such as human resources and communication, and 4) collect and analyse the tactic and operational opinions comparing the results with the executive perspective. Finally, the current Brazilian scenario favors studies in this area, attending the researcher's needs who are interested in this issue.

Keywords: Project management. Strategy implementation. Strategic planning. Strategy (implementation). 


\section{SUMÁRIO}

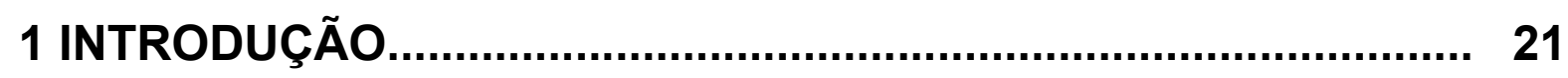

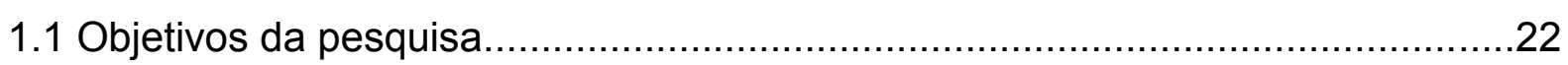

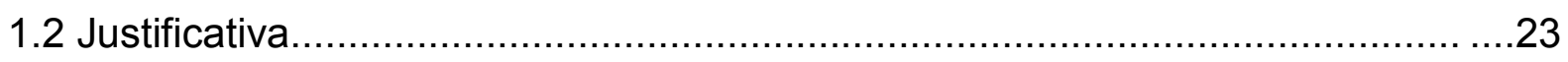

1.3 Aspectos metodológicos gerais da dissertação...........................................27

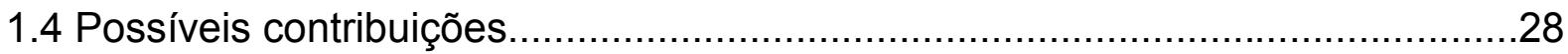

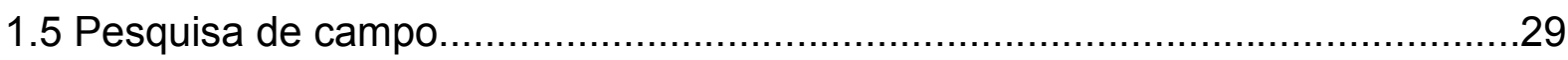

2 REVISÃO BIBLIOGRÁFICA - IMPLEMENTAÇÃO DE

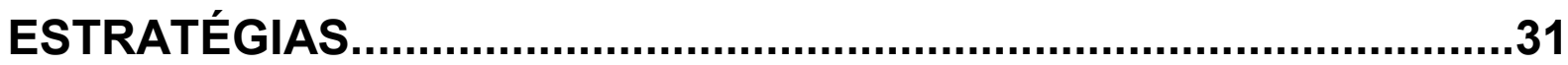

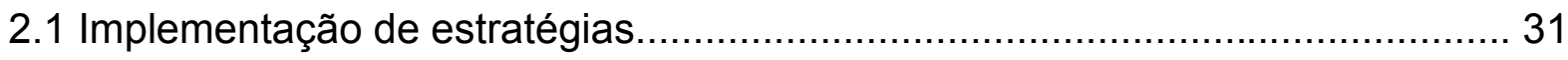

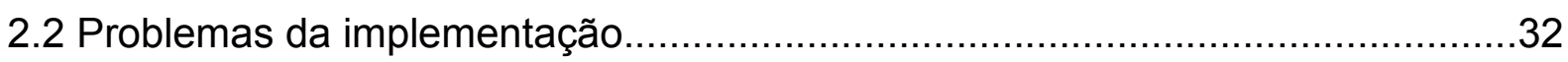

2.3 Implementação - soluções conceituais oferecidas pela literatura........................40

2.4 Considerações sobre implementação de estratégias....................................... 52

\section{REVISÃO BIBLIOGRÁFICA - GERENCIAMENTO DE PROJETOS COMO FERRAMENTA DE IMPLEMENTAÇÃO DE ESTRATÉGIAS...56}

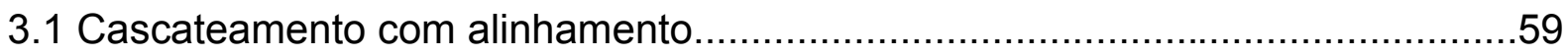

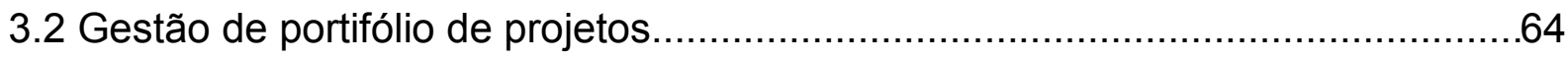

3.3 Utilização das técnicas e conceitos de gerenciamento de projetos (gestão

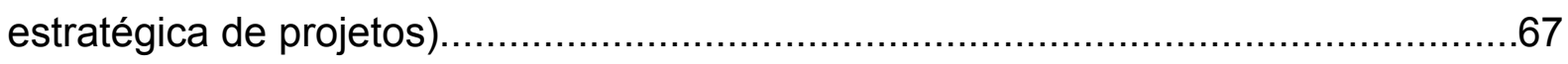

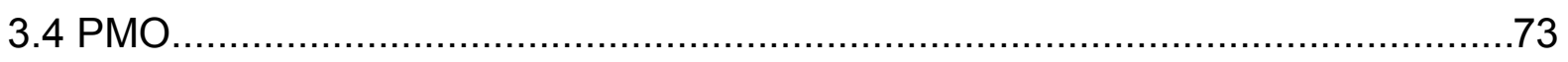

3.5 Maturidade em Gerenciamento de Projetos....................................................

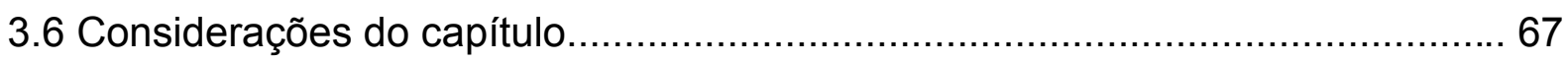

4 METODOLOGIA DE PESQUISA..................................................80

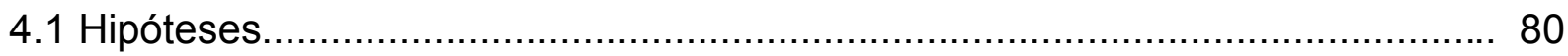

4.2 Metodologia e tipo de pesquisa ............................................................. 81

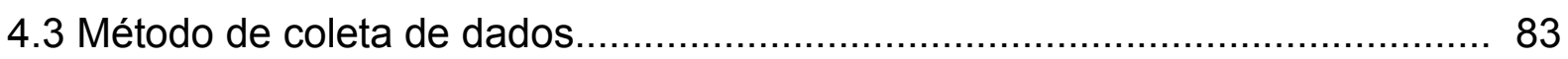

4.4 Ferramentas para análise de dados............................................................... 85

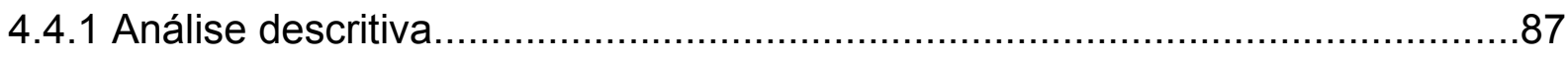




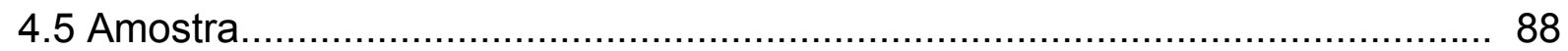

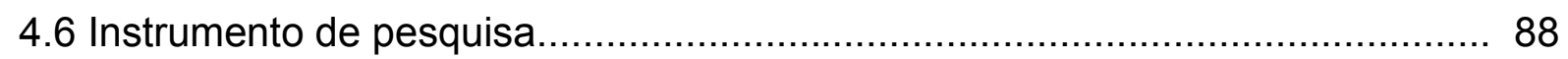

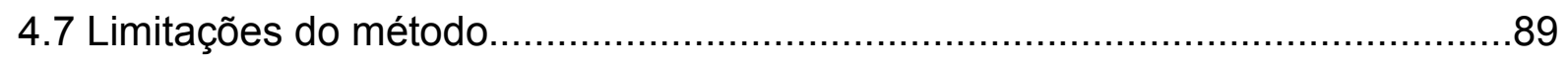

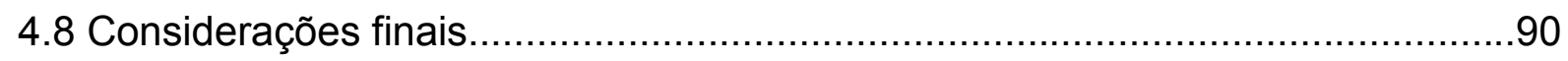

5 ANÁLISE E RESULTADOS..........................................................73

5.1 Análise descritiva dos dados da pesquisa............................................... 82

5.1.1 Análise descritiva dos respondentes e informações complementares..............92

5.1.2 Análise dos dados das entrevistas de estratégia.........................................94

5.1.3 Análise dos dados das entrevistas de gerenciamento de projetos.................122

5.1.4 Análise descritiva dos dados: cruzamento das entrevistas de gerenciamento de

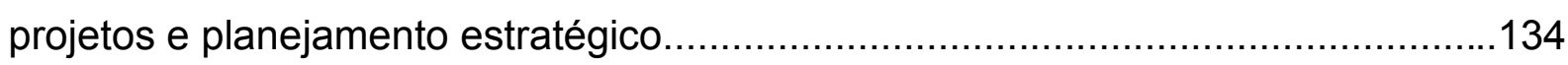

5.1.5 Análise descritiva dos dados: maturidade em gerenciamento de projetos.....148

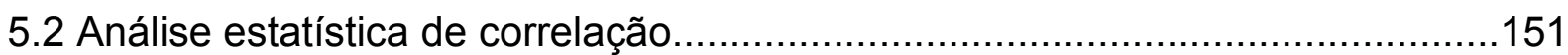

5.3 Análise estatística de regressão múltipla, ..................................................162

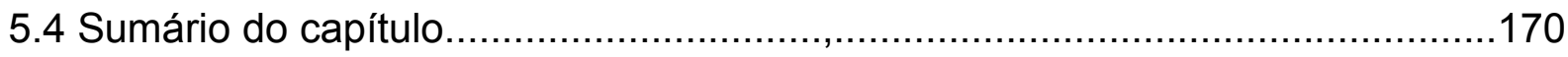

6. CONCLUSÕES......................................................................179

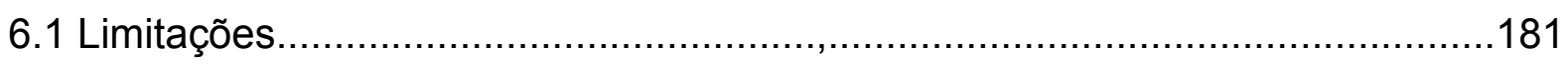

6.2 Sugestões para pesquisas futuras..........................................................182

7. REFERÊNCIAS........................................................................184 


\section{LISTA DE ILUSTRAÇÕES}

Figura 1 - Potencial de execução da empresa (MANKINS; STEELE, 2005)............ 35

Figura 2 - Matriz implementação x estratégia (BONOMA, 1985).............................36

Figura 3 - Desenho representativo do modelo de Galpin (1997)...........................47

Figura 4 - Modelo de execução de Hrebiniak (2005)..........................................52

Figura 5 - Estratégia, projetos, programas e portifólio de projetos...........................60

Figura 6 - Alinhamento da estratégia com objetivos do portifólio, programa e projetos

Figura 7 - As três etapas do cascateamento de Gaddie......................................61

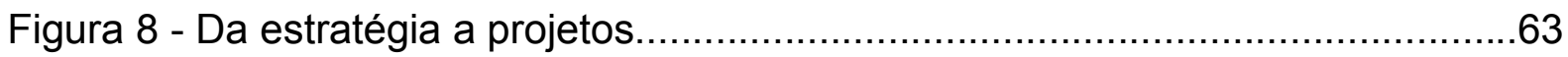

Figura 9 - Teoria de alinhamento do gerenciamento de projetos com o posicionamento competitivo da companhia / estratégia..........................................72

Figura 10 - Os cinco níveis de maturidade em gerenciamento de projetos...............78

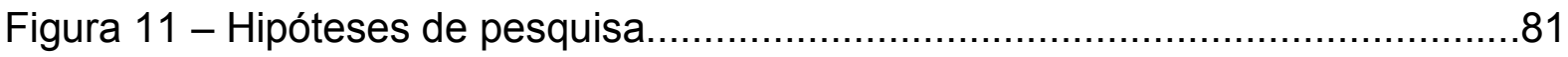

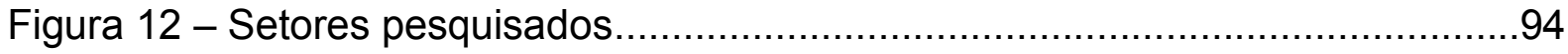

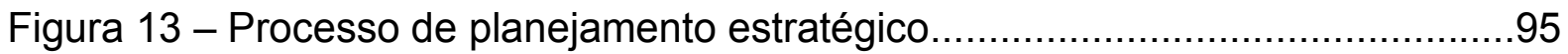

Figura 14 - Satisfação em relação à ferramenta de planejamento estratégico.........95

Figura 15 - Metodologia de implementação de estratégias....................................96

Figura 16 - Implementação da estratégia através de projetos................................96

Figura 17 - Compreensão da visão da empresa...................................................97

Figura 18 - Barreiras à implementação da visão..................................................

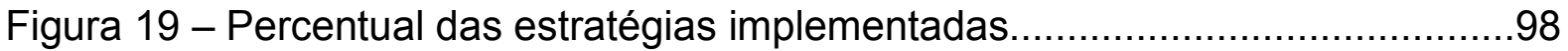

Figura 20 - Clareza das responsabilidades (executivos)....................................101

Figura 21 - Entendimento pelos funcionários de seus papéis e responsabilidades na

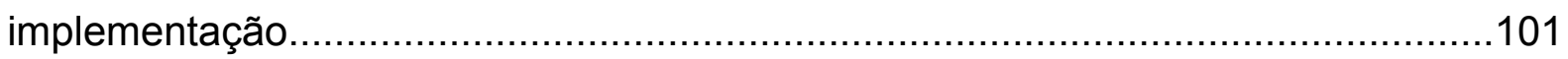

Figura 22 - Comprometimento dos funcionários com a estratégia.........................102

Figura 23 - Técnicas e conceitos utilizados na implementação..............................104

Figura 24 - Análise do contexto interno e externo.............................................105

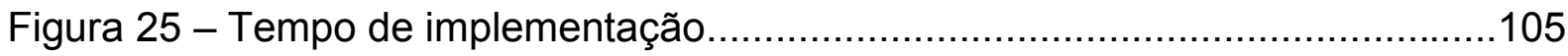

Figura 26 - Coordenação da implementação das estratégias................................106

Figura 27 - Freqüência de acompanhamento da implementação de estratégias...107 
Figura 28 - Satisfação com o processo de implementação de estratégias.............108

Figura 29 - Metodologia de Gerenciamento de Projetos.....................................123

Figura 30 - Metodologia atrelada às estratégias genéricas da organização..........124

Figura 31 - Divisão entre projetos e processos rotineiros................................124

Figura 32 - Planejamento estratégico implementado através de projetos...............125

Figura 33 - Freqüência de projetos considerados no planejamento estratégico.....126

Figura 34 - Organização dos projetos........................................................ 127

Figura 35 - Projetos entregues dentro do prazo, custo e qualidade .....................128

Figura 36 - Técnicas utilizadas de gerenciamento de projetos...........................129

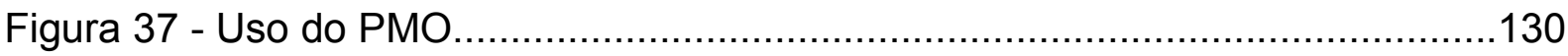

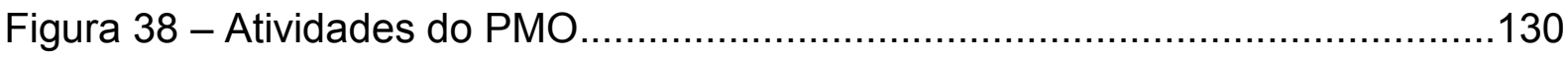

Figura 39 - Práticas, técnicas e conceitos utilizados de gerenciamento de projetos 133

Figura 40 - Práticas, técnicas e conceitos utilizados de gerenciamento de projetos (continuação) 


\section{LISTA DE TABELAS}

Tabela 1 - Falhas de implementação (HREBINIAK, 2005).......................................

Tabela 2 - As 3 classificações de estudos de implementação....................................53

Tabela 3 - Alinhamento dos fatores críticos de sucesso, indicadores, medidas e

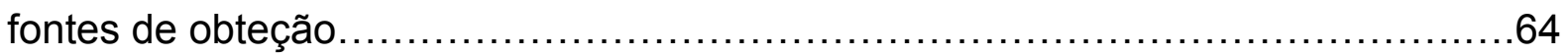

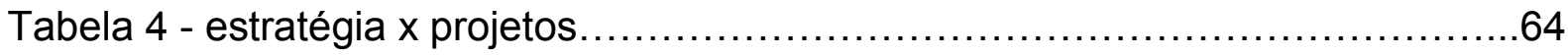

Tabela 5 - Elementos da gestão de projetos alinhados com o posicionamento

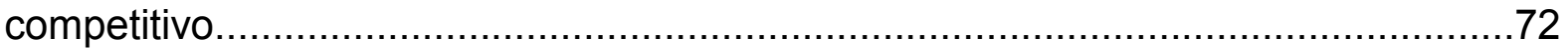

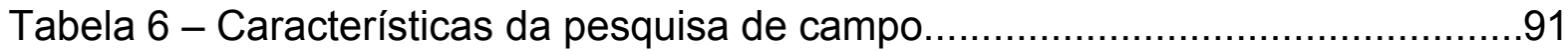

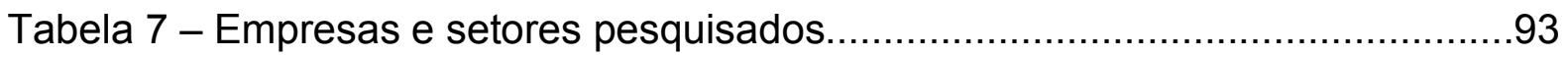

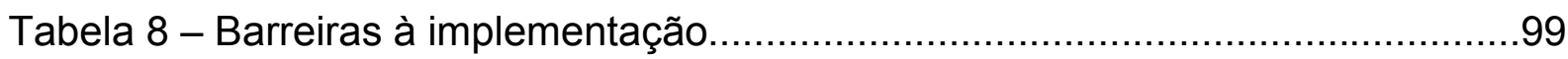

Tabela 8 - Coordenação eficaz x tempo de implementação..................................107

Tabela 9 - Utilização de metodologia de implementação de estratégia $x$ satisfação/sucesso com a implementação.......................................................108

Tabela 10 - Utilização de metodologia de implementação de estratégia x percentual

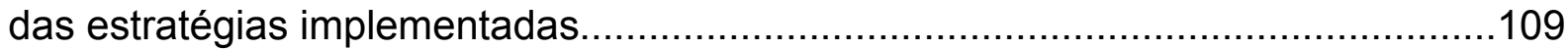

Tabela 11 - Compreensão da visão da empresa x satisfação com a implementação.

Tabela 12 - Compreensão da visão x percentual das estratégias implementadas.110 Tabela 13 - Percentual das estratégias implementadas x compreensão da visão da empresa

Tabela 14 - Percentual das estratégias implementadas x clareza do papel do executivo na implementação

Tabela 15 - Clareza do papel do executivo na implementação x percentual das estratégias implementadas.

Tabela 16 - Clareza do papel do executivo na implementação x satisfação com a implementação.

Tabela 17 - Satisfação com a implementação x clareza do papel do executivo na implementação.

Tabela 18 - Clareza do papel do executivo na implementação x percentual das estratégias implementadas. 
Tabela 19 - Comprometimento x satisfação com a implementação. 114

Tabela 20 - Comprometimento x percentual das estratégias implementadas. 114

Tabela 21 - Técnicas, conceitos e ferramentas do PE x percentual das estratégias implementadas.

Tabela 22 - Técnicas, conceitos e ferramentas do PE $\mathrm{x}$ satisfação com a implementação.

Tabela 23 - Organização da empresa (estrutura) x satisfação com a implementação.

Tabela 24 - Organização da empresa (estrutura) x percentual das estratégias implementadas.

Tabela 25 - Satisfação com a implementação x organização da empresa (estrutura).

Tabela 26 - Percentual das estratégias implementadas x organização da empresa (estrutura)

Tabela 27 - Organização da empresa (estrutura) x tempo de implementação.

Tabela 28 - Frequência de acompanhamento da implementação x percentual das estratégias implementadas.

Tabela 29 - Frequência de acompanhamento da implementação x satisfação com a implementação,

Tabela 30 - Percentual das estratégias im[plementadas x planejamento estratégico implementado através de projetos.

Tabela 30 - Planejamento estratégico implementado através de projetos $\mathrm{x}$ percentual das estratégias implementadas. 136

Tabela 31 - Organização e administração de portifólios, programas e projetos.....136 Tabela 32 - Projetos entregues dentro do prazo, custo e qualidade x percentual das estratégias implementadas.

Tabela 33 - Coordenação das atividades de implementação x satisfação com a implementação. 138

Tabela 34 - Coordenação das atividades de implementação x percentual das estratégias implementadas. 138

Tabela 35 - Conceitos e técnicas de projetos $\mathrm{x}$ percentual das estratégias implementadas.

Tabela 36 - Conceitos e técnicas de projetos x satisfação com a implementação.139 
Tabela 37 - Gerenciamento de projetos atrelados às estratégias genéricas $x$ percentual das estratégias implementadas

Tabela 38 - Gerenciamento de projetos atrelados às estratégias genéricas $\mathrm{x}$ satisfação com a implementação. 140

Tabela 39 - PMO x percentual das estratégias implementadas.

Tabela 40 - PMO x satisfação com a implementação

Tabela 41-Avaliação de gerenciamento de projetos $\mathrm{x}$ estratégias implementadas 143 Tabela 42 - Avaliação de gerenciamento de projetos $x$ sucesso na implementação.

Tabela 43 - Percentual das empresas por nível de maturidade e área do conhecimento.

Tabela 44 - Nível de maturidade por área do conhecimento e sucesso na

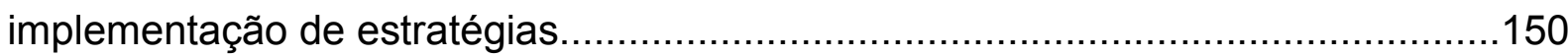

Tabela 45 - Correlação com o tempo de implementação. 151

Tabela 46 - Correlação com os projetos entregues dentro do prazo, custo e qualidade.

Tabela 47 - Correlação com as variáveis dependentes da pesquisa.

Tabela 48 - Correlação com as variáveis de comprometimento, papéis e responsabilidades.

Tabela 49 - Correlação com os conceitos, técnicas e práticas de gestão estratégica. 156

Tabela 50 - Correlação com estrutura, contexto, tempo de implementação, coordenação da implementação e freqüência de acompanhamento.

Tabela 51 - Correlação com os tipos de projeto.

Tabela 52 - Correlação com portifólio, programas e classificação de projetos.......158 Tabela 53 - Correlação com projetos entregues dentro do prazo, custo e qualidade. 159

Tabela 54 - Correlação com a avaliação das práticas de gerenciamento de projetos.

Tabela 55 - Correlação com a maturidade em gerenciamento de projetos. 162 Tabela 56 - Regressão da variável percentual das estratégias somente no questionário de estratégia 164

Tabela 57 - Regressão da variável satisfação com a implementação somente no questionário de estratégia. 
Tabela 58 - Regressão da variável percentual das estratégias nos questionários de estratégia e gerenciamento de projetos 165

Tabela 59 - Regressão da variável satisfação com a implementação no questionário de estratégia e de gerenciamento de projetos. 166 Tabela 60 - Regressão da variável percentual das estratégias nos questionários de estratégia, gerenciamento de projetos e maturidade 167

Tabela 61 - Regressão da variável satisfação com a implementação no questionário de estratégia, de gerenciamento de projetos e maturidade 168

Tabela 62 - Regressão da variável percentual das estratégias somente no questionário de gerenciamento de projetos. 168

Tabela 63 - Regressão da variável satisfação com a implementação somente no questionário de gerenciamento de projetos. 169

Tabela 64 - Regressão da variável percentual das estratégias somente no questionário de maturidade. 170

Tabela 65 - Regressão da variável satisfação com a implementação somente no questionário de maturidade.

Tabela 66 - Sumário das ferramentas, práticas, conceitos e técnicas de gestão estratégica e de projetos e seus resultados nas análises descritiva, correlação e regressão. 174

Tabela 67 - Sumário das técnicas de gestão de projetos e seus resultados nas análises descritivas

Tabela 68 - Sumário da avaliação de gerenciamento de projetos e seus resultados nas análises descritiva, correlação e regressão.

Tabela 69 - Sumário da maturidade e seus resultados nas análises descritiva, correlação e regressão.

Tabela 70 - Sumário da maturidade e seus resultados nas análises descritiva, correlação e regressão 


\section{Introdução}

Este capítulo apresenta o contexto geral do trabalho com o detalhamento dos seguintes tópicos: objetivos, questões-chave, justificativa e aspectos metodológicos do trabalho.

Esta dissertação visa identificar a importância da gestão de projetos na implementação do planejamento estratégico. O método utilizado será desenvolvido a partir de trabalhos disponíveis na literatura técnica e na condução de uma pesquisa de campo com empresas que têm ou não a metodologia de gestão de projetos implementada, correlacionando o grau de sucesso financeiro com as estratégias implementadas.

Inicialmente serão apresentados alguns conceitos, tais como projeto e implementação de estratégias. Projeto é aqui entendido como "um esforço temporário empreendido para criar um produto, serviço ou resultado exclusivo" (PMBOK, 2004).

Porter e Montgomery (1998) afirmam que "para enfrentar um ambiente mais competitivo há necessidade de uma análise mais sofisticada e de uma maior rapidez na transformação do planejamento em ação". Essa é a função da implementação.

A implementação, para Fischmann (1987), "é inerente à administração, constituindo-se na etapa em que se dá, ou não, a conversão do planejado em realidade. Como tal, apresenta-se usualmente como um momento de tensão, porque, em geral, nossas aspirações suplantam nossas capacidades e disponibilidades de recursos; essa tensão torna-se maior sempre que as aspirações, traduzidas em planos, se voltam para a introdução de inovações que representam mudanças organizacionais relevantes". Implementação também pode ser entendida pelo processo no qual a visão, missão, objetivos e estratégias são colocados em ação através de diversas ferramentas/conceitos como: gestão de projetos, balanced scorecard, gestão da mudança organizacional, alinhamento dos subsistemas de 
Recursos Humanos $(\mathrm{RH})$, gestão estratégica de pessoas, bem como o engajamento dos funcionários e dos gestores.

Algumas questões são importantes no que se refere à gestão estratégica como, por exemplo: como deve ser o processo de implementação do planejamento estratégico? Quais elementos compõem o processo de implementação? Quais ferramentas de gestão de projetos podem trazer melhores resultados para as empresas na ocasião da implementação? Como a gestão de projetos facilita e suporta a implementação de estratégias? Quais variáveis impactam no processo de implementação e como obter maiores resultados por meio da maximização das mesmas ou superação de barreiras?

Essas questões revelam a necessidade de uma ampliação dos estudos na área de gestão de projetos e implementação do planejamento estratégico. A tradução de tais inquietações pode ser sintetizada nas seguintes indagações:

- Qual é o grau de correlação entre a utilização da ferramenta de gestão de projetos e a implementação de estratégias?

- Como o processo de gerenciamento de projetos auxilia efetivamente à implementação do planejamento estratégico organizacional?

- Quais ferramentas de gestão de projetos podem trazer melhores resultados para as empresas na ocasião da implementação?

- Quais variáveis impactam no processo de implementação e como obter maiores resultados através da maximização das mesmas ou superação de barreiras?

- Como alinhar a estratégia e a execução através da gestão de projetos?

\subsection{Objetivos da pesquisa}

Os objetivos da pesquisa podem ser divididos em duas partes: objetivo geral e específicos. 


\section{Objetivo geral}

A partir das questões sucitadas anteriormente, o principal objetivo deste trabalho é identificar a relação entre a gestão de projetos e a implementação de estratégias, bem como identificar as principais barreiras e alavancadores na implementação.

\section{Objetivos específicos}

- Identificar as principais variáveis e elementos que impactam a implementação do planejamento estratégico organizacional, principalmente os aspectos relacionados à gestão de projetos;

- Apresentar as principais práticas de um grupo selecionado de empresas, nos aspectos relacionados à gestão de projetos, visando à implementação de estratégias;

- Analisar as soluções em gestão de projetos para o processo de implementação do planejamento estratégico organizacional.

É possível que a explicitação dos resultados da pesquisa possa dar suporte ao setor empresarial no caminho difícil para o sucesso na implementação de estratégias empresariais. Essa dificuldade enfrentada pelas empresas na implementação será detalhada no próximo item.

\subsection{Justificativa}

Esta dissertação aborda a importância das ferramentas de gestão de projetos e de estratégias que visam à implementação de ações de longo prazo do planejamento estratégico organizacional. Por planejamento estratégico entende-se, a definição de ações estratégicas relacionadas ao futuro da empresa em relação ao 
ambiente. O planejamento estratégico tem sido um tema amplamente debatido, tanto no meio acadêmico quanto nas empresas, entretanto, o debate sobre o seu processo de implementação é quase inexistente e não há uma metodologia consolidada no mercado. No levantamento bibliográfico, há somente três autores que pesquisaram sobre a identificação dos principais problemas na implementação de estratégias em empresas no Brasil: Fischmann (1987), Machado (1992) e Sobanski (1996). No entanto, não foi feita uma pesquisa sobre como solucionar esses problemas e também não foi elaborada uma metodologia integrada de implementação de estratégias e tão pouco foi verificada a importância da gestão de projetos nesse processo.

Rigby (2001) verificou em um estudo que a estratégia e a sua implementação são os principais assuntos discutidos atualmente na agenda dos principais executivos (CEOs). Porter apud Secretaria de Educação da Bahia (2007) destacou a importância do tema, afirmando que "deixar de pensar na estratégia é a morte". Ter uma estratégia é essencial, sendo fundamental sua comunicação e implementação. De acordo com a pesquisa de Hunger e Wheelen (2002), as organizações que adotam a gestão estratégica geralmente apresentam melhor desempenho do que as organizações que não a adotam.

Fischmann (1987), por outro lado, alerta que se tem dado ênfase à formulação e seleção de estratégias compatíveis com o ambiente empresarial e com os objetivos e metas da organização, mas em contrapartida, relativamente pouca atenção tem sido dirigida à implementação das mudanças estratégicas, principalmente nos aspectos de gestão de projetos. O autor ainda adverte que "esta desproporção seguramente tem contribuído para o insucesso de muitos planos estratégicos à medida que, estando a organização despreparada para adotar de fato as diretrizes estratégicas acaba percebendo que os planos não funcionam exatamente como seus autores pretendiam", sendo razão de críticas e fracassos.

Além disso, há uma defasagem entre as possibilidades profícuas do planejamento estratégico (PE) e os resultados obtidos de fato pelas empresas que o praticam (FISCHMANN, 1987). Fatores determinantes do fracasso do PE na prática 
são encontrados na fase de implementação, independente dos méritos das fases que a antecederam, bem como esforços e recursos nela despendidos.

Na mesma linha, verifica-se que cada vez mais a capacidade de executar a estratégia tem sido importante. Uma pesquisa realizada com 275 gestores de portfólio, pela Ernst \& Young (1998), mostrou que a capacidade de executar a estratégia é mais importante do que a qualidade da estratégia em si. Esses gerentes citaram a implementação da estratégia como o fator mais importante na avaliação da gerência e da corporação. No início da década de 80, uma pesquisa entre consultores revelou que menos de $10 \%$ das estratégias formuladas com eficácia foram implementadas com êxito (KIECHEL, 1982). Grandes companhias gastam milhares de bilhões de reais a cada ano em formulação de estratégias, às vezes sem muito retorno. Numerosos estudos mostram que há uma baixa relação entre a formulação da estratégia e a sua execução (SHIRAKI, 2002). Um deles foi conduzido por Charan \& Golvin (1999), no qual se verificou que somente 1 em 10 companhias que desenvolveu uma formulação de estratégia eficaz conseguiu implementá-la com sucesso. Para as outras nove, uma boa estratégia é perdida no dia-a-dia ou é guardada na gaveta do executivo. Ao mesmo tempo em que existem muitas empresas e executivos que guardam o planejamento "na gaveta", não o colocando em prática, há executivos que tentam implementar, contudo, encontram dificuldades, já que mesmo sendo aprovado não é implementado automaticamente, o que se constitui também como motivo de estudo.

Outro estudo muito difundido foi produzido por Collins e Porras (1995), no qual verificou-se que a estratégia por si só não separa as empresas "feitas para durar" das outras empresas comparadas. Todos desenvolvem estratégias, porém, não há evidência que as "feitas para durar" dedicam mais tempo ao planejamento estratégico que o restante das empresas. Há outro estudo realizado anualmente pela revista Fortune que identifica as empresas mais admiradas pelos americanos. Shiraki (2002), coordenador desse estudo, identificou que nas "empresas mais admiradas" a estratégia não é só meramente um exercício, é o foco em tudo o que a companhia faz, e o que diferencia estas empresas das demais é a sua capacidade de executar estratégias. Geralmente, as empresas mais admiradas têm um plano detalhado de implementação. Matiolli (2002) concorda com Collins e Shiraki 
afirmando que "o maior desafio de uma empresa não é montar uma boa estratégia, e sim conseguir implantá-la com sucesso". Pesquisas mostram, também, que a vida dos CEOs em uma empresa está cada vez mais curta e que o principal motivo é a dificuldade em implementar uma estratégia.

Diante desse contexto a implantação de estratégias é cada vez mais importante. Organizações que não implantam suas estratégias têm obtido resultados insatisfatórios e são mais sensíveis a recessões. Há muitos gastos com a elaboração de estratégias e a contratação de consultorias, mas estes mesmos investimentos não acontecem com a implementação, assim sendo, a organização não alcança os resultados desejáveis. Uma estratégia não apropriada pode ser ofuscada por uma implementação adequada, porém, a péssima implementação resultará em desempenho insatisfatório. Conclui-se que o sucesso depende de uma boa estratégia e uma boa implementação, sem a implementação a estratégia fracassa. Charan e Golvin (1999) relevam essa questão afirmando que "na maioria dos casos - estimamos em 70\% - o verdadeiro problema não é má estratégia, e sim, má execução. Assim, com índices de fracasso na faixa de $70 \%$ a $90 \%$, percebemos por que investidores sofisticados chegaram à conclusão de que a execução é mais importante do que a visão".

Esses problemas de implementação também ocorrem no Brasil. A principal conclusão apresentada por Schwarz apud Kallás (2003) revela que "mais de 90\% das organizações brasileiras pesquisadas também falham na implementação da estratégia, o que vale dizer que o Brasil está dentro dos péssimos padrões mundiais".

Uma das razões para isso acontecer, segundo Sobanski (1996), é que "a implementação de estratégias é uma atividade complexa que envolve não apenas competência técnica na elaboração e gerenciamento de projetos, mas também aspectos mais amplos, tais como sistemas de informação, comprometimento, etc".

Sabe-se que "não existe um melhor caminho" para a implementação de estratégias, tampouco existe um "melhor caminho" para organização. Formas bem diferentes funcionam em contextos particulares (MINTZBERG; QUINN, 2001). 
Apesar de acreditar na aplicabilidade dos resultados deste trabalho em diversos setores e em empresas de portes diferentes, há uma grande necessidade de entender qual abordagem poderá obter melhores resultados.

Embora alguns autores tenham tratado do tema da implementação, as abordagens têm sido pontuais, dispersas, e não significativas em termos de quantidade (FISCHMANN, 1987). E ainda, não há uma metodologia estabelecida e reconhecida no mercado como sendo geradora de resultados. Em decorrência desse cenário, a realização desta pesquisa de dissertação tem por objetivo último auxiliar as organizações a implementar estratégias com a maior probabilidade de se ter sucesso, por meio da gestão de projetos, conseguindo superar os obstáculos geralmente encontrados nesses tipos de iniciativas.

\subsection{Aspectos metodológicos gerais da dissertação}

O presente trabalho classifica-se na categoria modelo conceitual visando à solução de um problema particular, conforme demonstrado por Mazzon (1978), em sua dissertação de mestrado. Este apresentou uma classificação de dois tipos de modelos metodológicos:

- Modelo conceitual: estabelece, em termos amplos, a definição de um problema particular a ser resolvido;

- Modelo operacional: constitui-se num instrumento de operacionalização da teoria, permitindo testar as proposições nesta mesma teoria; permite a sua operacionalização nas organizações.

É importante ressaltar a distinção entre método e metodologia. A palavra método tem origem no vocábulo grego méthodos e tem vários significados, dentre eles: caminho, programa, processo, técnica, procedimento, forma ou modelo de ação. Métodos, então, formam o "caminho pelo qual se atinge um fim ou objetivo" (FERREIRA, 2002). Metodologia tem também origem no mesmo verbete grego e 
traduz a idéia de ordenação, seqüência, arte, estudo, técnica, processo. Diz-se dos "procedimentos e regras utilizadas por determinado método" (FERREIRA, 2002).

Para atingir os objetivos propostos nesta pesquisa, a estrutura deste texto está organizada da seguinte forma:

- Introdução: importância do tema e os principais conceitos sobre estratégia, implementação e gestão de projetos (pesquisa bibliográfica);

- Pesquisa de campo: a apresentação dos resultados da pesquisa de campo e suas conclusões sobre como as empresas têm conseguido obter sucesso na implementação de suas estratégias com o auxílio da gestão de projetos e gestão estratégica;

- Conclusão: realizar as considerações finais do trabalho, identificando os aspectos críticos da gestão de projetos na implementação de estratégias, comparando os aspectos teóricos com a pesquisa de campo.

Duas pesquisas foram realizadas neste trabalho: uma teórica e outra de campo. A primeira auxiliou na fundamentação teórica permitindo a construção do questionário/roteiro de entrevista/survey. A segunda constitui-se pela coleta de dados primários (entrevistas).

\subsection{Possíveis contribuições}

Espera-se que o trabalho proposto contribua para o avanço da compreensão da utilização da gestão de projetos visando implementar estratégias organizacionais. Que se caracteriza por ser um assunto complexo, muito discutido nos ambientes acadêmico e empresarial e desafiador para o futuro das organizações, Tal utilização tem como objetivo atingir a liderança de mercado, vantagem competitiva sustentável, aumentar o retorno e a perpetuação da companhia.

É importante destacar que este estudo não esgotará o tema por se tratar de um assunto muito abrangente, mas poderá trazer à tona pontos importantes para 
uma reflexão futura mais profunda. $O$ trabalho aqui apresentado não tem por propósito ser uma "receita de bolo", apesar de se acreditar na sua aplicabilidade em diversos setores empresariais, independentemente do seu porte. Entre os gestores há uma grande necessidade de entender qual abordagem poderá obter melhores resultados, no entanto, conselhos de grandes pensadores ou consultores nem sempre têm relevância para uma organização em um determinado contexto. Exemplificando, Peters (1982) induziu as empresas a não diversificarem e Foster (1986) sugeriu que a última coisa que a empresa deve fazer é continuar fazendo a mesma coisa à medida que o negócio amadurece.

Esses exemplos revelam que nenhum conselho, por melhor que seja, poderá ser aplicado sempre. Esses conflitos tornam famosas frases como a de Jung (1955): "o sapato que serve no pé de uma pessoa aperta o de outra; não existe uma receita de vida que sirva para todos os casos".

\subsection{Pesquisa de campo}

A pesquisa de campo apresentada neste trabalho tem por objetivo trazer maiores informações a respeito do que ocorre na prática, além de verificar como a teoria pode contribuir com a evolução da implementação da estratégia.

Para a condução dessa pesquisa empírica foram definidos alguns critérios com o objetivo de restringir o conjunto de empresas em relação ao número total das existentes. $O$ foco desse estudo está concentrado em empresas de grande porte pertencentes ao grupo das 1.000 maiores do país.

As variáveis tamanho e desempenho são consideradas como as mais apropriadas ao desenvolvimento da investigação do problema da pesquisa. Como fonte de informação para se determinar a população-alvo desta pesquisa tomou-se como base a edição das "Maiores e Melhores" da revista Exame e o "Valor 1.000" do jornal Valor Econômico. Foram realizadas entrevistas com os responsáveis de planejamento estratégico e pela prática de gestão de projetos, por meio de roteiro e questionário que se encontram em anexo. 
Devido às restrições de deslocamento, o estudo concentrou-se em empresas localizadas perto do estado de São Paulo, devido à facilidade, custos e tempo para a obtenção de dados.

O tipo de pesquisa adotado nesta dissertação é o descritivo, no qual procurou-se verificar a aceitação ou rejeição das hipóteses e as relações entre as variáveis envolvidas na implementação de estratégias. 


\section{Revisão bibliográfica - Implementação de estratégias}

Este capítulo tem por objetivo apresentar a revisão bibliográfica e as definições dos principais conceitos que serão utilizados durante o trabalho, bem como a respectiva importância da abordagem a ser construída.

\subsection{Implementação de estratégias}

Segundo Hrebiniak (2005), implementação é

um processo disciplinado ou um conjunto lógico de atividades conectadas que permite que uma organização utilize uma estratégia e a faça funcionar. Sem uma abordagem cuidadosa e planejada para a execução, as metas estratégicas não podem ser obtidas. Desenvolver uma abordagem lógica como essa, no entanto, representa um desafio formidável para a gerência.

Outra definição mais simples e difundida de implementação de estratégias é a tradução dessas em ações concretas que, se realizadas, irão contribuir com a estratégia e atingir os objetivos empresariais críticos.

Noble (1999) define implementação de estratégias como sendo "comunicação, interpretação, adoção e aprovação dos planos estratégicos". E ainda, Fleury (2006) reforça que se deve sempre levar em consideração o contexto, pois a implementação, como qualquer outra ação, ocorre em diferentes contextos afetando as práticas de negócio, a cultura, as políticas, a remuneração, entre outros. Cada contexto merece uma abordagem diferente de implementação, sempre ponderando que as empresas não implementam as estratégias e sim as pessoas. Mesmo em contextos diferentes, percebe-se que algumas ferramentas podem ajudar. Nesta dissertação são apresentadas algumas delas, principalmente a relevância dos conceitos de gerenciamento de projetos para o sucesso da implementação. 
A implementação envolve uma série de atividades, sendo as principais:

- Estabelecer quem irá conduzir quais atividades de implementação;

- Como as pessoas serão envolvidas para que elas façam o que tenha de ser feito;

- Criar as competências na organização para conduzir a estratégia com sucesso;

- Desenvolver orçamento para alocar recursos para as atividades e suportar a execução de estratégias (fundos para projetos alinhados com a estratégia, fortalecimento ou a criação de competências, mudanças organizacionais, etc.);

- Estabelecer política, procedimentos e a estrutura organizacional para suportar a estratégia;

- Estabelecer sistemas de informações, comunicações e operações, contendo informações precisas, no tempo adequado, incluindo o desenvolvimento e acompanhamento de indicadores de desempenho;

- Estabelecer incentivos e recompensas para o alcance de objetivos de desempenho e de estratégia;

- Moldar a cultura da organização para ajustá-la à estratégia;

- Institucionalizar as melhores práticas para a melhoria contínua da organização.

Com o intuito de desenvolver essas responsabilidades é necessário elaborar um método de implementação lógico com atividades conectadas. Esse é o grande desafio, já que se verifica na literatura que a grande maioria das empresas falham nesse ponto.

\subsection{Problemas da implementação}

É cada vez mais comum ouvir pronunciamentos sobre a implementação de estratégia nas empresas. Frases como, "sem a execução mesmo uma estratégia 
brilhante é inútil", têm sido muito difundida no meio empresarial. Para Woolridge e Floyd (1990) "é muito mais fácil pensar em uma boa estratégia do que a sua implementação". É possível notar também que muito da literatura disponível nestas últimas décadas estão focadas na formulação de estratégias e pouco tem sido dedicado à implementação. Sendo assim, os problemas de implementação continuam com pouca ou nenhuma solução. $E$ as atividades relacionadas ao planejamento, bem como o alinhamento com os sistemas organizacionais, sempre foram alocadas sob a responsabilidade da alta direção da empresa.

Todavia, os pesquisadores foram incapazes de estipular exatamente como o alinhamento ocorre. A literatura especializada é repleta de referências à liderança, comunicação e educação, mas fornece teorias que não são claras para explicar qual abordagem é melhor para implementar a estratégia. Entender como o alinhamento estratégico é implementado se torna mais importante (Beer; Eisenstat, 1996).

Para Bossidy e Charan (2002) "a execução é uma das principais questões ainda não resolvidas no mundo de negócios atual". Continuando, "a falta da implementação é uma das principais barreiras para o sucesso e causa um dos maiores desapontamentos que são atribuídos a outros fatores".

O problema ainda se agrava, pois, as escolas de negócios não oferecem uma visão interdisciplinar, como é necessário para a execução da estratégia. Hrebiniak (2005) descobriu que uma das razões para a implementação não dar certo é "que os gestores conhecem mais a respeito de formulação do que de implementação. Os gerentes são treinados para planejar, mas não para executar planos". Por exemplo, atualmente nos cursos de Pós-Graduação, oferecidos nas melhores escolas do Brasil, não há disciplinas voltadas à execução e as disponíveis tampouco oferecem uma visão para a execução de estratégias. Já a área de planejamento estratégico encontra-se com carga horária extensa.

Esse problema foi pesquisado por diversos autores que procuraram entender as implicações e identificar fatores que poderiam impactar positivamente o processo. 
Uma pesquisa realizada com 160 empresas durante cinco anos identificou que o sucesso das empresas estava intimamente relacionado, entre outras coisas, à capacidade de pôr as idéias em prática de forma impecável. Fatores como cultura, estrutura organizacional, projetos e aspectos da execução operacional eram essenciais para o sucesso da empresa, avaliado pelo retorno total aos acionistas (JOYCE; NOHRIA; ROBERSON, 2003). Hrebiniak (2005) corroborou com esse estudo mostrando que a ênfase na realização da estratégia rende grandes dividendos. Shiraki (2002) demostrou que $71 \%$ das organizações mais admiradas avaliaram a implementação de estratégias como eficaz, contra $47 \%$ das empresas comparadas.

Mesmo diante de tal importância, um dos principais problemas na área de estratégia é a falha no processo de implementação ao invés da formulação (BEER et al., 1990; WOOLRIDGE E FLOYD, 1990). Cerca de $70 \%$ dos CEOs perderam seus empregos devido à má execução da estratégia (CHARAN; COLVI, 1999). Outro estudo identificou que $80 \%$ das empresas têm estratégias corretas, porém, somente $14 \%$ falaram que a implementaram bem (TIMES apud CHAPMAN, 2007). De acordo com a Ernst \& Young apud Johnson (2004), 66\% das estratégias nunca foram executadas.

Outra pesquisa mostrou que somente $17 \%$ das empresas têm certeza que $90 \%$ dos objetivos da implementação foram atingidos. Quase 50\% dos executivos disseram que implementaram a sua estratégia entre $30 \%$ e $60 \%$, e $16 \%$ das companhias afirmaram que o percentual não chegou a $30 \%$ de sucesso (CHINOOK SOLUTIONS, 2006).

Todos esses problemas de má execução impactam no desempenho financeiro da empresa. As organizações empregam somente $63 \%$ do potencial financeiro. O grande objetivo é, então, identificar este gap de execução e cobrí-lo. Ao invés disso, a alta administração tenta melhorar a estratégia, perdendo tempo e dinheiro (MANKINS; STEELE, 2005). Na seqüência é demonstrado onde as empresas têm perdido, em média, seu desempenho. 
Com base na figura 1, observa-se que as empresas têm perdido desempenho por falta de recursos ou de sua inadequação, má comunicação da estratégia ou pela má definição das ações necessárias para a execução da estratégia.

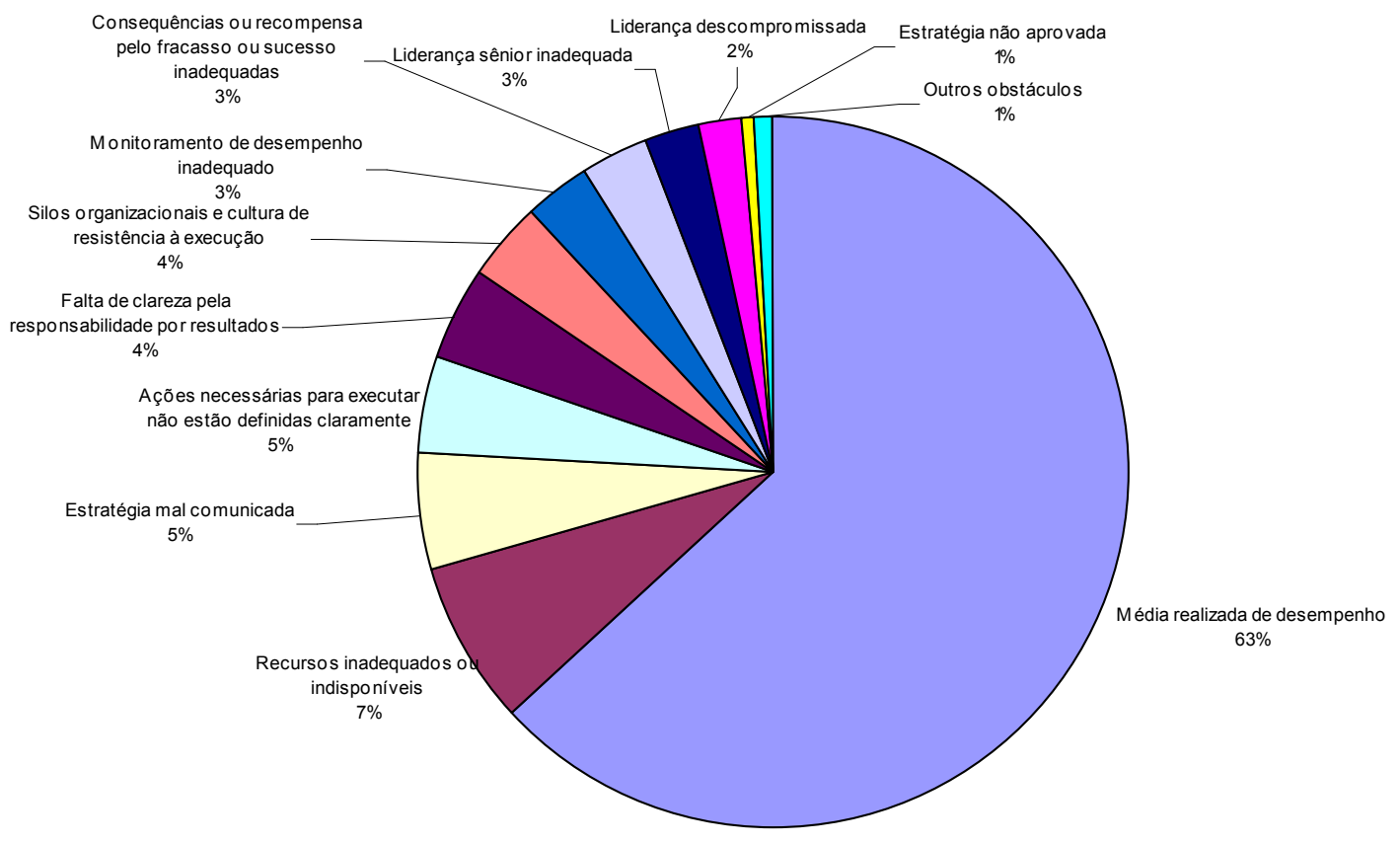

Figura 1 - Potencial de execução da empresa (MANKINS; STEELE, 2005)

Para facilitar o entendimento da importância de uma boa formulação e implementação pode-se utilizar a matriz abaixo (figura 2). Só é possível obter sucesso com uma boa formulação e implementação das estratégias. O não alcance de um desses objetivos pode acarretar em redução do desempenho financeiro da empresa. Se a empresa falhar no alcance dos dois objetivos seus gestores encontrarão dificuldades para saber o que ocorreu de errado. 


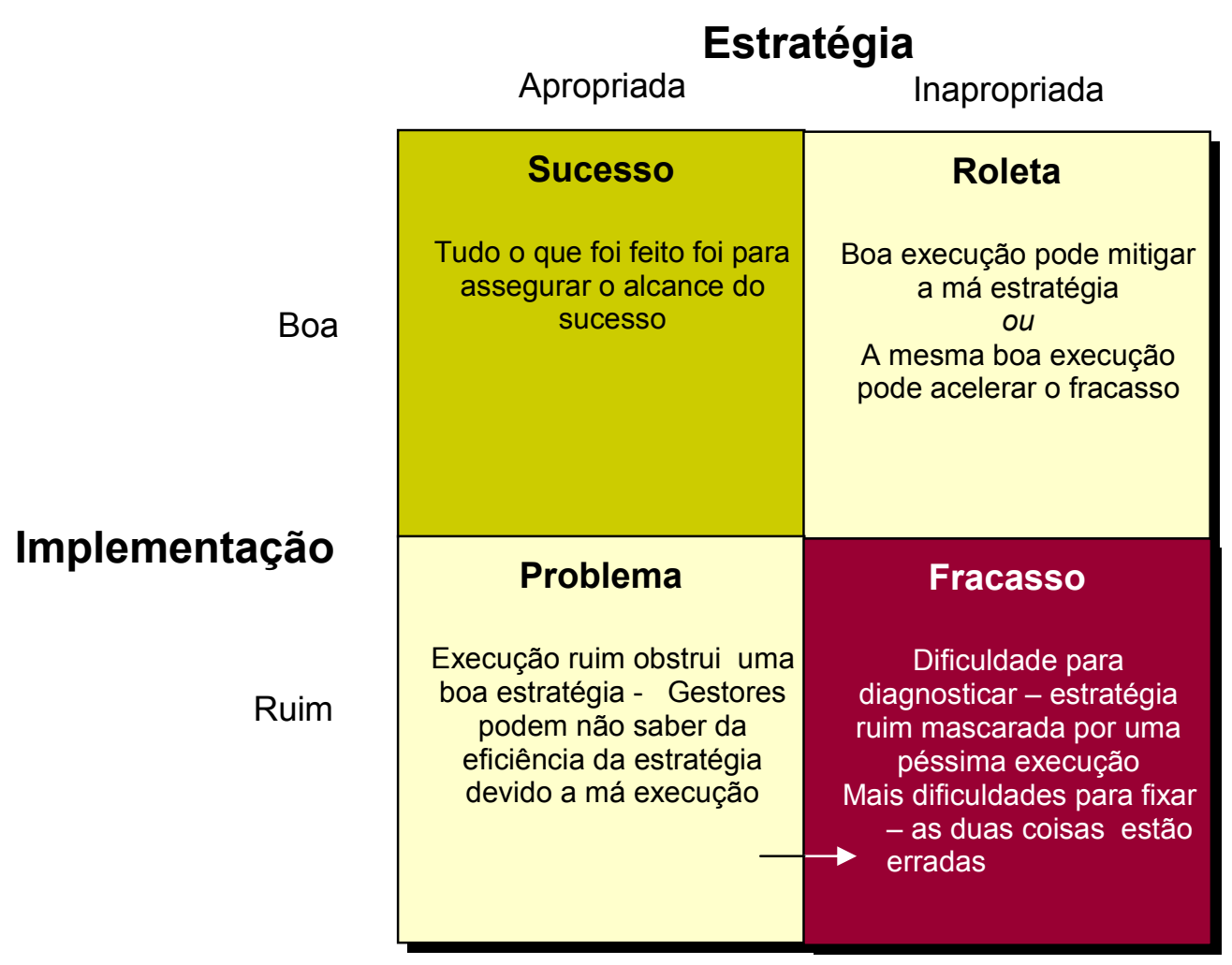

Figura 2 - Matriz implementação x estratégia (BONOMA, 1985)

Dos resultados apresentados nas figuras 1 e 2, conclui-se que as empresas têm enfrentado grandes problemas com a implementação de estratégias. Diversos estudos revelam que as pessoas encontram dificuldades em alguns pontos do processo, mostrando que muitas estratégias não são implementadas devido aos seguintes fatores:

- O tempo de implementação é maior do que o planejado;

- Os problemas enfrentados não são previstos;

- As atividades são coordenadas de forma ineficaz e/ou mal definidas;

- Os funcionários não têm as competências necessárias;

- Os treinamentos aos funcionários são inadequados;

- Fatores externos incontroláveis;

- Liderança inadequada e falta de suporte;

- Falha na comunicação vertical;

- As metas não são tão bem compreendidas;

- O nível gerencial não trabalha em equipe; 
- A alta direção não avalia realisticamente se a empresa consegue executar o plano (BOSSIDY; CHARAN, 2002);

- Crises e prioridades conflitantes, comprometendo a atenção necessária à implementação (falta disciplina de execução);

- Os principais formuladores das estratégias não participam ativamente da implementação;

- Sistemas de informações inadequados;

- Resistência à mudança, não iniciando o processo (pouca prioridade);

- Impaciência - as mudanças têm que acontecer o quanto antes. CEOs podem ser inflexíveis e quererem a mudança "para ontem";

- Falta de celebração do sucesso, faltando reconhecimento e recompensa pelo progresso (WHEELEN, HUNGER, 2002; WESSEL, 1993; AL-GHAMDI, 1998; FREEDMAN, 2003).

Além desses problemas identificados pelos estudos, houve outras pesquisas. Uma delas contou com 243 questionários a respeito dos obstáculos ao processo de execução da estratégia e outra com 200 executivos que realizaram programas de educação executiva da Wharton (HREBINIAK, 2005). Com o apoio desses estudos, foram verificados quais eram os principais obstáculos para a implementação da estratégia, sendo discriminados na tabela 1.

Tabela 1 - Falhas de implementação (HREBINIAK, 2005)

\begin{tabular}{|l|c|c|}
\hline \multicolumn{1}{|c|}{ Obstáculos } & $\begin{array}{c}\text { Pesquisa } \\
\text { Wharton-Gartner }\end{array}$ & $\begin{array}{c}\text { Pesquisa de } \\
\text { educação executiva } \\
\text { Wharton }\end{array}$ \\
\hline $\begin{array}{l}\text { Incapacidade de gerenciar a mudança } \\
\text { efetivamente ou separar a resistência interna à } \\
\text { mudança }\end{array}$ & 1 & 1 \\
\hline $\begin{array}{l}\text { Tentar executar uma estratégia que entre em } \\
\text { conflito com a estrutura existente de poder }\end{array}$ & 2 & 5 \\
\hline $\begin{array}{l}\text { Compartilhamento deficiente ou inadequado de } \\
\text { informações entre as pessoas ou unidades de } \\
\text { negócios responsáveis pela execução da } \\
\text { estratégia }\end{array}$ & 2 & 4 \\
\hline
\end{tabular}




\begin{tabular}{|c|c|c|}
\hline Obstáculos & $\begin{array}{c}\text { Pesquisa } \\
\text { Wharton-Gartner }\end{array}$ & $\begin{array}{l}\text { Pesquisa de } \\
\text { educação executiva } \\
\text { Wharton }\end{array}$ \\
\hline $\begin{array}{l}\text { Comunicação confusa de responsabilidade e/ou } \\
\text { obrigação para decisões ou ações de execução }\end{array}$ & 4 & 5 \\
\hline Estratégia vaga ou deficiente & 5 & 2 \\
\hline $\begin{array}{l}\text { Falta de sentimentos de pertencer a uma } \\
\text { estratégia ou a planos de execução entre os } \\
\text { principais funcionários }\end{array}$ & 5 & 8 \\
\hline $\begin{array}{l}\text { Não ter orientações ou um modelo para orientar os } \\
\text { esforços de execução da estratégia }\end{array}$ & 7 & 2 \\
\hline $\begin{array}{l}\text { Falta de entendimento da função da estrutura e } \\
\text { dos projetos organizacionais no processo de } \\
\text { execução }\end{array}$ & 9 & 5 \\
\hline $\begin{array}{l}\text { Incapacidade de gerar convicção ou acordos sobre } \\
\text { as etapas ou ações de execução }\end{array}$ & 7 & 10 \\
\hline $\begin{array}{l}\text { Falta de incentivos ou incentivos inadequados para } \\
\text { dar suporte aos objetivos de execução }\end{array}$ & 9 & 8 \\
\hline $\begin{array}{l}\text { Recursos financeiros insuficientes para executar a } \\
\text { estratégia }\end{array}$ & 11 & 12 \\
\hline $\begin{array}{l}\text { Falta de suporte para a execução da estratégia por } \\
\text { parte da alta administração }\end{array}$ & 12 & 11 \\
\hline
\end{tabular}

Além de não obter os resultados ou os objetivos desejados da execução, os gerentes classificaram nessas pesquisas, como altamente problemático, alguns itens da implementação. Esses resultados incluem os seguintes dados:

- Os funcionários não entendem como o trabalho que fazem contribui para os resultados importantes da execução;

- São desperdiçados tempo e dinheiro devido à ineficiência ou burocracia no processo de execução;

- As decisões de execução levam muito tempo para serem tomadas;

- A empresa reage de forma lenta ou inapropriada às pressões competitivas (HREBINIAK, 2005). 
É lógico que existem alguns motivos para esses problemas apresentados. Conforme Hrebiniak (2005), existem quatro causas principais para as falhas de implementação.

A primeira delas é que os administradores são treinados para planejar, não para executar. Estes não observam quais são os benefícios da execução eficaz (criação de vantagem competitiva e maiores retornos aos acionistas, etc.).

A segunda refere-se ao planejamento e à execução que são interdependentes. É possível obter resultados estratégicos bem-sucedidos quando os responsáveis pela execução também fazem parte do processo de planejamento. Quanto maior a interação entre os executores e os planejadores, ou quanto maior for a sobreposição dos dois processos ou tarefas, maior será a probabilidade do sucesso da execução. Os gerentes devem pensar na execução, inclusive, quando estão formulando planos.

A terceira diz respeito à execução que leva mais tempo do que a formulação. Assim, é necessário que as necessidades de longo prazo sejam transformadas em objetivos de curto prazo. Como a execução leva mais tempo, é preciso estabelecer controles para gerar feedback e manter a administração bem-informada dos choques externos e das mudanças.

E por último, a execução é um processo, e não uma ação ou uma etapa, envolvendo mais pessoas que a formulação da estratégia. Sendo assim, vincular os objetivos estratégicos com os objetivos e preocupações diárias da equipe de trabalho, em diferentes níveis e locais da organização, torna-se uma tarefa legítima, porém desafiadora.

Acredita-se que haja outros fatores que geram os problemas apresentados da implementação. Um deles pode ser a baixa aplicação das técnicas de gerenciamento de projetos. Se as empresas aplicassem os conceitos de gestão de projetos, elas não iriam ter problemas quanto a prazo, riscos, fatos imprevistos, gestão de mudanças, coordenação e liderança das atividades, disciplina de 
execução, reconhecimento e celebração do sucesso, conflito com a estrutura de poder, clareza de papéis e responsabilidades, entre outros citados acima.

\subsection{Implementação - soluções conceituais oferecidas pela literatura}

Neste bloco são apresentados alguns conceitos e soluções, abordados pela literatura, para o problema da implementação da estratégia empresarial, procurando inclusive apresentá-los em ordem cronológica.

Lorange (1982) identificou uma série de fatores críticos de sucesso para a implementação de estratégias, tais como:

- Deve haver potenciais benefícios com o planejamento para o presidente e para a organização como um todo;

- O planejamento estratégico deve ser explicado, aplicado e implementado para que os gestores importantes o compreendam;

- As atividades relativamente complexas do planejamento devem ser capazes de serem divididas em elementos menores;

- O plano deve identificar as partes do negócio que podem ser planejadas ou gerenciadas no meio estratégico;

- O sucesso na implementação ocorre como uma evolução natural da experiência e entendimento;

- Deve haver um patrocinador bem definido para cada atividade de planejamento e implementação;

- Deve mostrar claramente as necessidades dos clientes e cada nível gerencial deve ver os benefícios a serem entregues no atendimento dessas necessidades;

- O plano deve demonstrar alguns resultados relativamente rápido, mas como esforço inicial, as aspirações não devem ser tão altas;

- Deve haver um comprometimento para suportar e participar do esforço de planejamento; 
- Por fim, deve haver uma avaliação realística dos recursos necessários. Isso inclui disponibilizar pessoas e equipamentos necessários, fornecer orçamentos adequados para treinamento, reuniões, equipamentos, implementação, entre outros.

Como é possível analisar, Lorange (1982) traz uma série de contribuições. Alguns fatores apresentados fazem parte dos conceitos de gerenciamento de projetos. O primeiro item, verificar os benefícios para o presidente, é uma das análises de stakeholders. Outro item que está ligado ao gerenciamento de escopo de projetos é a necessidade de quebrar a implementação em partes para poderem ser gerenciadas com maior facilidade e a importância de averiguar as necessidades de recursos. A definição de patrocinador para cada atividade faz parte do processo de definição das atividades, tendo sempre uma pessoa como responsável.

Pettigrew e Whipp (1991) desenvolveram um modelo de gerenciamento de mudanças estratégicas, composto por cinco fatores importantes para a implementação:

- Avaliação ambiental, que envolve o acompanhamento das mudanças no ambiente externo da organização;

- Recursos Humanos, como recursos e responsabilidades. Os funcionários são vistos como ativos de valor e devem sentir que a organização confia neles;

- Ligação da mudança estratégica e operacional. A implementação ocorre num prazo muito longo. Deve-se agrupar as ações de implementação em pacotes operacionais de curto prazo;

- Conduzindo à mudança. A empresa deve se mover para alcançar seus objetivos através da criação de um clima de mudança e da coordenação de atividades;

- Coerência total. A estratégia deve ser consistente, estando alinhada com o contexto externo e interno, fornecendo vantagens competitivas para a empresa.

No mesmo ano de desenvolvimento do modelo anterior, Skivington e Daft (1991) investigaram 57 decisões relativas à implementação. Esses autores 
classificaram essas decisões em cinco grupos: estratégia pretendida, estrutura, sistemas, interações e sanções.

Schmidt (1994) procurou analisar os problemas de implementação, criando um dos primeiros modelos de implementação de estratégias. Esse modelo é constituído por um processo de quatro etapas, sendo elas:

- Avaliar as competências organizacionais e os comportamentos necessários para mover do estado atual da empresa para o desejado;

- Determinar quais processos de trabalho serão requeridos para implementar a estratégia e adaptar os processos atuais para integrar esses requisitos;

- Identificar quais informações serão necessárias para os processos de trabalhos criados e determinar quais sistemas de informações e banco de dados serão utilizados para o alcance das necessidades;

- Determinar qual estrutura organizacional oferece o melhor suporte para esses processos.

O referido modelo auxiliou na resolução de problemas de implementação ligados às competências necessárias para dar suporte ao processo, na definição de estrutura e atividades, bem como no sistema de informações necessário para a estratégia. No entanto, isso é apenas uma pequena parte do que deve ser feito na implementação de estratégias.

Os autores Lingle e Schiemann (1994) identificam seis áreas nas quais os gestores deveriam se preocupar durante o processo de implementação, sendo elas: mercado, pessoas, finanças, operação, adaptação e ambiente. Esses fatores contribuíram para o avanço do conhecimento na implementação de estratégias, mostrando inclusive a importância do ambiente externo e das pessoas.

Al-Ghamdi (1994) estudou o grau de sucesso na implementação em 24 empresas. O autor dividiu as 24 empresas em 2 grupos. O primeiro grupo era formado por empresas que obtiveram sucesso na implementação. Enquanto o segundo era composto por organizações que falharam. Essa pesquisa verificou que as 14 empresas que tiveram mais sucesso na implementação obtiveram uma média 
inferior em relação aos problemas de implementação descritos anteriormente do que o outro grupo, principalmente nos itens:

- Comunicação entre todos envolvidos no processo de implementação;

- Sistema de informações que assegure o melhor acompanhamento das atividades de implementação;

- Bom sistema de controle da qualidade e custos envolvidos no processo;

- Visão dos gestores de que a formulação e a implementação não podem estar separadas;

- Estrutura que dará suporte às pessoas para que acessem facilmente o que precisam em relação ao processo da implementação.

$\mathrm{Na}$ metade dos anos 90 surgiu um conceito muito importante chamado de Balanced Scorecard (BSC). Esse conceito foi visto como uma possível solução para os problemas apresentados de implementação de estratégias. Um dos pontos interessantes BSC é que ele pode servir como um sistema de controle, provendo um mecanismo de convergência das atuais ações com a estratégia, ou em outras palavras, o trabalho cotidiano, com a visão e metas de negócios futuros. Complementando, o BSC ajuda a prover aos executivos um sumário dos fatores críticos de sucesso para o negócio, facilitando o alinhamento da estratégia e a operação.

O Balanced Scorecard (Kaplan; Norton, 1991) é composto por indicadores com metas divididas em quatro perspectivas, sendo elas: financeira, clientes, processos e aprendizagem. Um dos componentes do processo de criação do BSC são os mapas estratégicos. Esses mapas oferecem clareza das atividades que irão guiar a empresa para o alcance de seus objetivos financeiros e estratégicos. Isso é realizado com a conversão das estratégias em objetivos e medidas tangíveis.

O BSC realmente agregou bastante conhecimento na área de implementação, porém, o conceito na prática só foi utilizado para melhorar o controle e o monitoramento da estratégia, ocorrendo apenas em uma parte do processo. O estudo de implementação de estratégias continuou após a introdução do conceito de BSC. 
Hussey (1996) pesquisou quais fatores podem auxiliar no processo de implementação de estratégias. Esses fatores são similares ao que será apresentado adiante, como sistemas de influência de Galpin (1997). Os fatores facilitadores da implementação são:

- Estratégia: visão e estratégia devem estar claramente definidas.

- Tarefas: quais tarefas a empresa deve realizar com os resultados da estratégia? Quais as tarefas existentes que deverão ser reforçadas, realizadas de forma mais rápida, ou com maior eficiência?

- Pessoas: quais habilidades ou competências as pessoas deverão ter para trabalhar na empresa? Quais os problemas de treinamento poderão enfrentar?

- Estrutura: pessoas são agrupadas de diversas maneiras na estrutura da organização. É fato que a estrutura atual deve ter sido estabelecida com o intuito de lidar com um conjunto diferente de tarefas estratégicas do que enfrenta atualmente. A estrutura atual facilita ou atrapalha a implementação da estratégia?

- Processo decisório: como é realizado o processo decisório, onde o poder se perde? Tentativas de empowerment nos níveis menores da organização para dar mais resposta aos clientes.

- Cultura

- Sistema de informações: informação é poder e a maneira de compartilhá-la na organização pode afetar sua estrutura de poder. O sistema de informação deve assegurar que a informação certa chegue à pessoa certa, no tempo adequado.

- Sistema de controle: deve estar relacionado com os elementos-chave da estratégia. Controle é um forte determinante da cultura.

- Sistema de recompensa: pode ser crítico para o sucesso, pois guia o comportamento. Recompensa é considerada como a soma de dinheiro com o reconhecimento e o desenvolvimento na carreira. 
Hussey (1996) ao identificar esses fatores procurou criar um modelo de implementação de estratégias, denominado de EASIER (envision, activate, support, install, ensure and recognize). Cada um desses elementos da metodologia de Hussey será detalhado em seguida.

O primeiro elemento é visionar/prever(envision) que envolve o desenvolvimento de uma visão coerente de futuro. A visão deve cobrir variáveis como tamanho, escopo de atividades, pontos fortes, relacionamento com clientes, cultura, incluindo os valores da organização.

O segundo elemento é o ativar/activate, que é a tarefa de assegurar que os outros dentro da organização compreendam, suportem e eventualmente compartilhem a visão.

O terceiro elemento é suportar/support, que busca ajudar os demais funcionários da empresa a terem um papel importante no processo de implementação, envolvendo a liderança. É o conhecimento das capacidades e talentos das pessoas.

O quarto componente é instalar/install que é o processo de desenvolvimento de planos detalhados para possibilitar a implementação e controle da estratégia. É necessário assegurar que todas as conseqüências das mudanças sejam entendidas. O processo de instalar envolve atividades, tais como:

Identificação de todas as ações que devem ser tomadas para efetivar as mudanças;

- Definição de responsáveis pelas ações;

- Estabelecimento de prioridades nas ações;

- Fornecer orçamento necessário para assegurar a implementação;

- Definir equipes e estruturas necessárias para implementação;

- Locação de recursos humanos certos para as tarefas. 
O penúltimo componente é o assegurar/ensuring que envolve 0 monitoramento e controle dos processos que irão assegurar que todas as ações serão tomadas no tempo certo e com os resultados esperados.

O último elemento é o reconhecimento/recognize que envolve atividade de reconhecimento das pessoas envolvidas no processo, podendo ser positivo ou negativo. O reconhecimento deve ser usado para reforçar a mudança ou a superação de obstáculos.

A década de 90 teve uma grande evolução na área de implementação de estratégias com a introdução de modelos de implementação linear da estratégia. Vasconcellos e Sá (1990) foram os primeiros autores dessa linha de pensamento, criando os dez passos da implementação. Em 1997, verificou-se uma grande evolução na área de implementação. Mesmo com as grandes contribuições do BSC, Galpin (1997), ainda, desenvolveu um modelo de implementação linear da estratégia bem consistente, denominado "Fazendo a Estratégia Funcionar". Devido a grande importância do trabalho desse autor, seu modelo será detalhado em seguida.

O modelo de Galpin (1997) tem diversas premissas e conceitos que moldam sua teoria. A primeira delas é que este considera que embora a alta direção tenha controle sobre o conteúdo da estratégia, ela não tem controle direto sobre a realização da estratégia e seus resultados desejados. A média e alta direção, supervisores e funcionários são os principais elos entre a estratégia de negócios e os resultados tangíveis.

O segundo conceito postula que as pessoas de todos os níveis organizacionais devem agir para implementar a estratégia com apoio das competências que possuem e dos comportamentos que demonstram. A alta direção não tem controle direto sobre os comportamentos ou competências das pessoas, podendo somente influenciá-las.

O terceiro conceito estabelece que as pessoas são o elo entre a estratégia e os resultados da empresa. As pessoas escolhem o que querem mudar ou não, para implementar a estratégia planejada. 
O quarto conceito de Galpin (1997) mostra que comunicar as pessoas para a mudança não é suficiente, sendo somente um entre doze sistemas de influência apresentados na figura 3 . As pessoas devem ter incentivos para implementar a estratégia ou parte dela.

E, por último, o processo de interação entre os sistemas de influência é sistemático, no qual cada um deles interage com o outro para moldar os comportamentos individuais e organizacionais esperados.

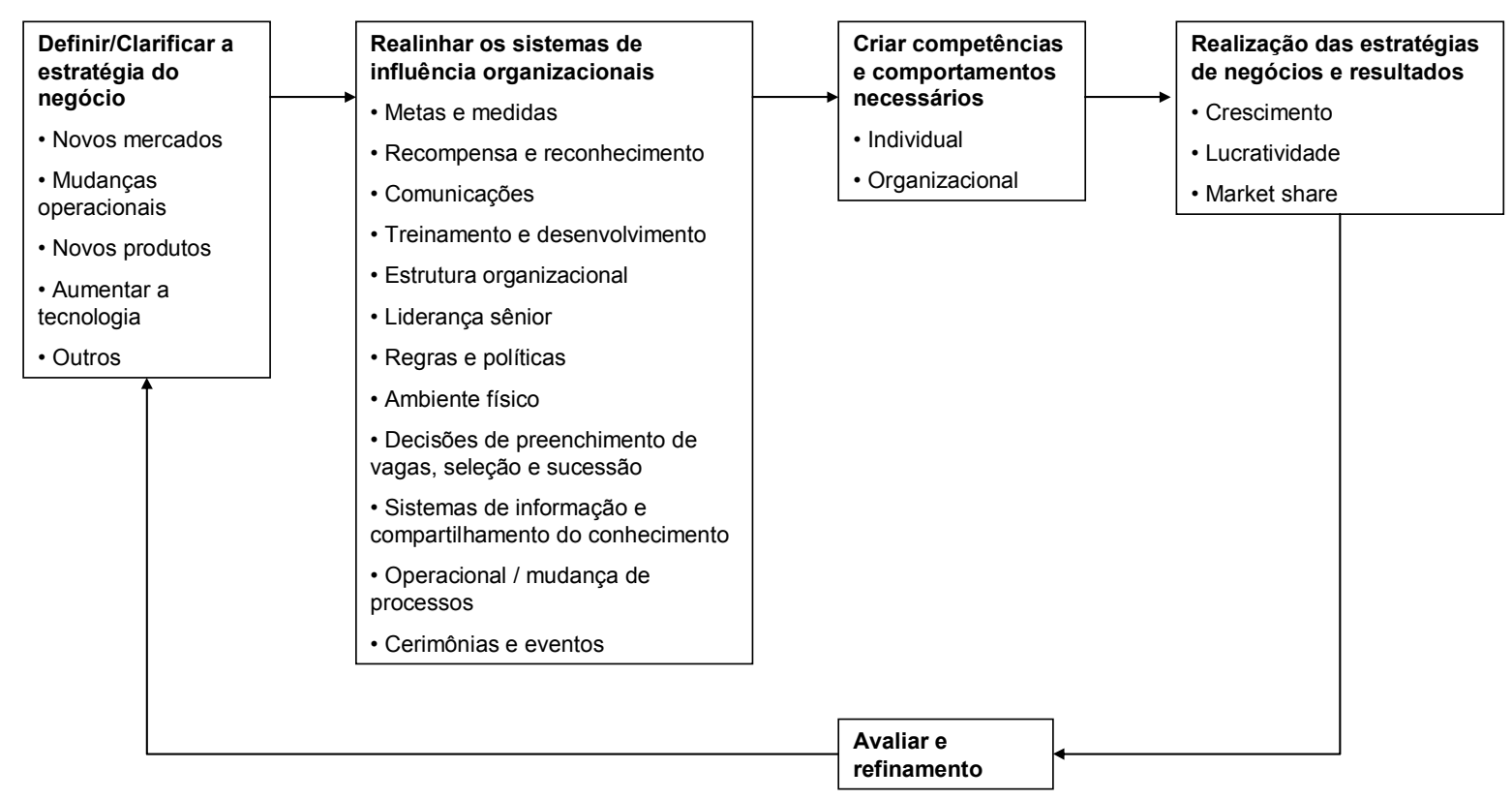

Figura 3 - Desenho representativo do modelo de Galpin (1997)

O modelo apresentado por Galpin (1997) na figura 3 está dividido em cinco etapas. A primeira etapa é a definição e clarificação da estratégia, que envolve atividades de seleção de mercados, desenvolvimento de novos produtos, identificação das mudanças necessárias e a tecnologia a ser implementada.

A segunda etapa, considerada chave para o processo, é o realinhamento dos sistemas de influência da organização. Esse realinhamento tem por premissa que os gestores não têm controle direto sobre as pessoas. Entretanto, as pessoas são influenciadas pelo ambiente de trabalho no qual vivem, pelo contexto da organização 
e agem conforme o ambiente criado, os treinamentos oferecidos, os reconhecimentos realizados, as recompensas dadas, etc.

Galpin (1997) identificou os doze principais fatores de influência apontados na figura 3, intituladas como "Realinhar os sistemas de influências organizacionais". Não há nenhum departamento ou pessoa responsável pelos sistemas de influência. A experiência mostra que não se pode ter somente uma área responsável pelos sistemas de influência, portanto, é necessário fazer um trabalho conjunto entre os gestores funcionais e de linha.

A terceira está focada na mudança estratégica baseada nos valores, crenças, comportamentos, conhecimentos e habilidades gerais. Neste momento, a empresa precisa definir os valores e comportamentos esperados, fazendo as mudanças necessárias frente à nova estratégia. Contudo, os conhecimentos, habilidades e comportamentos são mais fáceis de mudar do que os valores, que são muito enraizados nas pessoas.

A quarta etapa é a própria realização das estratégias de negócios, obtendo os seus resultados. Esse trabalho pode ter impactos em crescimento, lucratividade, participação de mercado entre outras medidas de negócios.

A última etapa é a avaliação e o refinamento do processo e das atividades realizadas.

Ao descrever essas etapas, Galpin (1997) procurou reforçar a importância de se ter um processo linear de implementação de estratégias. Antes de implementá-las é importante estabelecer um projeto. A gestão de projetos é crucial para tratar a complexidade da implementação de estratégias. É o nervo central para a coordenação de um processo compreendendo diversos subprojetos que resultam na implementação da estratégia.

Esse autor trouxe muitas contribuições no campo da implementação de estratégias. Ele foi o primeiro a reconhecer a gestão de projetos como crucial para implementação. Além de ter criado um processo lógico e de fácil compreensão tanto 
para acadêmicos quanto para as empresas. Outra inovação ao processo foi a inclusão dos sistemas de influência, onde muitos autores enfatizaram apenas alguns pontos, não os incluindo em um modelo maior, num processo linear, tornando-o mais abrangente.

Noble (1999), por sua vez, também contribuiu de forma valiosa ao apontar que existem duas visões do processo de implementação: uma estrutural e outra interpessoal. A perspectiva estrutural está voltada para a estrutura organizacional e para os mecanismos de controle da implementação. Enquanto o processo interpessoal diz respeito ao entendimento de questões relativas ao consenso das pessoas frente às estratégias, aos seus comportamentos, ao estilo de liderança presente na empresa, à comunicação e a outros processos interativos necessários para a execução da estratégia.

Okumus (2001) complementou o modelo de Noble, construindo uma abordagem conceitual que envolve diversos fatores relacionados à implementação, agrupando-os em quatro: conteúdo, contexto, processos e resultados. Esse modelo mostrou a importância do contexto em todo o processo de planejamento e implementação, bem como quais são os resultados finais esperados. Isso reforça a importância das pessoas entenderem por que estão fazendo algumas atividades.

Conteúdo da estratégia é entendido por Okumus (2001) como sendo a forma pela qual a estratégia é iniciada, considerando aspectos como consistência da nova estratégia, propósito claro das novas iniciativas, nível de participação de todos os níveis gerenciais e potenciais impactos na organização e em outros projetos.

Para o autor o contexto externo é o grau de incerteza e mudanças nas atividades e no ambiente externo. E o contexto interno envolve a estrutura organizacional, estrutura de responsabilidades e de cargos, distribuição do poder, tomada de decisão e liderança.

Os processos são entendidos como o desenvolvimento de um plano operacional, ou seja, um planejamento que define as atividades e tarefas de implementação, alocação de recursos, comunicação, fornecimento de treinamentos, pessoas e incentivos. A alocação de recursos envolve todo o processo necessário 
para assegurar que haja disponibilidade de tempo, recursos financeiros, e também, quais habilidades e conhecimentos devem estar disponíveis na época da implementação (OKUMUS, 2001).

E o último componente do modelo de Okumus (2001) abriga o resultado desejado e o indesejado, ambos obtidos com o processo de implementação, podendo ser tangíveis ou não.

Outros estudos recentes procuraram complementar e, ao mesmo tempo, sintetizar os fatores importantes na implementação de estratégias (AALTONEN e IKAVALKO, 2002; DOBNI, 2003; FREEDMAN, 2003; LINTON, 2002). Esses fatores incluem: estrutura organizacional, cultura receptiva à mudança, desenvolvimento de sistemas e habilidades para a mudança, comunicação, comprometimento dos funcionários com a visão e a utilização de incentivos.

Sterling (2003) desenvolveu um estudo que identificou que alguns fatores são importantes para o sucesso na implementação da estratégia, sendo eles:

- Alinhar o desenho e capacidades organizacionais com a estratégia. Identificar os gaps criados pela mudança da estratégia em termos de competências e capacidades;

- Considerar potencial reação dos competidores às estratégias;

- Envolver os gestores no processo de formulação da estratégia. Isso cria comprometimento e as pessoas se sentem responsáveis pelas estratégias;

- Comunicação consistente e persistente. Destacar como as ações e eventos recentes na empresa estão relacionados com a estratégia. Acompanhamento com periodicidade pelos executivos do andamento das ações, bem como comunicar esse progresso;

- Plano de ação e orçamento;

- Monitoramento, tendo responsáveis diretos pelos resultados. O monitoramento não tem grande significado se não houver responsáveis pelas atividades; 
- Ações simbólicas. Pode ter um grande poder de estímulo e reforço da implementação da estratégia. Essas ações podem incluir cerimônias, arranjo físico, a comunicação no dia-a-dia, histórias contadas, etc;

- Alinhamento dos recursos de informações com a estratégia. Aplicar a tecnologia por meio de sistemas gerenciais integrados, tecnologias de manufatura, que podem ajudar na implementação e no controle.

Hrebiniak (2005), um dos principais autores na área de implementação de estratégia, verificou, após anos de estudos, que algumas ações da empresa estavam relacionadas ao sucesso da execução, tais como:

- Desenvolver um modelo para orientar as decisões ou ações da execução;

- Entender como a criação da estratégia afeta sua execução;

- Gerenciar as mudanças de forma efetiva, incluindo as mudanças culturais. É muito mais do que manter as pessoas felizes e reduzir a resistência a novas idéias e métodos. Significa conhecer também as táticas ou as etapas necessárias para gerenciar o processo de execução ao longo do tempo;

- Entender o poder e a influência e usá-los para o sucesso da execução. Os programas de execução que entram em contradição com a estrutura de poder ou com a influência de uma organização estão condenados ao fracasso. $O$ poder reflete a estratégia, a estrutura e as dependências críticas que recaem sobre capacidades e recursos escassos. Conhecer o poder existente e saber como criar e usar a influência pode significar a diferença entre o sucesso e o fracasso da execução;

- Desenvolver estruturas organizacionais que estimulem o compartilhamento das informações, a coordenação e a clareza de responsabilidade;

- Desenvolver controles efetivos e mecanismos de feedback. Segundo o autor, esse é um dos mais importantes pré-requisitos para uma execução bemsucedida. Os gerentes devem saber quem está fazendo o quê, quando e por que, bem como quem é responsável pelas principais etapas no processo de execução;

- Saber como criar uma cultura de suporte à execução (cultura de realização, disciplina e sentimento de pertencer); 
- Aplicar a liderança com viés para a execução, estimulando o sentimento de pertencer das pessoas. A liderança afeta a forma como as organizações respondem a todos os desafios precedentes de execução.

A partir desses achados, Hrebiniak (2005) desenvolveu modelo mostrado na figura 4, no qual os conceitos são apresentados com suas relações de dependência.

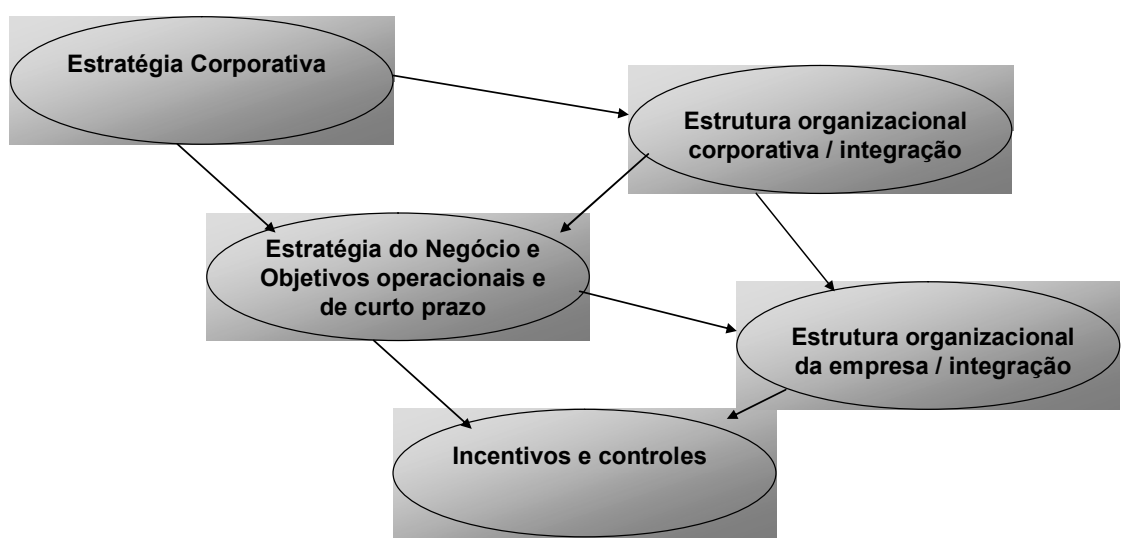

Figura 4 - Modelo de execução de Hrebiniak (2005)

Posteriormente, Hrebiniak (2006) acrescentou dois pontos ao seu modelo de implementação. O primeiro foi a noção de ter responsáveis pelos resultados finais de cada estratégia. O segundo foi a celebração do sucesso. O presidente pode prover um feedback para a organização a respeito do sucesso em relação ao desempenho e reconhecer as pessoas responsáveis pelo fruto desse sucesso. Isso reforça a importância do processo de implementação, dá um sinal de comprometimento da alta direção com o programa e mostra um exemplo a ser seguido futuramente. Tal descoberta vai ao encontro da pesquisa de Sterling (2003).

\subsection{Considerações sobre implementação de estratégias}


Dentre os autores citados, identifica-se que há três grandes categorias de soluções para o problema da implementação de estratégias (OKUMUS, 2003), conforme agrupamentos apresentados na tabela 2. A primeira categoria inclui os fatores que facilitam a implementação. A segunda é formada por autores que desenvolveram modelos lineares (passo-a-passo) para a implementação. A terceira enfatiza a importância do contexto e do processo, mas não inclui os fatores que facilitam a implementação, responsabilidades e atividades.

Tabela 2 - As 3 classificações de estudos de implementação (adaptado Okumus, 2003)

\begin{tabular}{|c|c|c|}
\hline $\begin{array}{c}\text { Autores que estudaram os } \\
\text { fatores que facilitam a } \\
\text { implementação }\end{array}$ & $\begin{array}{c}\text { Autores que desenvolveram } \\
\text { modelos passo-a-passo } \\
\text { para implementação }\end{array}$ & $\begin{array}{c}\text { Autores que enfatizam o } \\
\text { contexto e o processo }\end{array}$ \\
\hline Waterman et al. (1980) & Vasconcellos e Sá (1990) & Pettigrew (1987) \\
Stonich (1982) & Schmidt (1994) \\
Lorange (1982) & Galpin (1997) & Dawson (1994) \\
Hrebiniak e Joyce (1984) & Hussey (1996) \\
Skivington e Daft (1991) & De Feo e Janssen (2001) \\
Wessel (1993) & Hrebiniak (2005) & Hailey e Balogun (2002) \\
Al-Ghamdi (1994) & & \\
Al-Ghamdi (1998) & & \\
Bossidy e Charan (2002) & & \\
Aaltonen e Ikavalko (2002) & \\
Linton (2002) & \\
Wheelen e Hunger (2002) & \\
Sterling (2003) & \\
Dobni (2003) & \\
Freedman (2003) & \\
\end{tabular}


Apesar da maioria dos autores pesquisados se encaixar na primeira categoria, as duas outras têm ganhado um maior foco nestes últimos anos. A razão desse crescimento é a necessidade dos executivos terem um guia para fazer a implementação, levando em consideração o processo e o contexto no qual a sua empresa está inserida. É importante esse alinhamento do processo de implementação da estratégia com os contextos externo e interno. Conforme as mudanças ocorridas externamente, são necessárias modificações internas nos fatores que impactam na implementação.

Ainda que haja técnicas e fatores que facilitem a implementação, o processo é complexo e nenhuma abordagem consegue demonstrar o grau de complexidade desse processo. A grande razão desse fato está na própria base do que é um modelo, entendido como uma representação simples da realidade. É certo que o processo linear de implementação pode contribuir para facilitar o trabalho dos executivos por trazer uma abordagem lógica de implementação. Entretanto, ele não representa a complexidade desse processo e não leva em consideração o contexto da organização.

A decomposição da estratégia em atividades e ações que serão executadas em curto prazo, conforme mostra Boyadjian (2003) com o stair case, é uma das formas de reduzir a complexidade. A outra é através de um processo eficaz de gerenciamento de projetos.

Mesmo o contexto não sendo considerado, os pesquisadores que levantaram os fatores críticos de sucesso numa implementação trouxeram muitas contribuições. Somente Galpin (1997) utilizou a segunda opção, de reduzir a complexidade através do modelo linear e da utilização das técnicas de gerenciamento de projetos, para obter sucesso na implementação, por mais que o autor não o tenha detalhado o suficiente. Outros autores tangenciaram o tema ao afirmarem a importância da coordenação das atividades relacionadas à implementação, importância essa de controlar os custos, os prazos e os recursos.

É possível identificar, por meio da literatura, que a gestão de projeto pode melhorar o desempenho das pessoas e da execução das atividades, por trazer, por 
exemplo, uma clareza de papéis e de responsabilidades. Algumas dúvidas e questões enfrentadas na implementação e que poderão ser resolvidas com o uso do gerenciamento de projetos são:

- Quem irá conduzir as atividades da implementação?

- Quais atividades terão que ser executadas?

- Quem será responsável pelos resultados?

- Qual é o prazo estipulado e quem irá garantir o cumprimento dos prazos?

- Quando as pessoas estarão trabalhando para completar as tarefas?

- Quem deverá ser consultado antes da definição e da execução das atividades?

- Quais recursos deverão ser utilizados e controlados?

- Quais são os custos esperados?

- Quem deverá ser informado a respeito das atividades?

Observa-se ainda que o bom gerenciamento de projetos para a implementação de estratégias é similar ao gerenciamento eficaz de qualquer projeto. Três etapas importantes de gerenciamento de projetos devem ser atendidas. A primeira é o planejamento global do projeto. A segunda é a condução das atividades do projeto, que foram decompostas em tarefas lógicas ou subprojetos derivados da estratégia. E por último, o acompanhamento e mensuração do projeto, que envolve o acompanhamento de indicadores de progresso e a permissão do ajuste do projeto em andamento. 


\section{Revisão bibliográfica - Gerenciamento de projetos como ferramenta de implementação de estratégias}

A partir da análise do negócio são geradas as estratégias empresariais, sendo que estas podem ser implementadas por projetos. Nesta seção, será analisada a literatura de como ocorre essa interação.

No início do capítulo sobre implementação de estratégias, foram apresentados os diversos problemas que ocorrem durante a implementação. Como conseqüência destes problemas, a estratégia não passa de uma iniciativa fracassada e sem retorno para a empresa.

Contudo, Crawford, Hobbs e Turner (2005) identificaram que a alta administração acredita que os gestores de projetos não devem ser envolvidos na formulação da estratégia. Por outro lado, Thomas et al. (2002) descobriram que o gerenciamento de projetos é visto pelas pessoas como uma ferramenta orientada à execução, não sendo vista como uma importante estratégia pela alta administração. Ambos os trabalhos verificaram a necessidade de alinhar a capacidade de entrega dos projetos com a estratégia organizacional.

Archibald (2000) afirmou que para a empresa crescer, ela precisa de visão, consenso e comprometimento com o futuro, além da documentação dos objetivos, estratégias para atingir a missão e a execução de projetos específicos.

As empresas estão aumentando a percepção de que a estratégia corporativa é implementada através de projetos e que a capacidade de gerí-los é chave para o alcance da visão (TURNER apud CRAWFORD, 2005; HOBBS; TURNER, 2006). Castro (2006) identificou que "a gestão de projetos é talvez o instrumento de maior impacto na implementação efetiva de estratégias". Complementando, Kronmeyer (2003, p. 22) afirmou que: 
a estratégia de mudança e inovação das organizações é implementada através de projetos. A capacidade de implementar projetos com taxa de sucesso maior que seus concorrentes pode ser considerada uma competência essencial de uma organização como definido por Hamel e Prahalad (1994).

Mas, a razão que leva o planejamento a não funcionar está relacionada ao fato dos planos serem criados por pessoas ou equipes que não têm conhecimento ou experiência como gestores de projetos. A falha de não ter uma pessoa que conheça gerenciamento de projetos complexos, no momento do planejamento estratégico, faz aumentar o mercado de planos irrelevantes.

Outro motivo para que isto ocorra é que a gerência média considera a estratégia organizacional como responsabilidade das outras pessoas e que não tem domínio ou influência sobre a mesma (GRAY; LARSON, 2005). O que demonstra a falta de alinhamento e de cultura de implementação.

Os problemas de implementação que as empresas têm enfrentado são as maiores evidências de que várias organizações não têm desenvolvido um processo que claramente ligue a seleção de projetos ao planejamento estratégico. O resultado é a má utilização dos recursos da organização - pessoas, dinheiro, equipamentos e competências essenciais (GRAY; LARSON, 2005). A saída é considerar que os projetos devem ser freqüentemente utilizados como um meio de atingir o plano estratégico de uma organização (PMI, 2004).

Galpin (1997) também considera como parte fundamental do modelo de implementação de estratégias a gestão de projetos. O cascateamento e a implementação da estratégia podem ser endereçados pela estruturação de uma equipe de projetos e a aplicação rigorosa de uma metodologia de projetos. Uma clara coordenação, incluindo papéis e responsabilidades, tomadas de decisão, reportes, marcos, cronogramas, orçamentos e mensuração do progresso, são muito importantes para a obtenção do sucesso (lbid). 
A prática do gerenciamento de projetos traz a disciplina da execução que falta nas empresas. Assegurar a forte ligação entre o plano estratégico e projetos é uma tarefa demandante de muita atenção da alta e média gestão. Segundo Gray e Larson (2005), a implementação deve incluir atenção a diversas áreas-chave:

\footnotetext{
Primeiro, realizar tarefas requer alocação de recursos. Recursos tipicamente representam fundos, pessoas, gestão de talentos, habilidades e equipamentos. Frequentemente, implementação de projetos é tratada como um addendum ao invés de se tornar uma parte integral do processo de gestão estratégica. Entretanto, os diversos objetivos colocam conflitos de demandas nos recursos organizacionais. Segundo, a implementação requer uma organização formal e informal que complementa e suporta a estratégia e projetos. Autoridade, responsabilidade e desempenho, todos dependem da estrutura organizacional e cultura. Terceiro, sistemas de planejamento e controle devem estar no lugar de certas atividades do projeto necessárias para assegurar que as estratégias sejam eficazes. Quarto, os participantes motivados dos projetos poderão ser um grande fator no alcance do sucesso do projeto. Finalmente, a área que tem recebido mais atenção nos últimos anos é a priorização de projetos.
}

A estratégia da companhia deve guiar o critério de priorização de projetos. Os indicadores escolhidos e os respectivos pesos deverão estar alinhados com a estratégia. Dessa maneira, todos os projetos que serão iniciados serão explicitamente suportados pela estratégia da empresa. Um estudo revelou que empresas de sucesso no gerenciamento estratégico tendem a revisar os objetivos dos projetos em andamento, verificando o grau de ligação com a estratégia formulada (DIETRICH E LEHTONEN, 2005).

De acordo com a literatura, além da priorização, existe uma série de técnicas e ferramentas de gestão de projetos que podem auxiliar na implementação de estratégias, e que asseguram o cumprimento de prazo, orçamento, escopo e o alinhamento com a estratégia. Essas técnicas, tais como o cascateamento com alinhamento, a gestão de portifólios, o escritório de gerenciamento de projetos (PMO), bem como as ferramentas tradicionais de gestão de projetos abrangidas pelas nove áreas do conhecimento, citadas anteriormente, serão detalhadas adiante. 
Outro conceito que será detalhado posteriormente é o de maturidade de gestão de projetos, que procura mensurar o estágio atual do gerenciamento de projetos na empresa.

\subsection{Cascateamento com alinhamento}

Um estudo mostrou que apenas 14\% das empresas têm um processo de ligação formal entre o planejamento estratégico e os projetos, e $25 \%$ das empresas acreditam que poderiam melhorar essa conexão (CHINOOK SOLUTIONS, 2006).

Outra pesquisa, mais otimista, verificou que $90 \%$ das empresas diziam ter uma boa ou ótima conexão entre a estratégia e a gestão de projetos, sendo que $53 \%$ das empresas utilizavam o processo de cascateamento da estratégia em projetos para realizar esse alinhamento. Cerca de $75 \%$ das empresas utilizavam parte da estratégia como subsídio no gerenciamento de projetos (MORRIS; JAMIESON, 2005).

Conforme os autores da pesquisa acima, é esperado que as empresas alinhem suas estratégias através dos portifólios de projetos e de programas de modo sistemático, estruturado, utilizando também, a hierarquia de estratégias e objetivos. Esse processo começa com o cascateamento da visão para estratégia. O passo seguinte é realizar o mesmo alinhamento iniciando com a estratégia e derivando para os objetivos e iniciativas. Por fim, o processo ocorre com a tradução em projetos, formando um método sistemático e estruturado (MORRIS; JAMIESON, 2005).

Apesar de Morris e Jamieson (2005) mostrarem a importância do alinhamento das estratégias através de portifólios, os autores não propuseram um framework e nem trouxeram casos detalhados de como fazer esse alinhamento. A seguir serão apresentados três modelos de cascateamento da visão para projetos. 


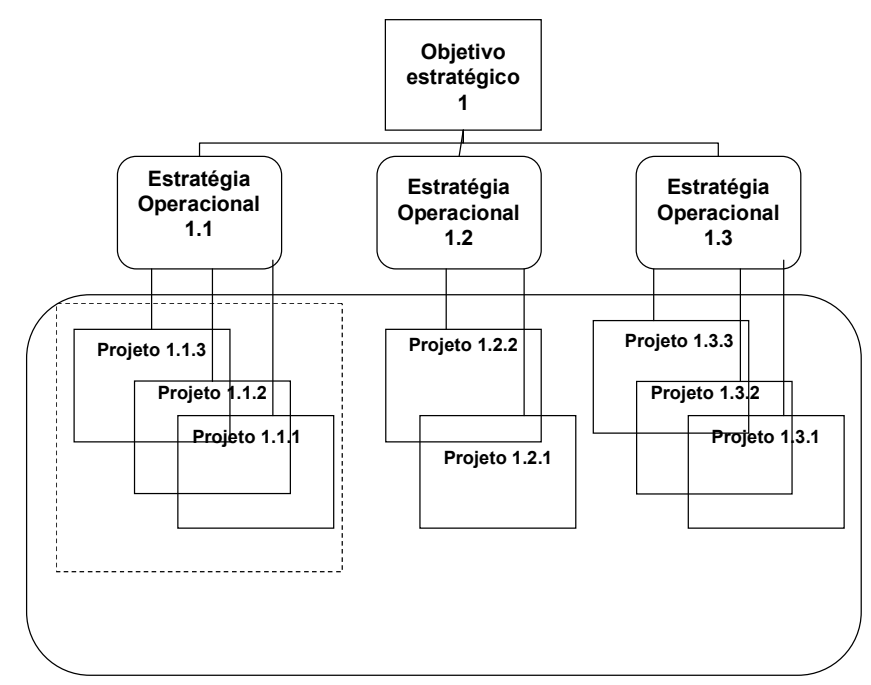

Figura 5 - Estratégia, projetos, programas e portifólio de projetos (ARCHIBALD, 2003, p.13)

Archibald (2003) vê a gestão de projetos como a executora de esforços específicos para atingir as estratégias de crescimento. Para planejar, controlar e liderar cada projeto simultaneamente com outros projetos de forma eficaz, para que cada um atinja seus objetivos, ou seja, alcançar os objetivos estratégicos relacionados produzindo resultados específicos dentro do prazo e do orçamento. Esse modelo prevê para cada objetivo estratégico da empresa o cascateamento para estratégias operacionais e posteriormente para projetos. Com isso, cada projeto deverá suportar uma estratégia.

O autor também verificou que nem todas as implementações da estratégia são de cima para baixo, do nível corporativo para o portifólio de programas e projetos. Há também projetos e programas que emergem dos níveis hierárquicos mais baixos das unidades de negócios. As estratégias emergentes são aquelas que não foram planejadas pela alta direção e cascateadas para os níveis hierárquicos inferiores. Um desafio importante é o estímulo à participação das pessoas procurando utilizar-se das estratégias que surgem das necessidades de negócios (ARTTO E DIETRICH apud SRIVANNABOON, 2006). 


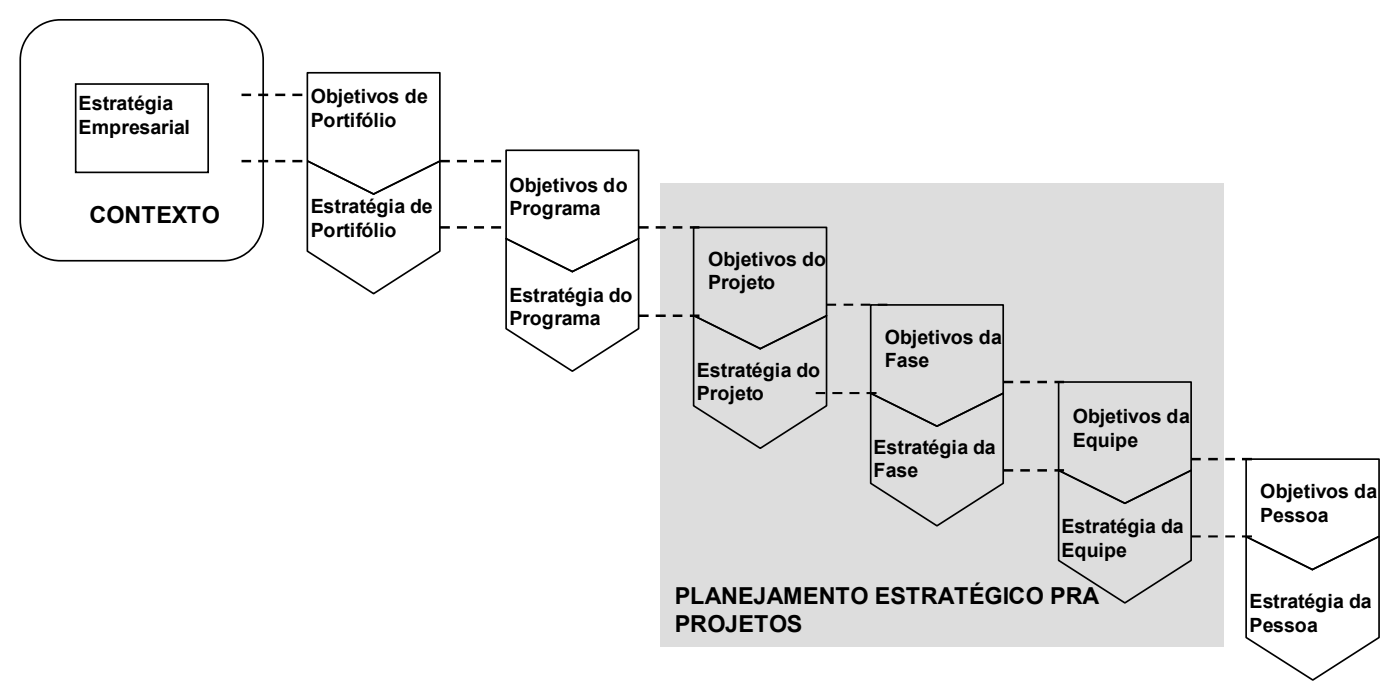

Figura 6 - Alinhamento da estratégia com objetivos do portifólio, programa e projetos (TURNER, 1999)

O modelo de Turner (1999), figura 6, mostra que o cascateamento da estratégia acontece através do alinhamento da estratégia e objetivos do portifólio, programas e projetos, até chegar ao nível do indivíduo.

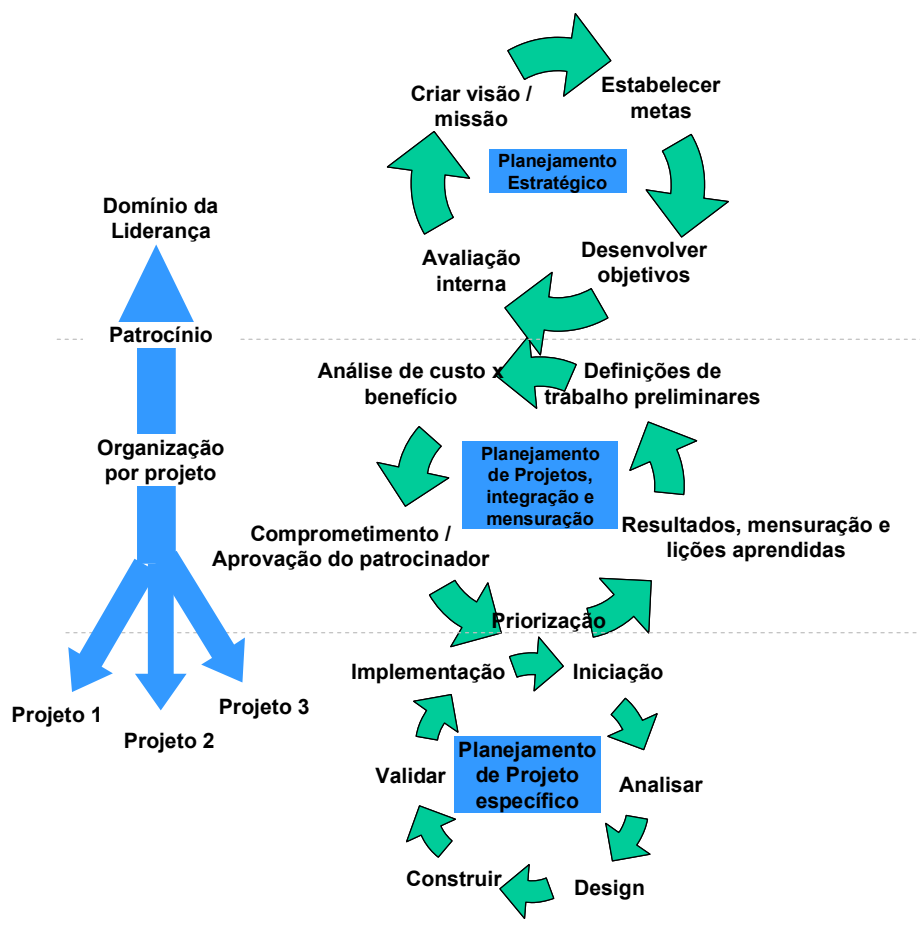

Figura 7 - As três etapas do cascateamento de Gaddie (2002) 
O modelo de Gaddie (2002), figura 7, demonstra o cascateamento em três níveis: o planejamento estratégico, que está nas responsabilidades dos executivos, a organização de projetos e os projetos propriamente ditos.

O primeiro nível é o planejamento estratégico no qual se busca o comprometimento das pessoas com a visão, estratégia e o direcionamento. Há também uma fase intermediária que envolve a aprovação do orçamento, definição dos objetivos e escopo. O segundo nível envolve a integração e interação entre os projetos. No terceiro ocorre o desenvolvimento de projetos específicos.

Um exemplo é a Halliburton Energy Services Group que procurou integrar suas estratégias, projetos e alocação de capital (orçamento). Anteriormente esses processos eram separados e recentemente foram unificados em apenas um processo, com o objetivo de alinhá-los. A empresa criou um processo de planejamento estratégico e de orçamento composto por um grupo de executivos seniores. Esse grupo decide como os fundos da companhia serão utilizados para atingir as estratégias. Somente as iniciativas ligadas às prioridades estratégicas irão obter fundos. Isso assegura o balanceamento das estratégias de longo prazo com a restrição financeira de curto prazo. As empresas que utilizam um sistema para assegurar o balanceamento, quando têm suas estratégias aprovadas, em geral estas são traduzidas em iniciativas ou campanhas estratégicas (ROTHSCHILD; DUGGAL; BALABAN, 2004). Vide figura 8. 


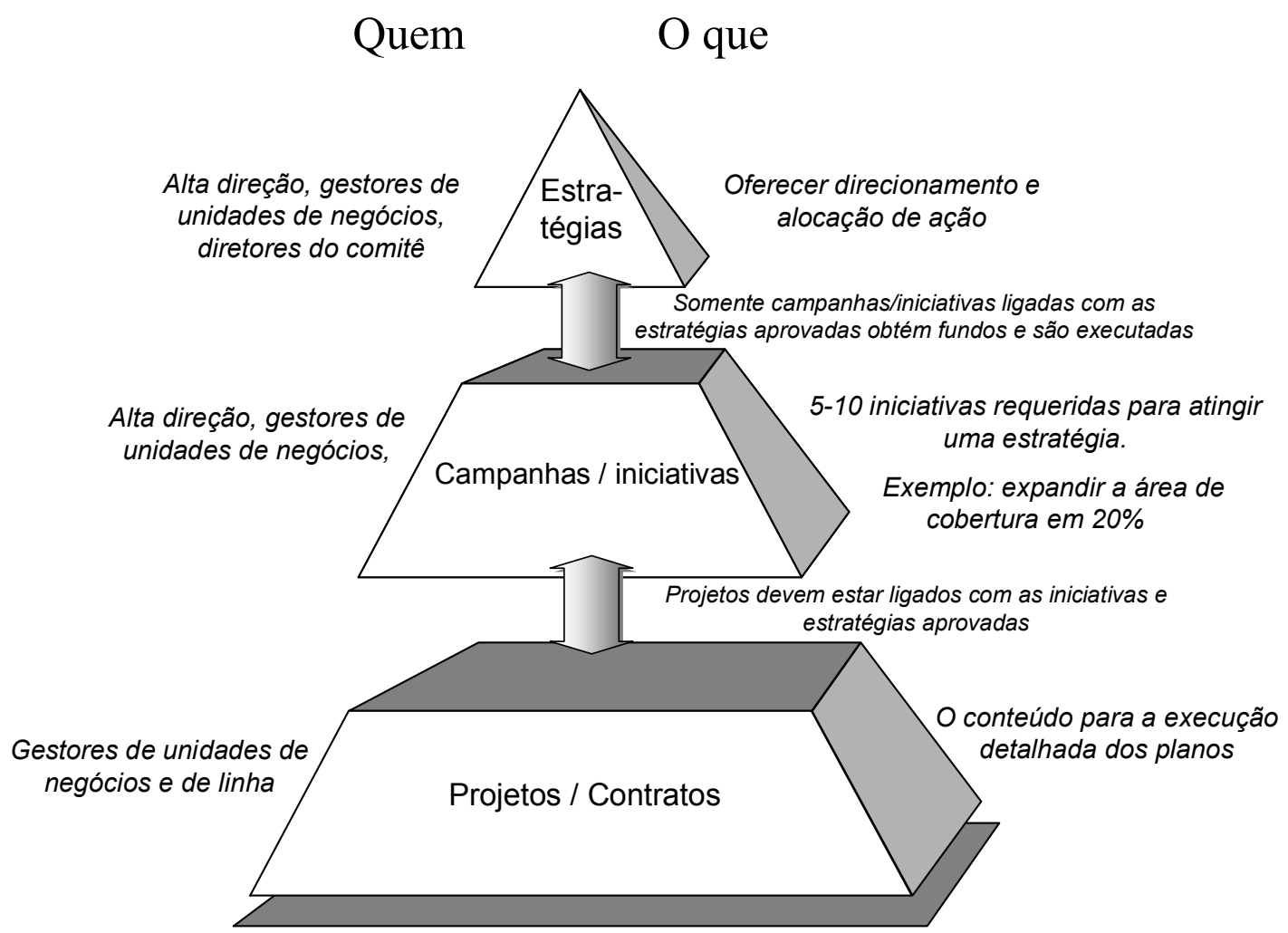

Figura 8 - Da estratégia a projetos. Adaptado de Rothschild, Duggal e Balaban (2004)

Villachica, Stone e Endicott (2004) recomendam que o alinhamento das estratégias e objetivos da organização deve ocorrer com os fatores críticos de sucesso que o projeto deve atingir. Esses fatores afetam o patrocinador do projeto, as partes interessadas, o desenvolvimento do projeto e a equipe de implementação. O que pode levar ao aumento das vendas, à satisfação do cliente, à produtividade, à redução do tempo para o mercado, etc.

Para cada fator crítico de sucesso há indicadores e medidas relacionadas, bem como as fontes de obtenção dos dados. A tabela a seguir mostra um exemplo de como pode ser conduzida essa fase: 
Tabela 3 - Alinhamento dos fatores críticos de sucesso, indicadores, medidas e fontes de obteção Villachica, Stone e Endicott (2004)

\begin{tabular}{|l|l|l|l|}
\hline $\begin{array}{l}\text { Fatores críticos de } \\
\text { sucesso }\end{array}$ & Possíveis indicadores & Mensuração & Fontes \\
\hline $\begin{array}{l}\text { Treinamento em just-in-time e } \\
\text { suporte online pode reduzir o } \\
\text { tempo ao mercado em 20\% }\end{array}$ & $\begin{array}{l}\text { Dados de Tempo ao mercado, } \\
\text { coletados a cada trimestre }\end{array}$ & $\begin{array}{l}\text { Os novos engenheiros navais } \\
\text { estão desenvolvendo novos } \\
\text { navios de forma mais rápida }\end{array}$ & $\begin{array}{l}\text { Formulários do } \\
\text { departamento de treinamento } \\
\text { desenvolvimento de } \\
\text { Lista de novos produtos }\end{array}$ \\
\hline $\begin{array}{l}\text { As ferramentas de marketing } \\
\text { permitirão aos gestores de } \\
\text { vendas aumentarem o market } \\
\text { share em um nicho específico }\end{array}$ & $\begin{array}{l}\text { Dados de vendas, coletados a } \\
\text { cada trimestre }\end{array}$ & $\begin{array}{l}\text { Como será o market share } \\
\text { deste nicho para os nossos } \\
\text { produtos comparados com o } \\
\text { atual }\end{array}$ & Relatórios de vendas \\
\hline
\end{tabular}

Há autores que sugerem a construção de tabelas e planilhas para iniciar a relação entre a estratégia e o gerenciamento de projetos (tabela 4). Essas tabelas podem ser úteis para os praticantes da área.

Tabela 4 - Estratégia x projetos (STRATEGIS, 2007)

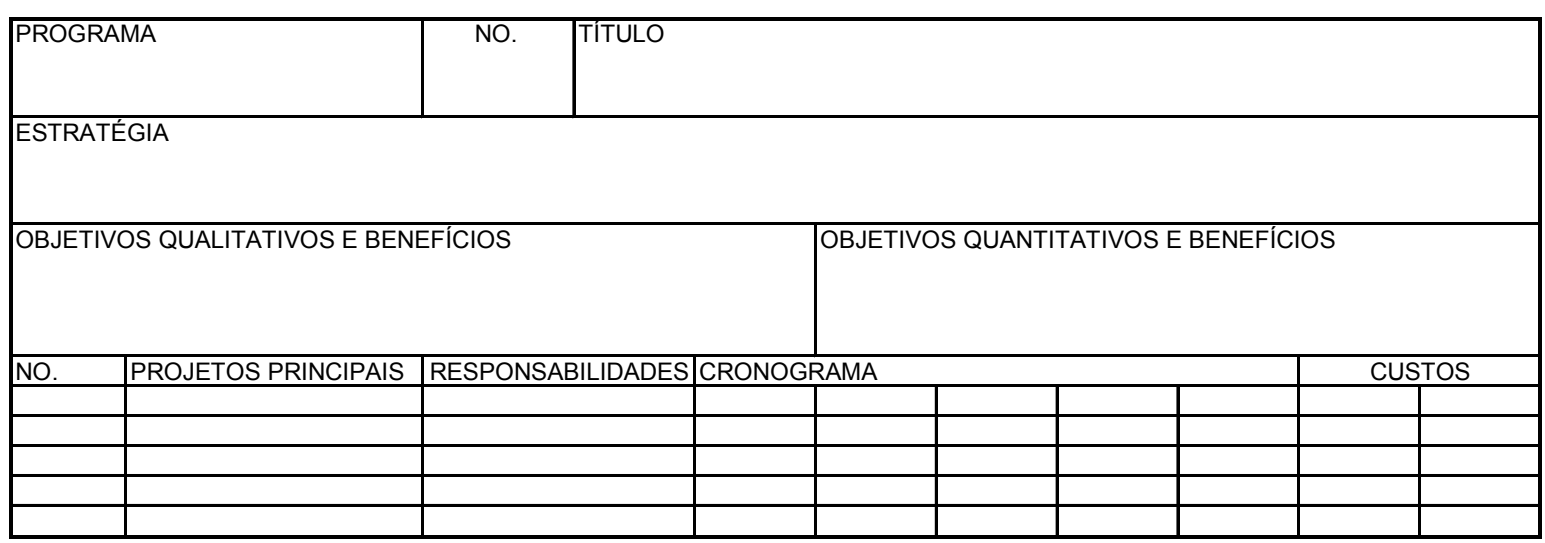

\subsection{Gestão de portifólio de projetos}

A ligação da estratégia da empresa com o portifólio de projetos é fundamental, principalmente quando há inovação, crescimento e desenvolvimento de novos produtos. Contudo, a literatura de como fazer essa ligação é diversificada, cheia de remendos e incompleta. Já a literatura sobre gestão de portifólio é quase completa do ponto de vista analítico e não relativo à implementação (MORRIS e JAMIESON, 2005). 
Apesar de a literatura ser escassa, verifica-se que o conceito é muito importante. Às vezes o processo de planejamento estratégico é adequado, porém a implantação peca pela amplitude. Trata-se de fazer a grande mudança e termina-se não mudando nada. Outras vezes não é a amplitude, mas a quantidade de frentes que se abre é ampla demais, perdendo-se o foco do que seja prioritário. O portifólio de projeto pode ser a solução (GAJ, 2002).

Uma forma de fazer o alinhamento do estado desejado (a visão) e a execução dos objetivos da companhia é criar e analisar um portifólio de projetos, observando o grau de contribuição e alinhamento de cada projeto frente às estratégias da companhia.

A gestão de portifólio de projetos é definida como a arte e a ciência da aplicação do conjunto de conhecimentos, habilidades, ferramentas e técnicas para a coleção de projetos ou programas, visando atingir ou exceder as necessidades e expectativas da estratégia de investimentos da organização (DYE; PENNYPACKER apud MORRIS e JAMIESON, 2005). De acordo com os autores Platje, Seidel e Wadman apud Morris e Jamieson (2005), o portifólio de projetos é um conjunto de projetos que são gerenciados de forma coordenada para entregar benefícios que não são possíveis de entregar se os projetos forem gerenciados de forma independente.

Segundo Archer e Ghasemzadeh apud Morris e Jamieson (2005), "a gestão de portifólios é uma etapa de seleção ou priorização dos melhores projetos ou programas para proceder com a execução". "Através da gestão de portifólios é possível avaliar, priorizar, selecionar, orçar e planejar os projetos corretos (...), esses que irão oferecer um grande valor e contribuição para os interesses estratégicos da organização" (BIGELOW, 2006). A gestão de portifólio de projetos é a seleção do projeto certo, enquanto a gestão de projetos dita como fazer corretamente o projeto (COOKE-DAVIES, 2004).

O portifólio tem como premissa a escassez e otimização de recursos na seleção de projetos, a sinergia entre eles e a ligação com a estratégia da 
companhia. A análise de portifólios requer foco, tempo e atenção, com isso pode ajudar os gestores a avaliar mais precisamente as necessidades de recursos.

Dietrich e Lehtonen (2005) selecionaram empresas que demonstraram sucesso ao longo de muitos anos. Eles concluíram que estas empresas agruparam os projetos em programas, além destas terem avaliado e comparado suas idéias de projetos quando selecionaram novos projetos para serem implementados. Houve correlação significativa estatisticamente no processo de utilização de métodos de avaliação de projetos e idéias, com o sucesso da organização.

Adicionalmente, diversas organizações de sucesso revisam seu portifólio de projetos constantemente, ligando com o processo de acompanhamento da estratégia (DIETRICH; LEHTONEN, 2005).

O alinhamento do portifólio de projetos pode ter alguns entraves (BIGELOW, 2006), tais como:

- Processos organizacionais rígidos demais;

- Ferramentas de gestão inadequadas ou inexistentes;

- Falta de comunicação;

- Falta de foco;

- Falta de treinamento gerencial - foco no planejamento ao invés de execução;

- Falta de recursos;

- Falta de políticas de governança.

O processo de gerenciamento de portifólio de projetos é composto em doze etapas (ARCHIBALD, 2003):

1. Definir os portifólios de projetos necessários.

2. Definir as categorias de projetos em cada portifólio baseados em um critério uniforme.

3. Identificar e agrupar os projetos novos e atuais dentro das categorias e programas apropriados. 
4. Validar/alinhar todos os projetos com os objetivos estratégicos da organização.

5. Priorizar os projetos dentro do portifólio e programas.

6. Desenvolver o cronograma geral do portifólio de projetos.

7. Estabelecer e manter banco de recursos críticos.

8. Alocar os recursos disponíveis para os programas e projetos dentro dos portifólios.

9. Comparar as necessidades financeiras com a disponibilidade.

10. Decidir como responder sobre a falta de dinheiro ou recursos e aprovação dos projetos fundeados e suas prioridades.

11. Planejar, autorizar e gerenciar cada programa e projeto usando os processos de gerenciamento de projetos, as ferramentas e sistemas para cada tipo de projeto.

12. Periodicamente avaliar as prioridades, realocar os recursos e reprogramar os prazos de todos os programas e projetos requeridos para cada portifólio.

\subsection{Utilização das técnicas e conceitos de gerenciamento de projetos (gestão estratégica de projetos)}

Outra forma de ligar a estratégia com a gestão de projeto é a definição e execução de cada uma das técnicas e conceitos de gerenciamento de projetos, colocando em prática seus benefícios.

Há diversas atividades de gerenciamento de projetos que podem auxiliar na implementação de estratégias (ECONOMIST INTELLIGENCE UNIT, 2007), sendo algumas delas:

- Identificação/análise das partes interessadas;

- Clarificação de papéis e responsabilidades;

- Definição dos recursos e dos prazos necessários para implementação;

- Diagnóstico das necessidades principais e problemas subjacentes; 
- Desenho da estratégia de projetos;

- Mensurar o sucesso da estratégia;

- Desenvolvimento de abordagens de governança em gerenciamento de projetos;

- Desenho das atividades de iniciação cobrindo: objetivos, escopo, análises de custo $\mathrm{x}$ benefícios, alocação de recursos, análise de risco, medidas de sucesso etc;

- Desenho do processo de controle de gerenciamento de projetos abrangendo: status do projeto, controle financeiro, identificação e gerenciamento de riscos e escopo do projeto.

Existem outras técnicas não mencionadas, mas que foram apresentadas no terceiro capítulo que, segundo a literatura, podem também ajudar na implementação. Grundy (1998) propôs uma ampla variedade de técnicas de gestão de projetos voltadas à implementação de estratégias, tais como o planejamento de cenários, estratégia de projetos, análise das partes interessadas (stakeholder), etc. Entretanto, não havia um modelo ou integração das técnicas entre si.

O planejamento de cenários envolve o entendimento dos cenários atuais e possíveis cenários futuros nos quais as estratégias estarão inseridas. Enquanto que a estratégia do projeto visa facilitar o alinhamento entre projetos e estratégias. A técnica procura auxiliar na sistematização da definição e desenvolvimento do projeto com as estratégias e objetivos corporativos. A maneira pela qual o projeto será conduzido é a própria estratégia do projeto (MORRIS e JAMIESON, 2005). Já a análise das partes interessadas é o processo de identificação sistemática dos principais envolvidos no projeto, avaliando a atitude de cada um deles frente à implementação dos projetos e como é possível influenciá-los em prol dos resultados finais esperados. Isso também pode envolver a criação de estratégias para remodelar o tipo de influência de cada interessado ou o envolvimento de novos stakeholders (Grundy, 1998).

Em outras palavras, a análise das partes interessadas ajuda a guiar a estratégia de implementação de projetos através da (Grundy, 1998): 
- identificação de quem são as partes interessadas em todas as fases de implementação;

- avaliação do nível de influência que as partes interessadas têm;

- avaliação do nível de apoio que você terá das partes interessadas.

Apesar de Grundy (1998) não ter criado um tipo de modelo a partir das diversas ferramentas apresentadas, posteriormente ele e outro autor construíram modelos de como fazer a estratégia acontecer. A seguir serão apresentados os dois modelos, um que tem a gestão de projetos mais presente no início do processo (Galpin, 1997) e o outro na qual a gestão está no centro do modelo (Grundy, 2001).

O modelo de Galpin (1997) para implementação de estratégias envolve seis passos, sendo que o primeiro deles é o estabelecimento do projeto. $O$ autor defende a incorporação da gestão de projetos em seu modelo afirmando que "é crucial para tratar a complexidade da implementação de estratégias. É o nervo central para a coordenação de um processo compreendendo diversos subprojetos que resultam na implementação da estratégia". Nesse modelo são necessários três elementos críticos do gerenciamento de projetos para a obtenção de uma implementação eficaz das estratégias, sendo eles:

- Estrutura do projeto: definição de quem trabalhará nos esforços da implementação, quem será o gestor do projeto, as linhas de reporte, onde e como as decisões serão tomadas, como os participantes se comunicarão, entre outros aspectos;

- Atividades do projeto: divisão do projeto em tarefas ou subprojetos gerenciáveis, com a definição de responsabilidades;

- Acompanhamento e mensuração do projeto: identificação de medidas de acompanhamento do progresso do projeto que possam permitir o ajuste no projeto em andamento.

Em 2001, Grundy trouxe uma grande contribuição, o conceito de gerenciamento de projetos estratégicos. Esse termo é definido como o processo de 
gerenciamento de projetos que envolve a combinação da análise de negócios e as técnicas de projetos com o objetivo de implementar as estratégias de negócios e alcançar resultados (GRUNDY, 2001).

Ainda segundo o autor, existem cinco passos para implementar o gerenciamento de projetos estratégicos:

- Definição do projeto. Este item é muito semelhante ao modelo de Galpin apresentado anteriormente;

- Criação da estratégia do projeto;

- Detalhamento do planejamento do projeto;

- Implementação e controle;

- Revisão e aprendizagem.

O primeiro tópico do modelo é a definição do projeto. Essa etapa envolve atividades como o diagnóstico dos problemas os quais o projeto pretende sanar, a definição do escopo, objetivos e foco do projeto, o tempo de duração, clarificar alguma interdependência entre os projetos e criar uma visão geral para o projeto. A análise das partes interessadas também será uma atividade necessária nesta etapa (GRUNDY, 2001).

O segundo item do modelo é a criação das estratégias dos projetos. Nessa etapa são conduzidas análises ambientais detalhadas do ambiente externo e interno para o projeto. Além de serem definidas com maiores detalhes as principais metas dos projetos, examinando opções do que deve ser feito ou não, as atratividades dos projetos e as dificuldades a serem enfrentadas (GRUNDY, 2001).

O terceiro tópico são os detalhamentos dos projetos. Isso requer analisar detalhadamente as principais atividades e/ou sub-projetos, verificando o nível de integração com as estratégias dos projetos e o seqüenciamento das atividades, dada as interdependências. A abordagem financeira também terá um grande peso, 
pois analisará os valores dos ganhos dos projetos (lucro, produtividade, etc) e os custos envolvidos (GRUNDY, 2001).

Na fase de implementação e controle são definidos os marcos do projeto e responsabilidades, bem como os planos de ações para os possíveis problemas e dificuldades a serem enfrentados (GRUNDY, 2001). É nesta fase que ocorre a execução do que foi planejado anteriormente.

E por último, a fase de revisão e aprendizagem que envolve atividades como a avaliação dos projetos, verificando se os resultados e objetivos foram atingidos e o posicionamento político do projeto. Além disso, é neste momento que as pessoas podem relembrar e rever os comportamentos adotados durante o projeto, bem como documentar as lições aprendidas dos projetos (GRUNDY, 2001).

Constata-se ainda que o alinhamento da estratégia com os elementos do gerenciamento de projetos, também, pode ser feito através da mudança do enfoque da gestão de projetos de acordo com o posicionamento estratégico da companhia no mercado. Se a empresa foca na qualidade do produto, a gestão de projetos focará nas especificações e na entrega do escopo declarado. Se a empresa foca no tempo para chegar seus produtos ao mercado (time-to-market), desde a etapa de desenvolvimento do produto até a sua distribuição, o foco será na gestão de prazos.

Além de o foco ser diferente na gestão de projetos, a estratégia, organização, processo, ferramentas, métricas e a cultura de projetos serão diferentes, conforme a figura a seguir (SRIVANNABOON e MILOSEVIC, 2006): 


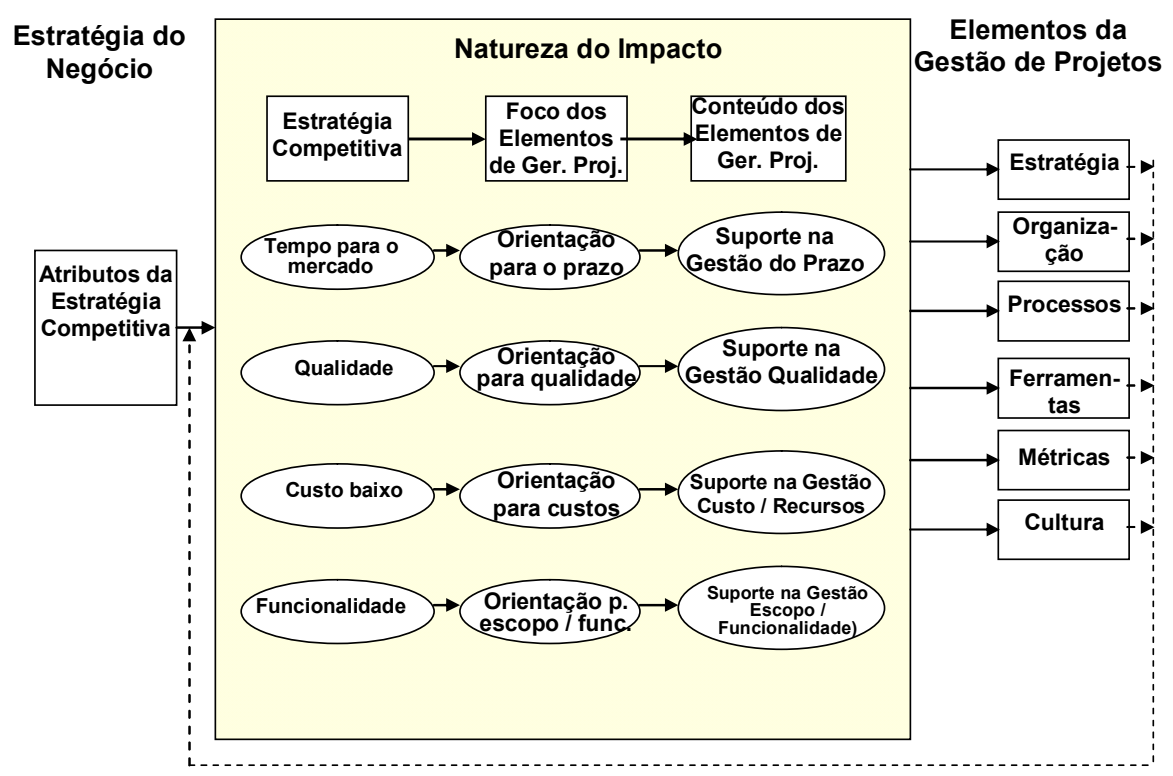

Figura 9 - Teoria de alinhamento do gerenciamento de projetos com o posicionamento competitivo da companhia / estratégia (SRIVANNABOON; MILOSEVIC, 2006)

Srivannaboon e Milosevic (2006) desenvolveram uma tabela detalhada com o alinhamento desses elementos da gestão de projetos e o posicionamento competitivo da companhia (custos, diferenciação, etc). Vide tabela 5.

Tabela 5 - Elementos da gestão de projetos alinhados com o posicionamento competitivo (SRIVANNABOON; MILOSEVIC, 2006)

\begin{tabular}{|c|c|c|}
\hline & \multicolumn{2}{|c|}{ Grau de diferenciação } \\
\hline & Baixo & Alto \\
\hline$\stackrel{0}{\frac{2}{4}}$ & & $\begin{array}{l}\text { (1) Estratégia de Diferenciação } \\
\text { (Exemplos: tempo para o mercado ou qualidade) } \\
\text { Ênfase em: } \\
\text { (Estratégia) Mensuração do sucesso do } \\
\text { projeto com base da gestão do tempo ou da } \\
\text { qualidade } \\
\text { (Organização) A estrutura flexível para facilitar } \\
\text { o andamento do projeto ou qualidade do } \\
\text { produto } \\
\text { (Processo) Processo flexível para aumentar a } \\
\text { velocidade do projeto ou maximizar a } \\
\text { qualidade do produto } \\
\text { (Ferramentas e Métricas) Métricas e } \\
\text { ferramentas orientadas para o prazo ou } \\
\text { qualidade } \\
\text { (Cultura) Recompensa pela agilidade (tempo } \\
\text { ao mercado) ou qualidade }\end{array}$ \\
\hline \multirow{8}{*}{$\begin{array}{l}\frac{0}{x} \\
\frac{\mathbb{\pi}}{\pi}\end{array}$} & (2) Estratégia de liderança em custo & (3) Estratégia best-cost \\
\hline & (Exemplo: melhoria do processo) & (Exemplo: Qualidade / Custo) \\
\hline & Ênfase: & Ênfase: \\
\hline & $\begin{array}{l}\text { ' (Estratégia) Métricas de sucesso do projeto voltas para } \\
\text { custo / benefício }\end{array}$ & $\begin{array}{l}\text { ' (Estratégia) Métricas de qualidade e custo do } \\
\text { projeto }\end{array}$ \\
\hline & $\begin{array}{l}\text { (Organização) Estrutura flexível para adaptar à } \\
\text { mudanças na melhoria de processos }\end{array}$ & $\begin{array}{l}\text { (Organização) A estrutura flexível para assegurar } \\
\text { a melhor qualidade do produto num custo mínimo }\end{array}$ \\
\hline & $\begin{array}{l}\text { '(Processos) Processos padronizados ou guiados por } \\
\text { templates }\end{array}$ & (Processos) Processo padronizado mas flexível \\
\hline & ' (Ferramentas e Métricas) Ferramentas e métricas & orientadas à qualidade/custo \\
\hline & $\begin{array}{l}\text { orientadas a prazo e custo } \\
\text { (Cultura) Cultura de consciência dos custos }\end{array}$ & $\begin{array}{l}\text { ' (Cultura) Recompensa a cultura da qualidade / } \\
\text { custo }\end{array}$ \\
\hline
\end{tabular}


Esse estudo complementou o trabalho de Morris e Jamieson (2005), mostrando o alinhamento dos elementos de gestão de projetos com a estratégia da empresa (posicionamento de custos, diferenciação, foco). O estudo apresentou oito casos, mostrando como ocorre o alinhamento no nível estratégico, tático e no nível de projetos com os elementos de gestão de projetos.

O estudo procurou criar uma teoria profunda e validá-la através dos casos. Apesar desses oito casos serem um número suficiente para a criação e validação de teorias, Eisenhardt (1989), sugeriu possíveis alternativas para continuar esse trabalho, sendo uma delas criar um método de mensuração para poder comparar os diversos casos de alinhamento de estratégias de negócios e tipos de projetos. O autor também citou a necessidade de ter um estudo mais amplo, com mais empresas participando, que enfocasse aspectos quantitativos, podendo utilizar técnicas de correlação entre os diversos tipos de estratégia e os elementos de gerenciamento de projetos. Nesta dissertação procurou-se seguir, em parte, nesta última linha de pesquisa definida por Srivannaboon e Milosevic (2006).

\subsection{PMO}

O último componente da implementação de estratégias através do gerenciamento de projetos, que foi tratado pela literatura, é a utilização do conceito de Project Management Office (PMO) ou a sua tradução, Escritório de Gerenciamento de Projetos. O PMO é um local físico dentro de uma organização que abriga pessoas com conhecimentos de gerenciamento de projetos capazes de fornecer apoio aos gerentes de projetos, ao time do projeto e aos patrocinadores. As questões relevantes para o sucesso dos projetos são discutidas, auxiliando os gerentes nas tomadas de decisão, concentrando-se no planejamento, priorização e execução coordenada de projetos vinculados aos objetivos gerais da organização (LESSA, 2007).

Outro papel do PMO é o de auxiliar na obtenção e avaliação das informações, na avaliação e seleção das estratégias e no controle da implementação através da 
execução com sucesso dos projetos, resultando no cumprimento das metas da organização (KRONMEYER FILHO e VALANDRO, 2004).

O PMO procura pesquisar e difundir as melhores práticas de gerenciamento de projetos dentro da empresa. De acordo com Crawford (2002), no nível mais avançado, o Escritório de Projetos realiza as seguintes atividades:

- Selecionar, priorizar e garantir a integração dos projetos que estejam alinhados à estratégia da organização;

- Desenvolver, atualizar e divulgar a metodologia de gerenciamento de projetos, bem como divulgar o conhecimento em gerenciamento de projetos;

- Tornar-se um centro de gestão do conhecimento por meio do armazenamento de informações dos projetos na forma de lições aprendidas;

- Validar as estimativas de recursos feitas pelos projetos, baseado nas experiências de projetos anteriores.

\subsection{Maturidade}

O meio pelo qual é possível verificar o estágio em que a empresa se encontra em termos de gerenciamento de projetos é denominado de níveis de maturidade.

Os três modelos mais utilizados nas empresas e entre os pesquisadores são o OPM3 do PMI, o KPMMM, de Kerzner e o PMMM da PM Solutions.

Para Kerzner (2002), a maturidade em gestão de projetos é definida como "desenvolvimento de sistemas e processos que são por natureza repetitivos e garantem uma alta probabilidade de que cada um deles seja um sucesso."

Conforme a LSM-International (2001, p.4), maturidade em gerenciamento de projeto é "o método de mensuração da extensão dos processos de gerenciamento de projetos definidos, implementados, gerenciados, mensurados e controlados". 
O modelo de maturidade geralmente é composto por cinco níveis de complexidade divididos nas nove áreas do conhecimento do gerenciamento de projetos. Assim, através de questionários e avaliações é possível verificar o estágio de maturidade da companhia no processo de gerenciamento de projetos como um todo ou para cada área do conhecimento, comparando aos níveis de maturidade definidos pelos autores em cima das práticas geralmente aceitas de gerenciamento de projetos. Dessa maneira, é possível identificar os pontos fortes e os de melhoria.

As premissas dos modelos de maturidade são a padronização e a melhoria das práticas em gestão de projetos das empresas, buscando a disseminação da cultura de projetos e a melhoria contínua (KERZNER, 2002), bem como o aumento do sucesso na condução de projetos (CRAWFORD, 2002).

Gareis apud Caulliraux e Valadares (2005) associa a maturidade em gestão de projetos à competência da organização para realizar os processos que os autores afirmam serem críticos para uma empresa orientada para projetos.

Kerzner (2001) desenvolveu um modelo de maturidade que avalia cinco níveis de classificação da maturidade de gestão de projetos, sendo eles: linguagem comum, processos comuns, metodologia singular, benchmarking e melhoria contínua. Esse modelo foi baseado no Capability Maturity Model (CMM), publicado em 1992, pelo Software Engineering Institute (SEI). O CMM tinha como objetivo avaliar e melhorar a capacitação de empresas de software. A análise de Kerzner sugere que todas as empresas passem por esses cinco níveis de maturidade.

Como o modelo de Kerzner (2001) e o PMMM de Crawford (2002) foram baseados no SEl, ambos são parecidos e bem aceitos. Por isso, serão detalhados os níveis utilizados por ambas as metodologias.

Fase 1 - Embrionária / linguagem comum: os gerentes devem reconhecer a necessidade, os benefícios e as aplicações da gestão de projetos. O gerente sênior precisa convencer-se de que a excelência em gestão de projetos pode contribuir para a melhoria da empresa. Quando os executivos reconhecem que a gestão de 
projetos não é apenas algo capaz de mexer com as bases da empresa, mas é, também, indispensável a sua sobrevivência, o processo de maturidade ganha rapidez (KERZNER, 2002 e 2005).

Nessa fase, as pessoas reconhecem a necessidade de entender os princípios básicos de gerenciamento de projetos, incluindo os termos e linguagens utilizadas na área. (KERZNER, 2002 e 2005). Não há práticas e metodologias definidas de gerenciamento de projetos e, geralmente, não há documentação guardada dos projetos (CRAWFORD, 2002).

Fase 2 - Processos comuns: é visível o apoio aos projetos por parte da alta administração. Geralmente há diversos processos de gerenciamento de projetos na empresa, mas não um único padrão. Há uma documentação básica do projeto e medidas básicas para acompanhar custos, prazos e desempenho. Nesse nível, a organização reconhece os processos comuns dos projetos procurando identificar algum padrão que conduza ao sucesso nos projetos. Nessa fase, obtém-se o reconhecimento e suporte dos princípios de gerenciamento de projetos para outras metodologias utilizadas na empresa (KERZNER, 2002; CRAWFORD, 2002).

Fase 3 - Metodologia singular: os gestores de projeto estão comprometidos na criação e utilização de uma única metodologia de gerenciamento de projetos, implicando inclusive na capacitação das pessoas em projetos. Observa-se nesse nível a combinação das diversas metodologias utilizadas na organização para a criação de uma metodologia única para gerenciar projetos. Com a criação desta, todos os projetos deverão ser conduzidos nessa metodologia, contendo os processos institucionalizados, documentações formais, etc. Há regularmente envolvimento da alta direção como fornecedora de informações e aprovação de projetos críticos (KERZNER, 2002 e CRAWFORD, 2002).

Outras características dessa fase envolvem a automação de alguns processos relativos aos projetos e a avaliação do desempenho do projeto à luz de outros na companhia. 
Fase 4 - Benchmarking: é a disseminação da metodologia de gerenciamento de projetos pela empresa, promovendo sua importância nas atividades da empresa. Nesse nível, as empresas comparam seus processos de gestão de projetos com os de outras empresas localizadas dentro ou fora do país, com o objetivo de melhorar o processo. Esse é um processo contínuo.

Nessa fase, os projetos são avaliados em relação ao desempenho passado e frente ao que era esperado. Todos os projetos e mudanças são avaliados através de métricas. As informações dos projetos são integradas com os outros sistemas corporativos para otimizar as decisões da empresa. Os processos são documentados para a criação e acompanhamento de indicadores.

Fase 5 - Melhoria contínua: é a avaliação da metodologia de gestão de projetos verificando constantemente melhorias para a sua abordagem. Nessa fase, busca-se a excelência através da capacitação e avaliação das práticas de mercado (outras empresas), buscando determinar possíveis melhorias e inovações na abordagem. São utilizadas também as lições aprendidas, procurando melhorar os processos da metodologia.

Na figura 10 são apresentados os cinco níveis de maturidade, sendo este o modelo utilizado nesta dissertação. 


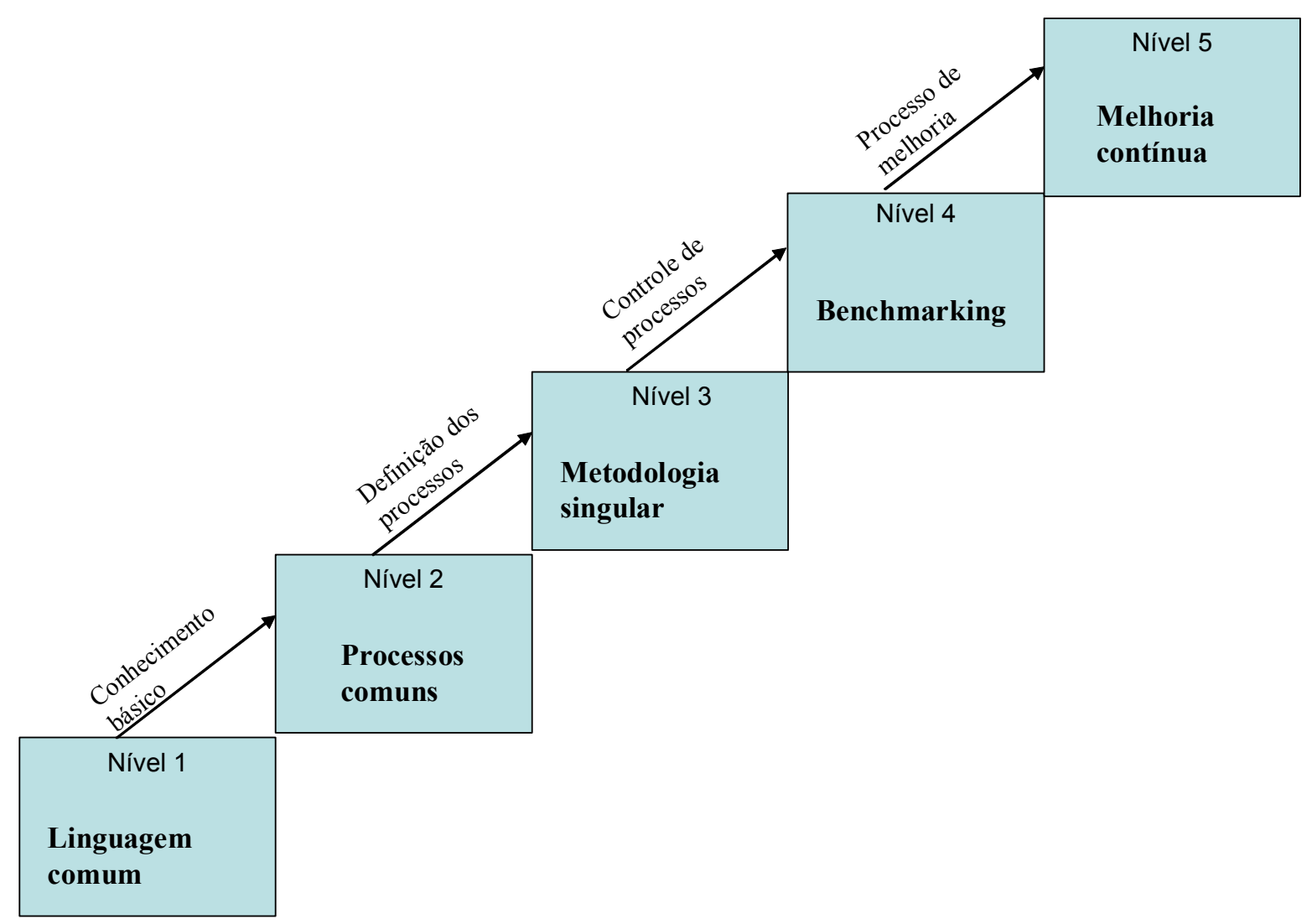

Figura 10 - Os cinco níveis de maturidade em gerenciamento de projetos (KERZNER, 2001;

CRAWFORD, 2002)

O conceito de maturidade é bem recente, sendo que as pesquisas estão mais concentradas nestes últimos 10 anos. Por meio da maturidade é possível analisar o atual estado do gerenciamento de projetos nas empresas e colocá-las num único instrumento, o que permite a comparação entre empresas. Além de possibilitar essa comparação, é possível determinar pontos de melhoria frente ao que é esperado nos níveis de maturidade.

Apesar de o conceito ser bem recente na literatura, as empresas e pesquisadores o têm utilizado muito. Outro ponto positivo é a possibilidade de utilizar ferramentas estatísticas mais avançadas de análise. Assim, o conceito é adotado para procurar entender as relações causais entre gestão de projetos e implementação de estratégias. 


\subsection{Considerações do capítulo}

Por mais que sejam importantes as recomendações da literatura citadas em cada parte deste capítulo, segundo os estudos apresentados anteriormente, os projetos frequentemente não estão relacionados com a estratégia.

As literaturas apresentadas mostram a necessidade de ter um modelo integrado de gestão estratégica por meio de projetos. Verifica-se que há diversas formas de realizar a implementação de estratégias por meio do gerenciamento de projetos, mas que deverão ser aprofundadas na pesquisa de campo conduzida nesta dissertação.

Essa união, reunindo as técnicas apresentadas desde o início, traz uma qualidade maior na tomada de decisão e um provável sucesso na implementação. $A$ vantagem competitiva pode ser alcançada pela implementação no tempo ou na antecipação de projetos, mantendo a qualidade. 


\section{METODOLOGIA DE PESQUISA}

Este capítulo expõe a metodologia da pesquisa de campo utilizada nesta pesquisa. São detalhados o tipo de pesquisa, o método, a justificativa pela escolha do método, a estrutura analítica da pesquisa, a amostra, o instrumento de pesquisa e as técnicas estatísticas de modelagem (regressão e correlação).

\subsection{HIPÓTESES}

A hipótese é utilizada para moldar e focar a pesquisa quantitativa, sendo esta o tipo de pesquisa conduzida nesta dissertação. As hipóteses são declarações de premissas ou de resultados esperados pelos pesquisadores relacionados ao modo de coletar as variáveis relacionadas à teoria analisada (CRESWELL, 2003). A hipótese é um relacionamento lógico entre duas ou mais variáveis (medidas) expressas na forma de frases testáveis (FORZA, 2002).

Para criar as hipóteses e as questões da pesquisa, levou-se em conta que:

- a forma mais rigorosa de uma pesquisa quantitativa é testar a teoria;

- geralmente existem três abordagens para utilizar variáveis nas hipóteses: 1) comparação de grupos; 2) relacionar uma variável independente com uma variável dependente; 3) descrever as respostas para uma variável dependente ou independente; e, a mensuração da variável dependente ou independente separadamente, reforçando a lógica de causa e efeito (CRESWELL, 2003).

Diante dessas premissas, para solucionar o problema da implementação da estratégia, foram desenvolvidas algumas hipóteses: 
- HIPÓTESE $1(\mathrm{H} 1)$ : a maturidade em projetos é a variável interveniente que garante uma probabilidade de sucesso maior na implementação de estratégias;

- HIPÓTESE $2(\mathrm{H} 2)$ : algumas ferramentas de gerenciamento de projetos e estratégico têm maior correlação com o sucesso na implementação de estratégias;

- HIPÓTESE 3 (H3): as empresas que têm maior maturidade em gerenciamento de projetos têm maior sucesso na implementação.

Abaixo estão representadas graficamente as hipóteses desta pesquisa.

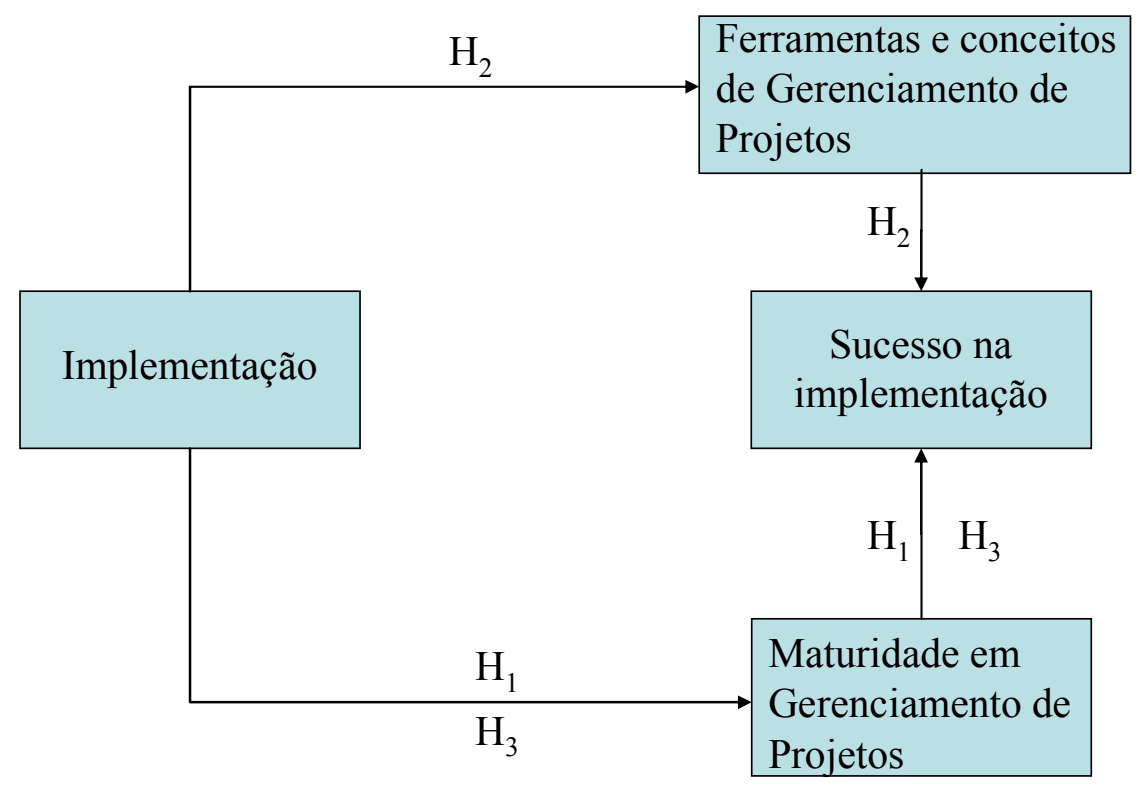

Figura 11 - Hipóteses de pesquisa

\subsection{METODOLOGIA E TIPO DE PESQUISA}

Nesta seção, é apresentado o tipo da pesquisa, incluindo suas classificações. É importante ressaltar, antes de prosseguir, o significado de método e metodologia. Por método, entende-se como o caminho, processo, técnica, procedimento, forma ou modelo de ação, ou seja, o caminho pelo qual se atinge um objetivo (FERREIRA, 
2002). Já a metodologia é o estudo dos métodos ou etapas a seguir num determinado processo.

Existem diversos tipos de abordagens ou modelos. Mazzon (1978) apresentou uma classificação de dois tipos:

- Modelo conceitual: estabelece em termos amplos a definição de um problema particular a ser resolvido;

- Modelo operacional: constitui-se em um instrumento de operacionalização da teoria, permitindo testar as proposições nesta mesma teoria; permite a sua operacionalização nas organizações.

Esta dissertação está classificada na categoria modelo conceitual, visando à solução de um problema particular. Para se chegar a esse modelo ou abordagem, será necessária a condução de um estudo. Este estudo pode ser exploratório, descritivo, causal/explicativa ou confirmatório.

O estudo exploratório tem por objetivo a familiarização com o fenômeno ou a obtenção de uma nova compreensão deste. Os estudos exploratórios mostram-se adequados quando há pouca importância ou pouco conhecimento sobre um assunto. Esse tipo de abordagem também fornece base para uma pesquisa mais estruturada e profunda posteriormente, tais como os estudos causais e descritivos. Nos estágios preliminares, o estudo exploratório pode ajudar a determinar os conceitos para serem mensurados em relação ao fenômeno de interesse e como melhor mensurá-los. O estudo exploratório também pode ajudar em uma primeira evidência de associação entre conceitos (FORZA, 2002). As técnicas de coleta de informações nesse tipo de abordagem são: levantamento bibliográfico, entrevistas com pessoas que tiveram experiências práticas com o fenômeno pesquisado, estudos de casos, entre outras técnicas.

O estudo descritivo tem por objetivo o entendimento da relevância de certo fenômeno, estabelecendo relações entre variáveis e descrevendo sua distribuição dentro da população. Sua primeira meta não é o desenvolvimento de uma teoria, embora os fatos descritos possam ajudar tanto na construção de uma teoria ou no 
seu refinamento (FORZA, 2002). Algumas técnicas de pesquisa utilizadas no estudo descrito são: a coleta de dados através de questionários (survey) ou de observação sistemática.

O estudo causal ou explicativo tem por objetivo reduzir o viés de pesquisa, aumentar a precisão do modelo, procurando inferências quanto às causas dos resultados e variáveis.

O estudo confirmatório é utilizado quando o conhecimento do fenômeno já está articulado em conceitos, modelos e preposições bem definidas na literatura. Nesse caso, a coleta de dados tem por objetivo testar a adequação dos conceitos desenvolvidos em relação a este fenômeno, ligações hipotéticas entre conceitos ou a validade das fronteiras desses modelos (FORZA, 2002).

Esta dissertação tem o caráter descritivo, procurando verificar a aceitação ou rejeição das hipóteses e as relações entre as variáveis. Sua abrangência é a criação de um modelo preliminar e o início de um modelo científico.

\subsection{MÉTODO DE COLETA DE DADOS}

Existem dois tipos de pesquisa: quantitativa e qualitativa. A quantitativa busca traduzir em números, as opiniões e informações visando classificá-las e analisá-las, geralmente utilizando recursos e técnicas estatísticas (GIL, 2002). Esse tipo de pesquisa procura utilizar informações factuais, focando em variáveis e com diversos casos coletados através de entrevistas e questionários. Uma de suas características é a imparcialidade do pesquisador.

A pesquisa qualitativa considera a ocorrência de uma relação dinâmica entre o mundo real e o sujeito, isto é, um vínculo indissociável entre o mundo objetivo e a subjetividade do sujeito que não pode ser traduzido em números, sendo um construto de uma realidade social, através da observação. A interpretação dos fenômenos e a atribuição de significados são comuns no processo de pesquisa 
qualitativa. O ambiente natural é a fonte direta de coleta de dados e o pesquisador é o instrumento-chave. Os pesquisadores tendem a analisar seus dados indutivamente. O processo e seu significado são os focos principais de abordagem.

Este trabalho adota a pesquisa quantitativa de campo, o survey, com grandes empresas (com diversos graus de sucesso empresarial e de implementação de estratégias). O survey é um procedimento para levantamento de dados primários a partir de indivíduos (HAIR et al., 2005) utilizando-se de questionários e entrevistas. Nesta pesquisa, optou-se pela condução de entrevistas.

As principais vantagens e desvantagens dessa escolha encontram-se abaixo.

\section{- Vantagens:}

- coleta de dados com maior quantidade de empresas;

- uso de questionários, com perguntas claras e validadas;

- perguntas iguais para todas as empresas, o que permite comparação entre resultados;

- fornece dados precisos, quantitativos e numéricos;

- velocidade da coleta dos dados;

- permite a realização de estatísticas simples e avançadas (correlação);

- é possível testar e validar as teorias já construídas;

- facilidade de preenchimento e tabulação;

- possibilidade de ampla abrangência geográfica;

- é possível generalizar uma pesquisa quando é replicada para diferentes populações, mostrando que não há interferência do pesquisador;

- é possível obter dados que permitam predições quantitativas;

- permite fazer relações de causa e efeito;

- procura dados para provar uma hipótese.

\section{- Desvantagens:}

- impossibilidade de maior profundidade na exploração de informações;

- o tema é muito abrangente, sendo muito maior do que um questionário; 
- o conhecimento produzido pode ser muito abstrato ou geral para aplicações, situações ou contextos específicos;

- as categorias e teorias utilizadas pelo pesquisador podem não refletir as necessidades locais ou do país;

- o pesquisador pode perder o acontecimento de um fenômeno devido ao foco na teoria ou o teste de hipótese ao invés da geração da teoria ou hipótese (JOHNSON e ANTHONY, 2004);

- dependência da capacidade e da disposição dos respondentes em cooperar (COOPER e SCHINDLER, 2003);

- dificuldade de avaliar a veracidade e a confiabilidade das respostas.

Além dessas desvantagens, há também críticas. Richardson et al. (1999) criticam a utilização de procedimentos puramente quantitativos para a explicação de fenômenos psicológicos e sociais complexos. Os autores também criticam a utilização somente de esquemas estatísticos para a explicação das inter-relações dos componentes de um modelo.

\subsection{FERRAMENTAS PARA ANÁLISE DE DADOS}

Este trabalho utiliza algumas ferramentas de análise estatística, tais como correlação e regressão múltipla. Ambas as técnicas foram utilizadas para demonstrarem a associação entre duas variáveis, entre elas: implementação, sucesso na implementação, gerenciamento de projetos, técnicas e conceitos, entre outras.

Através de fórmulas é possível identificar o grau da força da relação entre as variáveis (correlação). Esse grau, coeficiente, normalmente representado pela letra ' $r$ ', assume apenas valores entre -1 e 1 .

O r=1 significa uma correlação positiva entre as duas variáveis. Enquanto que $r=-1$ significa uma correlação negativa perfeita entre as duas variáveis, isto é, se 
uma aumenta, a outra sempre diminui, na mesma proporção. $O$ ' $r$ ' próximo de zero significa que as duas variáveis não dependem linearmente uma da outra. No entanto, pode existir uma outra dependência que seja "não linear". Assim, o resultado $r=0$ deve ser investigado por outros meios. Abaixo seguem as fórmulas de cálculo de correlação:

$$
\begin{aligned}
& b=\frac{\sum_{i=1}^{n} X_{i} Y_{i}-n \cdot \bar{X} \cdot \bar{Y}}{(n-1) \cdot S_{X}^{2}} \\
& a=\bar{Y}-b \cdot \bar{X} \\
& \hat{Y}=a+b X
\end{aligned}
$$

$\bar{X}$ e $\bar{Y}$ são as médias amostrais de $X$ e $Y$, respectivamente, $S_{X}$ e $S_{Y}$ são os desvios padrão de $X$ e $Y$,respectivamente.

Diferentemente da correlação, a regressão explicita a forma da relação entre duas variáveis. O problema de determinar equações de curvas que se ajustam a determinados conjuntos de dados observados é chamado de ajustamento de curvas.

Um dos principais objetivos do ajustamento é estimar uma das variáveis (a variável dependente) em função da outra (variável independente). Tal processo de estimação é denominado regressão.

Uma reta de regressão, também chamada de reta do ajuste ótimo, é aquela em que a soma dos quadrados dos resíduos é um mínimo. Sua equação pode ser usada para prever o valor de y para um dado valor de $\mathrm{x}$.

Com a regressão é possível montar uma equação com uma variável dependente e algumas independentes.

$$
Y=\text { Const }+B_{1} X_{1}+B_{2} X_{2}+B_{n} X_{n}+e
$$

Onde 'Y' é a variável dependente, 'Const' é a constante, ' $X$ ' são as variáveis independentes no modelo e 'e' é o erro aleatório. 
Os coeficientes (B) utilizados na equação são calculados e apresentados nas tabelas. O coeficiente padronizado (Beta) é utilizado para compreender o impacto de cada variável no resultado final do modelo. Esse cálculo é importante, pois as variáveis têm escalas diferentes e busca-se com esse processo a padronização das variáveis.

O coeficiente B é a estimativa do coeficiente das variáveis independentes utilizando os dados em seu estado bruto. Caso seja feita uma padronização nos dados, utiliza-se o coeficiente Beta. A padronização é feita através da subtração do resultado individual pela média das observações dividido pelo desvio padrão.

Ao se elaborar o modelo de regressão, obtém-se o coeficiente de correlação linear que é representado pela letra ' $r$ ' e tem valores entre -1 e 1 . O quadrado do ' $r$ ' é denominado de coeficiente de determinação que é a medida descritiva da proporção da variação de ' $Y$ ' que pode ser explicada pelas variáveis ' $X$ ' do modelo. Utiliza-se o

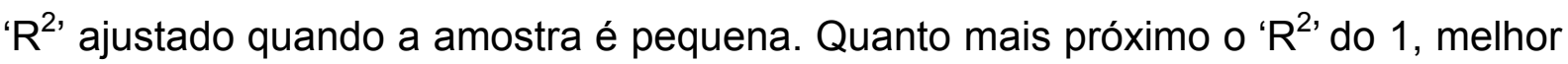
é a qualidade dele, cobrindo toda a variação do ' $Y$ '.

$O R^{2}$ utilizado é calculado divindo-se a variação explicada de $Y(S Q E)$ pela variação total de $\mathrm{Y}(\mathrm{SQT})$. Chega-se as equações:

$$
\begin{gathered}
S Q E=\sum_{i=1}^{n}\left(\left(\hat{\beta}_{0}+\hat{\beta}_{1} x_{i}\right)-\bar{Y}\right)^{2} \\
S Q T=\sum_{i=1}^{n}\left(y_{i}-\bar{Y}\right)^{2}
\end{gathered}
$$

Onde, $\beta_{0}$ é a estimativa da variável constante e $\beta_{1}$ dos coeficientes das variáveis independentes. A variável $\bar{Y}$ é a média dos valores estimados pela reta.

O método estatístico para realizar a regressão foi o stepwise que procura determinar quais as melhores variáveis para compor o modelo ideal (PIMENTEL et al., 2008). Além disso, procurou-se elaborar duas correlações, uma com dados originais e outra com dados padronizados segundo o método z-score. 


\subsubsection{ANÁLISE DESCRITIVA}

Segundo Cooper e Schindler (2003, p. 359), o objetivo da análise descritiva é desenvolver um conhecimento suficiente para descrever um conjunto de dados. Isso é feito por meio do entendimento dos dados coletados, do resumo das informações nele contidas e da disponibilização de tais informações em um formato mais interessante e inteligível.

Inicialmente será apresentada uma breve descrição das empresas participantes do estudo e posteriormente serão mostradas as distribuições de freqüências de todas as questões.

\subsection{AMOSTRA}

Para a condução da pesquisa de campo, buscou-se restringir o conjunto de empresas em relação ao número total das existentes. Assim, o foco do estudo concentrou-se em empresas de grande porte pertencentes ao grupo das 1.000 maiores do país.

Entende-se que a variável tamanho é a mais apropriada ao desenvolvimento da investigação do problema da pesquisa. Dessa maneira, foi utilizado como fonte de informação para se determinar a população-alvo da pesquisa, a edição das "Maiores e Melhores" da revista Exame e o "Valor 1.000" do jornal Valor Econômico. Com essa configuração, considera-se que o processo de amostragem desta dissertação é classificado como não probabilística, selecionando a amostra por conveniência e julgamento. Isso proporciona uma facilidade na seleção de pessoas que sejam mais acessíveis, mas que ao mesmo tempo são boas fontes de informação precisa. 
Foram realizadas entrevistas com os responsáveis pelo planejamento estratégico e pela prática de gestão de projetos, utilizando-se de roteiro e questionário. As entrevistas foram realizadas, pelo autor, pessoalmente ou em alguns casos via telefone.

\subsection{INSTRUMENTO DE PESQUISA}

Como foi apresentado nas seções anteriores, o principal instrumento de pesquisa foi o questionário aplicado nas entrevistas. O questionário proporcionou um instrumento de coleta de dados precisos e confiáveis. Uma vez delimitado o conteúdo do questionário é necessário definir o modo pelo qual as perguntas serão feitas, as escalas e o modo de organizar as questões visando motivar o respondente.

Foram construídos para esta pesquisa três questionários utilizados nas entrevistas:

- Um sobre o processo de implementação de estratégias, que foi respondido pelo responsável pelo processo (geralmente é o gerente de planejamento estratégico);

- Um sobre o processo de gerenciamento de projetos, visando suportar a implementação de estratégias;

- Um para mensurar a maturidade de gerenciamento de projetos na empresa.

O questionário, após finalizado, foi enviado para especialistas, colegas e algumas empresas para um piloto, isto é, um pré-teste. O que possibilitou serem feitas algumas melhorias em relação às instruções, texto das perguntas, conteúdo e problemas de entendimento.

O questionário de gerenciamento de projeto está dividido em duas partes: 
- Contexto da gestão de projetos na empresa, incluindo as técnicas utilizadas, PMO e interligação com a estratégia;

- Avaliação do nível da gestão de projetos na empresa. Para esta análise foi utilizado o questionário adaptado de Maximiano (2002).

O questionário de maturidade de gerenciamento de projetos foi baseado no instrumento já validado (PMMM) construido por Crawford (2002).

\subsection{LIMITAÇÕES DO MÉTODO}

Por mais que haja adequação do método de pesquisa ao objetivo da dissertação, há limitações existentes neste trabalho.

A amostragem não probabilística selecionada por conveniência e julgamento, não leva em consideração a representatividade da amostra para a população de empresas brasileiras. Assim, as conclusões e análises apresentadas nesta dissertação ficam restritas ao âmbito da população amostrada neste trabalho, não podendo ser inferidas para populações distintas desta.

Como foi utilizado o questionário como instrumento de coleta de dados desta pesquisa, preenchido durante as entrevistas, o estudo tem outras limitações decorrentes. Uma delas é a dificuldade em avaliar a veracidade e a confiabilidade das respostas oferecidas pelos executivos das empresas entrevistadas. Isso ocorre, pois só foram coletados dados através de uma entrevista com os executivos, não sendo possível confrontar esses dados com a realidade da empresa.

Além dessa dificuldade, a elaboração de um questionário pode limitar a quantidade de variáveis pesquisadas, já que não é possível abranger tudo sobre o tema dentro de apenas um instrumento. 
Outro ponto importante do trabalho está relacionado ao fato do conhecimento produzido poder ser geral, não sendo aplicado em situações ou contextos específicos.

Em relação à utilização de variáveis explicativas (preditoras) com respostas em escala ordinal, há limitação na realização de análises de correlação e regressão. Apesar dessa prática ser comum a várias áreas de pesquisa, pode haver uma perda de poder no ajuste dos modelos de predição.

\subsection{Considerações Finais}

Nesse capítulo foram apresentadas as hipóteses, a tipologia e metodologia de pesquisa, o método de coleta de dados, as técnicas de análise de resultados e amostragem e o instrumento de pesquisa. Foram também expostas as limitações do método intrínsecas a este trabalho. As principais informações que caracterizam a metodologia da presente pesquisa são resumidas na tabela 5.

Tabela 6 - Características da pesquisa de campo

\begin{tabular}{|c|c|}
\hline Característica & Classificação \\
\hline Tipologia de pesquisa & Estudo quantitativo-descritivo \\
\hline Amostra de pesquisa & $\begin{array}{l}\text { Estudo centrado nas } 1.000 \text { maiores empresas do } \\
\text { país }\end{array}$ \\
\hline Amostragem & $\begin{array}{l}\text { Não probabilística, selecionando a amostra por } \\
\text { conveniência e julgamento }\end{array}$ \\
\hline Método de coleta de dados & $\begin{array}{l}\text { Survey - elaboração de questionário / roteiro de } \\
\text { entrevista com os executivos das empresas }\end{array}$ \\
\hline Metodologia de pesquisa & Criação de um modelo conceitual \\
\hline Técnicas de análise de dados & $\begin{array}{l}\text { Análise descritiva } \\
\text { Utilização de técnicas estatísticas multivariadas: } \\
\text { correlação e regressão }\end{array}$ \\
\hline
\end{tabular}


Por fim, entende-se que, apesar das limitações apresentadas, a metodologia de pesquisa adotada atende às necessidades do trabalho, propiciando o alcance dos objetivos. Nos próximos capítulos serão apresentadas as análises dos resultados e as conclusões da pesquisa e, em seguida, serão tecidas as considerações finais deste trabalho. 


\section{ANÁLISE E RESULTADOS}

Neste capítulo são apresentadas as análises dos dados da pesquisa de campo. Conforme apresentado no capítulo anterior, o tratamento dos dados foi feito através de métodos estatísticos, sendo conduzida primeiramente a análise descritiva e, em seguida, a análise de correlação e regressão.

\subsection{Análise descritiva dos dados da pesquisa}

\subsubsection{Análise Descritiva dos Respondentes e Informações Complementares}

A presente pesquisa contou com a participação de 31 empresas, o que corresponde a um índice de retorno de aproximadamente 4\%. Acredita-se que o índice alcançado seja adequado a este estudo, provendo dados robustos o suficiente para a realização das análises estatísticas.

Os dados foram coletados por meio de duas entrevistas: uma com o responsável pelo planejamento estratégico ou sua implementação e outra com o gerente de projetos da empresa. Participaram das entrevistas os principais executivos das empresas (diretores, gerentes e coordenadores).

Houve a participação de empresas de diversos setores, sendo que os principais foram:

- Petroleo, gás e energia;

- Tecnologia;

- Indústria de papel, celulose e embalagens;

- Montadoras. 
$\mathrm{Na}$ tabela 7 são apresentadas as empresas participantes deste estudo e a distribuição dos respondentes por setor econômico.

Tabela 7 - Empresas e setores pesquisados

\begin{tabular}{|c|c|c|c|}
\hline Empresa & Setor & Empresa & Setor \\
\hline Accor & Serviços & Klabin & $\begin{array}{l}\text { Indústria de papel, } \\
\text { celulose e embalagens }\end{array}$ \\
\hline Albras & Alumínio & Light & Petroleo, gás, energia \\
\hline Ampla & Petroleo, gás, energia & Perdigão & Indústria Alimentícia \\
\hline Aracruz & $\begin{array}{l}\text { Indústria de papel, } \\
\text { celulose e embalagens }\end{array}$ & Petrobras & Petroleo, gás, energia \\
\hline Arcelor & Siderurgia & Procergs & Tecnologia \\
\hline Braskem & Indústria Química & Prodam & Tecnologia \\
\hline Bunge & Indústria Alimentícia & Rigesa & $\begin{array}{l}\text { Indústria de papel, } \\
\text { celulose e embalagens }\end{array}$ \\
\hline Camargo Corrêa & Construtora & RR donnelley & Gráfico editorial \\
\hline Cemig & Petroleo, gás, energia & Sabesp & Água e saneamento \\
\hline Correios & Serviços & Shell & Petroleo, gás, energia \\
\hline CPM Braxis & Tecnologia & Suzano & $\begin{array}{l}\text { Indústria de papel, } \\
\text { celulose e embalagens }\end{array}$ \\
\hline Embraer & Aeronaves & TIM & Telecomunicações \\
\hline Epson & Tecnologia & Vale & Mineração \\
\hline Fiat & Montadora & Villares & Siderurgia \\
\hline Ford & Montadora & Volkswagen & Montadora \\
\hline GOL & Aviação & & \\
\hline
\end{tabular}




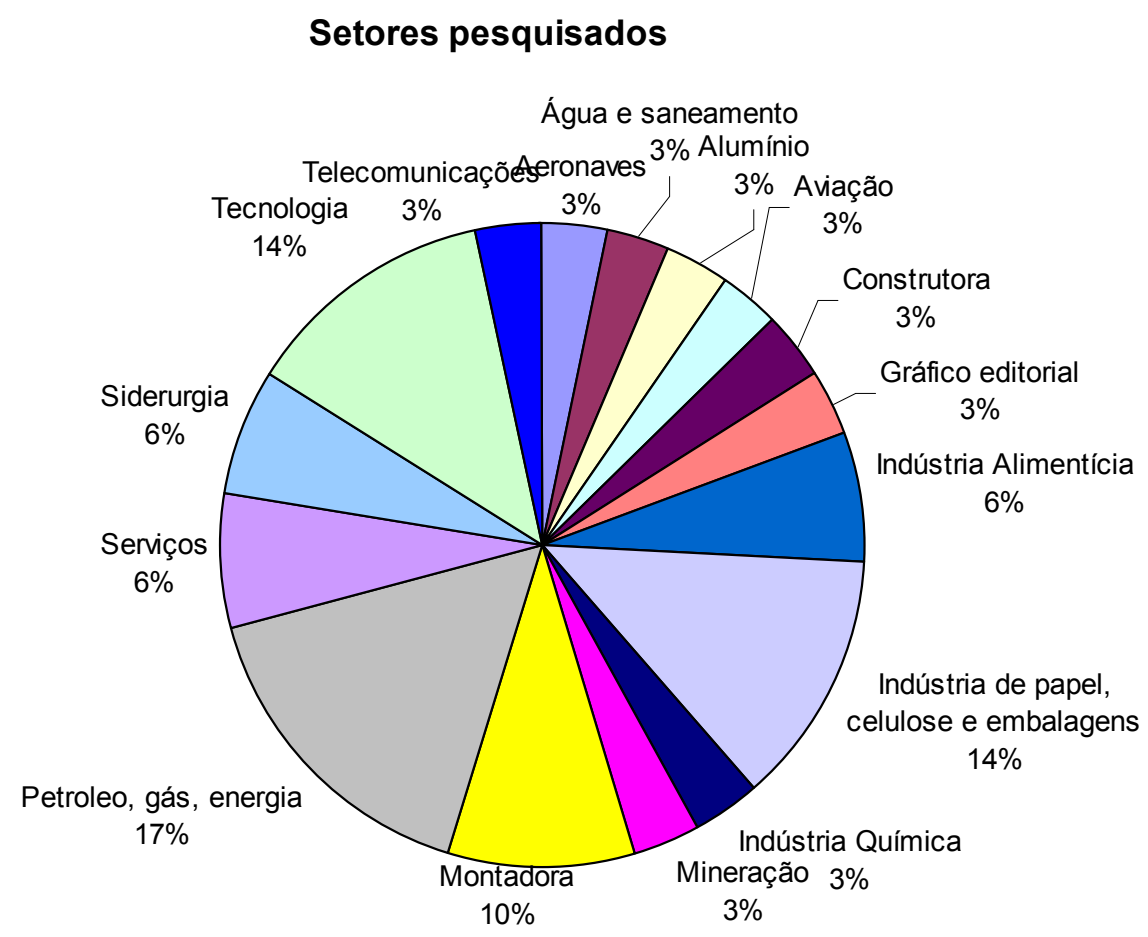

Figura 12 - Setores pesquisados

\subsubsection{Análise dos dados das entrevistas de estratégia}

As próximas análises são referentes às entrevistas com os executivos da área de estratégia empresarial.

Verifica-se na figura 13 que todas as empresas entrevistadas possuem processo de planejamento estratégico formal, sendo que em $96 \%$ dos casos o processo é extremamente formal. A prática de planejamento estratégico é bem disseminada. Isso ocorre principalmente pela amostra selecionada para esta pesquisa ser de grandes empresas. 


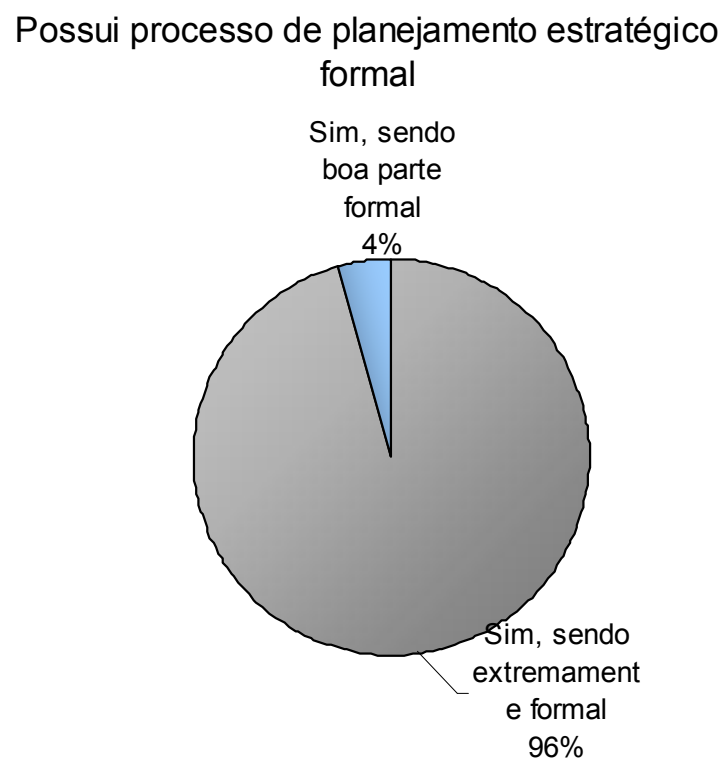

Figura 13 - Processo de planejamento estratégico

A figura 14 demonstra que o conceito de planejamento é geralmente bem aceito dentro das empresas, possuindo cerca de $85 \%$ de satisfação, somando as avaliações extremamente satisfeitas e satisfeitos.

\section{Satisfação em relação à ferramenta de} planejamento estratégico

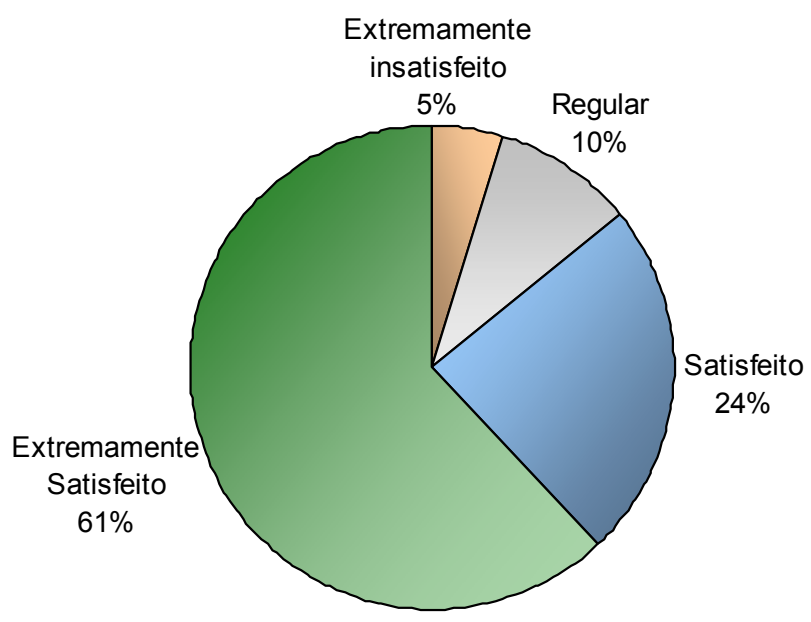

Figura 14 - Satisfação em relação à ferramenta de planejamento estratégico

A figura 15 aponta que apesar de todas as empresas pesquisadas terem processo de planejamento estratégico, 22\% delas não possuem metodologias para implementação de estratégias. Esse número pode demonstrar que apesar de as empresas conseguirem desenvolver estratégias, é possível verificar que há um gap 
entre planejamento e implementação, já que as pessoas não têm orientações de como implementar a estratégia.

A empresa tem metodologia de implementação de estratégias

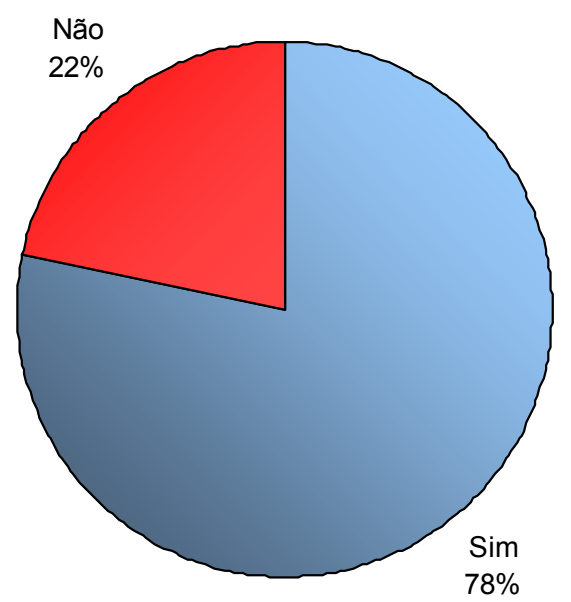

Figura 15 - Metodologia de implementação de estratégias

Apesar desse número, a implementação, na visão dos executivos de planejamento, está integrada com o processo de elaboração de projetos e iniciativas. Cerca de $80 \%$ dos executivos acreditam que o planejamento é implementado através de projetos e iniciativas.

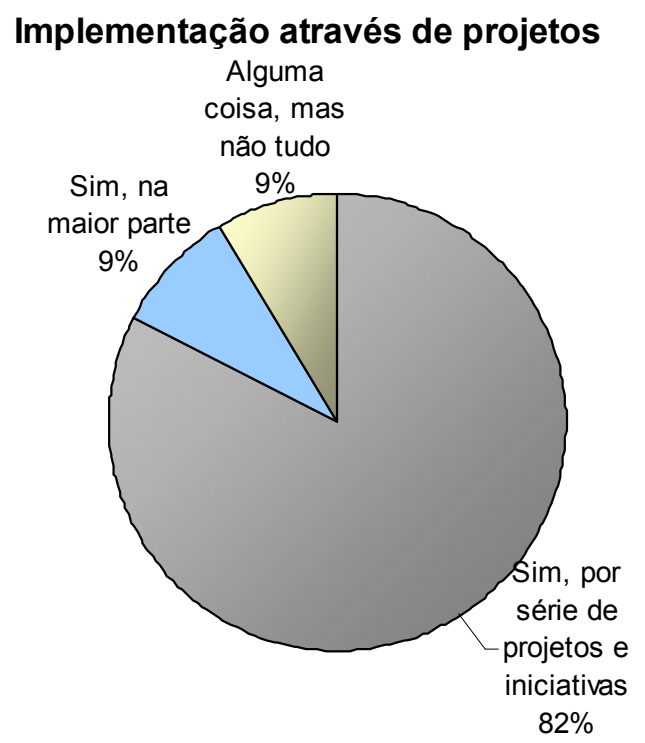

Figura 16 - Implementação da estratégia através de projetos 
Por mais que as empresas possuam estratégias, as pessoas ainda não compreendem bem a visão da empresa e o direcionamento de longo prazo, podendo ser um obstáculo ao sucesso da implementação. Isso é demonstrado na figura 17.

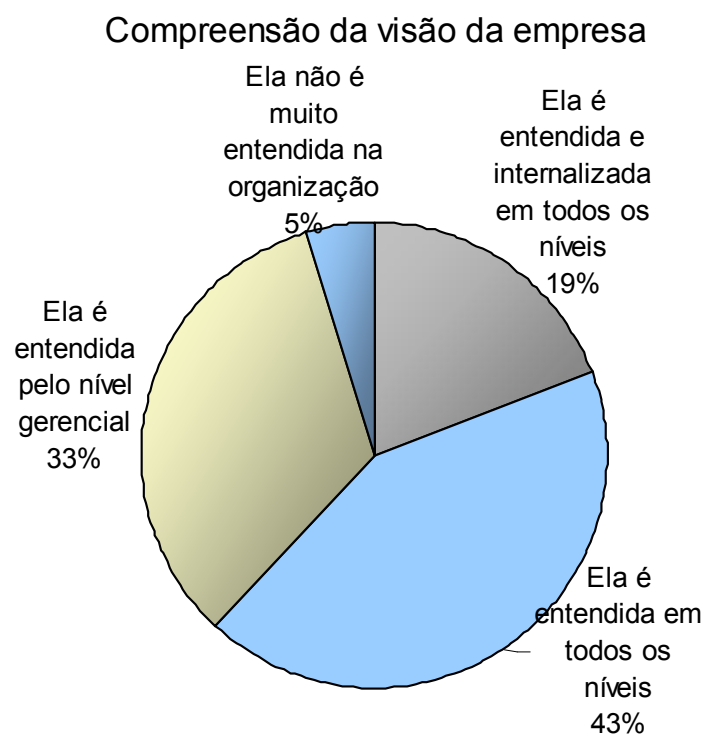

Figura 17 - Compreensão da visão da empresa

Assim, foi identificado na figura 18 as razões pelas quais as empresas têm obtido dificuldades na implementação da visão. A principal razão pela qual a visão não é totalmente entendida e internalizada pelas pessoas é a falta de comunicação (70\% dos respondentes). O segundo ponto principal foi a falta da tradução para papéis e responsabilidades, para $50 \%$ dos entrevistados que tiveram dificuldades na compreensão e internalização da visão.

Razões para a visão não ser totalmente compreendida e internalizada

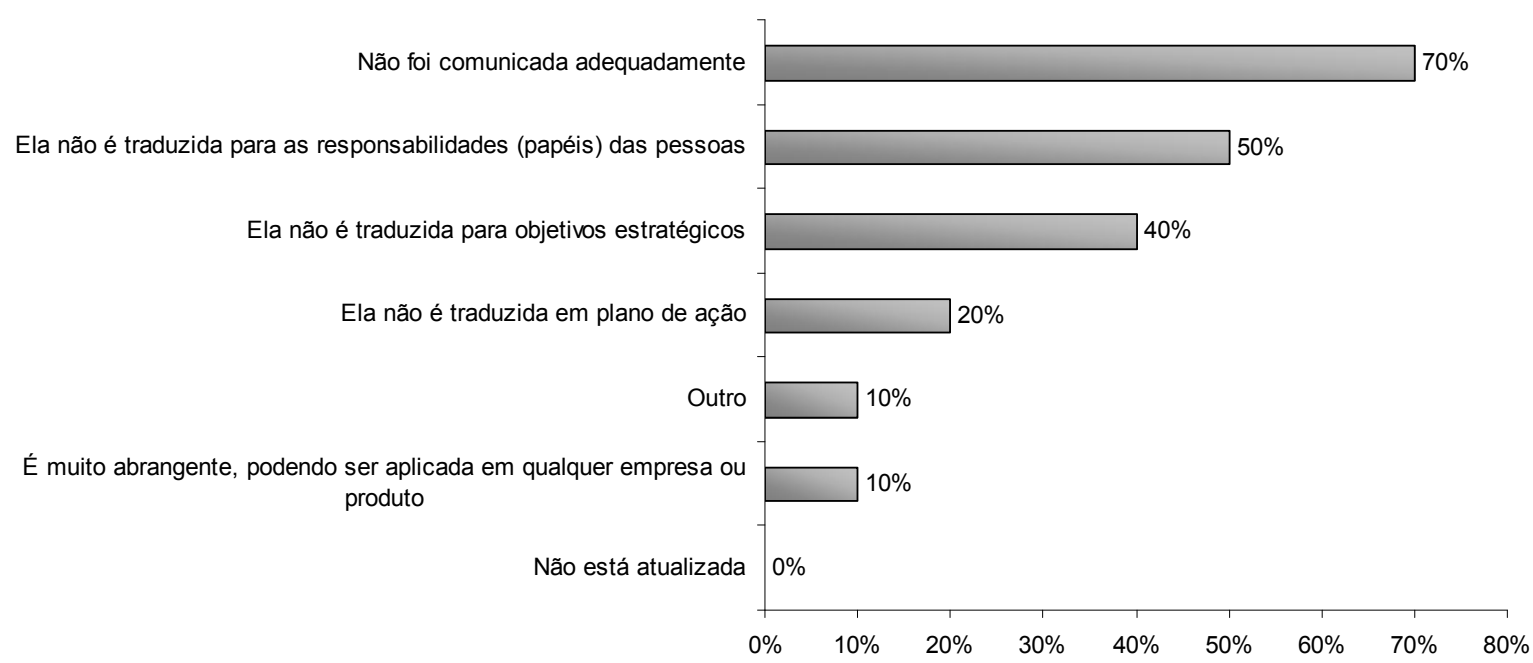

Figura 18 - Barreiras à implementação da visão 
Essas barreiras somente comprovam a importância da comunicação, apresentadas por diversos autores (MANKINS e STEELE, 2005; HREBINIAK, 2005; OKUMUS, 2001).

Sabe-se através de pesquisas que nem todas as estratégias são implementadas (MINTZBERG, 2000). Diferentemente do que foi apontado no nível internacional por Kiechel (1982) e Charan \& Golvin (1999), somente 10\% das estratégias que foram formuladas eram implementadas. De acordo com a figura 19, nota-se que $86 \%$ das empresas conseguiram implementar pelo menos $60 \%$ das suas estratégias. A média de sucesso na implementação de estratégias nesse estudo ficou em torno de $75 \%$.

Outra pesquisa com escopo nos Estados Unidos (CHINOOK SOLUTIONS, 2006) mostrou que somente $17 \%$ das empresas têm certeza que $90 \%$ dos objetivos da implementação foram atingidos (contra $41 \%$ das empresas pesquisadas nesta dissertação). Nos EUA, quase $50 \%$ dos executivos disseram que implementaram a sua estratégia entre $30 \%$ e $60 \%$, e $16 \%$ das companhias afirmaram que o percentual não chegou a $30 \%$ de sucesso (CHINOOK SOLUTIONS, 2006). Esses números são bem diferentes do que o apresentado no estudo conduzido nesta dissertação (figura 19)

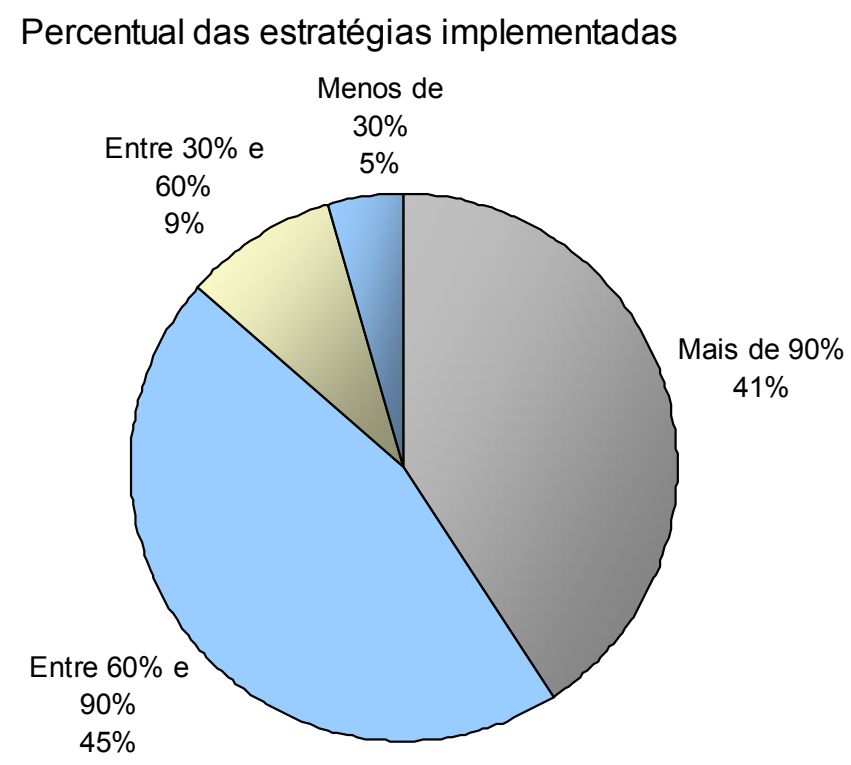

Figura 19 - Percentual das estratégias implementadas 
Neste estudo, procurou-se identificar, na visão dos respondentes, por que as empresas não atingiram mais de $90 \%$ de estratégias implementadas. Na tabela 8 são apresentadas as principais barreiras à implementação de estratégias. Novamente, confirmando os resultados apresentados na figura 18, a principal razão do insucesso na implementação é devida à falha de comunicação $(54 \%$ das empresas), seguida por mudanças internas e externas (46\% das empresas), bem como a falta da habilidade em gerenciamento de projetos (46\% das empresas). Mostra-se que os executivos percebem que se tivessem melhores habilidades para conduzir os projetos, conseguiriam ter mais estratégias implementadas.

Tabela 8 - Barreiras à implementação

\begin{tabular}{|c|c|}
\hline \multicolumn{2}{|l|}{ Principais barreiras a implementação de estratégias } \\
\hline Barreira & $\begin{array}{l}\text { Percentual das } \\
\text { empresas que } \\
\text { enfrentaram a } \\
\text { barreira }\end{array}$ \\
\hline Falha na comunicação & $54 \%$ \\
\hline Teve mudanças dentro da empresa que invalidaram a estratégia & $46 \%$ \\
\hline Houve mudanças no ambiente econômico externo que invalidou a estratégia & $46 \%$ \\
\hline Faltou uma melhor habilidade em gerenciamento de projetos & $46 \%$ \\
\hline A responsabilidade pela implementação não estava clara & $38 \%$ \\
\hline Faltou uma maior cobrança das pessoas que eram responsáveis por implementar & $38 \%$ \\
\hline Não havia incentivos ou as pessoas não estavam motivadas para implementar & $31 \%$ \\
\hline Os problemas enfrentados não foram previstos & $23 \%$ \\
\hline Os funcionários não tinham as competências necessárias & $15 \%$ \\
\hline As metas não são tão bem compreendidas & $15 \%$ \\
\hline Liderança inadequada e falta de suporte & $15 \%$ \\
\hline Recursos financeiros insuficientes para executar a estratégia & $15 \%$ \\
\hline $\begin{array}{l}\text { Falta de sentimentos de pertencer a uma estratégia ou a planos de execução entre os } \\
\text { principais funcionários }\end{array}$ & $15 \%$ \\
\hline Sistemas de informações inadequados & $15 \%$ \\
\hline $\begin{array}{l}\text { Impaciência - as mudanças têm que acontecer o quanto antes. CEOs podem ser inflexíveis e } \\
\text { quererem a mudança "para ontem". }\end{array}$ & $15 \%$ \\
\hline $\begin{array}{l}\text { Falta de entendimento da função da estrutura e do projeto organizacionais no processo de } \\
\text { execução }\end{array}$ & $8 \%$ \\
\hline O tempo de implementação foi maior do que o planejado & $8 \%$ \\
\hline $\begin{array}{l}\text { Incapacidade de gerenciar a mudança efetivamente ou separar a resistência interna à } \\
\text { mudança }\end{array}$ & $8 \%$ \\
\hline Fatores externos incontroláveis & $8 \%$ \\
\hline Falha na comunicação vertical & $8 \%$ \\
\hline $\begin{array}{l}\text { Crises e prioridades conflitantes, comprometendo a atenção necessária à implementação (falta } \\
\text { disciplina de execução) }\end{array}$ & $8 \%$ \\
\hline Os treinamentos aos funcionários foram inadequados & $8 \%$ \\
\hline $\begin{array}{l}\text { Compartilhamento deficiente ou inadequado de informações entre as pessoas ou unidades de } \\
\text { negócios responsáveis pela execução da estratégia }\end{array}$ & $8 \%$ \\
\hline Tentar executar uma estratégia que entre em conflito com a estrutura existente de poder & $8 \%$ \\
\hline A alta direção não avalia realisticamente se a empresa consegue executar o plano & $0 \%$ \\
\hline Os principais formuladores das estratégias não participam ativamente da implementação & $0 \%$ \\
\hline O nível gerencial não trabalha em equipe & $0 \%$ \\
\hline Falta de celebração do sucesso, faltando reconhecimento e recompensa pelo progresso & $0 \%$ \\
\hline Falta de suporte para a execução da estratégia por parte da alta administração & $0 \%$ \\
\hline Não ter orientações ou um modelo para orientar os esforços de execução da estratégia & $0 \%$ \\
\hline $\begin{array}{l}\text { Comunicação confusa de responsabilidade e/ou obrigação para decisões ou ações de } \\
\text { execução }\end{array}$ & $0 \%$ \\
\hline Estratégia vaga ou deficiente & $0 \%$ \\
\hline
\end{tabular}


Os dados apresentados na tabela 8 estão alinhados com o estudo de Hunger e Wheelen (2002), visto que dentre os quatro itens citados anteriormente pelos executivos brasileiros, três já constavam na lista dos dez maiores obstáculos da implementação produzida por estes autores.

Outro fato importante é a análise das opções não selecionadas pelas empresas brasileiras, não validando as teorias dos autores internacionais, principalmente Hrebiniak (2005 e 2006). As alternativas não selecionadas e os respectivos autores estão mencionados abaixo:

- A alta direção não avalia realisticamente se a empresa consegue executar o plano (BOSSIDY; CHARAN, 2002);

- Os principais formuladores das estratégias não participam ativamente da implementação (WESSEL, 1993);

- O nível gerencial não trabalha em equipe;

- Falta de celebração do sucesso, faltando reconhecimento e recompensa pelo progresso (HREBINIAK, 2006);

- Falta de suporte para a execução da estratégia por parte da alta administração (HREBINIAK, 2005);

- Não ter orientações ou um modelo para orientar os esforços de execução da estratégia (HREBINIAK, 2005);

- Comunicação confusa de responsabilidade e/ou obrigação para decisões ou ações de execução (HREBINIAK, 2005);

- Estratégia vaga ou deficiente (HREBINIAK, 2005).

Outro ponto analisado é a clareza de papéis e responsabilidades pela implementação por parte dos executivos e funcionários das empresas, pois esse fator pode facilitar ou dificultar a implementação. Verificou-se que os executivos tinham maior compreensão do seu papel na implementação das estratégias organizacionais. Conforme a figura 20 , cerca de $80 \%$ dos entrevistados afirmaram que os executivos tinham total clareza de seus papéis e responsabilidades na implementação, contra $32 \%$ da população de funcionários. 
Executivos têm clareza das suas responsabilidades na implementação

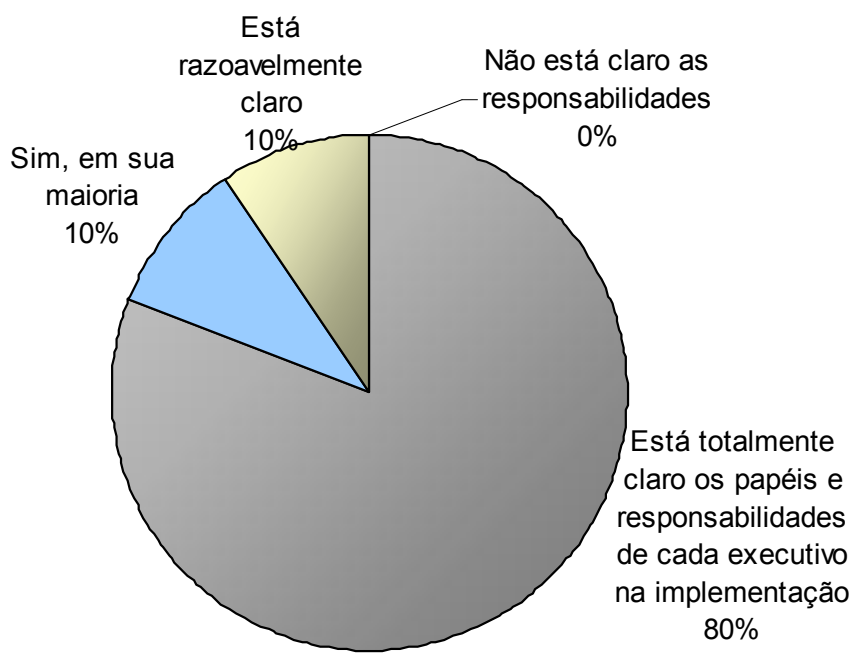

Figura 20 - Clareza das responsabilidades (executivos)

Entendimento pelos funcionários de seus papéis e responsabilidades na implementação de estratégias

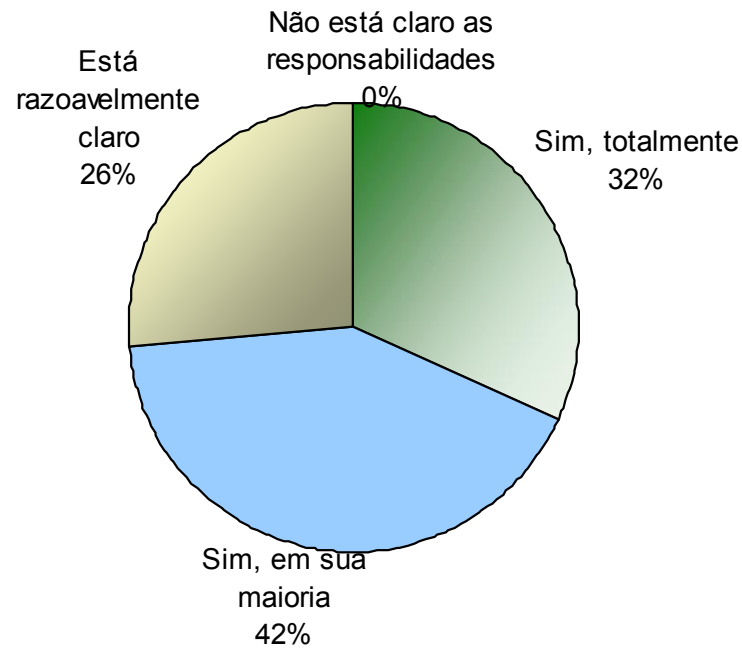

Figura 21 - Entendimento pelos funcionários de seus papéis e responsabilidades na implementação

Por mais que haja este gap de compreensão do papel e das responsabilidades pela implementação por parte dos funcionários, observa-se na figura 22 que as pessoas estão comprometidas com o processo de implementação de estratégia. Mais de $80 \%$ das empresas afirmaram que os funcionários estão com comprometimento muito alto ou alto. 
Comprometimento dos funcionários para implementação da estratégia

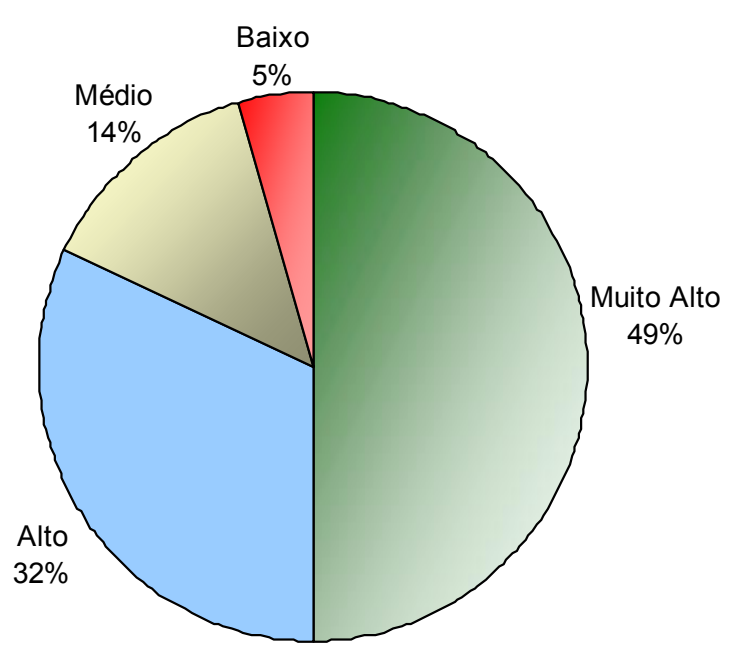

Figura 22 - Comprometimento dos funcionários com a estratégia

Procurou-se observar nas organizações técnicas, instrumentos e conceitos que as empresas têm utilizado para a implementação de estratégias. Verificou-se que estas têm:

- Definido os papéis e responsabilidades pela a implementação das estratégias (91\% dos respondentes);

- Desenvolvido orçamento para os projetos derivados da estratégia ( $82 \%$ dos respondentes);

- Buscado as melhores práticas de mercado para dentro da organização ( $77 \%$ dos respondentes);

- Cascateamento da estratégia (68\% dos respondentes);

- Alinhado as estratégias com os subsistemas de RH (64\% dos respondentes);

- Estabelecimento de incentivos e recompensas (64\% dos respondentes).

Mais da metade dessas técnicas e conceitos é de gerenciamento de projetos, mostrando sua importância.

$\mathrm{Na}$ questão que trata sobre o alinhamento com os subsistemas de $\mathrm{RH}$, verificou-se que cerca de $95 \%$ das empresas pesquisadas utilizam a remuneração 
variável como estímulo à implementação das estratégias. De forma espontânea, $52 \%$ das empresas afirmaram que realizam esse alinhamento com o subsistema de treinamento e desenvolvimento.

Entretanto, conforme a figura 23, as empresas não têm adotado algumas práticas, tais como:

- Mudança de cultura (16\% das empresas);

- Estabelecimento de sistemas de informações e comunicações sobre a estratégia (39\% das empresas);

- Desenvolvimento de competências necessárias para a implementação (42\% das empresas pesquisadas). 
Técnicas, instrumentos e conceitos de PE utilizados na implementação

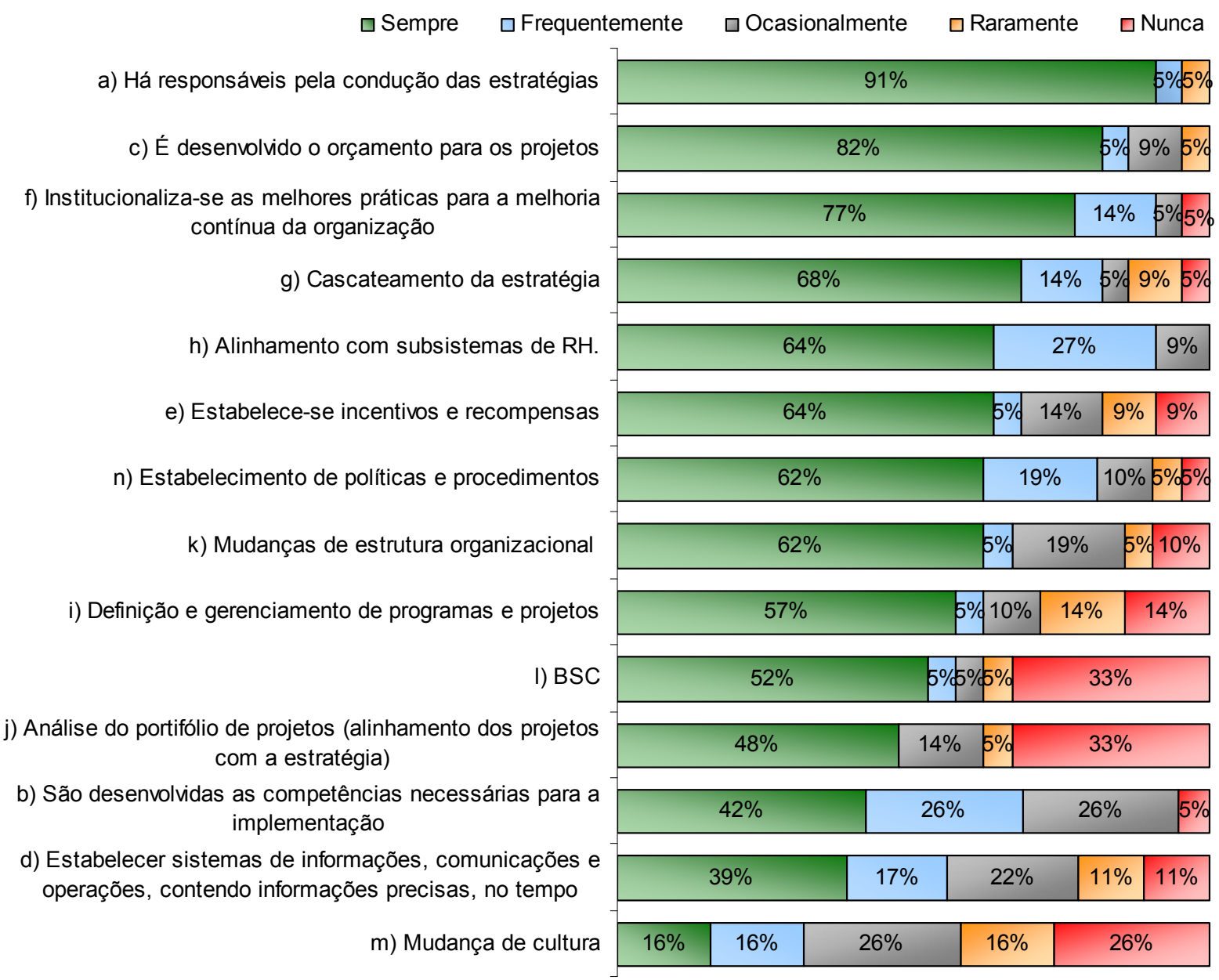

Figura 23 - Técnicas e conceitos utilizados na implementação

São compreensíveis as respostas dos executivos quanto à baixa utilização desses conceitos. É difícil a empresa fazer mudanças de cultura, já que é algo mais perene e só ocorrem a longo prazo. Para os outros dois pontos, o estabelecimento de sistemas de informações e o desenvolvimento de competências, necessitam de grandes investimentos. Assim, as empresas têm procurado outras soluções.

Além das técnicas, ferramentas e conceitos são necessárias análises do contexto interno e externo da empresa, segundo as sugestões de Pettigrew e Whipp (1991) e Okumus (2001), para verificar a aplicabilidade da estratégia. Nota-se na figura 24 que a análise do contexto interno e externo é realizada quase que na 
totalidade das empresas (95\%), mostrando a importância de ter a estratégia alinhada com o contexto organizacional, facilitando o processo de implementação.

Complementando, cerca de $80 \%$ das empresas avaliadas concordam que a maneira na qual a empresa está organizada facilita a implementação da estratégia. Percebe-se que $20 \%$ das empresas enxergam que necessitam melhorar sua estrutura para facilitar o processo de implementação.

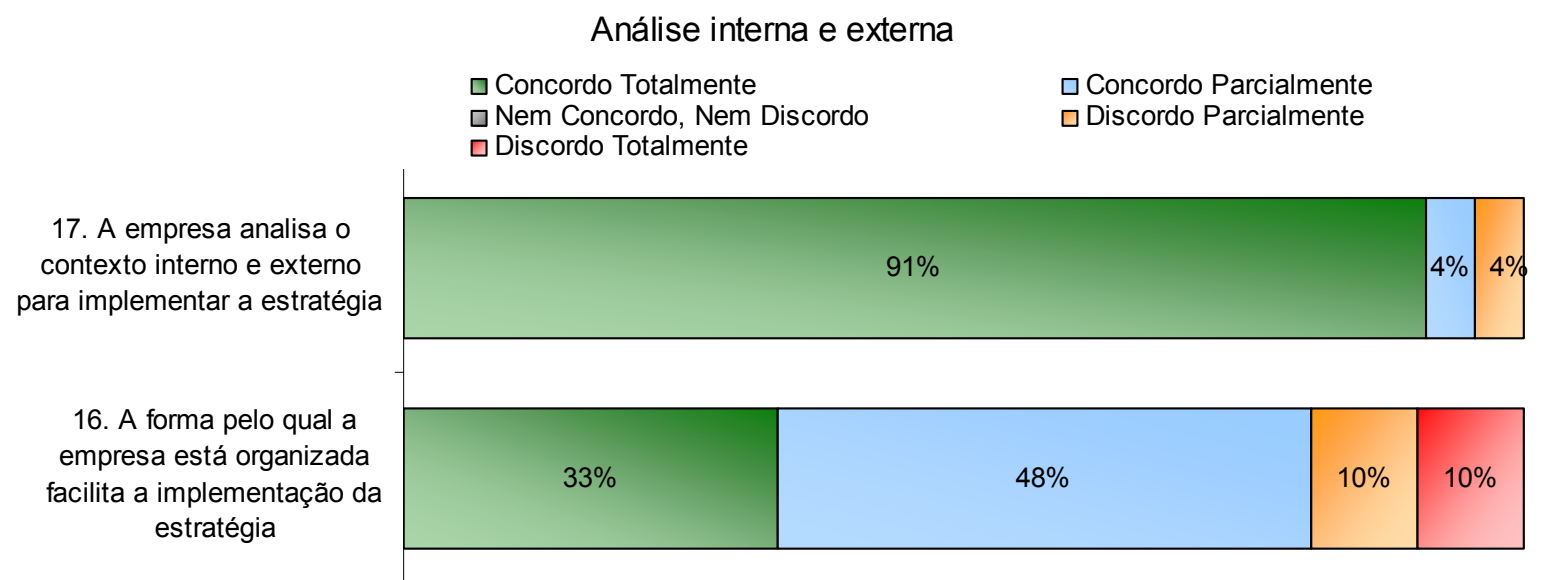

Figura 24 - Análise do contexto interno e externo

O sucesso na implementação ou da coordenação desse processo é refletido nos resultados e no tempo de implementação. Por meio da pesquisa, verificou-se que $66 \%$ das empresas implementaram suas estratégias com algum atraso. Observa-se que $5 \%$ das empresas implementaram seus planos antes do prazo previsto (figura 25).

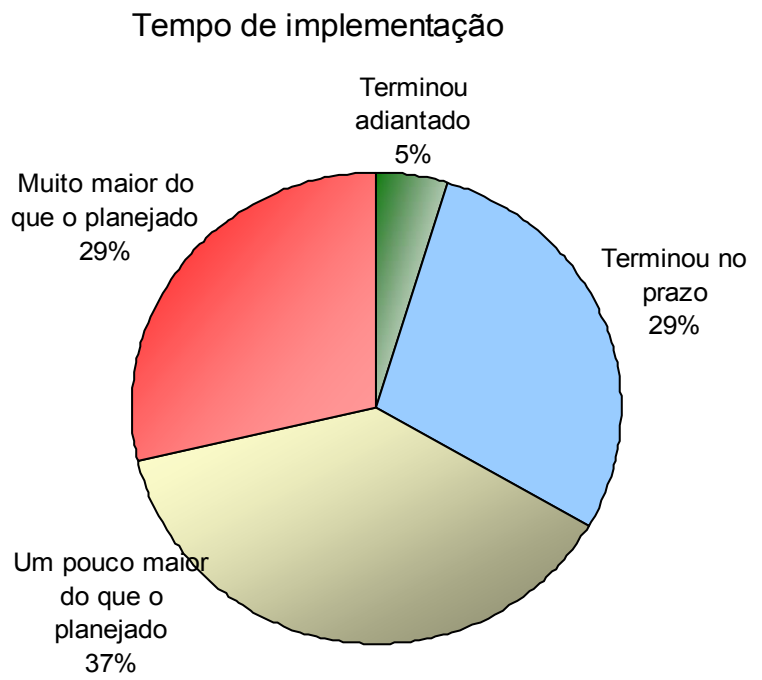

Figura 25 - Tempo de implementação 
Para verificar o impacto da coordenação do processo, no qual envolve o gerenciamento de projetos, no sucesso da implementação, há uma questão que trata sobre a eficácia da coordenação. Sobre esse tópico, obteve-se a média de 3,4, sendo que a nota máxima é 5 . Cerca de $45 \%$ dos entrevistados avaliaram a coordenação do processo de implementação com a nota 4, em termos de eficácia. (figura 26)

Coordenação da implementação

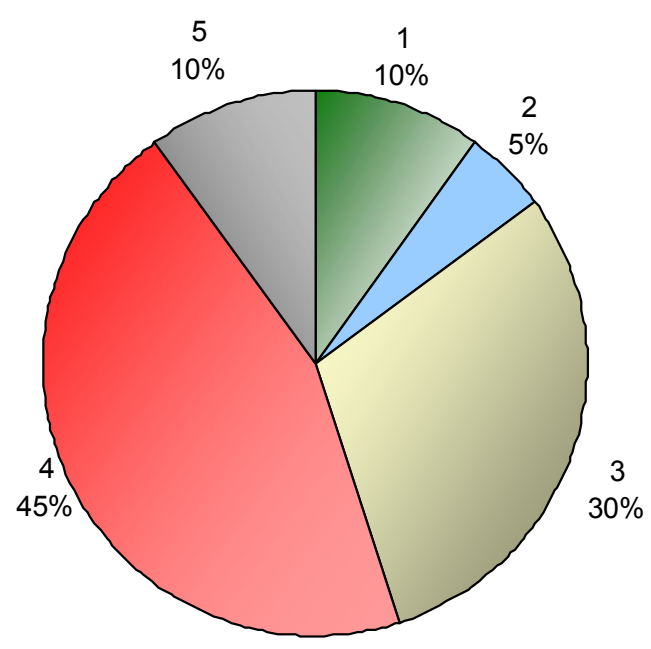

Figura 26 - Coordenação da implementação das estratégias

Ao cruzar as variáveis coordenação da implementação com o tempo de implementação, notou-se que as empresas que tiveram total eficácia na coordenação da implementação de estratégias (nota igual a 5) conseguiram terminar a execução no prazo definido ou até adiantado. $O$ inverso também ocorreu, as empresas que avaliaram que não tiveram eficácia na coordenação implementaram suas estratégias em um tempo muito maior do que o planejado. 
Tabela 9 - Coordenação eficaz x tempo de implementação

\begin{tabular}{|c|c|c|c|c|}
\hline \multirow{2}{*}{$\begin{array}{l}\text { 19.Coordenadação eficaz da } \\
\text { implementação }\end{array}$} & \multicolumn{4}{|c|}{ 18.Tempo de implementação } \\
\hline & \begin{tabular}{|c|}
$\begin{array}{c}\text { Muito maior do que } \\
\text { o planejado }\end{array}$ \\
\end{tabular} & $\begin{array}{c}\text { Um pouco maior do } \\
\text { que o planejado } \\
\end{array}$ & Terminou no prazo & Terminou adiantado \\
\hline 1 & $100 \%$ & $0 \%$ & $0 \%$ & $0 \%$ \\
\hline 2 & $0 \%$ & $100 \%$ & $0 \%$ & $0 \%$ \\
\hline 3 & $50 \%$ & $33 \%$ & $17 \%$ & $0 \%$ \\
\hline 4 & $11 \%$ & $56 \%$ & $33 \%$ & $0 \%$ \\
\hline 5 & $0 \%$ & $0 \%$ & $50 \%$ & $50 \%$ \\
\hline
\end{tabular}

\begin{tabular}{|c|c|c|c|c|c|}
\hline \multirow{2}{*}{ 18.Tempo de implementação } & \multicolumn{5}{|c|}{ 19.Coordenadaço eficaz da implementação } \\
\cline { 2 - 6 } & 1 & 2 & 3 & 4 & 5 \\
\hline Muito maior do que o planejado & $33 \%$ & $0 \%$ & $50 \%$ & $17 \%$ & $0 \%$ \\
\hline Um pouco maior do que o planejado & $0 \%$ & $13 \%$ & $25 \%$ & $63 \%$ & $0 \%$ \\
\hline Terminou no prazo & $0 \%$ & $0 \%$ & $20 \%$ & $60 \%$ & $20 \%$ \\
\hline Terminou adiantado & $0 \%$ & $0 \%$ & $0 \%$ & $0 \%$ & $100 \%$ \\
\hline
\end{tabular}

Metade das empresas faz o acompanhamento da execução das estratégias de forma mensal. Uma em cada quatro empresas monitora a implementação apenas uma vez ao ano, na reunião de planejamento estratégico.

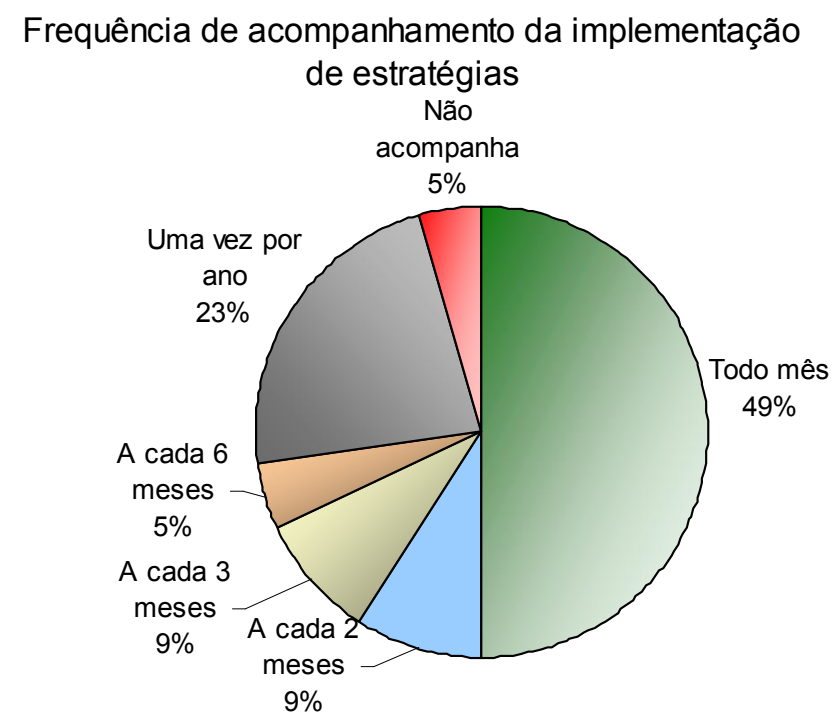

Figura 27 - Freqüência de acompanhamento da implementação de estratégias

Uma das variáveis mais importantes dessa pesquisa é a satisfação em relação ao processo de implementação de estratégias. Ela foi utilizada na maior parte do estudo por ser a variável dependente. Cerca de $40 \%$ dos entrevistados 
avaliaram sua satisfação em relação ao processo de implementação de estratégias com notas entre 8 e 10. Assim, a nota média ficou em torno de 7 (vide figura 28).

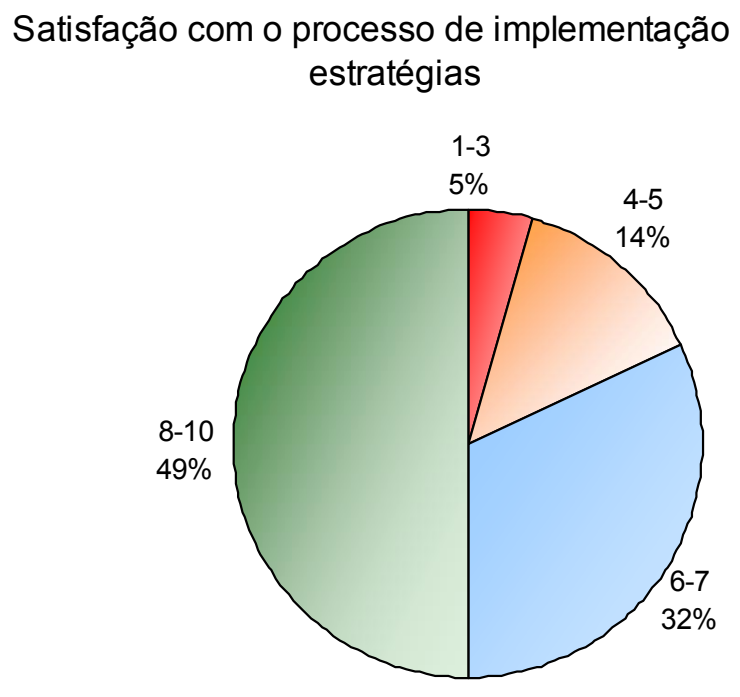

Figura 28 - Satisfação com o processo de implementação de estratégias

Um diferencial dessa pesquisa foi a realização de uma análise bi-variada com as respostas da pergunta que procurava identificar se as empresas tinham metodologia de implementação de estratégias com o grau da satisfação com o processo. As empresas que possuem metodologia de implementação têm satisfação média com os resultados do processo de implementação em torno de 7,5 , contra 6,2 daquelas que não possuem metodologia.

Tabela 10 - Utilização de metodologia de implementação de estratégia x satisfação/sucesso com a implementação

\begin{tabular}{|l|c|}
\hline $\begin{array}{l}\text { 4. Tem metodologia de } \\
\text { implementação }\end{array}$ & $\begin{array}{l}\text { 21. Satisfação/sucesso } \\
\text { com a implementação }\end{array}$ \\
\hline Sim & 7.5 \\
\hline Não & 6.2 \\
\hline
\end{tabular}

Procurou-se realizar o mesmo tipo de análise cruzando a utilização da metodologia de implementação com a variável dependente percentual das estratégias implementadas. Observa-se pelas tabelas seguintes que das empresas 
que conseguiram implementar mais de 90\% das estratégias, quase $90 \%$ delas possuem metodologia de implementação, mostrando a importância de tê-la.

Ao inverter essa análise, das empresas que possuem metodologia de implementação de estratégias, quase metade delas consegue implementar mais de $90 \%$ das estratégias.

Tabela 11 - Utilização de metodologia de implementação de estratégia x percentual das estratégias implementadas

\begin{tabular}{|c|c|c|c|c|}
\hline \multirow{2}{*}{$\begin{array}{c}\text { 4. Tem metodologia } \\
\text { de implementação }\end{array}$} & Mais de $90 \%$ & Entre $60 \%$ e $90 \%$ & Entre $30 \%$ e $60 \%$ & Menos de $30 \%$ \\
\cline { 2 - 5 } & $47 \%$ & $35 \%$ & $12 \%$ & $6 \%$ \\
\hline $\operatorname{Sim}$ & $20 \%$ & $80 \%$ & $0 \%$ & $0 \%$ \\
\hline Não & & & & \\
\hline
\end{tabular}

\begin{tabular}{|c|c|c|}
\hline \multirow{2}{*}{ 10. Percentual das estratégias implementadas } & 4. Tem metodologia de implementação \\
\cline { 2 - 3 } & Sim & Não \\
\hline Mais de $90 \%$ & $89 \%$ & $11 \%$ \\
\hline Entre $60 \%$ e $90 \%$ & $60 \%$ & $40 \%$ \\
\hline Entre $30 \%$ e $60 \%$ & $100 \%$ & $0 \%$ \\
\hline Menos de $30 \%$ & $100 \%$ & $0 \%$ \\
\hline
\end{tabular}

Com a tabela 12 busca-se demostrar a relação entre compreensão da visão e satisfação com a implementação. De acordo com essa tabela, verifica-se que há um padrão de respostas que mostra que quanto maior compreensão e internalização da visão, maior é a satisfação com os resultados do processo de implementação de estratégias. Mas, o contrário não é verdadeiro.

Cerca de $75 \%$ das empresas que tinham a visão entendida e internalizada em todos os níveis da organização, avaliaram a satisfação com a implementação entre 8 e 10 . 
Tabela 12 - Compreensão da visão da empresa x satisfação com a implementação

\begin{tabular}{|c|c|c|c|}
\hline \multirow{2}{*}{ 7. Compreensão da visão da empresa } & \multicolumn{3}{|c|}{ 21.Satisfação com a implementação } \\
\cline { 2 - 4 } & $1-5$ & $6-7$ & $8-10$ \\
\hline $\begin{array}{r}\text { Ela é entendida e internalizada em todos } \\
\text { os níveis }\end{array}$ & $25 \%$ & $0 \%$ & $75 \%$ \\
\hline Ela é entendida em todos os níveis & $20 \%$ & $30 \%$ & $50 \%$ \\
\hline Ela é entendida pelo nível gerencial & $14 \%$ & $43 \%$ & $43 \%$ \\
\hline Ela não é muito entendida na organização & $0 \%$ & $100 \%$ * & $0 \%$ \\
\hline
\end{tabular}

* - não obteve número de respostas suficientes para se obter uma estatística confiável

\begin{tabular}{|c|c|c|c|c|}
\hline $\begin{array}{c}\text { 21.Satisfação com a } \\
\text { implementação }\end{array}$ & $\begin{array}{c}\text { 7. Compreensão da visão da empresa } \\
\text { Ela é entendida e } \\
\text { internalizada em todos os } \\
\text { niveis }\end{array}$ & $\begin{array}{c}\text { Ela é entendida em todos } \\
\text { os níveis }\end{array}$ & $\begin{array}{c}\text { Ela é entendida pelo nivel } \\
\text { gerencial }\end{array}$ & $\begin{array}{c}\text { Ela não é muito entendida } \\
\text { na organização }\end{array}$ \\
\hline $1-5$ & $25 \%$ & $50 \%$ & $25 \%$ & $0 \%$ \\
\hline $6-7$ & $0 \%$ & $43 \%$ & $43 \%$ & $14 \%$ \\
\hline $8-10$ & $27 \%$ & $46 \%$ & $27 \%$ & $0 \%$ \\
\hline
\end{tabular}

Ao cruzar a pergunta sobre compreensão da visão com o percentual das estratégias implementadas, nota-se que:

- $50 \%$ das empresas que tinham a visão compreendida e internalizada conseguiram implementar mais de $90 \%$ de suas estratégias;

- $60 \%$ das empresas nas quais os funcionários entendiam a visão conseguiram implementar mais de $90 \%$ das estratégias.

Tabela 13 - Compreensão da visão x percentual das estratégias implementadas

\begin{tabular}{|c|c|c|c|c|}
\hline \multirow[b]{2}{*}{ 7. Compreensão da visão da empresa } & \multicolumn{4}{|c|}{ 10. Percentual das estratégias implementadas } \\
\hline & Mais de $90 \%$ & Entre $60 \%$ e $90 \%$ & Entre $30 \%$ e $60 \%$ & Menos de $30 \%$ \\
\hline $\begin{array}{l}\text { Ela é entendida e internalizada em todos } \\
\text { os níveis }\end{array}$ & $50 \%$ & $25 \%$ & $25 \%$ & $0 \%$ \\
\hline Ela é entendida em todos os níveis & $60 \%$ & $20 \%$ & $10 \%$ & $10 \%$ \\
\hline Ela é entendida pelo nível gerencial & $14 \%$ & $86 \%$ & $0 \%$ & $0 \%$ \\
\hline Ela não é muito entendida na organização & $0 \%$ & $100 \%$ & $0 \%$ & $0 \%$ \\
\hline
\end{tabular}

Apesar desse fato, quando se faz a análise de forma invertida (tabela 14), novamente não há um padrão claro. Pelas análises, percebe-se que a compreensão exata da visão não é tão relevante para o sucesso da implementação de estratégias. 
Uma inferência que pode ser feita é que possivelmente as pessoas não precisam conhecer precisamente a visão ou as frases da empresa que compõem o conceito. O que pode ser importante é o conhecimento do funcionário do direcionamento da companhia.

Tabela 14 - Percentual das estratégias implementadas x compreensão da visão da empresa

\begin{tabular}{|c|c|c|c|c|}
\hline $\begin{array}{c}\text { 10. Percentual das estratégias } \\
\text { implementadas }\end{array}$ & \begin{tabular}{c} 
7. Compreensão da visão da empresa \\
\cline { 2 - 4 } \\
internalizada em todos \\
os niveis
\end{tabular} & $\begin{array}{c}\text { Ela é entendida em } \\
\text { todos os niveis }\end{array}$ & $\begin{array}{c}\text { Ela é entendida pelo } \\
\text { nível gerencial }\end{array}$ & $\begin{array}{c}\text { Ela não é muito } \\
\text { entendida na } \\
\text { organização }\end{array}$ \\
\hline Mais de $90 \%$ & $22 \%$ & $67 \%$ & $11 \%$ & $0 \%$ \\
\hline Entre $60 \%$ e $90 \%$ & $10 \%$ & $20 \%$ & $60 \%$ & $10 \%$ \\
\hline Entre 30\% e 60\% & $50 \%$ & $50 \%$ & $0 \%$ & $0 \%$ \\
\hline Menos de 30\% & $0 \%$ & $100 \%$ & $0 \%$ & $0 \%$ \\
\hline
\end{tabular}

Ao analisar as perguntas 10 e 13 no conjunto, verificou-se que daquelas empresas que obtiveram sucesso implementando mais de $90 \%$ das estratégias, os executivos tinham clareza de seus papéis e responsabilidade no processo.

Tabela 15 - Percentual das estratégias implementadas x clareza do papel do executivo na implementação

\begin{tabular}{|c|c|c|c|}
\hline \multirow[b]{2}{*}{$\begin{array}{l}\text { 10. Percentual das estratégias } \\
\text { implementadas }\end{array}$} & \multicolumn{3}{|c|}{ 13. Clareza do papel do executivo na implementação } \\
\hline & $\begin{array}{c}\text { Está totalmente claro os } \\
\text { papéis e responsabilidades } \\
\text { de cada executivo na } \\
\text { implementação }\end{array}$ & Sim, em sua maioria & $\begin{array}{c}\text { Está razoavelmente } \\
\text { claro }\end{array}$ \\
\hline Mais de $90 \%$ & $100 \%$ & $0 \%$ & $0 \%$ \\
\hline Entre $60 \%$ e $90 \%$ & $80 \%$ & $10 \%$ & $10 \%$ \\
\hline Entre $30 \%$ e $60 \%$ & $0 \%$ & $50 \%$ & $50 \%$ \\
\hline Menos de $30 \%$ & $100 \%$ & $0 \%$ & $0 \%$ \\
\hline
\end{tabular}

Conforme a tabela 16, o contrário não ocorre da mesma forma. Das empresas nas quais os executivos tinham clareza de seus papéis e responsabilidades na implementação, somente $47 \%$ delas conseguiram implementar. Apesar disso, esse número é superior se comparado com as empresas nas quais esta clareza é parcial. 
Tabela 16 - Clareza do papel do executivo na implementação x percentual das estratégias implementadas

\begin{tabular}{|c|c|c|c|c|}
\hline $\begin{array}{c}\text { 13. Clareza do papel do } \\
\text { executivo na implementação }\end{array}$ & Mais de $90 \%$ & Entre $60 \%$ e $90 \%$ & Entre 30\% e 60\% & Menos de $30 \%$ \\
\hline $\begin{array}{c}\text { Está totalmente claro os papéis e } \\
\text { responsabilidades de cada } \\
\text { executivo na implementação }\end{array}$ & $47 \%$ & $47 \%$ & $0 \%$ & $6 \%$ \\
\hline Sim, em sua maioria & $0 \%$ & $50 \%$ & $50 \%$ & 0 \\
\hline Está razoavelmente claro & $0 \%$ & $50 \%$ & $50 \%$ & 0 \\
\hline
\end{tabular}

A grande diferença ocorre quando é analisada a clareza para o funcionário. De acordo com a tabela 17, 100\% das empresas que têm totalmente claro os papéis e responsabilidades dos funcionários em relação à implementação estão satisfeitas em relação aos processos e resultados da implementação de estratégias.

Tabela 17 - Clareza do papel do executivo na implementação x satisfação com a implementação

\begin{tabular}{|c|c|c|c|}
\hline \multirow{2}{*}{$\begin{array}{l}\text { 14. Clareza do papel dos } \\
\text { funcionarios na implementação }\end{array}$} & \multicolumn{3}{|c|}{ 21.Satisfação com a implementação } \\
\hline & $1-5$ & $6-7$ & $8-10$ \\
\hline Sim, totalmente & $0 \%$ & $0 \%$ & $100 \%$ \\
\hline Sim, em sua maioria & $20 \%$ & $30 \%$ & $50 \%$ \\
\hline Está razoavelmente claro & $20 \%$ & $80 \%$ & 0 \\
\hline Não está claro as responsabilidades & $100 \%$ * & $0 \%$ & $0 \%$ \\
\hline
\end{tabular}

Das empresas que tiveram alto grau de satisfação com a implementação de estratégias empresariais, cerca de $55 \%$ afirmaram que os funcionários tinham claro seu papel na implementação e $45 \%$ tinham o papel claro para a maioria das pessoas. Vide o detalhamento na tabela 18. 
Tabela 18 - Satisfação com a implementação x clareza do papel do executivo na implementação

\begin{tabular}{|c|c|c|c|c|}
\hline \multirow{2}{*}{$\begin{array}{c}\text { 21.Satisfação com } \\
\text { a implementação }\end{array}$} & \multicolumn{4}{|c|}{ 14. Clareza do papel dos funcionarios na implementação } \\
\cline { 2 - 5 } & Sim, totalmente & Sim, em sua maioria & $\begin{array}{c}\text { Está razoavelmente } \\
\text { claro }\end{array}$ & $\begin{array}{c}\text { Não está claro as } \\
\text { responsabilidades }\end{array}$ \\
\hline $1-5$ & $0 \%$ & $50 \%$ & $25 \%$ & $25 \%$ \\
\hline $6-7$ & $0 \%$ & $43 \%$ & $57 \%$ & $0 \%$ \\
\hline $8-10$ & $55 \%$ & $45 \%$ & $0 \%$ & $0 \%$ \\
\hline
\end{tabular}

Nota-se na tabela 19 , que cerca de $80 \%$ das empresas que têm claro o papel dos funcionários conseguem implementar mais de $90 \%$ das estratégias.

Tabela 19 - Clareza do papel do executivo na implementação x percentual das estratégias implementadas

\begin{tabular}{|c|c|c|c|c|}
\hline \multirow{2}{*}{$\begin{array}{c}\text { 14. Clareza do papel dos } \\
\text { funcionarios na implementação }\end{array}$} & Mais de $90 \%$ & Entre $60 \%$ e $90 \%$ & Entre 30\% e 60\% & Menos de $30 \%$ \\
\cline { 2 - 5 } & $83 \%$ & $17 \%$ & $0 \%$ & $0 \%$ \\
\hline Sim, totalmente & $22 \%$ & $56 \%$ & $22 \%$ & 0 \\
\hline Sim, em sua maioria & $20 \%$ & $80 \%$ & $0 \%$ & 0 \\
\hline Não está claro as responsabilidades & $0 \%$ & $0 \%$ & $0 \%$ & $100 \%$ \\
\hline
\end{tabular}

$\mathrm{Na}$ tabela 20 , procura-se entender a relação entre comprometimento dos funcionários e satisfação em relação à implementação. Observa-se que as empresas que responderam que possuem funcionários com índices de comprometimento muito altos obtêm maior sucesso na implementação de estratégias. Verifica-se que $80 \%$ das empresas que responderam que têm alto índice de comprometimento, atingiram notas de satisfação com a implementação entre 8 e 10. 
Tabela 20 - Comprometimento x satisfação com a implementação

\begin{tabular}{|c|c|c|c|}
\hline \multirow{2}{*}{$\begin{array}{c}\text { 15. Comprometimento dos } \\
\text { funcionários }\end{array}$} & $1-5$ & $6-7$ & $8-10$ \\
\cline { 2 - 4 } & $100 \%$ * & $0 \%$ & $0 \%$ \\
\hline Baixo & $33 \%^{*}$ & $67 \%$ * Satisfação com a implementação & $0 \%$ \\
\hline Médio & $12 \%$ & $50 \%$ & $38 \%$ \\
\hline Alto & $10 \%$ & $10 \%$ & $80 \%$ \\
\hline Muito Alto & & & \\
\hline
\end{tabular}

Isso também ocorre com o percentual das estratégias implementadas, onde se verificou que $70 \%$ das empresas que responderam que têm alto índice de comprometimento, atingiram percentuais de implementação acima de 90\%.

Tabela 21 - Comprometimento x percentual das estratégias implementadas

\begin{tabular}{|c|c|c|c|c|}
\hline \multirow{2}{*}{$\begin{array}{c}\text { 15. Comprometimento dos } \\
\text { funcionários }\end{array}$} & 10. Percentual das estratégias implementadas & \\
\cline { 2 - 5 } & Mais de $90 \%$ & Entre $60 \%$ e $90 \%$ & Entre $30 \%$ e $60 \%$ & Menos de $30 \%$ \\
\hline Baixo & $0 \%$ & $0 \%$ & $0 \%$ & $100 \%$ * \\
\hline Médio & $0 \%$ & $33 \% *$ & $67 \% *$ & $0 \%$ \\
\hline Alto & $25 \%$ & $75 \%$ & $0 \%$ & 0 \\
\hline Muito Alto & $70 \%$ & $30 \%$ & $0 \%$ & $0 \%$ \\
\hline
\end{tabular}

As empresas que tiveram mais estratégias implementadas apresentaram uma maior utilização das ferramentas, técnicas e conceitos durante o planejamento estratégico. Sendo eles:

- Desenvolvimento das competências necessárias para a implementação;

- Institucionalização das melhores práticas para a melhoria contínua da organização;

- Desenvolvimento do orçamento para os projetos;

- Definição de responsáveis pela condução das estratégias; 
- Estabelecimento de incentivos e recompensas;

- Alinhamento com subsistemas de RH.

Os resultados apresentados da primeira variável, desenvolvimento das competências para a implementação, corroborou com as pesquisas realizadas por Schmidt (1994), Sterling (2003), Galpin (1997), Kronmeyer (2003) e Hussey (1996).

Já a busca das melhores práticas mostra que as empresas desejam estar à frente de seus concorrentes e diferenciando-se. Assim, umas das possíveis preocupações dos executivos, nesse contexto, é melhorar a implementação para chegar antecipadamente ao mercado.

O terceiro instrumento que mais se destaca na implementação de estratégias é o orçamento (vide tabela 22). Por mais que a prática do orçamento seja bem difundida ( $82 \%$ das empresas pesquisadas utilizam), os dados apontam que as organizações que realizam orçamento conseguem obter maior percentual de estratégias implementadas.

O quarto que mais pode agregar valor ao processo de implementação é a definição de responsáveis, segundo os dados apresentados na tabela 22. A definição de responsáveis, defendida por Bossidy e Charan (2002), Hrebiniak (2005), Sterling (2003) e Hussey (1996), trouxe muitas contribuições às empresas que buscam um maior sucesso na implementação de estratégias. Dessa forma, é possível cobrar as responsabilidades e fazer um acompanhamento mais de perto.

O estabelecimento de incentivos e recompensa, bem como o alinhamento com os subsistemas de $\mathrm{RH}$, estão integrados. Os resultados foram ao encontro de diversas pesquisas acadêmicas (GALPIN, 1997; AALTONEN e IKAVALKO, 2002; DOBNI, 2003; FREEDMAN, 2003; LINTON, 2002; HREBINIAK, 2006). Esse resultado pode auxiliar os gestores de recursos humanos na justificativa da sua importância para o processo de implementação. 
O item mudança de cultura teve poucas respostas para obter um índice significativo.

Por outro lado, existem variáveis conduzidas no planejamento estratégico que tiveram menor impacto no percentual das estratégias implementadas, sendo elas:

- Portifólio de projetos;

- Mudanças de estrutura organizacional;

- Estabelecimento de políticas e procedimentos;

- Balanced Scorecard;

- Definição e gerenciamento de programas e projetos.

Nota-se na tabela 22, que o portifólio de projetos pouco contribuiu para a implementação de estratégias. Uma possível inferência é que as empresas pouco têm se utilizado dessa ferramenta, conseguindo realizar as atribuições do portifólio de projetos de forma informal, atingindo resultados aproximados. Da mesma forma pode estar ocorrendo o mesmo com o Balanced Scorecard. Durante as entrevistas muitos executios disseram que não têm Balanced Scorecard, mas que procuraram realizar as atividades da ferramenta de outra forma.

A mudança de estrutura organizacional já é uma prática muito corrente nas empresas e também se observa que não agregou muito valor para o processo de implementação, quando comparada com outras técnicas e conceitos. O que também ocorreu com o estabelecimento de política e procedimentos.

E por último, o conceito que menos agregou valor ao processo de implementação, segundo a análise apresentada na tabela 22, foi a de gerenciamento de projetos e programas. Esse resultado pode estar na linha dos autores Crawford, Hobbs e Turner (2005), para os quais o gerenciamento de projetos não é tratado no planejamento estratégico realizado pela Alta Direção. 
Tabela 22 - Técnicas, conceitos e ferramentas do PE x percentual das estratégias implementadas

* - não obteve número de respostas suficientes para se obter uma estatística confiável

\begin{tabular}{|c|c|c|c|c|c|c|}
\hline \multirow{2}{*}{\multicolumn{2}{|c|}{$\begin{array}{l}\text { Técnicas, instrumentos e conceitos de PE utilizados na } \\
\text { implementação }\end{array}$}} & \multicolumn{4}{|c|}{$\begin{array}{l}\text { 10. Percentual das estratégias } \\
\text { implementadas }\end{array}$} & \multirow{2}{*}{$\begin{array}{c}\text { Diferenca } \\
\text { sempre } x \\
\text { demais } \\
\text { respostas }\end{array}$} \\
\hline & & $\begin{array}{l}\text { Mais de } \\
90 \%\end{array}$ & $\begin{array}{c}\text { Entre } 60 \% \\
\text { e } 90 \%\end{array}$ & $\begin{array}{c}\text { Entre } 30 \% \\
\text { e } 60 \%\end{array}$ & $\begin{array}{c}\text { Menos de } \\
30 \%\end{array}$ & \\
\hline \multirow{3}{*}{$\begin{array}{l}\text { b) São desenvolvidas as competências necessárias para } \\
\text { a implementação }\end{array}$} & $\begin{array}{l}\text { Ocas., Raram. e } \\
\text { Nunca }\end{array}$ & $0 \%$ & $75 \%$ & $13 \%$ & $13 \%$ & \multirow{3}{*}{$63 \%$} \\
\hline & Frequentemente & $40 \%$ & $40 \%$ & $20 \%$ & $0 \%$ & \\
\hline & Sempre & $63 \%$ & $37 \%$ & $0 \%$ & $0 \%$ & \\
\hline \multirow{2}{*}{$\begin{array}{l}\text { f) Institucionaliza-se as melhores práticas para a melhoria } \\
\text { contínua da organização }\end{array}$} & \begin{tabular}{|l|} 
Freq., Ocas., \\
Raram. e Nunca
\end{tabular} & $0 \%$ & $40 \%$ & $40 \%$ & $20 \%$ & \multirow{2}{*}{$53 \%$} \\
\hline & Sempre & $53 \%$ & $47 \%$ & $0 \%$ & $0 \%$ & \\
\hline \multirow{2}{*}{ c) É desenvolvido o orçamento para os projetos } & \begin{tabular}{|l|} 
Freq., Ocas., \\
Raram. e Nunca \\
\end{tabular} & $0 \%$ & $75 \%$ & $25 \%$ & $0 \%$ & \multirow{2}{*}{$50 \%$} \\
\hline & Sempre & $50 \%$ & $39 \%$ & $0 \%$ & $0 \%$ & \\
\hline \multirow{2}{*}{ a) Há responsáveis pela condução das estratégias } & \begin{tabular}{|l|} 
Freq., Ocas., \\
Raram. e Nunca
\end{tabular} & $0 \%$ & $100 \%$ * & $0 \%$ & $0 \%$ & \multirow{2}{*}{$45 \%$} \\
\hline & Sempre & $45 \%$ & $40 \%$ & $10 \%$ & $5 \%$ & \\
\hline \multirow{2}{*}{ e) Estabelece-se incentivos e recompensas } & \begin{tabular}{|l|} 
Freq., Ocas., \\
Raram. e Nunca \\
\end{tabular} & $13 \%$ & $50 \%$ & $25 \%$ & $13 \%$ & \multirow{2}{*}{$44 \%$} \\
\hline & Sempre & $57 \%$ & $43 \%$ & $0 \%$ & $0 \%$ & \\
\hline \multirow{2}{*}{ h) Alinhamento com subsistemas de RH. } & \begin{tabular}{|l|} 
Freq., Ocas., \\
Raram. e Nunca \\
\end{tabular} & $13 \%$ & $62 \%$ & $13 \%$ & $13 \%$ & \multirow{2}{*}{$44 \%$} \\
\hline & Sempre & $57 \%$ & $36 \%$ & $7 \%$ & $0 \%$ & \\
\hline \multirow{2}{*}{ g) Cascateamento da estratégia } & \begin{tabular}{|l|} 
Freq., Ocas., \\
Raram. e Nunca \\
\end{tabular} & $14 \%$ & $57 \%$ & $14 \%$ & $14 \%$ & \multirow{2}{*}{$39 \%$} \\
\hline & Sempre & $53 \%$ & $40 \%$ & $7 \%$ & $0 \%$ & \\
\hline \multirow{2}{*}{$\begin{array}{c}\text { d) Estabelecer sistemas de informações, comunicações e } \\
\text { operações, contendo informações precisas, no tempo } \\
\text { adequado }\end{array}$} & \begin{tabular}{|l|} 
Freq., Ocas., \\
Raram. e Nunca
\end{tabular} & $27 \%$ & $45 \%$ & $18 \%$ & $9 \%$ & \multirow{2}{*}{$30 \%$} \\
\hline & Sempre & $57 \%$ & $43 \%$ & $0 \%$ & $0 \%$ & \\
\hline \multirow{2}{*}{$\begin{array}{l}\text { j) Análise do portifólio de projetos (alinhamento dos } \\
\text { projetos com a estratégia) }\end{array}$} & \begin{tabular}{|l|} 
Freq., Ocas., \\
Raram. e Nunca
\end{tabular} & $27 \%$ & $64 \%$ & $0 \%$ & $9 \%$ & \multirow{2}{*}{$23 \%$} \\
\hline & Sempre & $50 \%$ & $30 \%$ & $20 \%$ & $0 \%$ & \\
\hline \multirow{2}{*}{ k) Mudanças de estrutura organizacional } & \begin{tabular}{|l|} 
Freq., Ocas., \\
Raram. e Nunca \\
\end{tabular} & $25 \%$ & $37 \%$ & $25 \%$ & $13 \%$ & \multirow{2}{*}{$21 \%$} \\
\hline & Sempre & $46 \%$ & $54 \%$ & $0 \%$ & $0 \%$ & \\
\hline \multirow{2}{*}{ n) Estabelecimento de políticas e procedimentos } & \begin{tabular}{|l|} 
Freq., Ocas., \\
Raram. e Nunca
\end{tabular} & $25 \%$ & $50 \%$ & $12 \%$ & $12 \%$ & \multirow{2}{*}{$21 \%$} \\
\hline & Sempre & $46 \%$ & $46 \%$ & $0 \%$ & $0 \%$ & \\
\hline \multirow{2}{*}{ I) BSC } & \begin{tabular}{|l|} 
Freq., Ocas., \\
Raram. e Nunca \\
\end{tabular} & $30 \%$ & $50 \%$ & $10 \%$ & $10 \%$ & \multirow[t]{2}{*}{$16 \%$} \\
\hline & Sempre & $46 \%$ & $46 \%$ & $9 \%$ & $0 \%$ & \\
\hline \multirow{2}{*}{ i) Definição e gerenciamento de programas e projetos } & \begin{tabular}{|l|} 
Freq., Ocas., \\
Raram. e Nunca
\end{tabular} & $33 \%$ & $56 \%$ & $0 \%$ & $11 \%$ & \multirow{2}{*}{$9 \%$} \\
\hline & Sempre & $42 \%$ & $42 \%$ & $17 \%$ & $0 \%$ & \\
\hline \multirow{2}{*}{ m) Mudança de cultura } & \begin{tabular}{|l|} 
Freq., Ocas., \\
Raram. e Nunca
\end{tabular} & $31 \%$ & $50 \%$ & $13 \%$ & $6 \%$ & $\mathrm{~N} / \mathrm{A}$ \\
\hline & Sempre & $67 \%$ * & $33 \%$ * & $0 \%$ & $0 \%$ & \\
\hline
\end{tabular}

* - não obteve número de respostas suficientes para se obter uma estatística confiável

Nesse momento é realizada a mesma análise, mas cruzando a variável satisfação com a implementação. As empresas que tiveram maior satisfação com os resultados das estratégias apresentaram uma maior utilização das ferramentas, 
técnicas e conceitos desenvolvidos durante o planejamento estratégico. Conforme a seguir:

- Desenvolvimento das competências necessárias para a implementação;

- Estabelecimento de sistemas de informações, comunicações e operações, contendo informações precisas, no tempo adequado;

- Mudança da estrutura organizacional;

- Estabelecimento de políticas e procedimentos.

Tabela 23 - Técnicas, conceitos e ferramentas do PE x satisfação com a implementação

\begin{tabular}{|c|c|c|c|c|c|}
\hline \multirow{2}{*}{\multicolumn{2}{|c|}{$\begin{array}{l}\text { Técnicas, instrumentos e conceitos de PE utilizados na } \\
\text { implementação }\end{array}$}} & \multicolumn{3}{|c|}{$\begin{array}{l}\text { 21.Satisfação com a } \\
\text { implementação }\end{array}$} & \multirow{2}{*}{$\begin{array}{c}\text { Diferenca } \\
\text { sempre } x \\
\text { demais } \\
\text { respostas }\end{array}$} \\
\hline & & $1-5$ & $6-7$ & $8-10$ & \\
\hline \multirow{3}{*}{$\begin{array}{l}\text { b) São desenvolvidas as competências necessárias para } \\
\text { a implementação }\end{array}$} & \begin{tabular}{|l|} 
Freq., Ocas., \\
Raram. e Nunca \\
\end{tabular} & $33 \%$ & $67 \%$ & $0 \%$ & \multirow{3}{*}{$88 \%$} \\
\hline & Frequentemente & $20 \%$ & $40 \%$ & $40 \%$ & \\
\hline & Sempre & $12 \%$ & $0 \%$ & $88 \%$ & \\
\hline \multirow{2}{*}{$\begin{array}{l}\text { d) Estabelecer sistemas de informações, comunicações e } \\
\text { operações, contendo informações precisas, no tempo } \\
\text { adequado }\end{array}$} & \begin{tabular}{|l|} 
Freq., Ocas., \\
Raram. e Nunca \\
\end{tabular} & $27 \%$ & $55 \%$ & $18 \%$ & \multirow{2}{*}{$68 \%$} \\
\hline & Sempre & $14 \%$ & $0 \%$ & $86 \%$ & \\
\hline \multirow{2}{*}{$\begin{array}{l}\text { f) Institucionaliza-se as melhores práticas para a melhoria } \\
\text { contínua da organização }\end{array}$} & \begin{tabular}{|l|} 
Freq., Ocas., \\
Raram. e Nunca
\end{tabular} & $40 \%$ & $60 \%$ & $0 \%$ & \multirow{2}{*}{$64 \%$} \\
\hline & Sempre & $12 \%$ & $24 \%$ & $64 \%$ & \\
\hline \multirow{2}{*}{ c) É desenvolvido o orçamento para os projetos } & \begin{tabular}{|l|} 
Freq., Ocas., \\
Raram. e Nunca \\
\end{tabular} & $25 \%$ & $75 \%$ & $0 \%$ & \multirow{2}{*}{$61 \%$} \\
\hline & Sempre & $17 \%$ & $22 \%$ & $61 \%$ & \\
\hline \multirow{2}{*}{ e) Estabelece-se incentivos e recompensas } & \begin{tabular}{|l|} 
Freq., Ocas., \\
Raram. e Nunca \\
\end{tabular} & $25 \%$ & $62 \%$ & $13 \%$ & \multirow{2}{*}{$59 \%$} \\
\hline & Sempre & $14 \%$ & $14 \%$ & $72 \%$ & \\
\hline \multirow{2}{*}{ k) Mudanças de estrutura organizacional } & \begin{tabular}{|l|} 
Freq., Ocas., \\
Raram. e Nunca \\
\end{tabular} & $25 \%$ & $63 \%$ & $13 \%$ & \multirow{2}{*}{$57 \%$} \\
\hline & Sempre & $15 \%$ & $15 \%$ & $70 \%$ & \\
\hline \multirow{2}{*}{ g) Cascateamento da estratégia } & \begin{tabular}{|l|} 
Freq., Ocas., \\
Raram. e Nunca
\end{tabular} & $29 \%$ & $57 \%$ & $14 \%$ & \multirow[t]{2}{*}{$53 \%$} \\
\hline & Sempre & $13 \%$ & $20 \%$ & $67 \%$ & \\
\hline \multirow{2}{*}{ n) Estabelecimento de políticas e procedimentos } & \begin{tabular}{|l|} 
Freq., Ocas., \\
Raram. e Nunca \\
\end{tabular} & $13 \%$ & $63 \%$ & $25 \%$ & \multirow{2}{*}{$45 \%$} \\
\hline & Sempre & $23 \%$ & $8 \%$ & $70 \%$ & \\
\hline \multirow{2}{*}{ h) Alinhamento com subsistemas de RH. } & \begin{tabular}{|l|} 
Freq., Ocas., \\
Raram. e Nunca
\end{tabular} & $12 \%$ & $63 \%$ & $25 \%$ & \multirow{2}{*}{$40 \%$} \\
\hline & Sempre & $21 \%$ & $14 \%$ & $65 \%$ & \\
\hline \multirow{2}{*}{ l) BSC } & \begin{tabular}{|l|} 
Freq., Ocas., \\
Raram. e Nunca \\
\end{tabular} & $30 \%$ & $40 \%$ & $30 \%$ & \multirow[t]{2}{*}{$34 \%$} \\
\hline & Sempre & $9 \%$ & $27 \%$ & $64 \%$ & \\
\hline \multirow{2}{*}{ i) Definição e gerenciamento de programas e projetos } & \begin{tabular}{|l|} 
Freq., Ocas., \\
Raram. e Nunca \\
\end{tabular} & $22 \%$ & $44 \%$ & $33 \%$ & \multirow{2}{*}{$25 \%$} \\
\hline & Sempre & $17 \%$ & $25 \%$ & $58 \%$ & \\
\hline \multirow{2}{*}{$\begin{array}{l}\text { j) Análise do portifólio de projetos (alinhamento dos } \\
\text { projetos com a estratégia) }\end{array}$} & \begin{tabular}{|l|} 
Freq., Ocas., \\
Raram. e Nunca
\end{tabular} & $18 \%$ & $36 \%$ & $45 \%$ & \multirow{2}{*}{$5 \%$} \\
\hline & Sempre & $20 \%$ & $30 \%$ & $50 \%$ & \\
\hline \multirow{2}{*}{ m) Mudança de cultura } & \begin{tabular}{|l|} 
Freq., Ocas., \\
Raram. e Nunca \\
\end{tabular} & $19 \%$ & $31 \%$ & $50 \%$ & \multirow{2}{*}{ N/A } \\
\hline & Sempre & $33 \%$ * & $33 \%$ * & $33 \%$ * & \\
\hline \multirow{2}{*}{ a) Há responsáveis pela condução das estratégias } & \begin{tabular}{|l|} 
Freq., Ocas., \\
Raram. e Nunca \\
\end{tabular} & $0 \%$ & $100 \%$ * & $0 \%$ & \multirow{2}{*}{ N/A } \\
\hline & Sempre & $20 \%$ & $25 \%$ & $55 \%$ & \\
\hline
\end{tabular}


* - não obteve número de respostas suficientes para se obter uma estatística confiável

É interessante observar que na análise descritiva apenas uma variável apareceu nas duas listas de ferramentas e conceitos que mais impactaram na implementação: o desenvolvimento das competências necessárias para a implementação. Isso reforça a importância dessa variável para o processo.

$\mathrm{Na}$ outra extremidade, três técnicas/instrumentos/conceitos apareceram de novo como os menos agregadores de valor ao processo de implementação, na análise descritiva do questionário de estratégia, que são:

- Balanced Scorecard;

- Definição e gerenciamento de programas e projetos;

- Análise de portifólio.

Neste ponto, é analisada a importância de a empresa estar organizada e estruturada para a implementação de estratégias, idéia discutida por Chandler (1962). Nota-se pelas tabelas seguintes, que $72 \%$ das empresas que estão bem estruturadas e organizadas para a implementação têm satisfação com o processo de implementação de estratégias acima da nota 8.

Tabela 24 - Organização da empresa (estrutura) x satisfação com a implementação

\begin{tabular}{|c|c|c|c|}
\hline $\begin{array}{c}\text { 16. A forma pelo qual a empresa } \\
\text { está organizada facilita a } \\
\text { implementação da estratégia }\end{array}$ & $1-5$ & $6-7$ & $8-10$ \\
\cline { 2 - 4 } & $14 \%$ & $14 \%$ & $72 \%$ \\
\hline Concordo Totalmente & $20 \%$ & $40 \%$ & $40 \%$ \\
\hline Concordo Parcialmente & $50 \%$ * & $50 \%$ * & $0 \%$ \\
\hline Discordo Parcialmente & $0 \%$ & $50 \%$ * & $50 \%$ * \\
\hline Discordo Totalmente & & & \\
\hline
\end{tabular}

* - não obteve número de respostas suficientes para se obter uma estatística confiável 
Adicionalmente, $43 \%$ dessas empresas conseguem implementar mais de $90 \%$ das estratégias. Se forem somadas a implementação de mais de 60\% das estratégias, abrange-se a totalidade das empresas que estão organizadas para a implementação, corroborando com a teoria de Chandler (2002).

Tabela 25 - Organização da empresa (estrutura) x percentual das estratégias implementadas

\begin{tabular}{|c|c|c|c|c|}
\hline $\begin{array}{c}\text { 16. A forma pelo qual a empresa } \\
\text { está organizada facilita a } \\
\text { implementação da estratégia }\end{array}$ & Mais de $90 \%$ & Entre $60 \%$ e $90 \%$ & Entre 30\% e 60\% & Menos de $30 \%$ \\
\cline { 2 - 5 } & $43 \%$ & $57 \%$ & $0 \%$ & $0 \%$ \\
\hline Concordo Totalmente & $30 \%$ & $50 \%$ & $10 \%$ & $10 \%$ \\
\hline Concordo Parcialmente & $0 \%$ & $50 \%$ & $50 \%$ & $0 \%$ \\
\hline Discordo Parcialmente & $100 \%$ & $0 \%$ & $0 \%$ & $0 \%$ \\
\hline Discordo Totalmente & & & & \\
\hline
\end{tabular}

Se for invertida a análise, verificando as empresas que estão satisfeitas com a implementação e como elas avaliam a forma na qual estão organizadas, é possível identificar que:

- $50 \%$ das empresas que avaliaram o processo de implementação de estratégias com notas iguais ou acima a 8 estavam totalmente organizadas de maneira a facilitar o processo (tabela 26);

- $43 \%$ das empresas que conseguiram implementar mais de $90 \%$ das estratégias estavam igualmente organizadas (tabela 27).

Tabela 26 - Satisfação com a implementação x organização da empresa (estrutura)

\begin{tabular}{|c|c|c|c|c|}
\hline \multirow{2}{*}{$\begin{array}{c}\text { 21.Satisfação } \\
\text { com a } \\
\text { implementação }\end{array}$} & \multicolumn{4}{|c|}{\begin{tabular}{|c|}
$\mid 4$ \\
estratégia
\end{tabular}} \\
\cline { 2 - 5 } & $\begin{array}{c}\text { Concordo } \\
\text { Totalmente }\end{array}$ & $\begin{array}{c}\text { Concordo } \\
\text { Parcialmente }\end{array}$ & $\begin{array}{c}\text { Discordo } \\
\text { Parcialmente }\end{array}$ & $\begin{array}{c}\text { Discordo } \\
\text { Totalmente }\end{array}$ \\
\hline $1-5$ & $25 \%$ & $50 \%$ & $25 \%$ & $0 \%$ \\
\hline $6-7$ & $14 \%$ & $57 \%$ & $14 \%$ & $14 \%$ \\
\hline $8-10$ & $50 \%$ & $40 \%$ & $0 \%$ & $10 \%$ \\
\hline
\end{tabular}


Tabela 27 - Percentual das estratégias implementadas x Organização da empresa (estrutura)

\begin{tabular}{|c|c|c|c|c|}
\hline \multirow{2}{*}{$\begin{array}{c}\text { 10. Percentual } \\
\text { das estratégias } \\
\text { implementadas }\end{array}$} & \multicolumn{5}{|c|}{$\begin{array}{c}\text { 16. A forma pelo qual a empresa está organizada facilita a implementação da } \\
\text { estratégia }\end{array}$} \\
\cline { 2 - 5 } & $\begin{array}{c}\text { Concordo } \\
\text { Totalmente }\end{array}$ & $\begin{array}{c}\text { Concordo } \\
\text { Parcialmente }\end{array}$ & $\begin{array}{c}\text { Discordo } \\
\text { Parcialmente }\end{array}$ & $\begin{array}{c}\text { Discordo } \\
\text { Totalmente }\end{array}$ \\
\hline Mais de $90 \%$ & $43 \%$ & $43 \%$ & $0 \%$ & $14 \%$ \\
\hline Entre $60 \%$ e $90 \%$ & $40 \%$ & $50 \%$ & $10 \%$ & $0 \%$ \\
\hline Entre $30 \%$ e $60 \%$ & $0 \%$ & $50 \%$ & $50 \%$ & $0 \%$ \\
\hline Menos de $30 \%$ & $0 \%$ & $100 \%$ & $0 \%$ & $0 \%$ \\
\hline
\end{tabular}

A tabela 27 demonstra que ao organizar e estruturar a empresa para a implementação, as companhias tendem a terminar a implementação no prazo ou até adiantado. Das organizações que estão totalmente organizadas para facilitar a implementação das estratégias, 43\% terminaram a implementação no prazo ou adiantado. No outro extremo, as empresas que não estão organizadas, $50 \%$ delas implantam a estratégia num tempo muito maior do que o planejado.

Tabela 28 - Organização da empresa (estrutura) x Tempo de implementação

\begin{tabular}{|c|c|c|c|c|} 
16. A forma pelo qual a empresa & \multicolumn{5}{|l|}{$\begin{array}{l}\text { 18.Tempo de implementação } \\
\text { está organizada facilita a } \\
\text { implementaçäo da estratégia }\end{array}$} & $\begin{array}{c}\text { Muito maior do que } \\
\text { o planejado }\end{array}$ & $\begin{array}{c}\text { Um pouco maior } \\
\text { do que o planejado }\end{array}$ & Terminou no prazo & $\begin{array}{c}\text { Terminou } \\
\text { adiantado }\end{array}$ \\
\hline Concordo Totalmente & $0 \%$ & $57 \%$ & $14 \%$ & $29 \%$ \\
\hline Concordo Parcialmente & $40 \%$ & $30 \%$ & $30 \%$ & $0 \%$ \\
\hline $\begin{array}{c}\text { Discordo Parcialmente ou } \\
\text { Totalmente }\end{array}$ & $50 \%$ & $25 \%$ & $25 \%$ & $0 \%$ \\
\hline
\end{tabular}

Um dos pontos defendido por Bossidy e Charam (2002) de follow-up constante do andamento da execução e cobrança de responsabilidade não foi corroborado durante a análise descritiva conduzida por esta pesquisa. Cerca de dois terços das empresas que acompanham de uma a duas vezes ao ano o andamento da implementação, conseguem obter índices de implementação de estratégias acima de $90 \%$. 
Tabela 29 - Frequência de acompanhamento da implementação x percentual das estratégias implementadas

\begin{tabular}{|c|c|c|c|c|}
\hline $\begin{array}{c}\text { 20. Frequência de } \\
\text { acompanhamento da } \\
\text { implementação de } \\
\text { estratégias }\end{array}$ & \multicolumn{4}{|c|}{$\begin{array}{c}\text { 10. Percentual das estratégias } \\
\text { implementadas }\end{array}$} \\
\cline { 2 - 5 } & $\begin{array}{c}\text { Mais de } \\
90 \%\end{array}$ & $\begin{array}{c}\text { Entre } 60 \% \\
\text { e } 90 \%\end{array}$ & $\begin{array}{c}\text { Entre } 30 \% \\
\text { e } 60 \%\end{array}$ & $\begin{array}{c}\text { Menos de } \\
30 \%\end{array}$ \\
\hline Todo mês & $36 \%$ & $55 \%$ & $9 \%$ & $0 \%$ \\
\hline A cada 2 ou 3 meses & $25 \%$ & $50 \%$ & $25 \%$ & $0 \%$ \\
\hline Uma ou 2 vezes por ano & $67 \%$ & $17 \%$ & $0 \%$ & $17 \%$ \\
\hline Não acompanha & $0 \%$ & $100 \% *$ & $0 \%$ & $0 \%$ \\
\hline
\end{tabular}

* - não obteve número de respostas suficientes para se obter uma estatística confiável

Esses resultados ainda são mais acentuados quando analisada a satisfação com a implementação de estratégias, onde se verifica que quanto menos a empresa acompanha a implementação de estratégias mais satisfação ela tem com os resultados da estratégia.

Tabela 29 - Frequência de acompanhamento da implementação x satisfação com a implementação

\begin{tabular}{|c|c|c|c|}
\hline \multirow{2}{*}{$\begin{array}{c}\text { 20. Frequência de } \\
\text { acompanhamento da } \\
\text { implementação de estratégias }\end{array}$} & \multicolumn{3}{|c|}{$\begin{array}{c}\text { 21.Satisfação com a } \\
\text { implementação }\end{array}$} \\
\cline { 2 - 4 } & $1-5$ & $6-7$ & $8-10$ \\
\hline Todo mes & $18 \%$ & $36 \%$ & $46 \%$ \\
\hline A cada 2 ou 3 meses & $25 \%$ & $25 \%$ & $50 \%$ \\
\hline Uma ou duas vezes por ano & $17 \%$ & $17 \%$ & $67 \%$ \\
\hline Nao acompanha & $0 \%$ & $100 \%$ * & $0 \%$ \\
\hline
\end{tabular}

* - não obteve número de respostas suficientes para se obter uma estatística confiável

\subsubsection{Análise dos dados das entrevistas de gerenciamento de projetos}


As próximas tabulações e análises são referentes às entrevistas com os executivos da área de gerenciamento de projetos.

$\mathrm{Na}$ amostra pesquisada, três de cada quatro organizações possuem metodologia extremamente formal de gerenciamento de projetos. Esse número é superior ao $57 \%$ apresentado pelo estudo de benchmark em gerenciamento de projetos no Brasil (PMI Brasil, 2007). Possivelmente a razão para essa diferença é a amostragem, já que no estudo conduzido pelo PMI Brasil a amostra é formada por empresas de diferentes portes, sendo que nesta dissertação, o foco são as 1.000 maiores empresas.

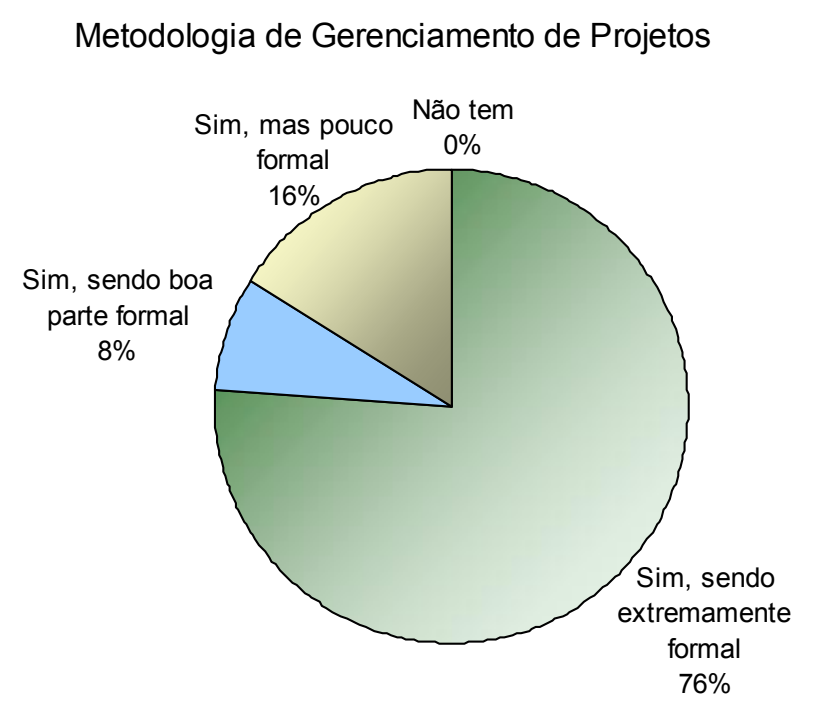

Figura 29 - Metodologia de Gerenciamento de Projetos

Como demonstrado na figura 29 , as empresa possuem metodologia de gerenciamento de projetos. Porém, quase metade das empresas não atrelam a sua metodologia com as estratégias genéricas (posicionamento estratégico) da organização, conceito defendido por Srivannaboon e Milosevic (2006). Durante as entrevistas, os executivos afirmaram que não é realizada esta ligação, tendo uma metodologia mais completa e abrangente, sem um foco específico dos pilares do gerenciamento de projetos (prazo, escopo, custo e qualidade). 
Gerenciamento de custo, qualidade, escopo e prazo estão atrelados as estratégias genéricas

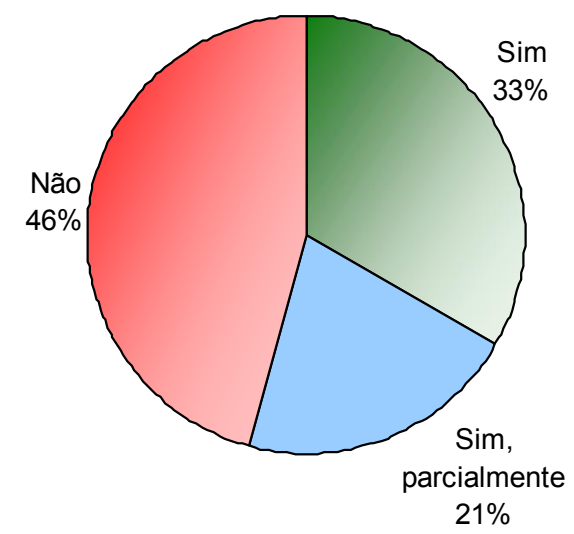

Figura 30 - Metodologia atrelada às estratégias genéricas da organização

A amostra das empresas pesquisadas é composta de organizações nas quais os projetos são parte complementar da rotina da empresa. Quase $90 \%$ dos entrevistados trabalham em empresas em que os projetos representam $25 \%$ dos trabalhos realizados pela empresa e $75 \%$ de rotina operacional.

Divisão entre projetos e processos rotineiros

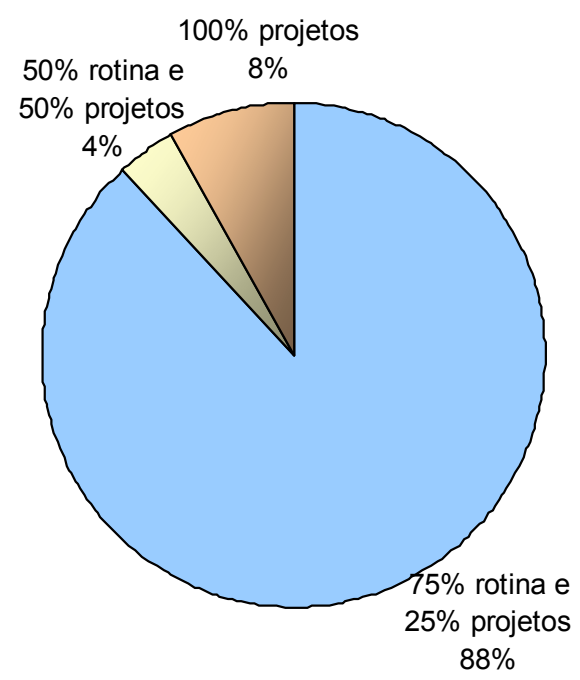

Figura 31 - Divisão entre projetos e processos rotineiros

Conforme apontado na figura 32, a interligação entre planejamento estratégico e gerenciamento de projetos, na visão dos executivos, é um processo bem integrado e flui dentro do esperado. 
Planejamento estratégico implementado através de um processo formal de definição de projetos e iniciativas

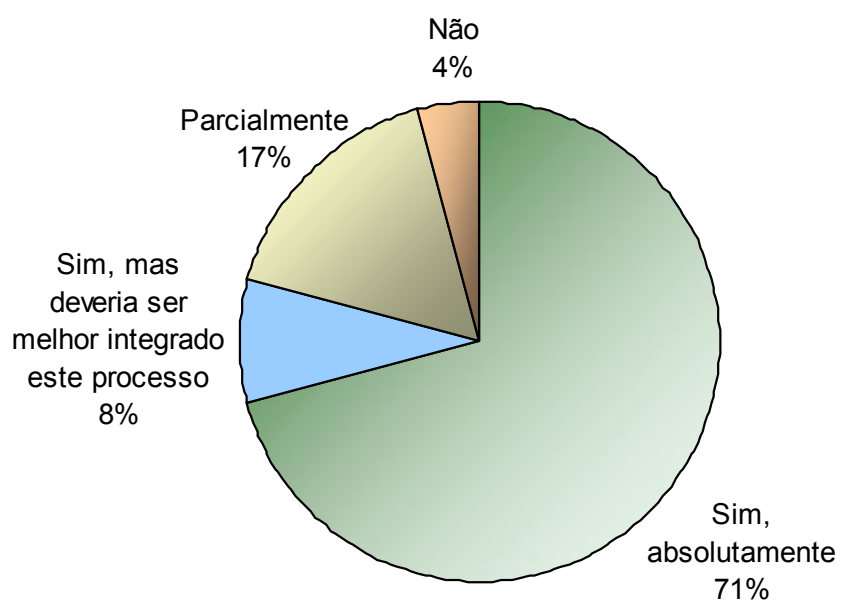

Figura 32 - Planejamento estratégico implementado através de projetos

Apesar desta boa integração entre planejamento estratégico e gerenciamento de projetos, procurou-se entender como ocorre esse processo. A maioria dos entrevistados afirmou que a área de gerenciamento de projetos não participa das reuniões de planejamento estratégico. No entanto, há reuniões específicas com a área de planejamento estratégico ou com a diretoria para realizar esse desdobramento. Outra forma de ocorrer essa interligação é o surgimento de projetos baseados nas necessidades das áreas e das idéias dos empregados. Assim como as estratégias emergentes, esses tipos de projetos são analisados para verificar seu grau de alinhamento com a estratégia, passando, inclusive, por processo de aprovação.

A diversidade de projetos inseridos no planejamento é grande, possibilitando a classificação destes em três grupos:

- Projetos de aprimoramento interno;

- Projetos de dispêndio de capital;

- Novos produtos para os clientes atuais. 
Esses três grupos de projetos estão muito presentes no planejamento estratégico. Segundo a presente pesquisa, $92 \%$ das empresas sempre possuiam projetos de aprimoramento interno, $88 \%$ de dispêndio de capital e $83 \%$ de novos produtos dentro do planejamento estratégico.

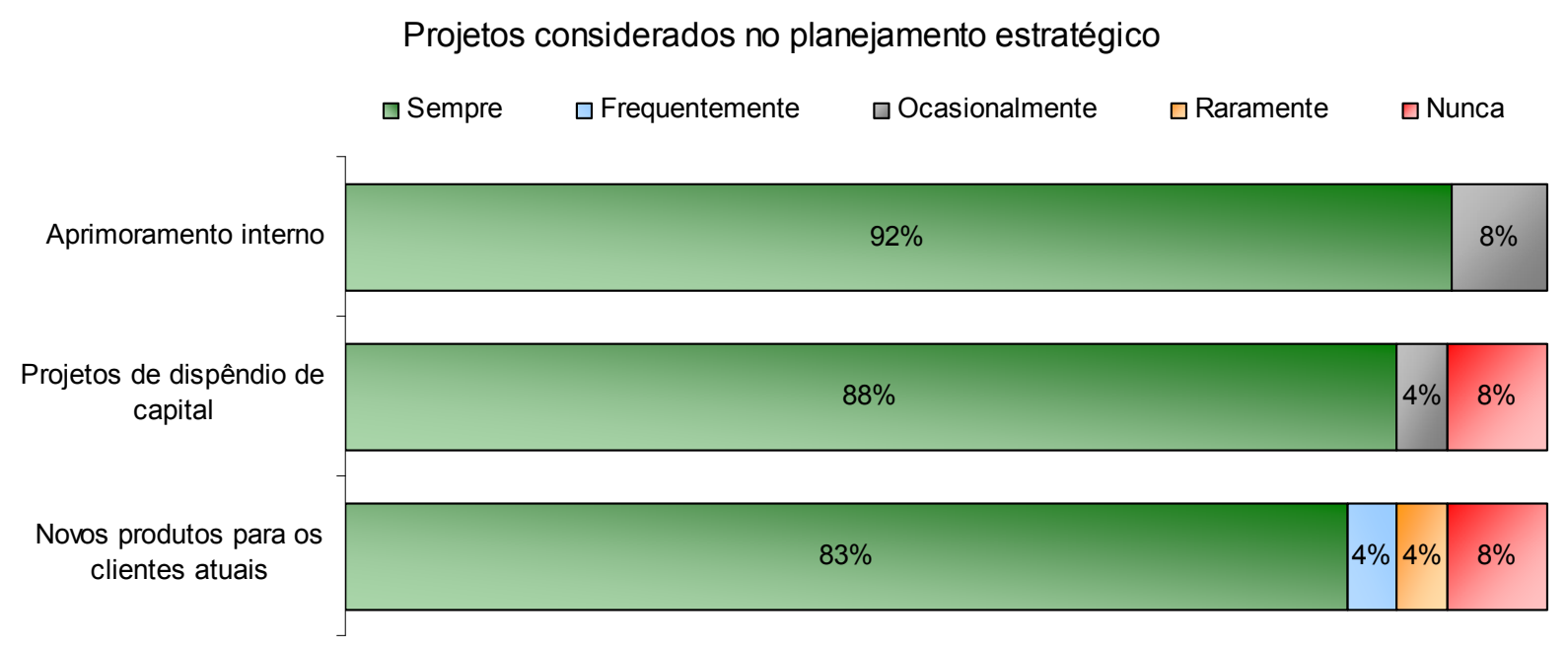

Figura 33 - Freqüência de projetos considerados no planejamento estratégico

Apesar da alta diversidade de projetos que estão presentes no planejamento estratégico, somente metade das empresas os organizam dentro de programas ou portifólios. Embora, para questões de priorização, $80 \%$ das empresas os têm classificado.

Nas entrevistas, os executivos afirmaram que os projetos eram classificados para que não houvesse conflitos de recursos e a redução de projetos que não agregassem tanto valor para a companhia, tendo como foco os principais. 
Organização dos projetos

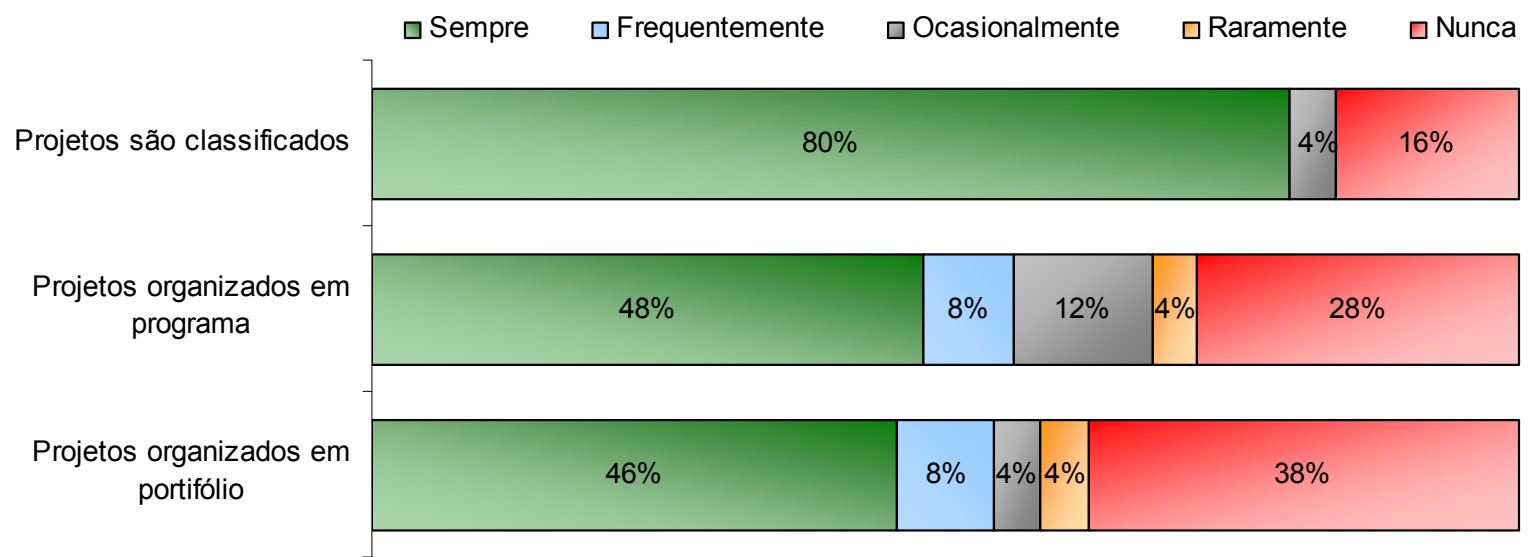

Figura 34 - Organização dos projetos

Para a criação de novos projetos, as empresas têm elaborado critérios de seleção. De acordo com a pesquisa, os critérios: financeiro, alinhamento com a estratégia e alinhamento com os produtos da empresa, são utilizados respectivamente em $96 \%, 91 \%$ e $52 \%$ das empresas.

Há outros critérios relatados pelos executivos durante as entrevistas, mas sem uma freqüência relevante, tais como: complexidade do projeto, impacto no meio ambiente, impacto político (empresas públicas), tecnologia e impacto nos processos da empresa.

Depois da escolha dos projetos, seguem-se as etapas de planejamento, execução e controle do projeto. Entre o planejamento e a execução existe uma lacuna. Na pesquisa identificou-se que $62 \%$ dos projetos eram entregues dentro do prazo, custo e qualidade. Segundo os executivos, o principal obstáculo dessa lacuna é o prazo, já que a precisão é menor. A qualidade não foi citada por nenhuma empresa como sendo um problema na entrega. 
Projetos entregues dentro do prazo, custo e qualidade

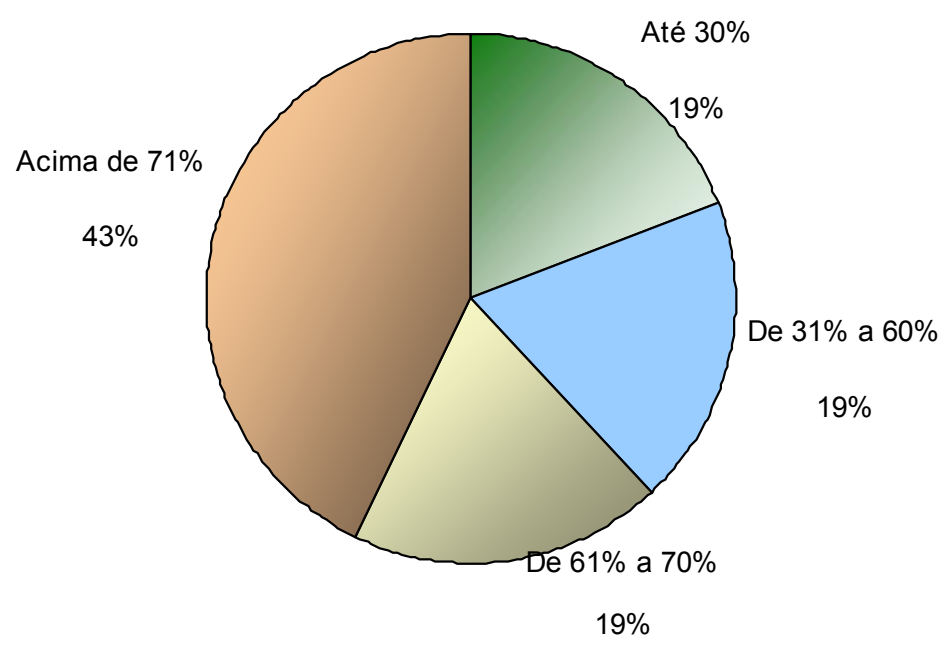

Figura 35 - Projetos entregues dentro do prazo, custo e qualidade

De acordo com a figura 35, quase metade dos respondentes consegue entregar projetos dentro do prazo, custo e qualidade em $71 \%$ dos projetos ou mais.

Para a execução dos projetos, as empresas vêm utilizando as técnicas de gerenciamento de projetos. As técnicas mais utilizadas são:

- Sequenciamento de atividades $(100 \%)$;

- Gráficos de Gantt (100\%);

- Project Charter (92\%);

- Fluxo de caixa de projetos (84\%). 


\begin{tabular}{|l|c|}
\hline Técnicas de Gerenciamento de Projetos utilizadas na empresd \\
\hline Técnica & $\begin{array}{l}\text { Percentual das empresas } \\
\text { que utilizam }\end{array}$ \\
\hline Sequenciamento de atividades & $100 \%$ \\
\hline Gráficos de Gantt & $100 \%$ \\
\hline Project charter & $92 \%$ \\
\hline Fluxo de caixa de projetos & $84 \%$ \\
\hline Fluxograma & $80 \%$ \\
\hline Matriz de responsabilidades & $76 \%$ \\
\hline WBS & $72 \%$ \\
\hline Matriz / análise de stakeholders & $68 \%$ \\
\hline Diagrama de causa-efeito & $60 \%$ \\
\hline Pontuaçẫo de projetos & $56 \%$ \\
\hline Gráfico de Pareto & $56 \%$ \\
\hline Inventário de habilidades & $44 \%$ \\
\hline EVA & $36 \%$ \\
\hline Análise de Monte Carlo & $24 \%$ \\
\hline Árore de decisẫo & $28 \%$ \\
\hline Mapa de melhoria da qualidade & $24 \%$ \\
\hline Gráfico de folgas & $16 \%$ \\
\hline Corrente crítica & $12 \%$ \\
\hline Abordagem de opçốes reais & $0 \%$ \\
\hline
\end{tabular}

Figura 36 - Técnicas utilizadas de gerenciamento de projetos

Por outro lado, verificou-se que existem algumas técnicas, conceitos e ferramentas de gerenciamento de projetos que não são muito utilizadas, sendo as principais:

- Gráfico de folgas;

- Corrente crítica (Goldratt);

- Abordagem de opções reais.

Além das técnicas de gerenciamento de projetos, as empresas têm procurado organizar suas práticas de gerenciamento em áreas específicas, como o PMO (Escritório de Gerenciamento de Projetos). Um pouco mais da metade das empresas $(56 \%)$ já possue esse tipo de organização. O número é muito próximo ao $52 \%$ obtido pelo PMI Brasil (2007). 


\section{A empresa tem PMO}

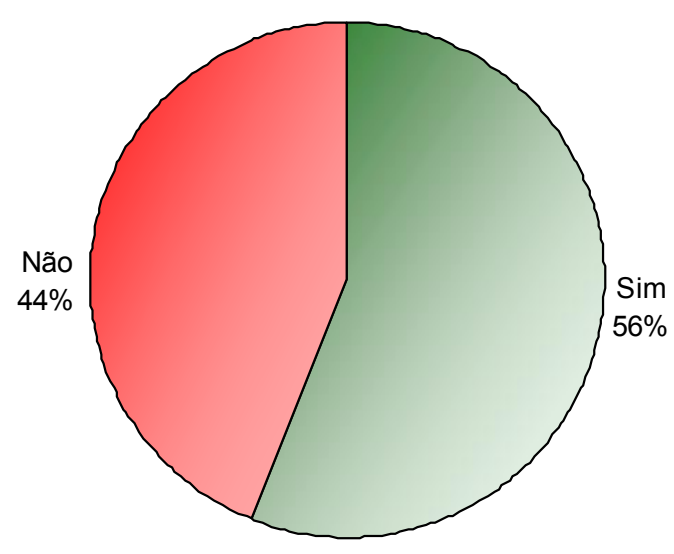

Figura 37 - Uso do PMO

Foram pesquisadas as atividades do Escritório de Gerenciamento de Projetos nas empresas segundo a definição e critérios de Lessa (2007), Kronmeyer Filho e Valandro (2004) e Crawford (2002). As atividades estão listadas na figura 38.

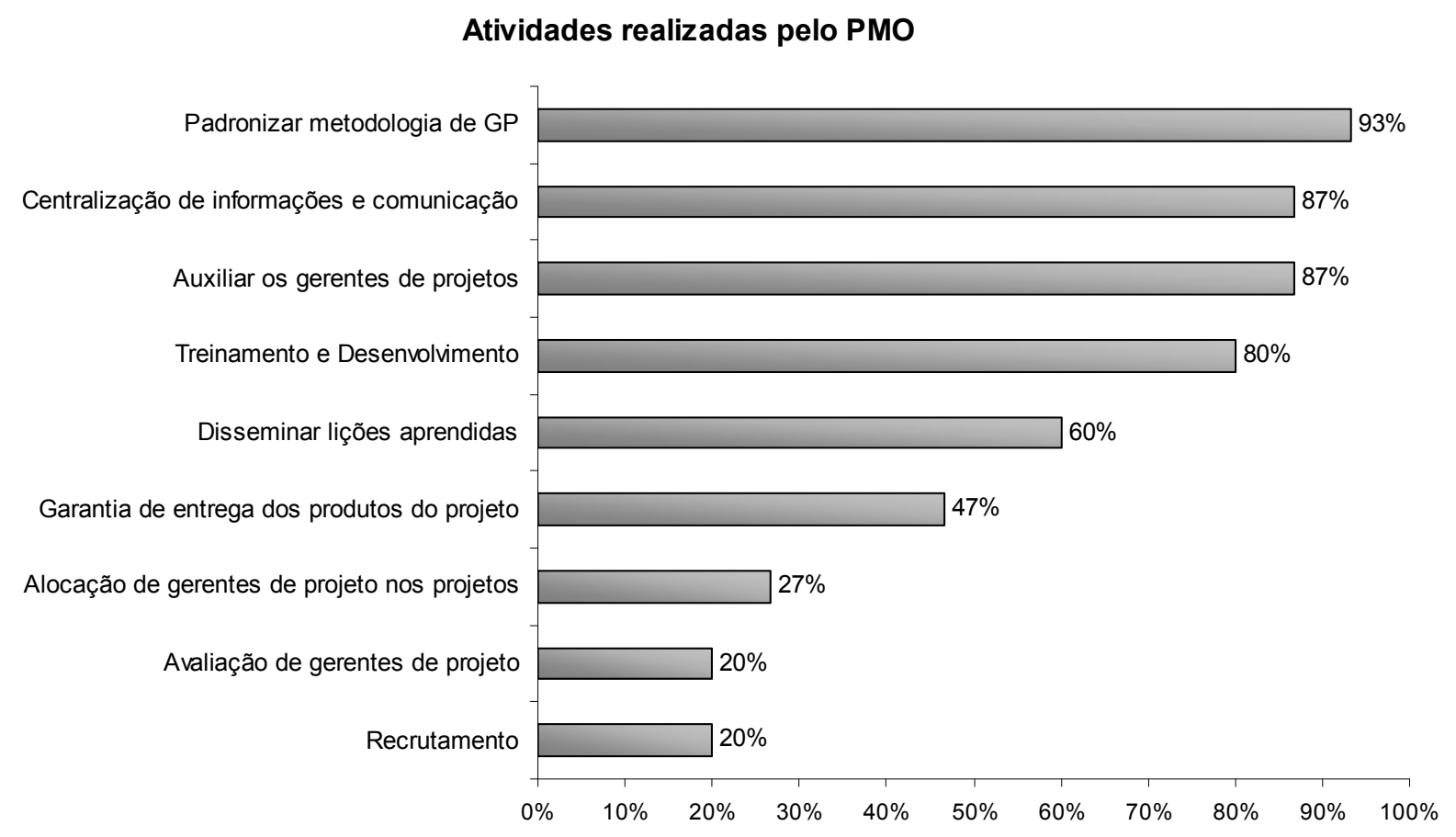

Figura 38 - Atividades do PMO

Quatro práticas dentre as atividades realizadas pelo PMO se destacaram como as mais presentes nas empresas, sendo elas: 
- Padronização da metodologia de Gerenciamento de Projetos (93\%);

- Centralização das informações e da comunicação dos projetos (87\%);

- Auxiliar os gerentes de projetos na condução de suas atividades (87\%);

- Treinamento e Desenvolvimento dos gestores de projetos (80\%).

Em contra partida, nas empresas pesquisadas, poucos PMOs têm realizado avaliações de desempenho dos gerentes de projetos e participado no recrutamento de novos gestores. Em ambos os casos, somente $20 \%$ das companhias realizavam esse tipo de atividade.

Outra etapa da entrevista com os gerentes de projetos procurou avaliar o atual estágio do conceito nas empresas. Assim, foram elaboradas 26 afirmativas nas quais os executivos podiam posicionar-se numa escala de concordância. Essa etapa é fundamental para verificar o impacto do gerenciamento de projetos na implementação de estratégias.

Dessa maneira, de acordo com a figura 39 , verifica-se que algumas práticas são mais utilizadas nas empresas do que outras. As cinco práticas, técnicas, instrumentos e conceitos mais utilizados são:

- Ferramentas e sistemas de informações para gerenciamento de projetos (83\% concordam totalmente e $9 \%$ parcialmente);

- Procedimentos para aprovação dos projetos (75\% concordam totalmente e $13 \%$ parcialmente);

- Modelo padronizado para elaborar um plano de projeto que todos conhecem (75\% concordam totalmente e $8 \%$ parcialmente);

- Patrocínio dos executivos durante o ciclo de vida do projeto (74\% concordam totalmente e $17 \%$ parcialmente);

- Envolvimento e comprometimento da equipe para o alcance dos resultados dos projetos ( $74 \%$ concordam totalmente e $17 \%$ parcialmente). 
Os resultados mostram que as empresas têm se preocupado com a instrumentalização dos seus gestores de projetos, oferecendo ferramentas e sistemas de informações para o planejamento e controle dos projetos.

Além disso, as empresas têm procurado padronizar e divulgar suas metodologias de gerenciamento de projetos aos colaboradores. Entretanto, essa divulgação não tem se transformado em aprendizado, já que $38 \%$ das empresas concordam totalmente e $25 \%$ parcialmente que seus colaboradores conseguem elaborar um plano de projeto.

Com o aumento da importância do gerenciamento de projetos nas empresas, a quantidade de projetos tem aumentado significativamente. Consequentemente, as organizações têm procurado filtrar quais são os projetos mais importantes, implementando procedimentos de aprovação de planos e propostas de projetos e oferecendo um patrocínio maior. Esse processo, conforme apresentado anteriormente, envolve critérios de seleção de projetos, tais como: financeiros, alinhamento com a estratégia e produtos.

Outro ponto importante é o comprometimento da equipe para a execução do projeto, pois sem isso as empresas não obteriam sucesso na implementação de projetos e estratégias. Nas conversas com os executivos, foi observado que os projetos têm sido utilizados como fonte de motivação para os indíviduos, uma vez que poderão trabalhar fora da rotina diária, trabalhando em atividades novas, podendo expor a sua capacidade de liderança e criação. 
Técnicas, instrumentos e conceitos de PE utilizados na implementação

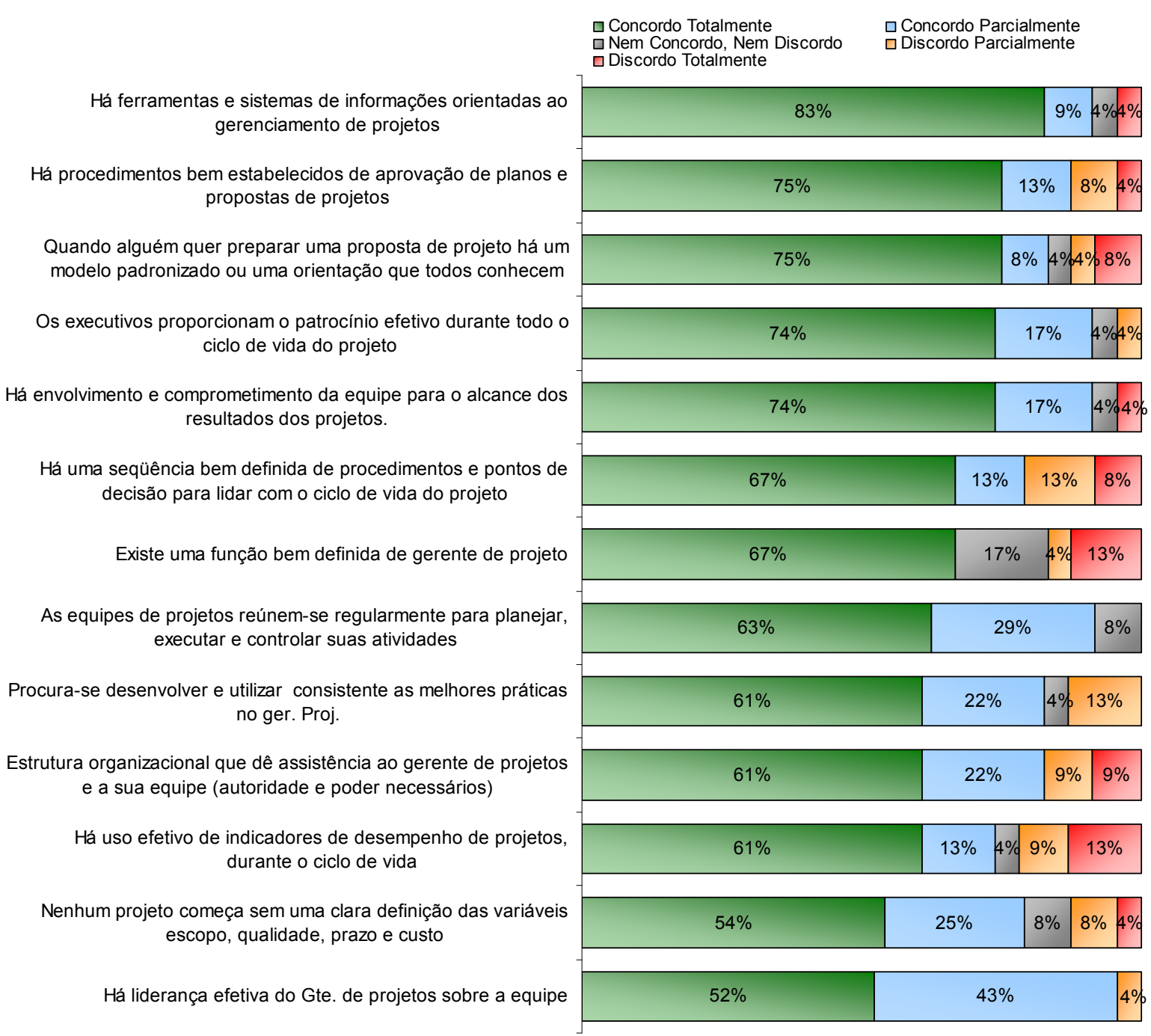

Figura 39 - Práticas, técnicas e conceitos utilizados de gerenciamento de projetos

Por mais valorizado que seja o gerenciamento de projetos nas empresas, percebeu-se que há poucas pessoas preparadas para exercer essa função, pois apenas $30 \%$ das empresas afirmaram que têm número de certificações em gerenciamento de projetos suficientes para a demanda da companhia e $38 \%$ visualizam que há um bom número de pessoas preparadas para desempenhar a função.

É possível constatar ainda que o crescimento da demanda de projetos tem afetado dois pontos: 
- as pessoas têm tido dificuldades de distinguir entre projetos e atividades que não são projetos;

- os executivos não sabem informar o status dos projetos em andamento. Isso reflete a mesma falha apresentada anteriormente sobre a comunicação da estratégia.

Técnicas, instrumentos e conceitos de PE utilizados na implementação

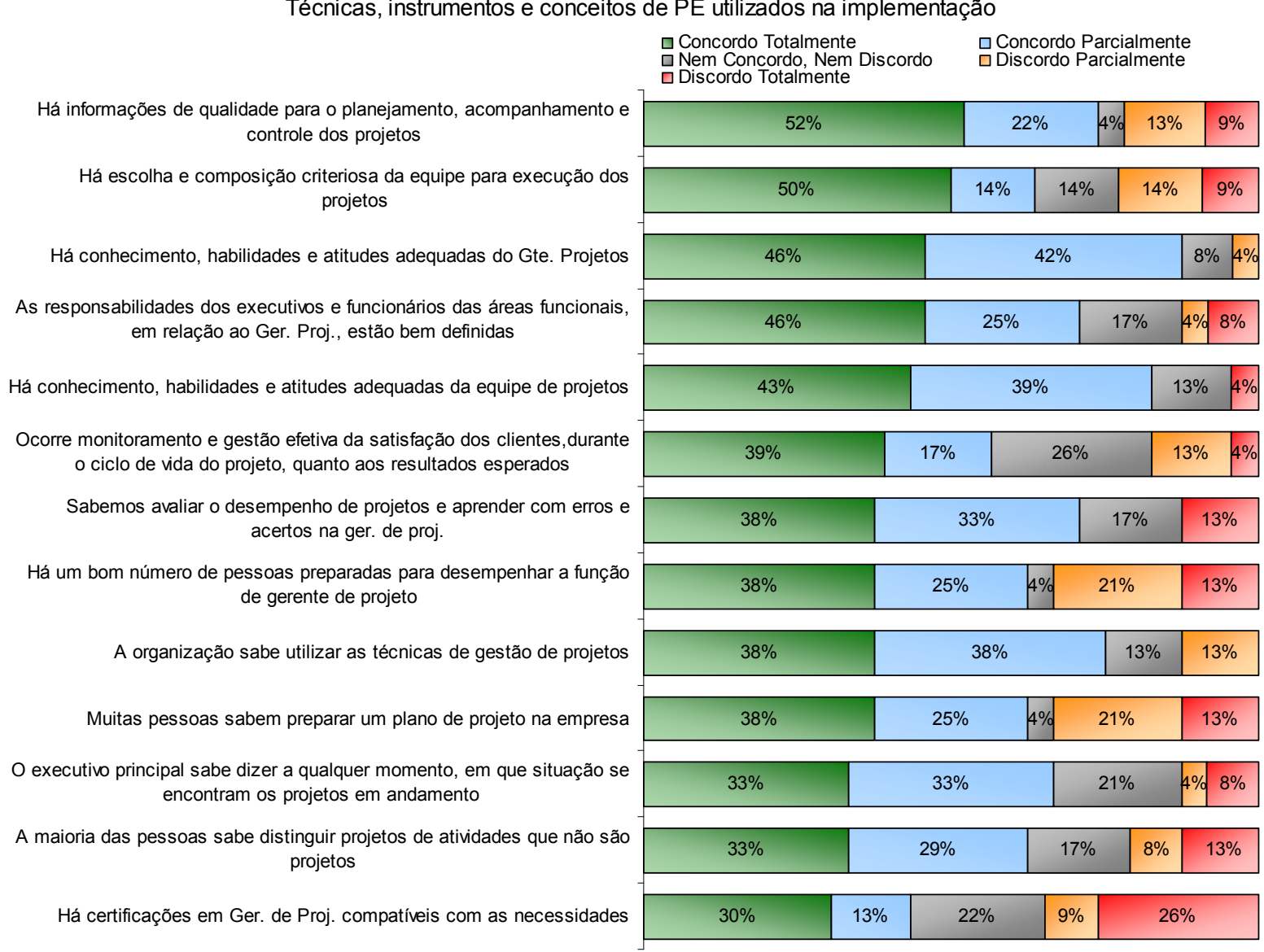

Figura 40 - Práticas, técnicas e conceitos utilizados de gerenciamento de projetos (continuação)

\subsubsection{Análise descritiva dos dados: cruzamento das entrevistas de gerenciamento de projetos e planejamento estratégico}

Nesta seção é realizada a análise bi-variada, cruzando as informações das entrevistas de gerenciamento de projetos e planejamento estratégico. 
A primeira análise visa entender a relação entre sucesso na implementação e a integração entre estratégia e projetos. Nota-se que todas as empresas pesquisadas que conseguiram implementar mais de $90 \%$ de suas estratégias têm o processo de planejamento estratégico implementado por meio de projetos e iniciativas estratégicas. Já as empresas que não atingiram nem $60 \%$ das estratégias, o processo não estava totalmente integrado. Assim, por mais que possa ter a separação apresentada anteriormente entre o gerenciamento de projetos e a condução do processo de planejamento estratégico, os executivos enxergam que é através de projetos que as estratégias são implementadas.

Tabela 30 - Percentual das estratégias implementadas $\mathrm{x}$ planejamento estratégico implementado através de projetos

\begin{tabular}{|c|c|c|c|c|}
\hline \multirow{2}{*}{$\begin{array}{l}\text { 10. Percentual das estratégias } \\
\text { implementadas }\end{array}$} & \multicolumn{4}{|c|}{$\begin{array}{l}\text { 03. Planejamento estratégico implementado através da definição de projetos e } \\
\text { iniciativas estratégicas }\end{array}$} \\
\hline & $\begin{array}{l}\text { Sim, } \\
\text { absolutamente }\end{array}$ & $\begin{array}{l}\text { Sim, mas deveria ser melhor } \\
\text { integrado este processo }\end{array}$ & Parcialmente & Não \\
\hline Mais de $90 \%$ & $100 \%$ & $0 \%$ & $0 \%$ & $0 \%$ \\
\hline Entre $60 \%$ e $90 \%$ & $75 \%$ & $25 \%$ & $0 \%$ & $0 \%$ \\
\hline Entre $30 \%$ e $60 \%$ & $0 \%$ & $0 \%$ & $100 \%$ & $0 \%$ \\
\hline Menos de $30 \%$ & $0 \%$ & $0 \%$ & $0 \%$ & $100 \%$ \\
\hline
\end{tabular}

Mas, quando trocadas as variáveis, colocando a variável de 'integração do planejamento estratégico com projetos' como predição do sucesso na implementação, verificou-se que $29 \%$ das empresas que implementaram o planejamento estratégico por meio de projetos, de forma bem integrada, conseguiram atingir sucesso em mais de $90 \%$ de sua implementação. Se for considerado o alcance de mais de $60 \%$ das estratégias, todas as empresas apresentaram a integração positiva entre o planejamento estratégico e projetos. 
Tabela 31 - Planejamento estratégico implementado através de projetos x percentual das estratégias implementadas

\begin{tabular}{|c|c|c|c|c|}
\hline 03. Planejamento estratégico & \multicolumn{4}{|l|}{ 10. Percentual das estratégias implementadas } \\
\cline { 2 - 5 } $\begin{array}{c}\text { implementado através da } \\
\text { definição de projetos e } \\
\text { iniciativas estratégicas }\end{array}$ & Mais de $90 \%$ & Entre $60 \%$ e $90 \%$ & Entre $30 \%$ e $60 \%$ & Menos de $30 \%$ \\
\hline Sim, absolutamente & $29 \%$ & $71 \%$ & $0 \%$ & $0 \%$ \\
\hline $\begin{array}{c}\text { Sim, mas deveria ser melhor } \\
\text { integrado este processo }\end{array}$ & $0 \%$ & $100 \%$ & $0 \%$ & $0 \%$ \\
\hline Parcialmente & $0 \%$ & $0 \%$ & $100 \%$ & $0 \%$ \\
\hline Não & $0 \%$ & $0 \%$ & $0 \%$ & $100 \%$ \\
\hline
\end{tabular}

Ao analisar os dados da tabela 32, não foram identificadas diferenças significativas de sucesso na implementação de estratégias entre as empresas que organizavam seus projetos em portifólio e programas e aquelas que não organizavam dessa forma.

Das três perguntas listadas na tabela 32, somente a classificação dos projetos pelas empresas têm impacto importante no sucesso da implementação de estratégias. Averiguou-se que quase a totalidade das empresas que classificavam seus projetos conseguiam implementar mais de $60 \%$ das estratégias.

Tabela 32 - Organização e administração de portifólios, programas e projetos

\begin{tabular}{|c|c|c|c|c|c|}
\hline \multirow[b]{2}{*}{ Pergunta } & \multirow[b]{2}{*}{ Resposta } & \multicolumn{4}{|c|}{ 10. Percentual das estratégias implementadas } \\
\hline & & Mais de $90 \%$ & Entre $60 \%$ e $90 \%$ & Entre $30 \%$ e $60 \%$ & Menos de $30 \%$ \\
\hline \multirow{2}{*}{$\begin{array}{l}\text { Projetos são } \\
\text { classificados }\end{array}$} & Nunca & $33 \%$ & $0 \%$ & $33 \%$ & $33 \%$ \\
\hline & Sempre & $33 \%$ & $58 \%$ & $8 \%$ & $0 \%$ \\
\hline \multirow{2}{*}{$\begin{array}{c}\text { Projetos } \\
\text { organizados } \\
\text { em portifólio }\end{array}$} & Nunca / raramente & $22 \%$ & $56 \%$ & $22 \%$ & $0 \%$ \\
\hline & sempre & $33 \%$ & $50 \%$ & $0 \%$ & $17 \%$ \\
\hline \multirow{2}{*}{$\begin{array}{c}\text { Projetos } \\
\text { organizados } \\
\text { em programa }\end{array}$} & nunca / raramente & $33 \%$ & $50 \%$ & $17 \%$ & $0 \%$ \\
\hline & $\begin{array}{c}\text { sempre / } \\
\text { frequentemente }\end{array}$ & $25 \%$ & $63 \%$ & $0 \%$ & $13 \%$ \\
\hline
\end{tabular}


Pode-se perceber na tabela 33 que a capacidade de execução de projetos tem impacto na execução das estratégias. Cerca de $40 \%$ das empresas que conseguiram implementar mais de $71 \%$ dos projetos atingiram mais de $90 \%$ de suas estratégias.

Tabela 33 -Projetos entregues dentro do prazo, custo e qualidade $x$ percentual das estratégias implementadas

\begin{tabular}{|c|c|c|c|c|}
\hline \multirow{2}{*}{$\begin{array}{c}\text { 11. Projetos entregues dentro } \\
\text { do prazo, custo e qualidade }\end{array}$} & 10. Percentual das estratégias implementadas \\
\cline { 2 - 5 } & Mais de $90 \%$ & Entre $60 \%$ e $90 \%$ & Entre $30 \%$ e $60 \%$ & Menos de $30 \%$ \\
\hline Até $50 \%$ & $0 \%$ & $33 \%$ & $67 \%$ & $0 \%$ \\
\hline Entre $51 \%$ e $70 \%$ & $33 \%$ & $67 \%$ & $0 \%$ & $0 \%$ \\
\hline Acima $71 \%$ & $40 \%$ & $60 \%$ & $0 \%$ & $0 \%$ \\
\hline
\end{tabular}

Não só a execução dos projetos tem impacto, mas também a coordenação das atividades de implementação, que nada mais é do que a gestão de projetos listados nas estratégias. Verifica-se que $63 \%$ das empresas que classificaram a coordenação da implementação como eficaz (notas 4 e 5) avaliaram com notas de 8 a 10 o item sucesso do processo de implementação.

Tabela 34 -Coordenação das atividades de implementação $x$ satisfação com a implementação

\begin{tabular}{|c|c|c|c|}
\hline $\begin{array}{c}\text { 19. Coordenação das atividades } \\
\text { de implementação } \\
\text { Nota 1 (ineficaz) e 5 eficaz }\end{array}$ & $1-5$ & $6-7$ & $8-10$ \\
\cline { 2 - 4 } & $33 \%$ & $44 \%$ & $22 \%$ \\
\hline $1-3$ & $9 \%$ & $27 \%$ & $63 \%$ \\
\hline $4-5$ & \multicolumn{3}{|c|}{ 21.Satisfac̃a com a implementação } \\
\hline
\end{tabular}

Esse número diminui quando considerado o percentual das estratégias implementadas (tabela 35). Cerca de $46 \%$ das empresas com coordenação eficaz conseguiram implementar mais de $90 \%$ das estratégias planejadas. 
Tabela 35 - Coordenação das atividades de implementação $x$ percentual das estratégias implementadas

\begin{tabular}{|c|c|c|c|c|}
\hline $\begin{array}{c}\text { 19. Coordenação das atividades } \\
\text { de implementação } \\
\text { Nota 1 (ineficaz) e 5 eficaz }\end{array}$ & Mais de $90 \%$ & Entre $60 \%$ e $90 \%$ & Entre $30 \%$ e $60 \%$ & Menos de $30 \%$ \\
\cline { 2 - 5 } & $22 \%$ & $56 \%$ & $11 \%$ & $11 \%$ \\
\hline $1-3$ & $46 \%$ & $46 \%$ & $8 \%$ & $0 \%$ \\
\hline $4-5$ &
\end{tabular}

$\mathrm{Na}$ tabela 36 são analisadas as técnicas e conceitos de gerenciamento de projetos, realizando uma comparação desta com o sucesso na implementação de estratégias. As empresas que não utilizam tais técnicas e conceitos obtiveram mais sucesso na implementação, isso se o foco recair sobre as empresas que atingiram mais de $90 \%$ de suas estratégias, com exceção do inventário de habilidades. Se o foco for nas empresas que atingiram mais de $60 \%$ das estratégias, o contexto é diferente, já que todas as técnicas, com exceção do inventário de habilidade, influienciaram positivamente na implementação das estratégias.

Tabela 36 - Conceitos e técnicas de projetos x percentual das estratégias implementadas

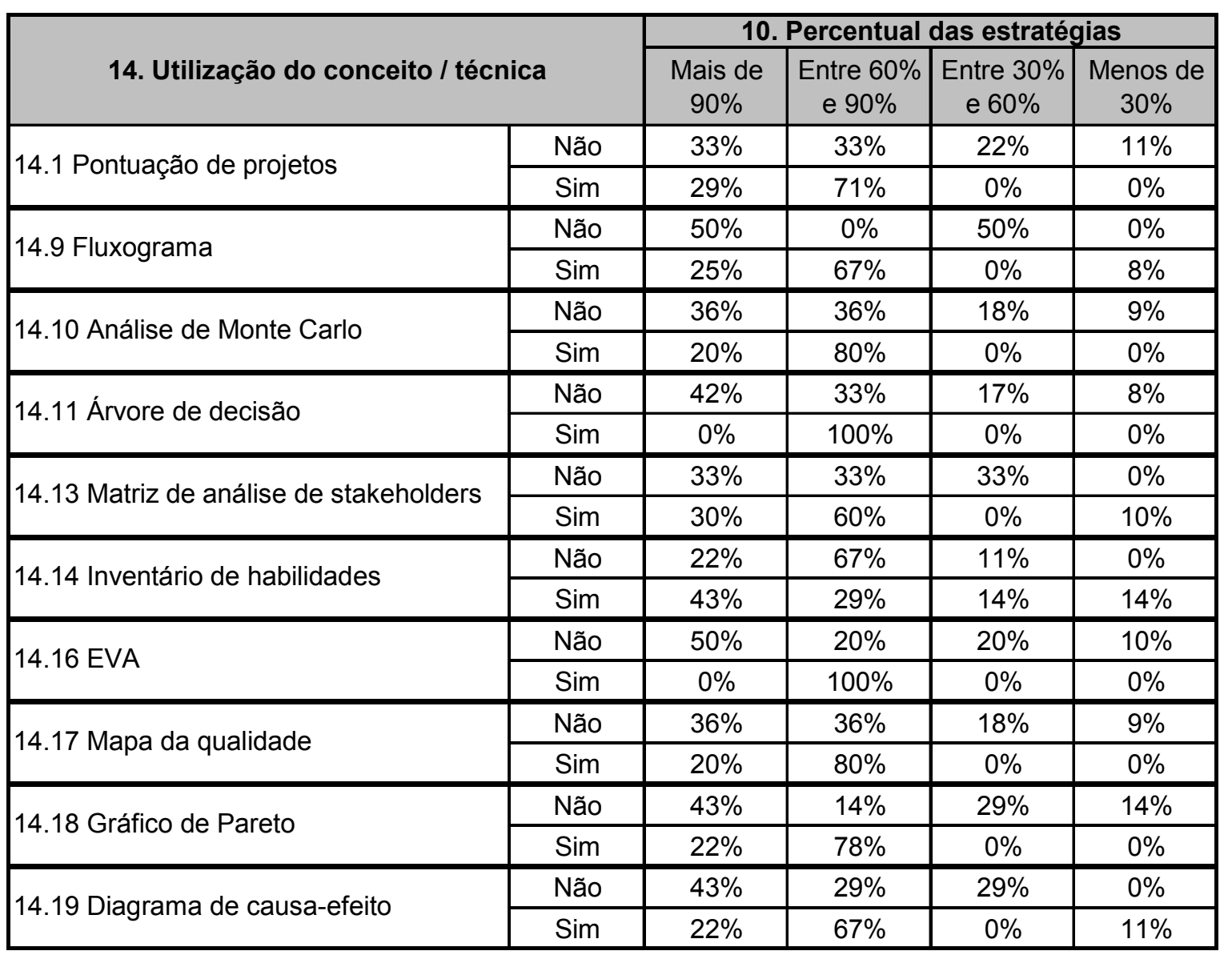


Outra variável de sucesso na implementação de estratégias é a satisfação com o projeto de implementação. Ao realizar uma análise dessa variável verifica-se que:

- as análises de Monte Carlo, Análise de Stakeholders, árvore de decisão e EVA têm baixo impacto ou impacto negativo na implementação de estratégias, quando analisado o sucesso com notas acima ou igual a 6;

- as técnicas e conceitos de pontuação de projetos, fluxograma, mapa da qualidade e gráfico de Pareto têm impacto positivo na satisfação com o processo de implementação de estratégias, quando analisadas as empresas com satisfação maior ou igual a 6;

- o inventário de habilidades e o diagrama de causa-efeito têm impacto somente nas empresas que atingiram notas igual ou acima de 8 na implementação.

Tabela 37 - Conceitos e técnicas de projetos x satisfação com a implementação

\begin{tabular}{|c|c|c|c|c|}
\hline \multirow{2}{*}{\multicolumn{2}{|c|}{ 14. Utilização do conceito / técnica }} & \multicolumn{3}{|c|}{ 21.Satisfação com a implementação } \\
\hline & & $1-5$ & 6-7 & $8-10$ \\
\hline \multirow{2}{*}{ 14.1 Pontuação de projetos } & Não & $22 \%$ & $33 \%$ & $44 \%$ \\
\hline & $\operatorname{Sim}$ & $14 \%$ & $29 \%$ & $57 \%$ \\
\hline \multirow{2}{*}{ 14.9 Fluxograma } & Não & $25 \%$ & $50 \%$ & $25 \%$ \\
\hline & $\operatorname{Sim}$ & $17 \%$ & $25 \%$ & $58 \%$ \\
\hline \multirow{2}{*}{ 14.10 Análise de Monte Carlo } & Não & $18 \%$ & $27 \%$ & $55 \%$ \\
\hline & $\operatorname{Sim}$ & $20 \%$ & $40 \%$ & $40 \%$ \\
\hline \multirow{2}{*}{ 14.11 Árvore de decisão } & Não & $17 \%$ & $33 \%$ & $50 \%$ \\
\hline & Sim & $25 \%$ & $25 \%$ & $50 \%$ \\
\hline \multirow{2}{*}{ 14.13 Matriz de análise de stakeholders } & Não & $17 \%$ & $17 \%$ & $67 \%$ \\
\hline & $\operatorname{Sim}$ & $20 \%$ & $40 \%$ & $40 \%$ \\
\hline \multirow{2}{*}{ 14.14 Inventário de habilidades } & Não & $11 \%$ & $44 \%$ & $44 \%$ \\
\hline & Sim & $29 \%$ & $14 \%$ & $57 \%$ \\
\hline \multirow{2}{*}{ 14.16 EVA } & Não & $20 \%$ & $30 \%$ & $50 \%$ \\
\hline & Sim & $17 \%$ & $33 \%$ & $50 \%$ \\
\hline \multirow{2}{*}{ 14.17 Mapa da qualidade } & Não & $27 \%$ & $27 \%$ & $45 \%$ \\
\hline & Sim & $0 \%$ & $40 \%$ & $60 \%$ \\
\hline \multirow{2}{*}{ 14.18 Gráfico de Pareto } & Não & $29 \%$ & $29 \%$ & $43 \%$ \\
\hline & Sim & $11 \%$ & $33 \%$ & $56 \%$ \\
\hline \multirow{2}{*}{ 14.19 Diagrama de causa-efeito } & Não & $14 \%$ & $43 \%$ & $43 \%$ \\
\hline & $\operatorname{Sim}$ & $22 \%$ & $22 \%$ & $56 \%$ \\
\hline
\end{tabular}


Nesta pesquisa, constatou-se que as empresas que buscam alinhar a sua metodologia de gerenciamento de projetos às estratégias genéricas se beneficiam dessa integração. Verifica-se que $60 \%$ das empresas que atrelam a gestão de custo, qualidade, escopo e prazo às estratégias da organização, conseguem implementar mais de $90 \%$ das estratégias. Se forem considerados os índices de implementação acima de $60 \%$ das estratégias, chega-se a totalidade das empresas.

Tabela 38 - Gerenciamento de projetos atrelados às estratégias genéricas x percentual das estratégias implementadas

\begin{tabular}{|c|c|c|c|c|}
\hline 15. Gerenciamento de custo, & \multicolumn{4}{|l|}{ 10. Percentual das estratégias implementadas } \\
\cline { 2 - 5 } $\begin{array}{c}\text { qualidade, escopo e prazo } \\
\text { atrelados as estratégias } \\
\text { genéricas }\end{array}$ & Mais de $90 \%$ & Entre $60 \%$ e $90 \%$ & Entre $30 \%$ e $60 \%$ & Menos de $30 \%$ \\
\hline Sim & $60 \%$ & $40 \%$ & $0 \%$ & $0 \%$ \\
\hline Sim, parcialmente & $0 \%$ & $100 \%$ & $0 \%$ & $0 \%$ \\
\hline Não & $14 \%$ & $43 \%$ & $29 \%$ & $14 \%$ \\
\hline
\end{tabular}

Todavia, quando se faz o cruzamento da satisfação com os resultados da implementação, não se verifica diferença nos resultados obtidos pelas empresas que têm ou não a metodologia de gerenciamento de projetos atrelada às estratégias genéricas.

Tabela 39 - Gerenciamento de projetos atrelados às estratégias genéricas x satisfação com a implementação

\begin{tabular}{|c|c|c|c|}
\hline \multirow{2}{*}{$\begin{array}{c}\text { 15. Gerenciamento de custo, } \\
\text { qualidade, escopo e prazo } \\
\text { atrelados as estratégias } \\
\text { genéricas }\end{array}$} & \multicolumn{3}{|c|}{ 21.Satisfação com a implementação } \\
\hline & $1-5$ & $6-7$ & $8-10$ \\
\hline Sim & $20 \%$ & $40 \%$ & $40 \%$ \\
\hline Sim, parcialmente & $0 \%$ & $33 \%$ * & $67 \%$ * \\
\hline Não & $29 \%$ & $29 \%$ & $42 \%$ \\
\hline
\end{tabular}

Segundo a tabela 40, as empresas que têm PMO possuem maior probabilidade de sucesso na implementação de estratégias. Das empresas que têm $\mathrm{PMO}, 46 \%$ conseguiram implementar mais de $90 \%$ das estratégias e esse número 
aumenta para cerca de $90 \%$ quando é analisado o sucesso de mais de $60 \%$ das implementações de estratégias.

Tabela 40 - PMO x percentual das estratégias implementadas

\begin{tabular}{|c|c|c|c|c|}
\hline \multirow{2}{*}{ 16. A empresa tem PMO } & \multicolumn{5}{|c|}{ 10. Percentual das estratégias implementadas } \\
\cline { 2 - 5 } & Mais de $90 \%$ & Entre $60 \%$ e $90 \%$ & Entre $30 \%$ e $60 \%$ & Menos de $30 \%$ \\
\hline Não & $25 \%$ & $50 \%$ & $12,5 \%$ & $12,5 \%$ \\
\hline Sim & $46 \%$ & $45 \%$ & $9 \%$ & $0 \%$ \\
\hline
\end{tabular}

Números parecidos são apresentados na tabela 41 quando é trocada a variável dependente para 'a satisfação com a implementação de estratégias'. Averigua-se que $55 \%$ das empresas que possuem PMO avaliaram o sucesso da implementação das estratégias com notas iguais ou superiores a 8.

Tabela 41 - PMO x satisfação com a implementação

\begin{tabular}{|c|c|c|c|}
\hline \multirow{2}{*}{ 16. A empresa tem PMO } & \multicolumn{3}{|c|}{ 21.Satisfação com a implementação } \\
\cline { 2 - 4 } & $1-5$ & $6-7$ & $8-10$ \\
\hline Não & $25 \%$ & $37 \%$ & $37 \%$ \\
\hline $\operatorname{Sim}$ & $9 \%$ & $36 \%$ & $55 \%$ \\
\hline
\end{tabular}

Ao cruzar a avaliação da empresa em termos de gerenciamento de projetos e o sucesso na implementação de estratégias, percebeu-se que há uma série de práticas que impactam positivamente a implementação. A análise foi feita com base na diferença entre as notas 'concordo totalmente' e 'parcialmente' contra as opiniões discordantes ou neutras, quando focado nas empresas que conseguiram implementar mais de $60 \%$ das estratégias. Os principais tópicos nos quais essas diferenças apresentam-se como mais relevantes são:

- $100 \%$ - Há conhecimentos, habilidades e atitudes adequadas dos gerentes de projetos (nesse caso há exceção no cálculo: comparação entre 'concordo totalmente' e a 'discordância' ou 'neutralidade' da avaliação'); 
- $75 \%$ - Procura desenvolver e utilizar consistentemente as melhores práticas no gerenciamento de projetos;

- $60 \%$ - Há uma seqüência bem definida de procedimentos e pontos de decisão para lidar com o ciclo de vida do projeto;

- $60 \%$ - Muitas pessoas sabem preparar um plano de projeto na empresa;

- $50 \%$ - Existe uma função bem definida de gerente de projeto.

Só foi possível realizar essa comparação quando havia grupos com número significativo de empresas para formar uma estatística mais realista. Com isso, alguns tópicos avaliados não tiveram essa comparação devido à quantidade baixa de casos (assinalados com asterisco nas tabelas).

Uma inferência possível acerca desse tipo de resultado é a de que provavelmente o tópico não seja algo que impacte positivamente no sucesso da implementação de estratégias, uma vez que quase todas as empresas enquadraram o tópico avaliado da mesma forma, não havendo diferença significativa. Para confirmar todos esses resultados é importante realizar a análise de correlação estatística. 
Tabela 42 - Avaliação gerenciamento de projetos $x$ estratégias implementadas

\begin{tabular}{|c|c|c|c|c|c|c|}
\hline \multirow{2}{*}{\multicolumn{2}{|c|}{ Itens de avaliação de Gerenciamento de Projetos }} & \multicolumn{4}{|c|}{$\begin{array}{l}\text { 10. Percentual das estratégias } \\
\text { implementadas }\end{array}$} & \multirow{2}{*}{$\begin{array}{c}\text { Dif Concordo } \\
\text { x Discordo } \\
\text { (mínimo de } \\
60 \% \\
\text { Implement.) }\end{array}$} \\
\hline & & $\begin{array}{l}\text { Mais de } \\
90 \%\end{array}$ & \begin{tabular}{|c|} 
Entre $60 \%$ \\
e $90 \%$
\end{tabular} & $\begin{array}{c}\text { Entre } 30 \% \\
\text { e } 60 \%\end{array}$ & $\begin{array}{c}\text { Menos de } \\
30 \%\end{array}$ & \\
\hline \multirow{2}{*}{$\begin{array}{l}\text { A maioria das pessoas sabe distinguir projetos de } \\
\text { atividades que não são projetos }\end{array}$} & DT, DP, NCND & $25 \%$ & $50 \%$ & $25 \%$ & $0 \%$ & \multirow{2}{*}{$7 \%$} \\
\hline & CT e CP & $27 \%$ & $55 \%$ & $9 \%$ & $9 \%$ & \\
\hline \multirow{2}{*}{$\begin{array}{c}\begin{array}{c}\text { A organização sabe utilizar as técnicas de gestão } \\
\text { de projetos }\end{array} \\
\text { ( }\end{array}$} & DT, DP, NCND & $25 \%$ & $25 \%$ & $25 \%$ & $25 \%$ & \multirow{2}{*}{$41 \%$} \\
\hline & CT e CP & $27 \%$ & $64 \%$ & $9 \%$ & $0 \%$ & \\
\hline \multirow{2}{*}{$\begin{array}{c}\text { Quando alguem quer preparar uma proposta de } \\
\text { projeto há um modelo padronizado ou uma } \\
\text { orientação que todos conhecem }\end{array}$} & DT, DP, NCND & $0 \%$ & $33 \%$ * & $33 \%$ * & $33 \%$ * & \multirow{2}{*}{ N/A } \\
\hline & CT e CP & $33 \%$ & $58 \%$ & $8 \%$ & $0 \%$ & \\
\hline \multirow{2}{*}{$\begin{array}{l}\text { Muitas pessoas sabem preparar um plano de } \\
\text { projeto na empresa }\end{array}$} & DT, DP, NCND & $20 \%$ & $20 \%$ & $40 \%$ & $20 \%$ & \multirow{2}{*}{$60 \%$} \\
\hline & CT e CP & $30 \%$ & $70 \%$ & $0 \%$ & $0 \%$ & \\
\hline \multirow{2}{*}{$\begin{array}{l}\text { Há procedimentos bem estabelecidos de } \\
\text { aprovação de planos e propostas de projetos }\end{array}$} & DT, DP, NCND & $0 \%$ & $33 \%$ * & $33 \%$ * & $33 \%$ * & \multirow{2}{*}{$\mathrm{N} / \mathrm{A}$} \\
\hline & CT e CP & $33 \%$ & $58 \%$ & $8 \%$ & $0 \%$ & \\
\hline \multirow{2}{*}{$\begin{array}{l}\text { Nenhum projeto começa sem uma clara definição } \\
\text { das variáveis escopo, qualidade, prazo e custo }\end{array}$} & DT, DP, NCND & $25 \%$ & $50 \%$ & $0 \%$ & $25 \%$ & \multirow{2}{*}{$7 \%$} \\
\hline & CT e CP & $27 \%$ & $55 \%$ & $18 \%$ & $0 \%$ & \\
\hline \multirow{2}{*}{$\begin{array}{l}\text { O executivo principal sabe dizer a qualquer } \\
\text { momento, em que situação se encontram os } \\
\text { projetos em andamento }\end{array}$} & DT, DP, NCND & $0 \%$ & $50 \%$ & $25 \%$ & $25 \%$ & \multirow{2}{*}{$41 \%$} \\
\hline & CT e CP & $36 \%$ & $55 \%$ & $9 \%$ & $0 \%$ & \\
\hline \multirow{2}{*}{$\begin{array}{l}\text { Existe uma função bem definida de gerente de } \\
\text { projeto }\end{array}$} & DT, DP, NCND & $33 \%$ & $17 \%$ & $33 \%$ & $17 \%$ & $50 \%$ \\
\hline & CT e CP & $22 \%$ & $78 \%$ & $0 \%$ & $0 \%$ & 5070 \\
\hline Há um bom número de pessoas preparadas para & DT, DP, NCND & $14 \%$ & $43 \%$ & $29 \%$ & $14 \%$ & $13 \%$ \\
\hline desempenhar a função de gerente de projeto & CT e CP & $38 \%$ & $63 \%$ & $0 \%$ & $0 \%$ & $40 \%$ \\
\hline Há uma sequéncia bem definida de & DT, DP, NCND & $0 \%$ & $40 \%$ & $40 \%$ & $20 \%$ & 60 \\
\hline com o ciclo de vida do projeto & CT e CP & $40 \%$ & $60 \%$ & $0 \%$ & $0 \%$ & $00 \%$ \\
\hline As equipes de projetos reúnem-se regularmente & DT, DP, NCND & $0 \%$ & $0 \%$ & $0 \%$ & $100 \%$ * & \\
\hline para planejar, executar e controlar suas & $\mathrm{CP}$ & $40 \%$ & $40 \%$ & $20 \%$ & $0 \%$ & $\mathrm{~N} / \mathrm{A}$ \\
\hline atividades & $\mathrm{CT}$ & $22 \%$ & $67 \%$ & $11 \%$ & $0 \%$ & \\
\hline $\begin{array}{c}\text { As responsabilidades dos executivos e } \\
\text { functis }\end{array}$ & DT, DP, NCND & $17 \%$ & $50 \%$ & $17 \%$ & $17 \%$ & $22 \%$ \\
\hline Ger. Proj., estão bem definidos & CT e CP & $33 \%$ & $56 \%$ & $11 \%$ & $0 \%$ & \\
\hline Sabemos avaliar o desempenho de projetos e & DT, DP, NCND & $0 \%$ & $33 \%$ * & $33 \%$ * & $33 \%$ * & $N / A$ \\
\hline projetos & CT e CP & $33 \%$ & $58 \%$ & $8 \%$ & $0 \%$ & \\
\hline Há escolha e composição criteriosa da equipe & DT, DP, NCND & $0 \%$ & $67 \%$ & $17 \%$ & $17 \%$ & $19 \%$ \\
\hline para execução dos projetos & CT e CP & $29 \%$ & $57 \%$ & $14 \%$ & $0 \%$ & $19 \%$ \\
\hline Há envolvimento e comprometimento da equipe & DT, DP, NCND & $0 \%$ & $100 \%$ * & $0 \%$ & $0 \%$ & N/A \\
\hline ח & CT e CP & $23 \%$ & $54 \%$ & $15 \%$ & $8 \%$ & \\
\hline Há conhecimento, habilidades e atitudes & DT, DP, NCND & $50 \%$ * & $50 \%$ * & $0 \%$ & $0 \%$ & N/A \\
\hline adequadas da equipe de projetos & CT e CP & $17 \%$ & $58 \%$ & $17 \%$ & $8 \%$ & IN/ \\
\hline Há liderança efetiva do Gte. de projetos sobre a & DT, DP, NCND & $0 \%$ & $0 \%$ & $0 \%$ & $0 \%$ & $N / A$ \\
\hline & CT e CP & $29 \%$ & $57 \%$ & $0 \%$ & $14 \%$ & \\
\hline & DT, DP, NCND & $0 \%$ & $0 \%$ & $50 \%$ & $50 \%$ & \\
\hline adequadas do Gte. Projetos & $\mathrm{CP}$ & $14 \%$ & $71 \%$ & $14 \%$ & $0 \%$ & $100 \%$ \\
\hline & CT & $50 \%$ & $50 \%$ & $0 \%$ & $0 \%$ & \\
\hline Há certificações em Ger. de Proj. compatíveis & DT, DP, NCND & $22 \%$ & $44 \%$ & $22 \%$ & $11 \%$ & 33 \\
\hline & CT e CP & $33 \%$ & $67 \%$ & $0 \%$ & $0 \%$ & \\
\hline Estrutura organizacional que dé assistència ao & DT, DP, NCND & $50 \%$ * & $0 \%$ & $50 \%$ * & $0 \%$ & $N / A$ \\
\hline poder necessários) & CT e CP & $25 \%$ & $58 \%$ & $8 \%$ & $8 \%$ & \\
\hline Os executivos proporcionam o patrocínio efetivo & DT, DP, NCND & $0 \%$ & $50 \%$ * & $50 \%$ * & $0 \%$ & $N / A$ \\
\hline durante todo o ciclo de vida do projeto & CT e CP & $33 \%$ & $50 \%$ & $8 \%$ & $8 \%$ & \\
\hline Procura-se desenvolver e utilizar consistente as & DT, DP, NCND & $0 \%$ & $25 \%$ & $50 \%$ & $25 \%$ & $75 \%$ \\
\hline melhores práticas no gerenciamento de Projetos & CT e CP & $40 \%$ & $60 \%$ & $0 \%$ & $0 \%$ & $15 \%$ \\
\hline Há uso efetivo de indicadores de desempenho de & DT, DP, NCND & $0 \%$ & $33 \%$ * & $33 \%$ * & $33 \%$ * & $N / A$ \\
\hline projetos, durante o ciclo de vida & CT e CP & $36 \%$ & $55 \%$ & $9 \%$ & $0 \%$ & \\
\hline Há ferramentas e sistemas de informações & DT, DP, NCND & $100 \%$ * & $0 \%$ & $0 \%$ & $0 \%$ & $N / A$ \\
\hline orientadas ao gerenciamento de projetos & CT e CP & $17 \%$ & $58 \%$ & $17 \%$ & $8 \%$ & $\mathrm{~N} / \mathrm{A}$ \\
\hline Há informaçóes de qualidade para o & DT, DP, NCND & $0 \%$ & $50 \%$ & $25 \%$ & $25 \%$ & $40 \%$ \\
\hline $\begin{array}{c}\text { projetos } \\
\end{array}$ & CT e CP & $40 \%$ & $50 \%$ & $10 \%$ & $0 \%$ & \\
\hline Ocorre monitoramento e gestāo efetiva da & DT, DP, NCND & $0 \%$ & $67 \%$ & $17 \%$ & $17 \%$ & $\%$ \\
\hline $\begin{array}{c}\text { projeto, quanto aos resultados esperados } \\
\end{array}$ & CT e CP & $50 \%$ & $38 \%$ & $13 \%$ & $0 \%$ & $21 \%$ \\
\hline
\end{tabular}


E por fim, foi realizado o cruzamento da avaliação da empresa em termos de gerenciamento de projetos e a satisfação com os processos/resultados da implementação de estratégias (tabela 43). Da mesma forma que foi feita a análise no item anterior, notou-se que existe uma série de práticas que impactaram positivamente a implementação. A análise foi feita com base na diferença entre as notas 'concordo totalmente' e 'parcialmente' contra as opiniões discordantes ou neutras, focando as empresas que conseguiram a satisfação com a implementação igual ou acima da nota 8 . As principais diferenças são:

- $70 \%$ - Há uma seqüência bem definida de procedimentos e pontos de decisão para lidar com o ciclo de vida do projeto;

- $61 \%$ - Há um bom número de pessoas preparadas para desempenhar a função de gerente de projeto;

- $61 \%$ - Há certificações em gerenciamento de projeto compatíveis com as necessidades.

Devido à quantidade de afirmações 'concordo totalmente' e 'parcialmente', em alguns casos foram analisados as diferenças entre essas duas avaliações para as empresas que estavam satisfeitas com a implementação da estratégia (notas iguais ou superiores a 8 ). As principais diferenças são:

- $38 \%$ - Há conhecimento, habilidades e atitudes adequadas da equipe de projetos;

- $38 \%$ - Estrutura organizacional que dê assistência ao gerente de projetos e a sua equipe (autoridade e poder necessários);

- $38 \%$ - Os executivos proporcionam o patrocínio efetivo durante todo o ciclo de vida do projeto.

Houve somente um caso de inversão quando foi analisada a diferença entre 'concordo totalmente' e 'parcialmente', isto é, a quantidade de respostas de concordância parcial superou a concordância total. O tópico em que ocorreu essa 
inversão foi: 'as equipes de projetos reúnem-se regularmente para planejar, executar e controlar suas atividades'.

Só foram possíveis fazer essas comparações quando havia grupos com número significativo de empresas para formar uma estatística mais realista. Em decorrência desse fato, alguns tópicos avaliados não tiveram essa comparação devido à baixa quantidade de casos (assinalados com o asterisco nas tabelas).

A mesma inferência anteriormente apresentada ocorre neste caso, de que possivelmente o tópico não seja algo que impacte positivamente no sucesso da implementação de estratégias, já que quase todas as empresas enquadraram o tópico avaliado da mesma forma, não havendo diferença significativa.

Em ambas as análises realizadas sobre a avaliação do estágio atual de gerenciamento de projetos, utilizando o percentual das estratégias implementadas e o nível de satisfação com os processos/resultados da implementação, há tópicos comuns que impactam positivamente o processo. Os principais são:

- Há conhecimento, habilidades e atitudes adequadas do gerente de projetos;

- Procura-se desenvolver e utilizar consistentemente as melhores práticas no gerenciamento de projetos;

- Muitas pessoas sabem preparar um plano de projeto na empresa;

- Há uma seqüência bem definida de procedimentos e pontos de decisão para lidar com o ciclo de vida do projeto;

- Existe uma função bem definida de gerente de projeto;

- Há um bom número de pessoas preparadas para desempenhar a função de gerente de projeto;

- A organização sabe utilizar as técnicas de gestão de projetos;

- O principal executivo sabe dizer a qualquer momento, em que situação se encontram os projetos em andamento;

- Há informações de qualidade para o planejamento, acompanhamento e controle dos projetos; 
- Há certificações em gerenciamento de projetos compatíveis com as necessidades.

Esses dez casos apareceram com uma diferença de mais de $30 \%$ entre as afirmações de concordância e discordância, em ambas as análises de sucesso de implementação. Essa diferença reflete a importância dessas variáveis para o processo de implementação de estratégias. 
Tabela 43 - Avaliação gerenciamento de projetos x sucesso na implementação

\begin{tabular}{|c|c|c|c|c|c|}
\hline \multirow{2}{*}{\multicolumn{2}{|c|}{ Itens de avaliação de Gerenciamento de Projetos }} & \multicolumn{3}{|c|}{$\begin{array}{l}\text { 21.Satisfação com a } \\
\text { implementação }\end{array}$} & \multirow{2}{*}{$\begin{array}{l}\text { Dif Concordo } \\
\text { x Discordo } \\
\text { (satisfação } \\
\text { acima de 8) }\end{array}$} \\
\hline & & $1-5$ & $6-7$ & $8-10$ & \\
\hline \multirow{2}{*}{$\begin{array}{l}\text { A maioria das pessoas sabe distinguir projetos de atividades que não } \\
\text { são projetos }\end{array}$} & DT, DP, NCND & $0 \%$ & $50 \%$ & $50 \%$ & \multirow{2}{*}{$-5 \%$} \\
\hline & CT e CP & $27 \%$ & $27 \%$ & $45 \%$ & \\
\hline \multirow{2}{*}{ A organização sabe utilizar as técnicas de gestão de projetos } & DT, DP, NCND & $50 \%$ & $25 \%$ & $25 \%$ & \multirow{2}{*}{$30 \%$} \\
\hline & CT e CP & $9 \%$ & $36 \%$ & $55 \%$ & \\
\hline \multirow{2}{*}{$\begin{array}{c}\text { Quando alguém quer preparar uma proposta de projeto há um modelo } \\
\text { padronizado ou uma orientação que todos conhecem }\end{array}$} & DT, DP, NCND & $67 \%$ * & $0 \%$ & $33 \%$ * & \multirow{2}{*}{$\mathrm{N} / \mathrm{A}$} \\
\hline & CT e CP & $8 \%$ & $42 \%$ & $50 \%$ & \\
\hline \multirow{2}{*}{ Muitas pessoas sabem preparar um plano de projeto na empresa } & DT, DP, NCND & $40 \%$ & $20 \%$ & $40 \%$ & \multirow{2}{*}{$10 \%$} \\
\hline & CT e CP & $10 \%$ & $40 \%$ & $50 \%$ & \\
\hline \multirow{2}{*}{$\begin{array}{l}\text { Há procedimentos bem estabelecidos de aprovação de planos e } \\
\text { propostas de projetos }\end{array}$} & DT, DP, NCND & $33 \%$ * & $33 \%$ * & $33 \%$ * & \multirow{2}{*}{$\mathrm{N} / \mathrm{A}$} \\
\hline & CT e CP & $17 \%$ & $33 \%$ & $50 \%$ & \\
\hline \multirow{2}{*}{$\begin{array}{l}\text { Nenhum projeto começa sem uma clara definição das variáveis } \\
\text { escopo, qualidade, prazo e custo }\end{array}$} & DT, DP, NCND & $25 \%$ & $50 \%$ & $25 \%$ & \multirow{2}{*}{$30 \%$} \\
\hline & CT e CP & $18 \%$ & $27 \%$ & $55 \%$ & \\
\hline \multirow{2}{*}{$\begin{array}{l}\text { O executivo principal sabe dizer a qualquer momento, em que } \\
\text { situação se encontram os projetos em andamento }\end{array}$} & DT, DP, NCND & $25 \%$ & $50 \%$ & $25 \%$ & $30 \%$ \\
\hline & CT e CP & $18 \%$ & $27 \%$ & $55 \%$ & $30 \%$ \\
\hline Fxiste uma funcão hem definida de gerente de proieto & DT, DP, NCND & $33 \%$ & $33 \%$ & $33 \%$ & $22 \%$ \\
\hline 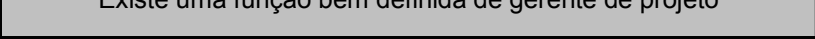 & CT e CP & $11 \%$ & $33 \%$ & $56 \%$ & \\
\hline Há um bom número de pessoas preparadas para desempenhar a & DT, DP, NCND & $29 \%$ & $57 \%$ & $14 \%$ & $610 \%$ \\
\hline função de gerente de projeto & CT e CP & $13 \%$ & $13 \%$ & $75 \%$ & $01 \%$ \\
\hline Há uma seqüência bem definida de procedimentos e pontos de & DT, DP, NCND & $40 \%$ & $60 \%$ & $0 \%$ & $70 \%$ \\
\hline decisão para lidar com o ciclo de vida do projeto & CT e CP & $10 \%$ & $20 \%$ & $70 \%$ & \\
\hline As equipes de proietos reúnem-se reqularmente para planeiar & DT, DP, NCND & $100 \%$ * & $0 \%$ & $0 \%$ & \\
\hline $\begin{array}{l}\text { As equipes de projetos reunem-se regularmente para planejar, } \\
\text { executar e controlar suas atividades }\end{array}$ & $\mathrm{CP}$ & $0 \%$ & $20 \%$ & $80 \%$ & $-47 \%$ \\
\hline & $\mathrm{CT}$ & $22 \%$ & $44 \%$ & $33 \%$ & \\
\hline As responsabilidades dos executivos e funcionários das áreas & DT, DP, NCND & $33 \%$ & $33 \%$ & $33 \%$ & $22 \%$ \\
\hline funcionais, em relação ao Ger. Proj., estão bem definidos & CT e CP & $11 \%$ & $33 \%$ & $56 \%$ & $22 \%$ \\
\hline & DT, DP, NCND & $33 \%$ * & $33 \%$ * & $33 \%$ * & \\
\hline $\begin{array}{c}\text { Sabemos avaliar o desempenho de projetos e aprender com erros e } \\
\text { acertos na gerência de projetos }\end{array}$ & $\mathrm{CP}$ & $17 \%$ & $50 \%$ & $33 \%$ & $33 \%$ \\
\hline & CT & $17 \%$ & $17 \%$ & $67 \%$ & \\
\hline Há escolha e composição criteriosa da equipe para execução dos & DT, DP, NCND & $33 \%$ & $33 \%$ & $33 \%$ & $10 \%$ \\
\hline projetos & CT e CP & $14 \%$ & $43 \%$ & $43 \%$ & $10 \%$ \\
\hline Há envolvimento e comprometimento da equipe para o alcance dos & DT, DP, NCND & $0 \%$ & $0 \%$ & $100 \%$ * & $N / A$ \\
\hline resultados dos projetos. & CT e CP & $23 \%$ & $38 \%$ & $38 \%$ & N/A \\
\hline & DT, DP, NCND & $50 \%$ * & $50 \%$ * & $0 \%$ & \\
\hline Ha conhecımento, habıllidades e atitudes adequadas da equipe de & $\mathrm{CP}$ & $25 \%$ & $38 \%$ & $38 \%$ & $38 \%$ \\
\hline & $\overline{\mathrm{CT}}$ & $0 \%$ & $25 \%$ & $75 \%$ & \\
\hline Há lideranca efetiva do Gte de proietos sobre a equine & $\mathrm{CP}$ & $0 \%$ & $0 \%$ & $0 \%$ & $29 \%$ \\
\hline & $\overline{\mathrm{CT}}$ & $29 \%$ & $43 \%$ & $29 \%$ & \\
\hline & DT, DP, NCND & $100 \%$ * & $0 \%$ & $0 \%$ & \\
\hline Há conhecimento, habilidades e atitudes adequadas do Gte. Projetos & $\mathrm{CP}$ & $14 \%$ & $43 \%$ & $43 \%$ & $24 \%$ \\
\hline & $\overline{\mathrm{CT}}$ & $0 \%$ & $33 \%$ & $67 \%$ & \\
\hline Há certificacões em Ger de Proi comnatíveis com as necessidades & DT, DP, NCND & $22 \%$ & $56 \%$ & $22 \%$ & $61 \%$ \\
\hline & CT e CP & $17 \%$ & $0 \%$ & $83 \%$ & \\
\hline & DT, DP, NCND & $50 \%$ * & $50 \%$ & $50 \%$ * & \\
\hline sua equipe (autoridade e poder necessários) & $\mathrm{CP}$ & $50 \%$ & $25 \%$ & $25 \%$ & $38 \%$ \\
\hline & CT & $0 \%$ & $38 \%$ & $63 \%$ & \\
\hline & DT, DP, NCND & $0 \%$ & $50 \%$ * & $50 \%$ * & \\
\hline de vida do proieto & $\mathrm{CP}$ & $50 \%$ & $25 \%$ & $25 \%$ & $38 \%$ \\
\hline & CT & $0 \%$ & $38 \%$ & $63 \%$ & \\
\hline Procura-se desenvolver e utilizar consistente as melhores práticas no & DT, DP, NCND & $50 \%$ & $25 \%$ & $25 \%$ & $35 \%$ \\
\hline 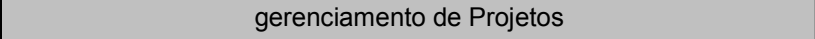 & CT e CP & $0 \%$ & $40 \%$ & $60 \%$ & \\
\hline Há uso efetivo de indicadores de desempenho de projetos, durante o & DT, DP, NCND & $33 \%$ * & $33 \%$ * & $33 \%$ * & $\mathrm{N} / \mathrm{A}$ \\
\hline ciclo de vida & CT e CP & $9 \%$ & $36 \%$ & $55 \%$ & \\
\hline Há ferramentas e sistemas de informações orientadas ao & $\mathrm{DT}, \mathrm{DP}, \mathrm{NCND}$ & $0 \%$ & $50 \%$ * & $50 \%$ * & N/A \\
\hline gerenciamento de projetos & CT e CP & $17 \%$ & $33 \%$ & $50 \%$ & $\mathrm{~N} / \mathrm{A}$ \\
\hline Há informações de qualidade para o planejamento, acompanhamento & DT, DP, NCND & $25 \%$ & $50 \%$ & $25 \%$ & $35 \%$ \\
\hline e controle dos projetos & CT e CP & $10 \%$ & $30 \%$ & $60 \%$ & $35 \%$ \\
\hline Ocorre monitoramento e gestão efetiva da satisfação dos clientes, & DT, DP, NCND & $17 \%$ & $33 \%$ & $50 \%$ & \\
\hline durante o ciclo de vida do projeto, quanto aos resultados esperados & CT e CP & $13 \%$ & $38 \%$ & $50 \%$ & \% \\
\hline
\end{tabular}




\subsubsection{Análise descritiva dos dados: maturidade em gerenciamento de projetos}

O último instrumento respondido pelas empresas foi o questionário de maturidade criado por Crawford (2002). O objetivo desse preenchimento foi o de compreender a relação entre maturidade e implementação de estratégias.

Como o questionário era enviado posteriormente à entrevista, houve alguns casos de não devolução dos mesmos.

O questionário abrange as nove áreas de gerenciamento de projetos. Para cada área de conhecimento, o executivo respondia uma pergunta dentro de uma escala de 1 a 5 , sendo:

- $1^{\circ}$. Estágio: processos iniciais/linguagem comum;

- $2^{\circ}$. Estágio: processos comuns;

- $3^{\circ}$. Estágio: metodologia singular/processos institucionalizados e padrões organizacionais;

- $4^{\circ}$. Estágio: processos gerenciados/benchmarking;

- $5^{\circ}$. Estágio: melhoria contínua/processos de otimização.

O próximo quadro apresenta o percentual de empresas em cada nível de maturidade e área do conhecimento. $A$ área de conhecimento com a média mais baixa foi a de gerenciamento do risco $(1,9)$ e a mais alta foi a de gerenciamento das aquisições $(3,1)$. No gerenciamento do risco, cerca de um terço das empresas localizavam-se no primeiro nível da escala. 
Tabela 44 - Percentual das empresas por nível de maturidade e área do conhecimento

\begin{tabular}{|c|c|c|c|c|c|c|}
\hline \multirow{2}{*}{ Área do conhecimento } & \multicolumn{6}{|c|}{ Nível de maturidade } \\
\hline & 1 & 2 & 3 & 4 & 5 & Média \\
\hline Gerenciamento da integração & $5.3 \%$ & $47.4 \%$ & $26.3 \%$ & $21.1 \%$ & $0.0 \%$ & 2.6 \\
\hline Gerenciamento do escopo & $5.3 \%$ & $57.9 \%$ & $26.3 \%$ & $5.3 \%$ & $5.3 \%$ & 2.5 \\
\hline Gerenciamento do tempo & $10.5 \%$ & $31.6 \%$ & $47.4 \%$ & $5.3 \%$ & $5.3 \%$ & 2.6 \\
\hline Gerenciamento do custo & $10.5 \%$ & $36.8 \%$ & $26.3 \%$ & $15.8 \%$ & $10.5 \%$ & 2.8 \\
\hline Gerenciamento da qualidade & $26.3 \%$ & $31.6 \%$ & $31.6 \%$ & $0.0 \%$ & $10.5 \%$ & 2.4 \\
\hline Gerenciamento de RH & $5.3 \%$ & $63.2 \%$ & $21.1 \%$ & $10.5 \%$ & $0.0 \%$ & 2.4 \\
\hline Gerenciamento da comunicação & $10.5 \%$ & $57.9 \%$ & $21.1 \%$ & $5.3 \%$ & $5.3 \%$ & 2.4 \\
\hline Gerenciamento do risco & $31.6 \%$ & $47.4 \%$ & $15.8 \%$ & $5.3 \%$ & $0.0 \%$ & 1.9 \\
\hline Gerenciamento das aquisições & $5.3 \%$ & $15.8 \%$ & $57.9 \%$ & $10.5 \%$ & $10.5 \%$ & 3.1 \\
\hline
\end{tabular}

Tanto a área onde as empresas estão com maior maturidade (aquisições) quanto a que está com menor maturidade (riscos) estão alinhadas com os resultados americanos dentro da mesma metodologia (CENTER FOR BUSINESS PRACTICES REPORT, 2002).

A média de maturidade em gerenciamento de projetos das empresas pesquisadas foi de 2,5. A metade das empresas está situada entre o primeiro e o segundo estágio de maturidade. Esse número é menor do que o americano, onde cerca de $90 \%$ das empresas estão localizadas entre o primeiro e segundo nível de maturidade. Possivelmente essa diferença ocorra devido ao perfil de empresas pesquisadas no Brasil ser diferente do americano.

Verificou-se que existem poucas diferenças no nível de maturidade das empresas quando comparado aos percentuais de estratégias implementadas. As maiores diferenças entre as empresas que conseguiram implementar mais estratégias e aquelas que implementaram menos de $60 \%$ delas foram nas áreas de aquisições, custo e escopo. 
Ao analisar o grau de satisfação com a implementação, a diferença de maturidade entre os dois grupos comparados foi maior $(0,6)$. As maiores diferenças de maturidade entre as empresas que têm alto grau de satisfação em relação às de baixo grau são em três áreas do conhecimento de gerenciamento de projetos, sendo estas: qualidade, escopo, tempo e custo.

Tabela 45 - Nível de maturidade por área do conhecimento e sucesso na implementação de estratégias

\begin{tabular}{|l|c|c|c|c|c|}
\hline \multirow{2}{*}{\multicolumn{1}{|c|}{ Área do conhecimento }} & \multicolumn{3}{|c|}{$\begin{array}{c}\text { 10. Percentual das estratégias } \\
\text { implementadas }\end{array}$} & \multicolumn{2}{|c|}{$\begin{array}{l}\text { 21.Satisfação com a } \\
\text { implementação }\end{array}$} \\
\cline { 2 - 7 } & $\begin{array}{c}\text { Mais de } \\
90 \%\end{array}$ & $\begin{array}{c}\text { Entre } 60 \% \\
\text { e } 90 \%\end{array}$ & Até $60 \%$ & $8-10$ & Até 7 \\
\hline Gerenciamento da integração & 2.4 & 2.8 & 2.3 & 2.7 & 2.2 \\
\hline Gerenciamento do escopo & 2.5 & 2.4 & 1.7 & 2.6 & 1.8 \\
\hline Gerenciamento do tempo & 2.5 & 2.6 & 2.3 & 2.9 & 2 \\
\hline Gerenciamento do custo & 2.5 & 2.8 & 1.7 & 3 & 2.2 \\
\hline Gerenciamento da qualidade & 2.2 & 2.6 & 1.7 & 2.6 & 1.6 \\
\hline Gerenciamento de RH & 2.3 & 2 & 2 & 2.1 & 2 \\
\hline Gerenciamento da comunicação & 2.3 & 2 & 2.3 & 2.3 & 2.2 \\
\hline Gerenciamento do risco & 2 & 2.4 & 1.7 & 2.3 & 1.6 \\
\hline Gerenciamento das aquisições & 3.3 & 2.8 & 2.3 & 3.1 & 2.4 \\
\hline
\end{tabular}




\subsection{Análise estatística de correlação}

As análises estatísticas de correlação e regressão múltipla auxiliam no entendimento de como uma variável está associada ou impactada pelas demais variáveis pesquisadas. Assim, essa estatística colabora na complementação das análises descritivas, tendo mais informações para verificar quanto a variável contribui para a implementação de estratégias.

Para a realização da correlação, pegou-se os dados das respostas dos executivos para cada pergunta e procurou-se verificar os resultados das outras variáveis. Assim, através da observação dos resultados de duas variáveis, obtém-se através da estatística um índice de correlação.

Através da correlação percebe-se que algumas variáveis estão muito associadas com o tempo de implementação das estratégias, tais como:

- Maturidade: Gerenciamento do escopo (69\%);

- Coordenação das atividades de implementação (63\%);

- Estabelecimento de Incentivos e recompensas (62\%);

- Comprometimento dos funcionários na implementação (58\%).

Tabela 46 - Correlação com o tempo de implementação

\begin{tabular}{|l|c|}
\hline \multicolumn{1}{|c|}{ Pergunta / Variável } & $\begin{array}{c}\text { 18. Tempo de } \\
\text { implementação }\end{array}$ \\
\cline { 2 - 2 } & Correlação \\
\hline $\begin{array}{l}\text { 14. Os funcionários entendem seus papéis e responsabilidades na implementação } \\
\text { da estratégia? }\end{array}$ & $54 \%$ ** \\
\hline $\begin{array}{l}\text { 15. Qual é o nível de comprometimento das pessoas pelas estratégias da } \\
\text { empresa? }\end{array}$ & $58 \%$ ** \\
\hline b) São desenvolvidas as competências necessárias para a implementação & $57 \%$ * \\
\hline c) É desenvolvido o orçamento para os projetos & $50 \%$ * \\
\hline e) Estabelece-se incentivos e recompensas & $62 \%$ ** \\
\hline g) Cascateamento da estratégia & $48 \%$ * \\
\hline 19. As atividades foram coordenadas de forma? Nota 1 (ineficaz) e 5 eficaz & $63 \%$ ** \\
\hline j) Há uma seqüência bem definida de procedimentos e pontos de decisão para lidar \\
com o ciclo de vida do projeto
\end{tabular}

* Correlação significativa a 5\% ** Correlação significativa a 1\% 
É interessante visualizar que o tempo de implementação está associado à coordenação das atividades de implementação (gerenciamento de projetos das iniciativas de planejamento estratégico), mostrando a sua importância. Além disso, dois aspectos de recursos humanos também impactam o tempo - o comprometimento e o nível de comprometimento. Verificou-se uma correlação de apenas $36 \%$ entre a entrega dos projetos dentro do prazo, custo e qualidade e a variável tempo de implementação das estratégias.

Por outro lado, o tempo, a qualidade e o custo de implementação dos projetos estão associados a outras variáveis, tais como:

- Há um bom número de pessoas preparadas para desempenhar a função de gerente de projeto $(74 \%)$;

- Muitas pessoas sabem preparar um plano de projeto na empresa $(73 \%)$;

- Instituicionalização das melhores práticas para a melhoria contínua da organização $(72 \%)$;

- O principal executivo sabe dizer em qualquer momento o status dos projetos em andamento (65\%).

Todas essas variáveis têm impacto significativo (1\%) e positivos no tempo, qualidade e custos dos projetos. Dois aspectos de capacitação estão correlacionadas ao tempo, qualidade e custo. Por consegüinte, quanto maior o número de gestores de projetos preparados, melhor será a entrega dos projetos. A institucionalização das melhores práticas demonstra a importância da empresa em querer fazer melhor suas atividades, o que inclui os projetos.

Entretanto, percebeu-se que a gestão de portifólio de projetos está negativamente correlacionada com o tempo, qualidade e custos dos projetos. 
Tabela 47 - Correlação com o projetos entregues dentro do prazo, custo e qualidade

\begin{tabular}{|c|c|}
\hline \multirow[t]{2}{*}{ Pergunta / Variável } & $\begin{array}{c}\text { 11. Projetos entregues } \\
\text { dentro do prazo, custo e } \\
\text { qualidade }\end{array}$ \\
\hline & Correlação \\
\hline $\begin{array}{l}\text { 15. Qual é o nível de comprometimento das pessoas pelas estratégias da } \\
\text { empresa? }\end{array}$ & $62 \%$ * \\
\hline e) Estabelece-se incentivos e recompensas & $50 \%$ \\
\hline f) Institucionaliza-se as melhores práticas para a melhoria contínua da organização & $72 \%$ ** \\
\hline j) Análise do portifólio de projetos (alinhamento dos projetos com a estratégia) & $-81 \%$ ** \\
\hline 18 d) Muitas pessoas sabem preparar um plano de projeto na empresa & $73 \%$ ** \\
\hline $\begin{array}{l}18 \text { e) Há procedimentos bem estabelecidos de aprovação de planos e propostas de } \\
\text { projetos }\end{array}$ & $61 \%$ ** \\
\hline $\begin{array}{l}18 \mathrm{~g}) \text { O executivo principal sabe dizer a qualquer momento, em que situação se } \\
\text { encontram os projetos em andamento }\end{array}$ & $65 \%$ ** \\
\hline $\begin{array}{l}18 \text { i) Há um bom número de pessoas preparadas para desempenhar a função de } \\
\text { gerente de projeto }\end{array}$ & $74 \%$ ** \\
\hline $\begin{array}{l}18 \text { s) Há certificações em gerenciamento de projetos compatíveis com as } \\
\text { necessidades. }\end{array}$ & $63 \%$ ** \\
\hline $\begin{array}{l}18 \text { u) Os executivos proporcionam o patrocínio efetivo durante todo o ciclo de vida } \\
\text { do projeto }\end{array}$ & $51 \%$ * \\
\hline $\begin{array}{l}18 \text { v) Procura-se desenvolver e utilizar consistente as melhores práticas no } \\
\text { gerenciamento de projetos. }\end{array}$ & $58 \%$ ** \\
\hline $\begin{array}{l}18 \text { w) Há uso efetivo de indicadores de desempenho de projetos, durante o ciclo de } \\
\text { vida }\end{array}$ & $56 \%$ * \\
\hline $\begin{array}{l}18 \text { z) Ocorre monitoramento e gestão efetiva da satisfação dos clientes, durante o } \\
\text { ciclo de vida do projeto, quanto aos resultados esperados }\end{array}$ & $51 \%$ * \\
\hline
\end{tabular}

${ }^{*}$ Correlação significativa a $5 \%{ }^{* *}$ Correlação significativa a $1 \%$

As duas variáveis mais utilizadas na dissertação (perguntas 10 e 21) são variáveis de resultado e impacto e estão relacionadas diretamente com o objetivo principal da pesquisa. Procurou-se constatar o quanto elas estão correlacionadas entre si. A correlação foi alta (71\%) e significativa (1\%). Apesar da percepção inicial ser de que as duas variáveis poderiam ter uma grande sobreposição ou identificar que constituiam-se em uma mesma variável, verificou-se que as duas são independentes, mas com alto índice de relacionamento.

Tabela 48 - Correlação com as variáveis dependentes da pesquisa

\begin{tabular}{|c|c|}
\hline Pergunta / Variável & $\begin{array}{l}\text { 10. Percentual das } \\
\text { estratégias }\end{array}$ \\
\cline { 2 - 2 } & Correlação \\
\hline 21. Satisfação/sucesso com a implementação & $71 \%$ ** \\
\hline
\end{tabular}

* Correlação significativa a 5\% $\quad$ ** Correlação significativa a 1\% 
Assim, as análises seguintes estão embasadas nestes dois itens: satisfação com a implementação e percentual das estratégias implementadas.

De acordo com a tabela 49, constata-se que os itens 14 e 15 têm impacto significativo e alto na implementação de estratégias. A clareza das responsabilidades dos executivos na implementação de estratégias teve impacto, mas foi relativamente baixo comparado com as outras variáveis. Isso se deve principalmente porque esses itens já fazem parte do processo de planejamento, então, independente se a empresa teve sucesso ou não na implementação, os executivos tinham claro seus papéis e responsabilidades.

Em contra partida, os funcionários necessitam ter clareza de seus papéis e responsabilidades. Isso ocorre por meio da comunicação, desdobramento da estratégia e o alinhamento com os subsistemas de recursos humanos.

O comprometimento dos funcionários é importante para que seja possível ter sucesso na implementação, sem eles essa tarefa se torna impossível. A estatística corroborou para a confirmação da importância desse comprometimento.

Tabela 49 - Correlação com as variáveis de comprometimento, papéis e responsabilidades

\begin{tabular}{|l|c|c|}
\hline \multicolumn{1}{|c|}{ Pergunta / Variável } & $\begin{array}{l}\text { 10. Percentual das } \\
\text { estratégias } \\
\text { implementadas }\end{array}$ & $\begin{array}{l}\text { 21.Satisfação com } \\
\text { a implementação }\end{array}$ \\
\cline { 2 - 3 } & Correlação & Correlação \\
\hline $\begin{array}{l}\text { 13. Cada executivo tem clareza das suas responsabilidades na } \\
\text { implementação da estratégia? }\end{array}$ & $48 \%$ * & $21 \%$ \\
\hline $\begin{array}{l}\text { 14. Os funcionários entendem seus papéis e responsabilidades na } \\
\text { implementação da estratégia? }\end{array}$ & $57 \%$ ** & $71 \%{ }^{* *}$ \\
\hline $\begin{array}{l}\text { 15. Qual é o nível de comprometimento das pessoas pelas estratégias } \\
\text { da empresa? }\end{array}$ & $84 \%$ ** & $72 \%{ }^{* *}$ \\
\hline
\end{tabular}

* Correlação significativa a 5\% $\quad{ }^{\text {** }}$ Correlação significativa a $1 \%$

Algumas práticas e conceitos de estratégia possuem alta correlação e significância no sucesso da implementação de estratégias (vide tabela 50), sendo elas: 
- Institucionalização das melhores práticas para a melhoria contínua da organização;

- Cascateamento da estratégia;

- Alinhamento com os subsistemas de RH;

- Desenvolvimento das competências necessárias para a implementação;

- Estabelecimento de incentivos e recompensas.

Os resultados anteriores comprovam as teorias de Morris e Jamieson (2005) e Archibald (2003) de que o cascateamento da estratégia é um fator importante na implementação.

Outro ponto compravado foi o alinhamento com os subsistemas de $\mathrm{RH}$. Pettigrew e Whipp (1991) quando elaboraram os cinco principais fatores de implementação apontaram a importância do RH na implementação de estratégias. Tais necessidades também foram apontadas por Schmidt (1994), Galpin (1997) e Sterling (2003).

O estabelecimento de incentivos é muito divulgado na literatura, e os resultados comprovam a teoria (HREBINIAK, 2005; HUSSEY, 1996; OKUMUS, 2001; AALTONEN e IKAVALKO, 2002; DOBNI, 2003; FREEDMAN, 2003; LINTON, 2002).

Outros pontos que valem ser ressaltados são os de que existem variáveis que possuem baixa correlação entre a satisfação, a implementação e o percentual de estratégias implementadas. São eles:

- Mudança de cultura;

- Análise do portifólio de projetos;

- Balanced Scorecard. 
Esses resultados não comprovam as teorias sobre a importância da mudança de cultura para a implementação de estratégias (HREBINIAK, 2005) e da gestão de portifólio de projetos no mesmo processo (MORRIS e JAMIESON, 2005; GAJ, 2002).

Os pontos mais relevantes foram a correlação negativa de $5 \%$ do Balanced Scorecard com a variável percentual das estratégias (KAPLAN e NORTON, 1991), e a baixa correlação (16\%) da satisfação com a implementação de estratégias. A relevância dessa análise é devida ao conceito ter sido muito difundido pelos autores como a principal ferramenta de implementação de estratégias. Muitos executivos compraram consultorias e investiram dinheiro, mas não necessariamente apresentaram evolução na implementação. Uma das provavéis possibilidades é a de que não é necessário ter a ferramenta de Balanced Scorecard e sim uma série de conceitos e técnicas de gestão estratégica e de projetos integradas entre si, reforçando o processo. Essas técnicas e conceitos estão por trás do conceito de Balanced Scorecard.

Tabela 50 - Correlação com os conceitos, técnicas e práticas de gestão estratégica 


\begin{tabular}{|c|c|c|}
\hline Pergunta / Variável & $\begin{array}{l}\text { 10. Percentual das } \\
\text { estratégias } \\
\text { implementadas }\end{array}$ & $\begin{array}{l}\text { 21.Satisfação com } \\
\text { a implementação }\end{array}$ \\
\hline No planejamento estrategico: & Correlação & Correlação \\
\hline a) Há responsáveis pela condução das estratégias & $15 \%$ & $13 \%$ \\
\hline $\begin{array}{l}\text { b) São desenvolvidas as competências necessárias para a } \\
\text { implementação }\end{array}$ & $52 \%$ * & $49 \%$ * \\
\hline c) É desenvolvido o orçamento para os projetos & $34 \%$ & $28 \%$ \\
\hline $\begin{array}{l}\text { d) Estabelecer sistemas de informações, comunicações e operações, } \\
\text { contendo informações precisas, no tempo adequado }\end{array}$ & $31 \%$ & $44 \%$ \\
\hline e) Estabelece-se incentivos e recompensas & $60 \%$ ** & $40 \%$ \\
\hline $\begin{array}{l}\text { f) Institucionaliza-se as melhores práticas para a melhoria contínua da } \\
\text { organização }\end{array}$ & $83 \%$ ** & $70 \%$ ** \\
\hline g) Cascateamento da estratégia & $72 \%$ ** & $59 \%$ * \\
\hline h) Alinhamento com subsistemas de RH & $56 \%$ ** & $40 \%$ \\
\hline i) Definição e gerenciamento de programas e projetos & $12 \%$ & $31 \%$ \\
\hline $\begin{array}{l}\text { j) Análise do portifólio de projetos (alinhamento dos projetos com a } \\
\text { estratégia) }\end{array}$ & $7 \%$ & $13 \%$ \\
\hline k) Mudanças de estrutura organizacional & $27 \%$ & $33 \%$ \\
\hline l) BSC & $-5 \%$ & $16 \%$ \\
\hline m) Mudança de cultura & $-2 \%$ & $-16 \%$ \\
\hline n) Estabelecimento de políticas e procedimentos & $22 \%$ & $15 \%$ \\
\hline
\end{tabular}

* Correlação significativa a $5 \%$ ** Correlação significativa a 1\%

Por meio desta pesquisa empírica, verificou-se que as empresas que obtiveram altos índices de estratégias implementadas ou de satisfação com a implementação conseguiram concluir num tempo menor e realizar a coordenação do processo com eficácia.

Por outro lado, não houve correlação com a frequência de acompanhamento da implementação. Assim, um dos pilares do conceito 'disciplina na execução' (cobrança e acompanhamento pelos gestores da empresa da execução da estratégia), difundido por Bossidy e Charam (2002), não foi comprovado por esta pesquisa.

A análise do contexto interno e externo teve correlação negativa de $-8 \%$ com o percentual das estratégias implementadas e $-20 \%$ com a satisfação com o processo. Uma inferência possível de ser realizada é de que como quase a 
totalidade das empresas utilizam a análise do contexto interno e externo, o indicador não conseguiu verificar a diferença entre a realização ou não dessa análise no impacto no sucesso da implementação.

A forma na qual a empresa está organizada (estrutura organizacional) tem pouco impacto no sucesso da implementação de estratégias.

Tabela 51 - Correlação com estrutura, contexto, tempo de implementação, coordenação da implementação e freqüência de acompanhamento

\begin{tabular}{|l|c|c|}
\hline \multicolumn{1}{|c|}{ Pergunta / Variável } & $\begin{array}{l}\text { 10. Percentual das } \\
\text { estratégias } \\
\text { implementadas }\end{array}$ & $\begin{array}{l}\text { 21.Satisfação com } \\
\text { a implementação }\end{array}$ \\
\cline { 2 - 3 } & Correlação & Correlação \\
\hline $\begin{array}{l}\text { 16. A forma pelo qual a empresa está organizada facilita a } \\
\text { implementação da estratégia }\end{array}$ & $4 \%$ & $20 \%$ \\
\hline $\begin{array}{l}\text { 17. A empresa analisa o contexto interno e externo para implementar a } \\
\text { estratégia }\end{array}$ & $-8 \%$ & $-20 \%$ \\
\hline $\begin{array}{l}\text { 18. O tempo de implementação foi maior do que o planejado? } \\
\text { (variável adaptada: nível alto da escala é o adiantamento da } \\
\text { implementação) }\end{array}$ & $64 \%$ ** & $68 \%$ ** \\
\hline $\begin{array}{l}\text { 19. As atividades foram coordenadas de forma? Nota 1 (ineficaz) e 5 } \\
\text { eficaz }\end{array}$ & $50 \%$ * & $68 \%$ ** \\
\hline $\begin{array}{l}\text { 20. Qual é a freqüência que a empresa mensura e acompanha o } \\
\text { progresso na implementação da estratégia? (variável adaptada para a } \\
\text { quantidade de vezes realizada em um período de um ano) }\end{array}$ & $6 \%$ & $3 \%$ \\
\hline
\end{tabular}

* Correlação significativa a 5\% $\quad$ ** Correlação significativa a 1\%

Da mesma maneira que a estrutura organizacional, os tipos de projeto têm pouco ou nenhum impacto na implementação. O tipo que tem correlação um pouco maior são os projetos de dispêndio de capital. Há cerca de $40 \%$ de correlação entre esse tipo de projeto e o percentual das estratégias implementadas, mas somente $8 \%$ de correlação entre a satisfação e a implementação, ou seja, nenhuma.

Tabela 52 - Correlação com os tipos de projeto

\begin{tabular}{|l|c|c|}
\hline \multicolumn{1}{|c|}{ Pergunta / Variável } & $\begin{array}{l}\text { 10. Percentual das } \\
\text { estratégias } \\
\text { implementadas }\end{array}$ & $\begin{array}{l}\text { 21.Satisfação com } \\
\text { a implementação }\end{array}$ \\
\hline 5a) aprimoramento interno & $5 \%$ & Correlação \\
\hline 5b) projetos de dispêndio de capital & $40 \%$ & $17 \%$ \\
\hline 5c) novos produtos para os clientes atuais & $1 \%$ & $8 \%$ \\
\hline
\end{tabular}

* Correlação significativa a 5\% $\quad$ ** Correlação significativa a 1\% 
A organização dos projetos em portifólio de projetos e programas tem pouca correlação com o percentual das estratégias implementadas e correlação negativa da satisfação com a implementação de estratégias. Por outro lado, a classificação dos projetos segundo critérios definidos pelas empresas tem correlação significativa e alta com o percentual das estratégias implementadas.

Tabela 53 - Correlação com portifólio, programas e classificação de projetos

\begin{tabular}{|c|c|c|}
\hline Pergunta / Variável & $\begin{array}{l}\text { 10. Percentual das } \\
\text { estratégias } \\
\text { implementadas }\end{array}$ & $\begin{array}{l}\text { 21.Satisfação com } \\
\text { a implementação }\end{array}$ \\
\hline & Correlação & Correlação \\
\hline 06. Os projetos são organizados em um portifólio? & $5 \%$ & $-23 \%$ \\
\hline 07. Os projetos são organizados em programas? & $8 \%$ & $-28 \%$ \\
\hline 08. Os projetos são classificados & $54 \%$ * & $41 \%$ \\
\hline
\end{tabular}

A ligação entre projetos entregues dentro do prazo, custo e qualidade e percentual das estratégias implementadas é de $82 \%$, com alto grau de significância (1\%). Entretanto, a correlação da satisfação com a implementação é de $19 \%$.

Tabela 54 - Correlação com projetos entregues dentro do prazo, custo e qualidade

\begin{tabular}{|c|c|c|}
\hline \multirow{2}{*}{ Pergunta / Variável } & $\begin{array}{l}\text { 10. Percentual das } \\
\text { estratégias } \\
\text { implementadas }\end{array}$ & $\begin{array}{l}\text { 21.Satisfação com } \\
\text { a implementação }\end{array}$ \\
\cline { 2 - 3 } & Correlação & Correlação \\
\hline 11. Projetos entregues dentro do prazo, custo e qualidade & $82 \%$ ** & $19 \%$ \\
\hline
\end{tabular}

* Correlação significativa a 5\% ** Correlação significativa a 1\%

Foram analisadas também todas as relações entre a avaliação da empresa em termos de gerenciamento de projetos e implementação de estratégias com o objetivo de entender como a gestão de projetos está ligada ao sucesso das estratégias (vide tabela 55). As principais correlações são:

- Há informações de qualidade para o planejamento, acompanhamento e controle dos projetos; 
- Procura-se desenvolver e utilizar consistentemente as melhores práticas no gerenciamento de projetos;

- Há procedimentos estabelecidos de aprovação de planos e propostas de projetos;

- Há um bom número de pessoas preparadas para desempenhar a função de gerente de projeto;

- Uso efetivo de indicadores de desempenho de projetos durante o ciclo de vida do projeto;

- Há conhecimento, habilidades e atitudes adequadas do gerente de projetos;

- Há uma seqüência bem definida de procedimentos e pontos de decisão para lidar com o ciclo de vida do projeto;

- Executivos proporcionam o patrocínio efetivo durante todo o projeto;

- Muitas pessoas sabem preparar um plano de projeto na empresa;

- A organização sabe utilizar as técnicas de gestão de projetos.

Como foi observado, muitos aspectos de gerenciamento de projetos estão correlacionados com o sucesso na implementação de estratégias, inclusive a utilização de suas técnicas. As empresas que buscam as melhores práticas de gerenciamento de projetos estão na dianteira na implementação de estratégias.

Contudo, há variáveis que estão pouco ou negativamente correlacionadas com a implementação de estratégias, tais como:

- Há liderança efetiva do gerente de projetos sobre a equipe;

- A maioria das pessoas sabe distinguir entre projetos e atividades que não são projetos;

- Há envolvimento e comprometimento da equipe para o alcance dos resultados dos projetos;

- Nenhum projeto começa sem uma clara definição das variáveis de desempenho - escopo, qualidade, prazo e custo;

- Estrutura organizacional que dê assistência ao gerente de projetos e a sua equipe (autoridade e poder necessários);

- Existe uma função bem definida de gerente de projeto; 
- Sabemos avaliar o desempenho de projetos e aprender com erros e acertos na gerencia de projetos;

- Há escolha e composição criteriosa da equipe para execução dos projetos;

- Há ferramentas e sistemas de informações orientadas ao gerenciamento de projetos;

- Há conhecimento, habilidades e atitudes adequadas da equipe de projetos.

Tabela 55 - Correlação com a avaliação das práticas de gerenciamento de projetos 


\section{Pergunta / Variável}

Avaliação da empresa (gestão de projetos):

a) A maioria das pessoas sabe distinguir projetos de atividades que não são projetos

b) A organização sabe utilizar as técnicas de gestão de projetos

c) Quando alguém quer preparar uma proposta de projeto há um modelo padronizado ou uma orientação que todos conhecem

d) Muitas pessoas sabem preparar um plano de projeto na empresa

e) Há procedimentos bem estabelecidos de aprovação de planos e propostas de projetos

f) Nenhum projeto começa sem uma clara definição das variáveis de desempenho - escopo, qualidade, prazo e custo

g) O executivo principal sabe dizer a qualquer momento, em que situação se encontram os projetos em andamento

h) Existe uma função bem definida de gerente de projeto

i) Há um bom número de pessoas preparadas para desempenhar a função de gerente de projeto

j) Há uma seqüência bem definida de procedimentos e pontos de decisão para lidar com o ciclo de vida do projeto

k) As equipes de projetos reúnem-se regularmente para planejar, executar e controlar suas atividades

l) As responsabilidades dos executivos e funcionários das áreas funcionais, em relação ao gerenciamento de projetos, estão bem definidos

m) Sabemos avaliar o desempenho de projetos e aprender com erros e acertos na gerencia de projetos

n) Há escolha e composição criteriosa da equipe para execução dos projetos.

o) Há envolvimento e comprometimento da equipe para o alcance dos resultados dos projetos.

p) Há conhecimento, habilidades e atitudes adequadas da equipe de projetos.

q) Há liderança efetiva do gerente de projetos sobre a equipe.

r) Há conhecimento, habilidades e atitudes adequadas do gerente de projetos.

s) Há certificações em gerenciamento de projetos compatíveis com as necessidades.

t) Estrutura organizacional que dê assistência ao gerente de projetos e a sua equipe (autoridade e poder necessários)

u) Os executivos proporcionam o patrocínio efetivo durante todo o ciclo de vida do projeto

v) Procura-se desenvolver e utilizar consistente as melhores práticas no gerenciamento de projetos.

w) Há uso efetivo de indicadores de desempenho de projetos, durante o ciclo de vida

x) Há ferramentas e sistemas de informações orientadas ao gerenciamento de projetos

y) Há informações de qualidade para o planejamento, acompanhamento e controle dos projetos

z) Ocorre monitoramento e gestão efetiva da satisfação dos clientes, du

10. Percentual das estratégias implementadas Correlação

21.Satisfação com a implementação

(r)

$+2$

\begin{tabular}{l|l}
$33 \%$ & $-8 \%$ \\
\hline
\end{tabular}

\begin{tabular}{|l|l}
\hline $52 \%^{*}$ & $35 \%$ \\
\hline $68 \%^{* *}$ & $26 \%$ \\
\hline
\end{tabular}

\begin{tabular}{|l|l}
\hline $77 \%{ }^{* *}$ & $35 \%$ \\
\hline
\end{tabular}

\begin{tabular}{|l|l}
\hline $23 \%$ & $3 \%$ \\
\hline
\end{tabular}

\begin{tabular}{|l|l}
\hline $45 \%$ & $27 \%$ \\
\hline
\end{tabular}

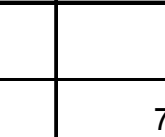

$25 \%$

$71 \%$

\begin{tabular}{l|l}
$25 \%$ & $12 \%$
\end{tabular}

\begin{tabular}{l|l}
$76 \%$ ** & $54 \%$
\end{tabular}

$46 \%$

\begin{tabular}{l|l}
$71 \%{ }^{* *}$ & $66 \%$ ** \\
\hline
\end{tabular}

\begin{tabular}{l|l}
\hline $46 \%$ & $31 \%$ \\
\hline
\end{tabular}

\begin{tabular}{|c|c|}
\hline $45 \%$ & $17 \%$ \\
\hline $58 \%$ * & $12 \%$ \\
\hline $58 \%$ * & $13 \%$ \\
\hline $25 \%$ & $-2 \%$ \\
\hline
\end{tabular}


Quando avaliada a maturidade em gerenciamento de projetos que estão divididos pelas nove áreas do conhecimento, nota-se que o gerenciamento do escopo e das aquisições têm correlações altas e significativas com o percentual das estratégias implementadas e a satisfação com o processo de implementação.

Tabela 56 - Correlação com a maturidade em gerenciamento de projetos

\begin{tabular}{|l|c|c|}
\hline \multicolumn{1}{|c|}{ Mergunta / Variável } & $\begin{array}{l}\text { 10. Percentual das } \\
\text { estratégias }\end{array}$ & $\begin{array}{l}\text { 21.Satisfação com } \\
\text { a implementação }\end{array}$ \\
\cline { 2 - 3 } & Correlação & Correlação \\
\hline Gerenciamento da integração & $27 \%$ & $28 \%$ \\
\hline Gerenciamento do escopo & $70 \%$ * área do conhecimento: & $79 \%$ ** \\
\hline Gerenciamento do tempo & $33 \%$ & $23 \%$ \\
\hline Gerenciamento do custo & $50 \%$ & $33 \%$ \\
\hline Gerenciamento da qualidade & $39 \%$ & $32 \%$ \\
\hline Gerenciamento dos Recursos Humanos & $32 \%$ & $14 \%$ \\
\hline Gerenciamento da comunicação & $14 \%$ & $-10 \%$ \\
\hline Gerenciamento do risco & $29 \%$ & $36 \%$ \\
\hline Gerenciamento das aquisições & $49 \%$ & $58 \%$ * \\
\hline
\end{tabular}

* Correlação significativa a $5 \% \quad$ ** Correlação significativa a $1 \%$

O gerenciamento de escopo possivelmente foi o de maior correlação por estar estreitamente relacionado com o foco na estratégia e com os objetivos da organização interligados com os projetos.

Já a gestão da comunicação tem baixa correlação com o percentual das estratégias implementadas e correlação negativa com a satisfação com a implementação.

\subsection{Análise estatística de regressão múltipla}

As análises estatísticas de regressão múltipla auxiliam na compreensão de como uma variável está associada ou impactada pelas demais variáveis 
pesquisadas. É a avaliação do efeito exercido por duas ou mais variáveis independentes sobre uma variável dependente (implementação). Com isso, a regressão linear múltipla ajuda na previsão de sucesso de implementação de estratégias.

Assim, procurou-se colocar os resultados dos questionários preenchidos pelas empresas nas questões 10 e 21 (variáveis dependentes) e verificar o grau de explicação de cada variável dos questionários, verificando seus resultados.

Para quase todas as equações apresentadas abaixo há a presença do erro estatístico, já que não atingiram a totalidade (1) da explicação da variância. Para obter-se a confiança de $95 \%$ dos casos, é necessário multiplicar o erro estatístico por 1,96 .

Vale a pena ressaltar que para Dunlap e Landis (1998), o uso de preditores redundantes, correlacionados entre si ao construírem medidas internamente consistentes, incluem múltiplas medidas correlacionadas ao mesmo construto, o que pode levar, em alguns casos, à exclusão de variáveis importantes na explicação da variável em foco.

Ao analisar apenas o questionário de estratégia colocando como variável dependente a questão 10 (percentual das estratégias implementadas), percebeu-se que somente uma variável integrava o modelo de regressão, ou seja, o comprometimento das pessoas.

A equação que prediz o percentual das estratégias implementadas ficou:

$Y=16.36+18.17\left(X_{1}\right) \pm 0.54 \% e$

Onde:

$Y$ é o percentual das estratégias implementadas

$\mathrm{X}_{1}$ é a variável comprometimento das pessoas

e é o erro estatístico. 


\begin{tabular}{|c|c|c|c|c|c|c|c|c|}
\hline & \multicolumn{8}{|c|}{ Variável dependente: 10 . Percentual das estratégias implementadas } \\
\hline & \multirow[b]{2}{*}{$\mathbf{R}$} & \multirow[b]{2}{*}{$\mathbf{R}^{2}$} & \multirow{2}{*}{$\begin{array}{c}\mathbf{R}^{2} \\
\text { ajustado }\end{array}$} & \multirow{2}{*}{$\begin{array}{c}\text { Coeficiente } \\
\text { Padronizado } \\
\text { (Beta) }\end{array}$} & \multicolumn{2}{|c|}{ Antes Padronização (Z-Score) } & \multicolumn{2}{|c|}{ Depois Padronização (Z-Score } \\
\hline & & & & & B & $\begin{array}{l}\text { Erro padrão } \\
\text { da estimativa }\end{array}$ & B & \begin{tabular}{|c|} 
Erro padrão \\
da estimativa
\end{tabular} \\
\hline $\begin{array}{l}\text { 15. Comprometimento } \\
\text { das pessoas }\end{array}$ & 0.87 & 0.76 & 0.74 & 0.87 & $\begin{array}{c}16.36 \text { (const.) } \\
18.17 \text { (var.) }\end{array}$ & $10.10 \%$ & $\begin{array}{c}-0.09 \text { (const.) } \\
0.83 \text { (var.) }\end{array}$ & 0.54 \\
\hline
\end{tabular}

Tabela 57 - Regressão da variável percentual das estratégias somente no questionário de estratégia

Diferentemente do que ocorreu na tabela 57 , ao analisar a variável satisfação com a implementação de estratégias, verificou-se que quatro perguntas faziam parte do modelo de regressão. A pergunta com maior impacto, isto é, com o maior Beta, foi a coordenação das atividades de implementação. Essa variável está muito integrada com a gestão de projetos, mostrando a sua importância no processo. A outra variável com maior impacto foi o tempo de implementação, com o beta de 0.51 .

O modelo gerado através da regressão múltipla se mostrou com o ' $R$ ', ajustado bem alto (0.88), demonstrando um alto grau de enquadramento das variáveis no modelo e, em conseqüência, um erro padrão da estimativa pequeno (0.77).

A equação resultante da regressão múltipla é:

$Y=15.27+1.21\left(X_{1}\right)+1.53\left(X_{2}\right)-3.44\left(X_{3}\right)+0.34\left(X_{4}\right) \pm 0.77 e$

Tabela 58 - Regressão da variável satisfação com a implementação somente no questionário de estratégia 


\begin{tabular}{|c|c|c|c|c|c|c|c|c|}
\hline & \multicolumn{8}{|c|}{ Variável dependente: 21.Satisfação com a implementação } \\
\hline & \multirow[b]{2}{*}{$\mathbf{R}$} & \multirow[b]{2}{*}{$\mathbf{R}^{2}$} & \multirow{2}{*}{$\begin{array}{c}\mathbf{R}^{2} \\
\text { ajustado }\end{array}$} & \multirow{2}{*}{$\begin{array}{c}\text { Coeficiente } \\
\text { Padronizado } \\
\text { (Beta) }\end{array}$} & \multicolumn{2}{|c|}{ Antes Padronização (Z-Score) } & \multicolumn{2}{|c|}{ Depois Padronização (Z-Score) } \\
\hline & & & & & B & $\begin{array}{l}\text { Erro padrão } \\
\text { da estimativa }\end{array}$ & B & $\begin{array}{c}\text { Erro padrão } \\
\text { da estimativa }\end{array}$ \\
\hline $\begin{array}{l}\text { 19. As atividades foram } \\
\text { coordenadas de forma? } \\
\text { Nota } 1 \text { (ineficaz) e } 5 \\
\text { eficaz }\end{array}$ & \multirow{4}{*}{0.96} & \multirow{4}{*}{0.91} & \multirow{4}{*}{0.88} & 0.52 & $\begin{array}{c}15.27 \text { (const.) } \\
1.21 \text { (var.) }\end{array}$ & \multirow{4}{*}{0.77} & $\begin{array}{c}0.07 \text { (const.) } \\
0.66 \text { (var.) }\end{array}$ & \multirow{4}{*}{0.38} \\
\hline $\begin{array}{l}\text { 18. O tempo de } \\
\text { implementação foi maior } \\
\text { do que o planejado? } \\
\text { (variável adaptada: nível } \\
\text { alto da escala é o } \\
\text { adiantamento da } \\
\text { implementação) }\end{array}$ & & & & 0.51 & 1.53 (var. 2) & & 0.73 (var. 2) & \\
\hline $\begin{array}{l}\text { 15a) Há responsáveis } \\
\text { pela condução das } \\
\text { estratégias }\end{array}$ & & & & -0.42 & $-3.44($ var. 3) & & -1.14 (var. 3) & \\
\hline 15I) BSC & & & & 0.27 & 0.34 (var. 4) & & 0.32 (var. 4) & \\
\hline
\end{tabular}

Quando analisados os questionários de estratégia e o de gerenciamento de projetos, com a exceção da maturidade, o ' $\mathrm{R}^{2}$ ' ajustado aumentou, mostrando que a inserção de novas variáveis no modelo foi importante, o que reduziu o erro padrão da estimativa (de $10 \%$ para $4 \%$ ).

Com apenas duas variáveis, o modelo consegue explicar mais de $90 \%$ das varianças dos resultados do percentual das estratégias implementadas. Novamente a variável 'comprometimento das pessoas' apresentou-se como a de maior impacto na regressão $($ Beta $=0.74)$.

A equação da regressão ficou:

$Y=-53.4+18.19\left(X_{1}\right)+15.23\left(X_{2}\right) \pm 4.48 \mathrm{e}$

Tabela 59 - Regressão da variável percentual das estratégias nos questionário de estratégia e gerenciamento de projetos

\begin{tabular}{|c|c|c|c|c|c|c|c|c|}
\hline & \multicolumn{8}{|c|}{ Variável dependente: 10 . Percentual das estratégias implementadas } \\
\hline & \multirow[b]{2}{*}{$\mathbf{R}$} & \multirow[b]{2}{*}{$\mathbf{R}^{2}$} & \multirow[b]{2}{*}{$\begin{array}{c}\mathbf{R}^{2} \\
\text { ajustado }\end{array}$} & \multirow{2}{*}{$\begin{array}{l}\text { Coeficiente } \\
\text { Padronizado } \\
\text { (Beta) }\end{array}$} & \multicolumn{2}{|c|}{ Antes Padronização (Z-Score) } & \multicolumn{2}{|c|}{ Depois Padronização (Z-Score) } \\
\hline & & & & & B & $\begin{array}{l}\text { Erro padrão } \\
\text { da estimativa }\end{array}$ & B & $\begin{array}{l}\text { Erro padrão } \\
\text { da estimativa }\end{array}$ \\
\hline $\begin{array}{l}\text { 15. Comprometimento } \\
\text { das pessoas }\end{array}$ & \multirow[b]{2}{*}{0.98} & \multirow[b]{2}{*}{0.96} & \multirow[b]{2}{*}{0.94} & \multirow[t]{2}{*}{0.74} & \begin{tabular}{|c|}
-53.4 (const.) \\
18.19 (var.)
\end{tabular} & \multirow[b]{2}{*}{$4.48 \%$} & \begin{tabular}{|c|}
-0.21 (const.) \\
0.83 (var.)
\end{tabular} & \multirow[b]{2}{*}{0.24} \\
\hline $\begin{array}{l}\text { 18q) Liderança efetiva } \\
\text { do gerente de projetos } \\
\text { sobre a equipe }\end{array}$ & & & & & 15.23 (var. 2) & & 0.59 (var. 2) & \\
\hline
\end{tabular}


A variável satisfação com a implementação é totalmente explicada $\left(R^{2}\right.$ ajustado =1) por cinco variáveis, segundo a regressão apresentada a seguir.

A pergunta de maior impacto foi a $18 \mathrm{r}$ (o gerente de projetos tem $\mathrm{o}$ conhecimento, habilidade e atitudes adequados), com Beta de 0,83.

A equação resultante da regressão múltipla é:

$Y=0+1.88\left(X_{1}\right)-0.38\left(X_{2}\right)+0.75\left(X_{3}\right)-0.25\left(X_{4}\right)-0.13\left(X_{5}\right) \pm 0 e$

Tabela 60 - Regressão da variável satisfação com a implementação no questionário de estratégia e de gerenciamento de projetos

\begin{tabular}{|c|c|c|c|c|c|c|c|c|}
\hline & \multicolumn{8}{|c|}{ Variável dependente: 21 .Satisfação com a implementação } \\
\hline & \multirow[b]{2}{*}{$\mathbf{R}$} & \multirow[b]{2}{*}{$\mathbf{R}^{2}$} & \multirow{2}{*}{$\begin{array}{c}\mathbf{R}^{2} \\
\text { ajustado }\end{array}$} & \multirow{2}{*}{$\begin{array}{c}\text { Coeficiente } \\
\text { Padronizado } \\
\text { (Beta) }\end{array}$} & \multicolumn{2}{|c|}{ Antes Padronização (Z-Score) } & \multicolumn{2}{|c|}{ Depois Padronização (Z-Score } \\
\hline & & & & & B & $\begin{array}{l}\text { Erro padrão } \\
\text { da estimativa }\end{array}$ & B & $\begin{array}{l}\text { Erro padrão } \\
\text { da estimativa }\end{array}$ \\
\hline \begin{tabular}{|l} 
18r) Há conhecimento, \\
habilidades e atitudes \\
adequadas do gerente \\
de projetos.
\end{tabular} & \multirow{5}{*}{1} & \multirow{5}{*}{1} & \multirow{5}{*}{1} & 0.83 & $\begin{array}{l}0 \text { (const.) } \\
1.88 \text { (var.) }\end{array}$ & \multirow{5}{*}{0} & $\begin{array}{c}0.19 \text { (const.) } \\
0.75 \text { (var.) }\end{array}$ & \multirow{5}{*}{ 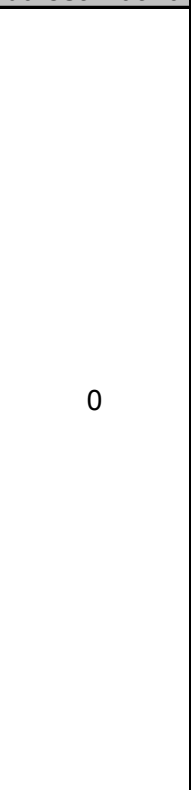 } \\
\hline $\begin{array}{l}181) \text { As } \\
\text { responsabilidades dos } \\
\text { executivos e } \\
\text { funcionários das áreas } \\
\text { funcionais, em relação } \\
\text { ao gerenciamento de } \\
\text { projetos, estão bem } \\
\text { definidos }\end{array}$ & & & & -0.35 & -0.38 (var. 2 ) & & -0.24 (var. 2) & \\
\hline $\begin{array}{l}\text { 15. Comprometimento } \\
\text { das pessoas }\end{array}$ & & & & 0.36 & 0.75 (var. 3) & & 0.32 (var. 3) & \\
\hline \begin{tabular}{|l} 
18p) Há conhecimento, \\
habilidades e atitudes \\
adequadas da equipe de \\
projetos.
\end{tabular} & & & & -0.08 & -0.25 (var. 4) & & -1.12 (var. 4) & \\
\hline $\begin{array}{l}\text { 18i) Há um bom número } \\
\text { de pessoas preparadas } \\
\text { para desempenhar a } \\
\text { função de gerente de } \\
\text { projeto }\end{array}$ & & & & -0.11 & -0.13 (var. 5$)$ & & -0.09 (var. 5$)$ & \\
\hline
\end{tabular}

A partir da análise dos três questionários: de estratégia, de gerenciamento de projetos e de maturidade, verificou-se que a variável dependente 'percentual das estratégias implementadas' foi totalmente explicada por quatro variáveis. Assim, o erro padrão da estimativa é próximo a zero $(0.77 \%)$. 
A pergunta 15j (portifólio de projetos) teve o maior impacto na equação da regressão, com o Beta de -1.07 .

A equação da regressão ficou:

$Y=104.29-10.34\left(X_{1}\right)-4.07\left(X_{2}\right)-1.27\left(X_{3}\right)+4.31\left(X_{4}\right) \pm 0.77 \% e$

Tabela 61 - Regressão da variável percentual das estratégias nos questionário de estratégia, gerenciamento de projetos e maturidade.

\begin{tabular}{|c|c|c|c|c|c|c|c|c|}
\hline & \multicolumn{8}{|c|}{ Variável dependente: 10 . Percentual das es } \\
\hline & \multirow[b]{2}{*}{$\mathbf{R}$} & \multirow[b]{2}{*}{$\mathbf{R}^{2}$} & \multirow{2}{*}{\begin{tabular}{|c|}
$R^{2}$ \\
ajustado
\end{tabular}} & \multirow{2}{*}{\begin{tabular}{|c|}
$\begin{array}{c}\text { Coeficiente } \\
\text { Padronizado } \\
\text { (Beta) }\end{array}$ \\
\end{tabular}} & \multicolumn{2}{|c|}{ Antes Padronização (Z-Score) } & \multicolumn{2}{|c|}{ Depois Padronização (Z-Score } \\
\hline & & & & & B & $\begin{array}{c}\text { Erro padrão } \\
\text { da estimativa }\end{array}$ & B & $\begin{array}{c}\begin{array}{c}\text { Erro padrão } \\
\text { da estimativa }\end{array} \\
\end{array}$ \\
\hline $\begin{array}{l}\text { 15j) Análise do portifólio } \\
\text { de projetos (alinhamento } \\
\text { dos projetos com a } \\
\text { estratégia) }\end{array}$ & \multirow{4}{*}{1} & \multirow{4}{*}{1} & \multirow{4}{*}{1} & -1.07 & $\begin{array}{c}104.29 \text { (const. } \\
\text { ) } \\
-10.34 \text { (var.) }\end{array}$ & \multirow{4}{*}{$0.77 \%$} & $\begin{array}{l}0.88 \text { (const.) } \\
-1.22 \text { (var.) }\end{array}$ & \multirow{4}{*}{0.04} \\
\hline $\begin{array}{l}\text { 18c) Quando alguém } \\
\text { quer preparar uma } \\
\text { proposta de projeto há } \\
\text { um modelo padronizado } \\
\text { ou uma orientação que } \\
\text { todos conhecem }\end{array}$ & & & & -0.35 & -4.07 (var. 2) & & -0.28 (var. 2) & \\
\hline $\begin{array}{l}\text { 18m) Sabemos avaliar o } \\
\text { desempenho de projetos } \\
\text { e aprender com erros e } \\
\text { acertos na gerencia de } \\
\text { projetos }\end{array}$ & & & & -0.12 & -1.27 (var. 3) & & 0.09 (var. 3) & \\
\hline $\begin{array}{l}\text { 15. Comprometimento } \\
\text { das pessoas }\end{array}$ & & & & 0.18 & 4.31 (var. 4) & & $-0.19($ var. 4$)$ & \\
\hline
\end{tabular}

O mesmo resultado de ' $R$ ' ajustado igual a 1 foi obtido na regressão da totalidade do questionário (estratégia, gerenciamento de projetos e maturidade) com a variável dependente 'satisfação com a implementação de estratégias', resultando no erro padrão de zero.

Nesse caso, a variável de maior impacto na regressão é a mudança cultural, com o Beta de 1,06 . 
A equação resultante da regressão múltipla é:

$$
\mathrm{Y}=0.25+1.5\left(\mathrm{X}_{1}\right)+0.5\left(\mathrm{X}_{2}\right)-0.25\left(\mathrm{X}_{3}\right)+0.25\left(\mathrm{X}_{4}\right) \pm 0 \mathrm{e}
$$

Tabela 62 - Regressão da variável satisfação com a implementação no questionário de estratégia, de gerenciamento de projetos e maturidade

\begin{tabular}{|c|c|c|c|c|c|c|c|c|}
\hline & \multicolumn{8}{|c|}{ Variável dependente: 21.Satisfação com a implementação } \\
\hline & \multirow[b]{2}{*}{$\mathbf{R}$} & \multirow[b]{2}{*}{$\mathbf{R}^{2}$} & \multirow{2}{*}{$\begin{array}{c}\mathrm{R}^{2} \\
\text { ajustado }\end{array}$} & \multirow{2}{*}{$\begin{array}{c}\text { Coeficiente } \\
\text { Padronizado } \\
\text { (Beta) }\end{array}$} & \multicolumn{2}{|c|}{ Antes Padronização (Z-Score) } & \multicolumn{2}{|c|}{ Depois Padronização (Z-Score } \\
\hline & & & & & B & $\begin{array}{l}\text { Erro padrão } \\
\text { da estimativa } \\
\end{array}$ & B & \begin{tabular}{|c|} 
Erro padrão \\
da estimativa \\
\end{tabular} \\
\hline $\begin{array}{l}\text { 15k) Mudanças de } \\
\text { estrutura organizacional }\end{array}$ & \multirow{4}{*}{1} & \multirow{4}{*}{1} & \multirow{4}{*}{1} & 1.06 & $\begin{array}{c}0.25 \text { (const.) } \\
1.5 \text { (var.) }\end{array}$ & \multirow{4}{*}{0} & $\begin{array}{c}0.35 \text { (const.) } \\
1.04 \text { (var.) }\end{array}$ & \multirow{4}{*}{0} \\
\hline $\begin{array}{l}\text { 6.Os projetos são } \\
\text { organizados em um } \\
\text { portifólio }\end{array}$ & & & & 0.44 & 0.5 (var. 2) & & 0.47 (var. 2) & \\
\hline $\begin{array}{l}\text { 18h) Existe uma função } \\
\text { bem definida de gerente } \\
\text { de projeto }\end{array}$ & & & & -0.27 & -0.25 (var. 3) & & -0.19 (var. 3) & \\
\hline $\begin{array}{l}\text { 13. Cada executivo tem } \\
\text { clareza das suas } \\
\text { responsabilidades na } \\
\text { implementação da } \\
\text { estratégia }\end{array}$ & & & & 0.11 & 0.25 (var. 4) & & 0.11 (var. 4) & \\
\hline
\end{tabular}

Ao ter como foco apenas o questionário de gerenciamento de projetos, observa-se que com apenas duas variáveis já é possível ter ' $\mathrm{R}^{2}$ ' ajustado de $83 \%$, tendo o maior peso para a questão 18t (estrutura organizacional suportante o gerente de projetos).

A equação resultante da regressão múltipla é:

$$
Y=-26.65+12.46\left(X_{1}\right)+9.68\left(X_{2}\right) \pm 7 \% e
$$


Tabela 63 - Regressão da variável percentual das estratégias somente no questionário de gerenciamento de projetos

\begin{tabular}{|c|c|c|c|c|c|c|c|c|}
\hline & \multicolumn{8}{|c|}{ Variável dependente: 10 . Percentual das estratégias implementadas } \\
\hline & \multirow[b]{2}{*}{$\mathbf{R}$} & \multirow[b]{2}{*}{$\mathbf{R}^{2}$} & \multirow[b]{2}{*}{$\begin{array}{c}\mathbf{R}^{2} \\
\text { ajustado }\end{array}$} & \multirow{2}{*}{$\begin{array}{c}\text { Coeficiente } \\
\text { Padronizado } \\
\text { (Beta) }\end{array}$} & \multicolumn{2}{|c|}{\begin{tabular}{|l|} 
Antes Padronização (Z-Score) \\
\end{tabular}} & \multicolumn{2}{|c|}{ Depois Padronização (Z-Score } \\
\hline & & & & & B & $\begin{array}{l}\text { Erro padrão } \\
\text { da estimativa }\end{array}$ & B & $\begin{array}{l}\text { Erro padrão } \\
\text { da estimativa }\end{array}$ \\
\hline $\begin{array}{l}\text { 18t) Estrutura } \\
\text { organizacional que dê } \\
\text { assistência ao gerente } \\
\text { de projetos e a sua } \\
\text { equipe (autoridade e } \\
\text { poder necessários) }\end{array}$ & \multirow[t]{2}{*}{0.93} & \multirow[t]{2}{*}{0.87} & \multirow[t]{2}{*}{0.83} & 0.68 & $\begin{array}{c}-26.65 \text { (const.) } \\
12.46 \text { (var.) }\end{array}$ & \multirow[t]{2}{*}{$7 \%$} & $\begin{array}{c}-0.55 \text { (const.) } \\
0.88 \text { (var.) }\end{array}$ & \multirow[t]{2}{*}{0.37} \\
\hline $\begin{array}{l}\text { 18r) Há conhecimento, } \\
\text { habilidades e atitudes } \\
\text { adequadas do gerente } \\
\text { de projetos. }\end{array}$ & & & & 0.38 & 9.68 (var. 2) & & 0.41 (var. 4) & \\
\hline
\end{tabular}

Quando a variável dependente é a 'satisfação com a implementação', novamente obtivemos o ' $\mathrm{R}^{2}$ ' ajustado de quase $100 \%$, com erro padrão de apenas 0,12 . A questão com o maior peso foi a 18b (a organização sabe utilizar as técnicas de gestão de projetos).

A equação da regressão ficou:

$$
Y=4.92+0.45\left(X_{1}\right)+1.26\left(X_{2}\right)-0.71\left(X_{3}\right)-0.20\left(X_{4}\right)-0.12\left(X_{5}\right) \pm 0.12 e
$$

Tabela 64 - Regressão da variável satisfação com a implementação somente no questionário de gerenciamento de projetos

\begin{tabular}{|c|c|c|c|c|c|c|c|c|}
\hline & \multicolumn{8}{|c|}{ Variável dependente: 21 .Satisfação com a implementação } \\
\hline & \multirow[b]{2}{*}{$\mathbf{R}$} & \multirow[b]{2}{*}{$\mathbf{R}^{2}$} & \multirow{2}{*}{\begin{tabular}{|c|}
$\mathbf{R}^{2}$ \\
ajustado
\end{tabular}} & \multirow{2}{*}{$\begin{array}{c}\text { Coeficiente } \\
\text { Padronizado } \\
\text { (Beta) }\end{array}$} & \multicolumn{2}{|c|}{ Antes Padronização (Z-Score) } & \multicolumn{2}{|c|}{ Depois Padronização (Z-Score } \\
\hline & & & & & B & $\begin{array}{l}\text { Erro padrão } \\
\text { da estimativa }\end{array}$ & B & $\begin{array}{c}\text { Erro padrão } \\
\text { da estimativa }\end{array}$ \\
\hline $\begin{array}{l}\text { 18i) Há um bom número } \\
\text { de pessoas preparadas } \\
\text { para desempenhar a } \\
\text { função de gerente de } \\
\text { projeto }\end{array}$ & \multirow{5}{*}{1} & \multirow{5}{*}{1} & \multirow{5}{*}{0.99} & 0.5 & $\begin{array}{c}4.92 \text { (const.) } \\
0.45 \text { (var.) }\end{array}$ & \multirow{5}{*}{0.12} & $\begin{array}{c}0.15 \text { (const.) } \\
0.31 \text { (var.) }\end{array}$ & \multirow{5}{*}{0.06} \\
\hline $\begin{array}{l}\text { 18b) A organização } \\
\text { sabe utilizar as técnicas } \\
\text { de gestão de projetos }\end{array}$ & & & & 0.95 & 1.26 (var. 2) & & 0.64 (var. 2) & \\
\hline $\begin{array}{l}\text { 180) Há envolvimento e } \\
\text { comprometimento da } \\
\text { equipe para o alcance } \\
\text { dos resultados dos } \\
\text { projetos. }\end{array}$ & & & & 0.61 & $-0.71($ var. 3) & & -0.34 (var. 3) & \\
\hline $\begin{array}{l}\text { 06. Os projetos são } \\
\text { organizados em um } \\
\text { portifólio? }\end{array}$ & & & & -0.22 & $-0.20($ var. 4$)$ & & -0.19 (var. 4) & \\
\hline $\begin{array}{l}\text { 08. Os projetos são } \\
\text { classificados }\end{array}$ & & & & -0.13 & -0.12 (var. 5) & & -0.09 (var. 5) & \\
\hline
\end{tabular}


Ao evidenciar somente o questionário de maturidade em gerenciamento de projetos, ambas as variáveis dependentes 'percentual das estratégias implementadas' e 'satisfação com a implementação' foram cobertas por somente uma variável, 'gerenciamento do escopo'.

A partir da regressão, percebeu-se que o modelo, cuja variável dependente é o percentual das estratégias implementadas, é explicada com o ' $R$ ' ajustado de 0,44. O erro padrão da estimativa é de $16.38 \%$. Com isso, a equação ficou:

$$
Y=14.84+24.59\left(X_{1}\right) \pm 16.38 e
$$

Tabela 65 - Regressão da variável percentual das estratégias somente no questionário de maturidade

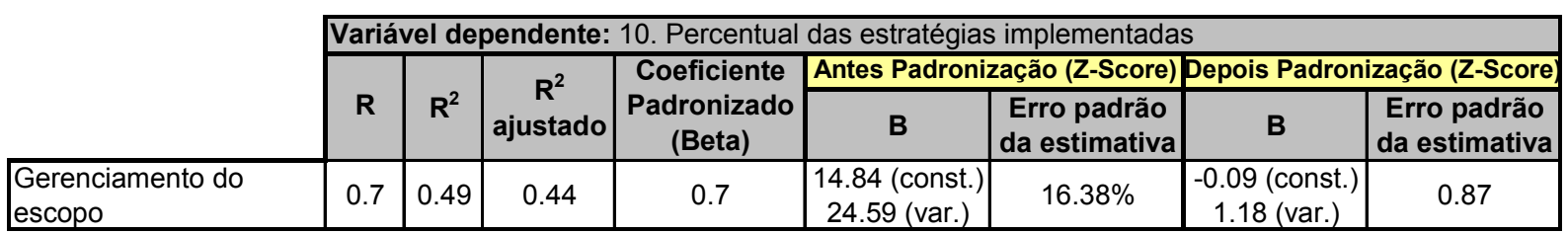

Já no modelo em que a variável dependente é a 'satisfação com a implementação', o ' $\mathrm{R}^{2}$ ' ajustado ficou mais alto (0.59).

A equação resultante da regressão múltipla é:

$$
Y=0.33+3\left(X_{1}\right) \pm 1.96 e
$$

Tabela 66 - Regressão da variável satisfação com a implementação somente no questionário de

\begin{tabular}{|c|c|c|c|c|c|c|c|c|}
\hline & \multicolumn{8}{|c|}{ Variável dependente: 21 .Satisfação com a implementação } \\
\hline & \multirow[b]{2}{*}{$\mathbf{R}$} & \multirow[b]{2}{*}{$\mathbf{R}^{2}$} & \multirow[b]{2}{*}{$\begin{array}{c}\mathbf{R}^{2} \\
\text { ajustado }\end{array}$} & \multirow{2}{*}{\begin{tabular}{|c|} 
Coeficiente \\
Padronizado \\
(Beta)
\end{tabular}} & \multicolumn{2}{|c|}{ Antes Padronização (Z-Score) } & \multicolumn{2}{|c|}{ Depois Padronização (Z-Score } \\
\hline & & & & & B & $\begin{array}{c}\text { Erro padrão } \\
\text { da estimativa }\end{array}$ & B & $\begin{array}{l}\text { Erro padrão } \\
\text { da estimativa }\end{array}$ \\
\hline $\begin{array}{l}\text { Gerenciamento do } \\
\text { escopo }\end{array}$ & 0.79 & 0.63 & 0.59 & 0.79 & $\begin{array}{c}0.33 \text { (const.) } \\
3 \text { (var.) }\end{array}$ & 1.50 & $\begin{array}{c}0.31 \text { (const.) } \\
1.35 \text { (var.) }\end{array}$ & 0.75 \\
\hline
\end{tabular}
maturidade 


\subsection{Sumário do capítulo}

Ao consolidar as três análises realizadas neste capítulo, a descritiva, a correlação e a regressão linear múltipla, identificou-se que há conceitos, ferramentas e técnicas que podem impactar mais o sucesso e o percentual de implementação de estratégias do que outras. Assim, algumas teorias foram corroboradas e outras não, tanto de gestão estratégica quanto de projetos.

Essa consolidação está dividida em quatro partes. A primeira promoveu uma visão geral das principais técnicas e conceitos de estratégia e projetos. A segunda apresentou algumas técnicas de gerenciamento de projetos que só podiam ser analisadas de forma descritiva, não se aplicando as técnicas estatísticas. E a terceira estava focada no questionário de avaliação do nível de gerenciamento de projetos nas organizações. E o último bloco focou na escala de maturidade em gerenciamento de projetos.

\footnotetext{
Para as tabelas-sumário desta pesquisa, utilizou-se da seguinte legenda:

Legenda da tabela

alta correlação ou diferença percentual alta

- média-alta correlação ou diferença percentual média-alta

(1) média correlação ou diferença percentual média

baixa-média correlação ou diferença percentual baixa-média

sem correlação ou negativa. Diferença percentual nula

x variável presente na regressão linear múltipla
}

Dentro da primeira parte, verificou-se que o envolvimento e comprometimento das pessoas foi a variável de maior impacto na implementação de estratégias. Esse resultado comprovou as teorias de Lorange (1982), Sobanski (1996), Aaltonen e Ikavalko (2002), Linton (2002) e Dobni (2003), Freedman (2003), Sterling (2003).

Havia a percepção de que essa variável realmente teria um impacto grande no sucesso da implementação. A premissa era de que sem o comprometimento das 
pessoas, a empresa não conseguiria conduzir seus planos com agilidade, não atingindo os resultados esperados.

O segundo ponto de maior impacto foi a institucionalização das melhores práticas. O resultado dessa variável possivelmente é explicado em decorrência da procura da empresa em ser uma referência e posicionar-se à frente de seus concorrentes, apresentando assim, resultados acima da média. Essa preocupação faz com que a empresa sempre esteja na vanguarda das práticas de gestão, resultando na melhoria da implementação.

A clareza das responsabilidades foi o terceiro ponto de maior impacto no sucesso da implementação de estratégias. Esta ocorre quando há comunicação do direcionamento da empresa, bem como o reforço através dos diversos sistemas organizacionais, incluindo os de recursos humanos, liderança, etc. Além disso, reforça-se a teoria de que, quanto mais o funcionário sabe de suas responsabilidades, melhor serão os seus esforços em prol do direcionamento da empresa.

O desdobramento das estratégias, ou seja, o cascateamento, apresentado anteriormente na conceituação por meio dos modelos de Turner (1999), Gaddie (2002), Archibald (2003), também tem impacto importante na implementação. Esse processo operacionaliza as estratégias, que muitas vezes estão em um nível muito macro.

Os incentivos e recompensas sempre apareceram na literatura de Recursos Humanos como um instrumento de estímulo aos funcionários para atuarem em prol da empresa e de seu direcionamento. Nas empresas brasileiras esse instrumento de estímulo está muito presente, principalmente, por poder interligar as estratégias de negócios e a remuneração variável do funcionário.

E o sexto ponto mais impactante no processo foi o da coordenação das atividades de implementação, isto é, a gestão do projeto. Assim, nesse ponto a gestão de projetos é importante, já que é necessário ter uma pessoa ou um grupo de pessoas que esteja acompanhando o andamento das ações derivadas da estratégia, 
tanto no escopo das atividades quanto no cronograma definido no planejamento estratégico.

Por outro lado, ficou comprovado que algumas teorias, conceitos e ferramentas não auxiliam ou pouco contribuem para o processo de implementação de estratégias. A disciplina de acompanhamento ou execução proferida por Bossidy e Charam (2002) não tem impacto positivo, de acordo com a pesquisa de campo conduzida. E não há correlação entre a freqüência de acompanhamento e o sucesso na implementação de estratégias. Fato que também ocorre com os projetos agrupados em programas. Na visão dos executivos entrevistados, agrupar os projetos em programas não auxilia na implementação de estratégias.

Um dos pontos mais difundido por autores da área de gerenciamento de projetos é a análise das partes interessadas (stakeholders). Não foi verificada através desta pesquisa nenhuma ligação linear entre esse tipo de análise e o percentual das estratégias implementadas.

A avaliação do ambiente interno e externo é muito utilizada pelas empresas. Com isso, constatou-se que esse tipo de análise não tem impacto, pois independente do grau de sucesso na implementação a análise é realizada.

De acordo com a pesquisa de campo, a mudança de cultura também não foi identificada como tendo impacto positivo linear com o sucesso na implementação de estratégias. Segundo as empresas pesquisadas, é muito difícil mudar a cultura para que haja uma maior facilidade na implementação de estratégias. Muitas empresas afirmaram que é melhor verificar a aplicabilidade das estratégias frente à cultura organizacional do que impor uma mudança de cultura, já que esse tipo de processo é muito lento. 
Tabela 67 - Tabela sumário das ferramentas, práticas, conceitos e técnicas de gestão estratégica e de projetos e seus resultados nas análises descritiva, correlação e regressão

\begin{tabular}{|c|c|c|c|c|c|c|}
\hline \multirow[t]{2}{*}{ Ferramentas, práticas, conceitos, técnicas } & \multicolumn{3}{|c|}{$\begin{array}{l}\text { 10. Percentual das estratégias } \\
\text { implementadas }\end{array}$} & \multicolumn{3}{|c|}{$\begin{array}{l}\text { 21. Satisfação com a } \\
\text { implementação de estratégias }\end{array}$} \\
\hline & Descritiva & Correlaçäo & Regressão & Descritiva & Correlação & Regressão \\
\hline Envolvimento e comprometimento das pessoas & $\bullet$ & $\bullet$ & $\mathrm{x}$ & $\bullet$ & $\bullet$ & $\mathrm{x}$ \\
\hline Institucionalizaçẫo das melhores práticas & 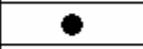 & 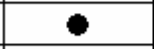 & & 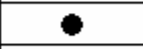 & 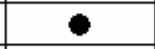 & \\
\hline Clareza das responsabilidades dos funcionários & 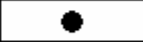 & a & & 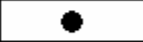 & 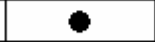 & \\
\hline $\begin{array}{l}\text { Desdobramento das estratégias em projetos e açôes / } \\
\text { cascateamento da estratégia }\end{array}$ & 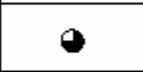 & $\bullet$ & & $\bullet$ & $\bullet$ & \\
\hline Incentivos e recompensas & 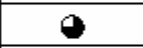 & 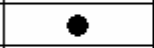 & & $\bullet$ & ( & \\
\hline Gestẫo/coordenaçẫo da implantaçẫo/mudança & ( & $\mathbf{O}$ & & 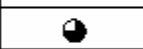 & $\bullet$ & $\mathrm{x}$ \\
\hline Criaçẫo das competências para a implementação & 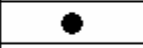 & $\mathbf{1}$ & & 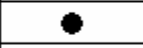 & ( & \\
\hline Orçamento e alocaçẫo de recursos & 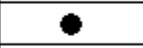 & ( & & 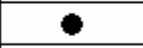 & 0 & \\
\hline Recursos Humanos & O & $\boldsymbol{\theta}$ & & $\boldsymbol{\theta}$ & () & \\
\hline Estabelecimento de sistemas de informação & ( & 0 & & $\bullet$ & ( & \\
\hline Estrutura organizacional & 0 & 0 & & $\bullet$ & 0 & $\mathrm{x}$ \\
\hline Modelo/orientaçẫo para a execuçẫo & o & & & 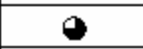 & & \\
\hline Clareza das responsabilidades dos executivos & a & ( & & - & 0 & \\
\hline Projetos entregues dentro do prazo, custo e qualidade & 0 & 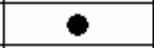 & & - & 0 & \\
\hline Estabelecimento de políticas, procedimentos e processos & ( & 0 & & $\boldsymbol{\theta}$ & 3 & \\
\hline $\begin{array}{l}\begin{array}{l}\text { Estabelecimento e compreensão do direcionamento } \\
\text { (visẫo) }\end{array} \\
\text { (a) }\end{array}$ & 0 & - & & 0 & - & \\
\hline Liçỗes aprendidas & - & 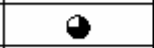 & & 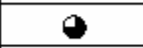 & 0 & \\
\hline Balanced Scorecard / indicadores & 0 & 0 & & 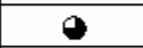 & 0 & $\mathrm{x}$ \\
\hline Classificaçẫo, priorizaçẫo, seleçẫo de projetos & 0 & o & & - & ( & \\
\hline $\begin{array}{l}\text { Alinhamento das áreas do conhecimento com estratégias } \\
\text { genéricas }\end{array}$ & $\bullet$ & & & O & & \\
\hline Modelo de implementaçẫo & ( & & & ( & & \\
\hline Escritório de gerenciamento de projetos (PMO) & ( & & & (1) & & \\
\hline Portifólio de Projetos & 0 & 0 & & 0 & 0 & $\mathrm{x}$ \\
\hline Mudança cultural & - & 0 & & - & 0 & \\
\hline Avaliaçẫo do ambiente interno e externo & - & 0 & & - & 0 & \\
\hline Identificação/análise das partes interessadas & 0 & & & 0 & & \\
\hline Projetos agrupados em programas & 0 & 0 & & 0 & 0 & \\
\hline Disciplina de acompanhamento & 0 & 0 & & 0 & 0 & \\
\hline
\end{tabular}

Um dos pontos focados são as técnicas de gerenciamento de projetos. Algumas dessas técnicas também são utilizadas na área de produção. Verificou-se que as técnicas e ferramentas de gerenciamento de projetos que mais impactam na implementação de estratégias são: pontuação de projetos, fluxograma, mapa da qualidade e Gráfico de Pareto. Não houve nenhum grande destaque positivo entre elas, já que não teve nenhuma técnica que se diferenciasse na análise descritiva.

Por outro lado, na amostra pesquisada observou-se que três técnicas não demonstraram ter impacto positivo e linear no sucesso da implementação, sendo elas: árvore de decisão, EVA e inventário de habilidades. Nenhuma delas 
apresentou uma diferença positiva entre a sua utilização ou não na empresa e o índice de sucesso na implementação obtido.

Tabela 68 - Tabela sumário das técnicas de gestão de projetos e seus resultados nas análises descritivas

\begin{tabular}{|l|c|c|}
\multirow{2}{*}{$\begin{array}{c}\text { Técnicas de Gestão de } \\
\text { Projetos }\end{array}$} & $\begin{array}{l}\text { 10. Percentual das } \\
\text { estratégias } \\
\text { implementadas }\end{array}$ & $\begin{array}{l}\text { 21. Satisfação com } \\
\text { a implementação } \\
\text { de estratégias }\end{array}$ \\
\cline { 2 - 3 } & Descritiva & Descritiva \\
\hline Pontuaçẫo de projetos & - & 0 \\
\hline Fluxograma & - & 0 \\
\hline Mapa da qualidade & - & 0 \\
\hline Gráfico de Pareto & 0 & 0 \\
\hline Diagrama de causa-efeito & - & 0 \\
\hline Análise de Monte Carlo & 0 & 0 \\
\hline Árvore de decisẫo & 0 & 0 \\
\hline Inventário de habilidades & 0 & 0 \\
\hline EVA & 0 & \\
\hline
\end{tabular}

Além de algumas técnicas de gerenciamento de projetos auxiliarem na implementação de estratégias, a pesquisa procurou identificar como as práticas e o estágio/nível de gerenciamento de projetos podem impactar na execução das estratégias. Foram evidenciadas pelo estudo que algumas práticas têm alto impacto na implementação, sendo elas:

- Há uma seqüência bem definida de procedimentos e pontos de decisão para lidar com o ciclo de vida do projeto;

- Há um bom número de pessoas preparadas para desempenhar a função de gerente de projeto;

- Há conhecimento, habilidades e atitudes adequadas do gerente de projetos;

- Institucionalização das melhores práticas em gerenciamento de projetos;

- A organização sabe utilizar as técnicas de gestão de projetos;

- Há informações de qualidade para o planejamento, acompanhamento e controle dos projetos. 
Entretanto, foi possível perceber que há quatro práticas que não foram evidenciadas pela correlação e regressão linear significativa e nem uma diferença relevante para o processo de implementação, sendo elas:

- Há envolvimento e comprometimento da equipe para o alcance dos resultados dos projetos;

- As equipes de projetos reúnem-se regularmente para planejar, executar e controlar suas atividades;

- A maioria das pessoas sabe distinguir projetos de atividades que não são projetos;

- Há ferramentas e sistemas de informações orientadas ao gerenciamento de projetos.

Das quatro práticas listadas, três são muito difundidas nas empresas, o que provavelmente aponta que essas técnicas presentes ou não, podem não fazer a diferença no momento da execução das estratégias. Uma inferência que pode ser feita é a de que ter um sistema de informações não é mais um diferencial, basta fazer uma aquisição e essa prática já é superada.

Com o crescimento verificado da área de gerenciamento de projetos nos últimos anos, cada vez há menos confusão entre o que não é projeto e o que é.

Todas as empresas realizam, mas com frequências diferenciadas, o planejamento e controle periódico do projeto. Notou-se que não há impacto significativo para o sucesso da implementação dessa prática. 
Tabela 69 - Tabela sumário da avaliação de gerenciamento de projetos e seus resultados nas análises descritiva, correlação e regressão

\begin{tabular}{|c|c|c|c|c|c|c|}
\hline \multirow{2}{*}{ Avaliação de Gerenciamento de Projetos } & \multicolumn{3}{|c|}{ 10. Percentual das estratégias } & \multicolumn{3}{|c|}{ 21. Satisfação com a } \\
\hline & Descritiva & Correlação & Regressão & Descritiva & Correlação & Regressão \\
\hline $\begin{array}{l}\text { j) Há uma seqüência bem definida de procedimentos e } \\
\text { pontos de decisấo para lidar com o ciclo de vida do } \\
\text { projeto }\end{array}$ & $\bullet$ & $\bullet$ & & $\bullet$ & $\bullet$ & \\
\hline $\begin{array}{l}\text { i) Há um bom número de pessoas preparadas para } \\
\text { desempenhar a funçẫo de gerente de projeto }\end{array}$ & $\bullet$ & $\bullet$ & & $\bullet$ & $\boldsymbol{\bullet}$ & $\mathrm{x}$ \\
\hline $\begin{array}{l}\text { i) Há conhecimento, habilidades e atitudes adequadas do } \\
\text { gerente de projetos. }\end{array}$ & $\bullet$ & $\bullet$ & $\mathrm{x}$ & ( & $\bullet$ & \\
\hline $\begin{array}{l}\text { V) Institucionalização das melhores práticas em } \\
\text { gerenciamento de projetos }\end{array}$ & $\bullet$ & $\bullet$ & & $\bullet$ & $\bullet$ & \\
\hline $\begin{array}{l}\text { b) A organizaçẫo sabe utilizar as técnicas de gestẫo de } \\
\text { projetos }\end{array}$ & $\bullet$ & $\bullet$ & & - & $\bullet$ & $\mathrm{x}$ \\
\hline $\begin{array}{l}\text { y) Há informaçốes de qualidade para o planejamento, } \\
\text { acompanhamento e controle dos projetos }\end{array}$ & $\bullet$ & $\bullet$ & & $\bullet$ & $\boldsymbol{\theta}$ & \\
\hline $\begin{array}{l}\text { s) Há certificaçốes em gerenciamento de projetos } \\
\text { compativeis com as necessidades. }\end{array}$ & $\mathbf{O}$ & 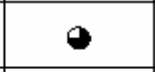 & & $\bullet$ & $\mathbf{O}$ & \\
\hline $\begin{array}{l}\text { d) Muitas pessoas sabem preparar um plano de projeto } \\
\text { na empresa }\end{array}$ & $\bullet$ & $\bullet$ & & 0 & 0 & \\
\hline $\begin{array}{l}\text { u) Os executivos proporcionam o patrocínio efetivo } \\
\text { durante todo o ciclo de vida do projeto }\end{array}$ & - & $\bullet$ & & $\theta$ & 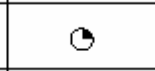 & \\
\hline $\begin{array}{l}\text { g) O executivo principal sabe dizer a qualquer momento, } \\
\text { em que situaçẫo se encontram os projetos em } \\
\text { andamento }\end{array}$ & 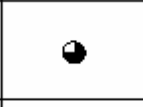 & ( & & ( & 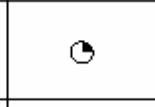 & \\
\hline h) Existe uma função bem definida de gerente de projeto & $\bullet$ & 0 & & $\mathbf{0}$ & 0 & \\
\hline $\begin{array}{l}\text { l) As responsabilidades dos executivos e funcionários das } \\
\text { áreas funcionais, em relaçấo ao gerenciamento de } \\
\text { projetos, estẫo bem definidos }\end{array}$ & ( & ( & & ( & 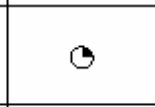 & \\
\hline $\begin{array}{l}\text { n) Há escolha e composiçẫo criteriosa da equipe para } \\
\text { execuçẫo dos projetos. }\end{array}$ & O & $\bullet$ & & 0 & 0 & \\
\hline $\begin{array}{l}\text { z) Ocorre monitoramento e gestẫo efetiva da satisfaçẫo } \\
\text { dos clientes,durante o ciclo de vida do projeto, quanto aos } \\
\text { resultados esperados }\end{array}$ & ( & 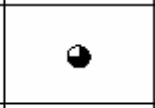 & & 0 & ( & \\
\hline $\begin{array}{l}\text { e) Há procedimentos bem estabelecidos de aprovação de } \\
\text { planos e propostas de projetos }\end{array}$ & - & $\bullet$ & & - & - & \\
\hline $\begin{array}{l}\text { w) Há uso efetivo de indicadores de desempenho de } \\
\text { projetos, durante o ciclo de vida }\end{array}$ & - & $\bullet$ & & - & - & \\
\hline $\begin{array}{l}\text { t) Estrutura organizacional que dê assistência ao gerente } \\
\text { de projetos e a sua equipe (autoridade e poder } \\
\text { necessários) }\end{array}$ & - & 3 & $\mathrm{x}$ & 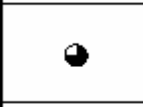 & 0 & \\
\hline $\begin{array}{l}\text { q) Há liderança efetiva do gerente de projetos sobre a } \\
\text { equipe. }\end{array}$ & - & 0 & $\mathrm{x}$ & ( & O & \\
\hline $\begin{array}{l}\text { c) Quando alguém quer preparar uma proposta de projeto } \\
\text { há um modelo padronizado ou uma orientaçấo que todos } \\
\text { conhecem }\end{array}$ & - & (1) & & - & ( & \\
\hline p) Há conhecimento, habilidades e atitudes adequadas da & - & 0 & & 0 & 0 & \\
\hline $\begin{array}{l}\text { f) Nenhum projeto começa sem uma clara definição das } \\
\text { variáveis de desempenho - escopo, qualidade, prazo e } \\
\text { custo }\end{array}$ & 0 & 0 & & 0 & 0 & \\
\hline $\begin{array}{l}\text { o) Há envolvimento e comprometimento da equipe para o } \\
\text { alcance dos resultados dos projetos. }\end{array}$ & - & 0 & & - & 0 & $\mathrm{x}$ \\
\hline $\begin{array}{l}\text { k) As equipes de projetos reúnem-se regularmente para } \\
\text { planejar, executar e controlar suas atividades }\end{array}$ & - & 0 & & 0 & 0 & \\
\hline $\begin{array}{l}\text { a) A maioria das pessoas sabe distinguir projetos de } \\
\text { atividades que nẫo sắo projetos }\end{array}$ & 0 & 0 & & 0 & 0 & \\
\hline $\begin{array}{l}\text { x) Há ferramentas e sistemas de informaçôes orientadas } \\
\text { ao gerenciamento de projetos }\end{array}$ & - & 0 & & - & 0 & \\
\hline
\end{tabular}

Para finalizar, foram feitas análises com os resultados dos níveis de maturidade. A maturidade de duas áreas do conhecimento obtiveram maiores impactos na implementação, sendo elas: escopo e aquisições. Apenas a maturidade 
da área de escopo apareceu na regressão linear múltipla, bem como obteve correlação siginifica e positiva, mostrando a sua importância.

A maturidade da área de comunicação teve pouco impacto na implementação. Teve apenas uma baixa correlação com o percentual das estratégias implementadas.

Tabela 70 - Tabela sumário da maturidade e seus resultados nas análises descritiva, correlação e regressão

\begin{tabular}{|c|c|c|c|c|c|c|}
\hline \multirow{2}{*}{ Maturidade - Áreas do conhecimento } & \multicolumn{3}{|c|}{ 10. Percentual das estratégias } & \multicolumn{3}{|c|}{ 21. Satisfação com a } \\
\hline & \begin{tabular}{|l|} 
Descritiva \\
\end{tabular} & Correlação & Regressão & Descritiva & Correlaçäo & Regressão \\
\hline Gerenciamento do escopo & $\theta$ & 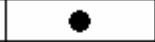 & $\mathrm{x}$ & $\theta$ & 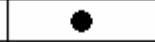 & $\mathrm{x}$ \\
\hline Gerenciamento das aquisiçỗes & 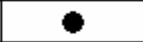 & ( & & $\theta$ & $\theta$ & \\
\hline Gerenciamento do custo & $\theta$ & O & & $\theta$ & 0 & \\
\hline Gerenciamento da qualidade & 0 & ( & & $\bullet$ & 0 & \\
\hline Gerenciamento do tempo & 0 & 0 & & $\bullet$ & 0 & \\
\hline Gerenciamento do risco & 0 & 0 & & $\theta$ & ( & \\
\hline Gerenciamento da integraçẫo & 0 & 0 & & $\mathbf{1}$ & 0 & \\
\hline Gerenciamento dos Recursos Humanos & 0 & 0 & & 0 & 0 & \\
\hline Gerenciamento da comunicaçẫo & 0 & 0 & & 0 & 0 & \\
\hline
\end{tabular}




\section{CONCLUSÕES}

Os resultados obtidos nesta pesquisa permitiram o desenvolvimento de algumas conclusões. Essas conclusões foram delineadas com base na estatística descritiva e nas técnicas de correlação e regressão linear múltipla.

Observou-se que o percentual das estratégias implementadas ficou acima de $70 \%$. Índice bem acima do que é visto internacionalmente, conforme divulgado Kiechel (1982), Charan e Golvin (1999) e Schwarz apud Kállas (2003). Possivelmente esta diferença ocorre devido:

- Atualidade deste estudo. Os demais estudos foram feitos há mais de 5 anos, sendo que os internacionais foram feitos há mais de 10 anos.

- As empresas selecionadas no Brasil estão entre as maiores organizações do país, sendo que o processo de amostragem é diferente do que foi feito pelos demais estudos.

É importante ressaltar que todas as análises de ligação entre duas variáveis só são possíveis de afirmar quando a ocorrência dessa relação for linear. Da mesma forma o oposto ocorre, quando for afirmado que não há correlação/regressão significativa entre duas variáveis, não se tem a afirmação de que não haja essa associação. Só é possível afirmar que na amostra considerada não há evidência de relacionamento linear entre as variáveis.

Por mais que haja a importância de análise da maturidade da organização apresentada na teoria e na pesquisa de campo, não se verificou que a hipótese 1 ocorra. A hipótese previa que a maturidade em projetos seria a variável interveniente que garanteria uma probabilidade de maior sucesso na implementação de estratégias. Obteve-se um alto índice de correlação entre duas áreas do conhecimento ao utilizar-se a escala de maturidade. Além disso, o índice de explicação da variância calculada por meio da regressão linear múltipla, utilizando os níveis de maturidade, foi menor do que se comparado com as demais práticas, conceitos e técnicas pesquisadas individualmente. 
Foram apresentadas evidências muito positivas em relação à hipótese 2 de que algumas ferramentas de gerenciamento estratégico e de projetos têm maior correlação com o sucesso na implementação de estratégias. Os fatores mais importantes para a implementação de estratégia, segundo as estatísticas de correlação, regressão e a diferença significativa na análise descritiva dos dados, são:

- Envolvimento e comprometimento das pessoas;

- Institucionalização das melhores práticas;

- Clareza das responsabilidades dos funcionários na implementação;

- Desdobramento das estratégias em projetos e ações/cascateamento da estratégia;

- Incentivos e recompensas para as pessoas implementarem as estratégias;

- Gestão/coordenação da implantação/mudança;

- Pontuação de projetos;

- Fluxograma;

- Mapa da qualidade;

- Gráfico de Pareto.

Além das técnicas de gerenciamento estratégico e de projetos, há uma série de práticas identificadas na pesquisa que tem alto impacto, segundo as análises descritivas e de correlação e regressão múltipla. As principais práticas de gerenciamento de projetos, segundo os critérios acima, são:

- Há uma seqüência bem definida de procedimentos e pontos de decisão para lidar com o ciclo de vida do projeto;

- Há um bom número de pessoas preparadas para desempenhar a função de gerente de projeto;

- Há conhecimento, habilidades e atitudes adequadas do gerente de projetos;

- Institucionalização das melhores práticas em gerenciamento de projetos;

- A organização sabe utilizar as técnicas de gestão de projetos; 
- Há informações de qualidade para o planejamento, acompanhamento e controle.

É possível gerar algumas inferências em relação aos resultados acima apresentados. Tanto o primeiro item quanto o último estão ligados diretamente as funções vitais da gestão de projetos. Assim, o gestor de projetos deve procurar a estratégia da empresa com o planejamento e controle de seus projetos.

O segundo e terceiro itens estão relacionados à qualidade e quantidade dos gestores de projetos. Assim, pensa-se que tendo mais gestores de projetos preparados, maior será o sucesso nos projetos e na implementação de estratégias.

A variável de institucionalização das melhores práticas em gerenciamento de projetos foi um dos pontos com maior destaque no sucesso na implementação de estratégias. Uma inferência possível de realizada é de que as empresas que buscam as melhores práticas sempre estão na vanguarda e já estão num estágio maior de maturidade em termos de gestão. Assim, com a melhor gestão da empresa, os resultados da implementação tendem a ser melhores.

E por último, verificou-se que as organizações que sabiam lidar com as técnicas de gestão de projetos conseguiram obter maior quantidade de estratégias implementadas. Essa relação possivelmente ocorre devido a importância da gestão de projetos na operacionalização das estratégias das empresas, trazendo a disciplina da execução.

A hipótese 3 afirmava que as empresas que têm maior maturidade em gerenciamento de projetos teriam maior sucesso na implementação, fato este que aconteceu principalmente quando foram comparadas as empresas que possuiam mais de $90 \%$ com as que obtiveram menos de $60 \%$ das estratégias implementadas. Essa diferença foi de 0.5 , ou seja, a metade de um nível de maturidade.

Quando comparadas as empresas que possuiam a satisfação com a implementação de estratégias igual ou acima de 8 com aquelas com satisfação entre 1 e 7, verificou-se uma diferença de 0.6 de maturidade. O único ponto a ser 
ressaltado é que há um número menor de respondentes devido ao não preenchimento do questionário de maturidade por algumas empresas.

\subsection{Limitações}

Segundo Campbell e Stanley (1979), os experimentos, se bem-sucedidos, necessitam réplica e validação cruzadas em outros tempos, sob outras condições, antes que se possam incorporar à ciência, antes que possam ser teoricamente interpretados com confiança.

As possíveis limitações desta pesquisa foram:

- Depender da boa vontade dos respondentes, já que cada entrevista durava de 45 minutos a 1 hora e os respondentes tinham agendas comprometidas. Muitas vezes algumas respostas foram perdidas devido à limitação do tempo. Nesse caso, foi solicitado que respondessem posteriormente por email, mas nem sempre os respondentes as enviavam.

- Havia a necessidade de ter dois respondentes por empresa, um da área de planejamento estratégico e outro de gerenciamento de projetos. Muitas vezes um dos respondentes aceitava e o outro não, o que comprometeu algumas respostas e análises estatísticas. Como havia um terceiro questionário, havia a dependência de sua resposta posterior à entrevista.

- A resposta de um executivo contava como sendo a resposta da empresa, o que não necessariamente é a verdade.

- Depender da sinceridade dos respondentes e da percepção da realidade de suas empresas. A percepção do respondente era levada muito em consideração para algumas perguntas. E, nem sempre percepção é realidade e depende muito da característica do respondente.

\subsection{Sugestões para pesquisas futuras}


A partir do que foi elaborado nesta dissertação, considera-se que há alguns tópicos que podem ser melhor explorados, enquanto que alguns novos podem ser desenvolvidos.

A utilização de uma amostra maior e mais diversificada poderia ser interessante em diversos aspectos. Um deles seria obter uma estatística mais rica. $\mathrm{O}$ outro ponto é que poderia se ter uma comparação entre setores diferentes da economia ou uma comparação dos resultados dentro de um mesmo setor. Ao focar um setor específico provavelmente possibilitaria verificar como cada uma das empresas tem atuado na sua indústria.

Outro ponto que poderia ser pesquisado é a segmentação das empresas por porte. Com isso diminuiria a diversidade apresentada, podendo trazer resultados interessantes. Com esse tipo de amostra, algumas relações poderiam ser estudadas com maior detalhamento.

Há melhorias que poderiam ser desencadeadas em estudos futuros. Por exemplo, houve diversas variáveis que não foram construídas para uma análise de correlação e regressão (exemplo: metodologia de implementação, alinhamento da metodologia de gerenciamento de projetos com as estratégias genéricas, as técnicas e ferramentas de gerenciamento de projetos, etc.). Com a mudança de escala esse tipo de análise já seria possível.

Poderiam ser pesquisados ainda aspectos de recursos humanos, liderança, comunicação, recursos, trabalho em equipe, estrutura informal da organização, bem como outros temas que também poderiam impactar a implementação de estratégias, mas que nesta pesquisa restringiu-se a outras variáveis.

Outro aspecto que poderia ser complementado seria a utilização de pesquisas com os funcionários das empresas, para que não houvesse apenas o ponto de vista do executivo como a resposta da organização.

Por último, é possível pesquisar o conteúdo das estratégias e a interligação com as ferramentas de gerenciamento de projetos, trazendo casos práticos. Assim 
será possível analisar estratégias específicas e as soluções encontradas pelas empresas, em conjunto com os projetos interligados.

Pesquisas vindouras nesta área podem ampliar consideravelmente a compreensão sobre o papel do gerenciamento de projetos na implementação de estratégias. Espera-se que este estudo inspire pesquisas futuras na área. 


\section{REFERÊNCIAS}

AL-GHAMDI, S.M. Obstacles to successful implementation of strategic decisions: the British experience. Bradford. European Business Review. Vol.98. Num. 6. 1998. $322 \mathrm{p}$.

ARCHIBALD, R. D. Managing High-Technology Programs and Projects. New York. John Wiley and Sons. 2003. 3296 p.

ARCHIBALD, R. D. What CEOs Must Demand To Achieve Effective Project Management. Disponível em www.pmforum.org/library/papers . Acesso em: 01 de Novembro de 2007. 2003

BEER, M. Developing the Competitive Organization: Interventions and Strategies. American Psychologist. v., 45:2. Fevereiro, 1990.

BEER, M.; EISENSTAT, R. Developing an Organization Capable of Strategy Implementation and Reformulation: A Preliminary Test. In: MOINGEON, B.; EDMONDSON, A. Organizational Learning and Competitive Advantage. London: Sage Publications. 1996. p. 165-184.

BIGELOW, D. Making Strategy Work: How does a CPO help ensure its organization's strategies are executed? Disponível em www.chiefprojectofficer.com/article/84 . Acesso em: 20 de Agosto de 2006.

BONOMA, T. V. The Marketing Edge. New York: The Free Press. 1985. 241 p.

BOSSIDY, L; CHARAN, R. Execução. São Paulo. Editora Campus. 2002.

CAMPBELL, D.T.; STANLEY, J.C. Delineamentos experimentais e quaseexperimentais de pesquisa. São Paulo. EPU. 1979.

CASTRO, L. R. K. OSM - Office of Strategic Management e PMO - Project Management Office: Uma questão de estratégia! Mundo Project Management. Curitiba, edição6, Dezembro - Janeiro, 2006. 
CAULLIRAUX, H.M.; VALADARES, A. Aplicação da Gestão de Projetos para o Gerenciamento de Incubadoras de Empresas. Trabalho apresentado a XV Seminário de Parques Tecnológicos e Incubadoras de Empresas, Curitiba, 2005.

CENTER FOR BUSINESS PRACTICES REPORT. Project Management Maturity Benchmark. Disponível em http://season2.pmpcafe.com/bbs . 2002. Acesso em: 10 de Janeiro de 2007.

CHANDLER, A. Strategy and Structure. Cambridge. MIT Press. 1962.

CHAPMAN, A. Strategy implementation and realisation. Disponível em www.businessballs.com/businessstrategyimplementation.htm . Acesso em: 26 de Fevereiro de 2007.

CHARAN, R.; GOLVIN, G. Why CEO's fail. Fortune. v. 139, n. 12, p. 69-78, 21 de junho de 1999.

CHINOOK SOLUTIONS. Business Leaders Report - Executive Decision-Making. Disponível em http://www.chinooksolutions.com/docs. Acesso em: 20 de julho de 2006.

COLLINS, J. C., PORRAS, J. I. Feitas para durar. Rio de Janeiro. Rocco. 1995. 408p.

COOPER, D. R., SCHINDLER, P. S. Métodos de pesquisa em administração. Porto Alegre. Bookman. 2003. 640 p.

CRAWFORD, J. K. The strategic project office. Nova lorque. Marcel Dekker. 2002. $367 \mathrm{p}$.

CRAWFORD, L.; HOBBS, B.; TURNER, J. R. Aligning capability with strategy: categorizing projects to do the right projects and to do them right. Project management journal. Sylva. v. 37, n. 2, p. 38-51, June 2005.

CRESWELL, J. W. Research Design - qualitative, quantitative and mixed methods approaches. 2nd ed., London. Sage. 2003. 
DIETRICH, P.; LEHTONEN, P. Successful management of strategic intentions through multiple projects - Reflections from empirical study. International Journal of Project Management. v. 23, n. 5, p. 386-391, Julho, 2005.

ECONOMIST INTELLIGENCE UNIT. Strategy execution: achieving operational excellence. Disponível em www.eiu.com . Acesso em: 16 de Maio de 2007.

ERNST \& YOUNG. Measure that matter. Ernst \& Young Center of Business Innovation. Boston. 1998.

FERREIRA, A. B. H. Novo Dicionário da Língua Portuguesa. Editora Nova Fronteira. Rio de Janeiro. 2002.

FISCHMANN, A. A. Implementação de estratégias: identificação e análise de problemas. São Paulo. 1987. Tese (Livre-Docência) - Faculdade de Economia, Administração e Contabilidade, Universidade de São Paulo. São Paulo. 1987

FLEURY, A. Metodologia científica e o contexto da construção de um modelo. Escola Politécnica. 2006. Anotação de aula.

FORZA, C. Survey research in operations management: A process-based perspective. International Journal of Operations \& Production Management; v. 22, n. 2, p. 152-194. 2002

FOSTER, R. Inovação: A vantagem do atacante. $3^{\circ}$ edição. Editora Nova Cultural Ltda. São Paulo, 1986.

FREEDMAN, M. The Genius is in the implementation. Journal of business strategy. Março/Abril 2003.

GADDIE, S. Effectively Shaping the Strategy of an Organization. Disponível em www.projectcorps.com. Acesso em: 10 de Julho de 2007.

GAJ, L. O estrategista. São Paulo. Pearson Education. 2002. 206 p.

GALPIN, T. J. Making strategy work. San Francisco. Jossey-Bass Inc Publishers. 1997. 234 p. 
GIL, A. C. Como elaborar projetos de pesquisa. São Paulo. Atlas. 2002. 176 p.

GRAY, C. F.; LARSON, E. Project management: The Managerial Process.

Boston. McGraw-Hill Professional. 2005. 589 p.

GRUNDY, T. Strategy implementation and project management. International Journal of Project Management. v. 16, n. 1, p. 43-50, Fevereiro, 1998.

GRUNDY, T. Strategy implementation through project management. Londres. Hawksmere. 2001. 119 p.

GUROWITZ, E. M. The Challenge of Strategy Implementation. Version 1.0. Disponível em: www.gurowitz.com/articles. Acesso em 31 de agosto 2006.

HAIR, J. et al. Fundamentos de métodos de pesquisa em administração. Porto Alegre. Bookman. 2005. 471 p.

HAUC, A.; KOVAC, J. Project management in strategy implementation experiences in Slovenia. International Journal of Project Management. v. 18, n. 1, p. 61-67, Fevereiro, 2000.

HREBINIAK, L. G. Fazendo a estratégia funcionar: o caminho para uma execução bem-sucedida. Porto Alegre. Bookman. 2005. 368 p.

HREBINIAK, L. G. Strategies That "work". KnowledgeLeadership. Disponível em www.thomasgroup.com/Downloads/hrebiniak_interview.pdf. Acesso em 13 de março de 2007.

HUSSEY, D. Implementation challenge. Chichester. Wiley. 1996. 306 p.

JOHNSON, L. K. Execute Your Strategy -Without Killing It. Harvard management update. December. 2004. 3 p.

JOHNSON, R. B.; ONWUEGBUZIE, A. J. Mixed Methods Research: A Research Paradigm Whose Time Has Come. Educational Researcher. v. 33, n. 7, p. 14-26, Outubro, 2004. 
JOYCE, W.; NOHRIA, N.; ROBERSON, B. What (really) works. New York. Harper Business. 2003. 320 p.

JUNG, C. G. Modern Man in Search of a Soul. London. Kegan Paul Trench Trubner. 1955. 252p

KALLÁS, D. Balanced Scorecard: Aplicação e Impactos - Um estudo de caso com jogos de empresa. 2003. Dissertação (Mestrado em Administração).

Universidade de São Paulo. São Paulo. 2003.

KAPLAN, S R. NORTON, P. D. A estratégia em ação: Balanced Scorecard. 4 ed. Rio de Janeiro. Campus. 1991. 344p.

KERZNER, H. Applied project management: best practices on implementation. New York. John Wiley \& Sons. 2000. 544 p.

Strategic Planning for Project Management Using a Project

Management Maturity Model. New York. John Wiley \& Sons. 2001. 232 p.

KIECHEL, W. Corporate Strategists under fire. Fortune. v.38, p.34-39. 1982

KRONMEYER FILHO, O.R.; VALANDRO, A. A. Transformando estratégias empresariais em resultados com balanced scorecard e gerência por projetos. Trabalho apresentado a XXIV Encontro Nacional de Engenharia de Produção. 2004. Florianópolis.

KRONMEYER FILHO, O.R.; KLIENMANN, F. J. A viabilização da gestão de projetos integrada com a gestão da estratégia organizacional. Trabalho apresentado a XXIII Encontro Nacional de Engenharia de Produção. 2003. Ouro Preto.

LEITE, M. M. Pressupostos para Implantação de Estratégias de Relacionamento com os Clientes em Pequenas e Médias Organizações: uma Abordagem baseada em Gerenciamento de Projetos. 2004. 324 p. Tese de doutorado Universidade Federal de Santa Catarina. Florianópolis, junho de 2004.

LESSA, L. Qual o papel do PMO (Project Management Office) nas Estruturas Organizacionais. Version 1.0. Disponível em: http://www.pmimg.org.br/artigos/. Acesso em: 14 de maio de 2007. 
LINGLE, J.; SCHIEMANN, W. IS data scatter subverting your strategy. Management Review. v. 83, n. 5, p. 53-56, 1994.

LINTON, J.D. Implementation research: state-of-the-art and future directions. Technovation. v. 22, n. 1, p. 65-79, 2002.

LOCK, D. The nature and purpose of project management. In: project management handbook. 1987

LORANGE, P. (ed). Implementation of Strategic Planning. Englewood Cliffs. Prentice Hall. 1982. 231 p.

LSM-International. LSM-International. Enterprise improvement platform (EIP1). Disponível em: http://www.lsmzone.com/Default.htm Acesso em: 15 de Maio de 2002. 2001

MANKINS, M. C.; STEELE, R. Turning great strategy into great performance. harvard business review. p. $65-72$, July-august, 2005.

MATIOLLI FILHO, A. A Construção de BSC a partir do Mapa Estratégico. In Seminário Sistemas de Gestão. Vila Velha. 2002

MAXIMIANO, A. C. A. Administração de Projetos. São Paulo. Atlas. 2002

MAZZON, J.A. Formulação de um modelo de avaliação e comparação de modelos em marketing. São Paulo. 1978.Dissertação (Mestrado em Administração) - Departamento de Administração da Faculdade de Economia, Administração e Contabilidade da Universidade de São Paulo. São Paulo. 1978

MINTZBERG, H. \& etalli. Safari de Estratégia: um roteiro pela selva do planejamento. Porto Alegre. Bookman. 2000.

MORRIS, P.W.G.; JAMIESON, H.A.Translating Corporate Strategy into Project Strategy. Newton Square, PA: Project Management Institute. 2003.

Moving from corporate strategy to project strategy. Project management journal. v. 36, n. 4, December. 2005. 
NOBLE, C.H.; MOKWA, M. P. Implementing Marketing Strategies: Developing and Testing a Managerial Theory. Journal of Marketing. v. 63, No. 4. p. 57-73. Outubro, 1999.

OKUMUS, F. A framework to implement strategies in organizations. Management Decision. p. 871-882, v.41, n. 9. 2003.

OKUMUS, F. Towards a strategy implementation framework. International Journal of Contemporary Hospitality Management. v. 13, n. 7, p. 327-338. 2001

PETERS, T. J.; WATERMAN, R. H. In search of excellence: Lessons from America's best-run companies. Nova lorque. Harper and Row, 1982.

PETTIGREW, A.; WHIPP, R. Managing Change for Competitive Success. Oxford: Blackwell Publishers Ltd. 1991.

PIMENTEL, R. et al. Elementos determinantes da rentabilidade das carteiras de instrumentos financeiros em instituições financeiras brasileiras. Disponível em: http://www.furb.br/congressocont/ Acesso em: 15 de Maio de 2008.

PMBOK. Um guia do conjunto de conhecimentos em gerenciamento de projetos (Guia PMBOK). 3ª. Edição. 2004.

PMI BRASIL. Estudo de Benchmarking em Gerenciamento de Projetos Brasil 2007. Disponível em: http://www.pmiba.org.br/modulos/downloads/downloads.asp Acesso em: 01 de Junho de 2008.

PORTER, M.; MONTGOMERY, C. A. Estratégia: a busca de vantagem competitiva. Rio de Janeiro. Campus, 1998.

RICHARDSON, R. J. et al. Observação. In: . Pesquisa Social: métodos e técnicas. 3 ed. rev. ampl. São Paulo. Atlas. 1999. p. 259-264.

RIGBY, D. Management tools and techniques: A survey. California Management Review. P 139-160, v. 43(2). 2001

ROTHSCHILD, P.; DUGGAL, J.; BALABAN, R. Strategic Planning Redux. Mercer Management Journal. p 35-52, v.17, n. 1, 2004. 
RUBENSTEIN, H.; McGRAW, B. Strategic Planning and Project Management: The Key to Successful Implementation. Disponível em:

http://www.refresher.com/!hbbmkey.html. Acesso em: 15 de Abril de 2007.

SECRETARIA DE EDUCAÇÃO DA BAHIA. Sistema organização de matrícula na rede pública. Disponível em: http://www.sec.ba.gov.br/matricula2007. Acesso em: 20 de Junho de 2007.

SHIRAKI, J. Strategy Implementation: Secrets to Success. Lessons Learned From the Most Admired Companies. Apresentação. 2002.

SKIVINGTON, J. E.: DAFT, R. A study of organizational otrganizational 'framework' and 'process' modalities for the implementation of business-level strategic decision. Journal of Management Studies. v. 28. p. 45-68. 1991.

SOBANSKI, A.R. Implementação de Estratégias: Estudo Exploratório de Alguns Fatores Críticos". 1996. Dissertação (Mestrado em Administração) - Universidade de São Paulo. São Paulo. 1996.

SRIVANNABOON, S.; MILOSEVIC, D. Z. A two-way influence between business strategy and project management. International Journal of Project Management. v. 24, n. 6, p. 493-505. 2006.

STERLING, J. Translating strategy into effective implementation: dispelling the myths and highlighting what works. Strategy \& Leadership. v. 31, n. 3, p. 27-34. 2003.

STRATEGIS. Departamento de indústria - Canadá. Disponível em:

http://strategis.ic.gc.ca/pics/sv/if.pdf. Acesso em: 15 de Abril de 2007.

THOMAS, J. et al. Selling Project Management to Senior Executives. Project Management Institute Inc., Newtown Square. 2002. 168 p.

TURNER, J. R. The handbook of project-based management. Londres. McGrawHill. 1999. 540 p.

VILLACHICA, S. W.; STONE, D. L.; ENDICOTT, J. Project alignment: ensuring successful development and implementation. Performance Improvement; v. 43, n. 10, Novembro - Dezembro, 2004. 
WHEELEN, T. L.; HUNGER, J. D. Strategic Management and Business Policy. 8 ed. Upper Saddle River. Prentice Hall. 2002. 392 p.

WIKIPÉDIA. Coeficiente de correlação de Pearson. Disponível em: http://pt.wikipedia.org . Acesso em: 4 de junho de 2007.

WOOLRIDGE, B. FLOYD, S.W. The Strategy Process: Middle Management Involvement and Organizational Performance. Strategic Management Journal. v. 11: $p$ 231-241. 1990 
ANEXOS

ANEXO A - QUESTIONÁRIOS 


\section{ANEXO A - QUESTIONÁRIO - ESTRATÉGIA}

\begin{tabular}{|l|l|l|l|l|}
\hline $\begin{array}{l}\text { Dados da } \\
\text { Empresa }\end{array}$ & Data da coleta & & Telefone \\
\hline
\end{tabular}

\begin{tabular}{|c|c|c|c|c|c|c|}
\hline III. Email & & \multicolumn{2}{|l|}{ 'IV. Ocupação" } & & & \\
\hline $\begin{array}{l}\text { 01. A organização tem um processo de } \\
\text { planejamento estratégico formal? Qual é } \\
\text { o nível de formalidade do processo? }\end{array}$ & $\begin{array}{l}01 \square \text { Sim, sendo } \\
\text { extremamente formal }\end{array}$ & \multicolumn{2}{|c|}{$\begin{array}{l}02 \square \text { Sim, sendo boa } \\
\text { parte formal }\end{array}$} & \multicolumn{2}{|c|}{ pouco formal } & $04 \square$ Não tem \\
\hline $\begin{array}{l}\text { 02. A empresa está satisfeita com relação } \\
\text { à ferramenta de planejamento }\end{array}$ & $\begin{array}{l}\text { 01. Extremamente } \\
\text { Insatisfeito } \\
\square\end{array}$ & $\begin{array}{l}\text { 02. Insatisfeito } \\
\qquad \square\end{array}$ & 03. $\mathrm{Re}$ & ular & $\begin{array}{l}\text { 04. Satisfeito } \\
\square\end{array}$ & $\begin{array}{l}\text { 05. Extremamente } \\
\text { Satisfeito } \\
\square\end{array}$ \\
\hline
\end{tabular}

03. Como que é o processo de planejamento estratégico da empresa?

04. A empresa tem uma metodologia de

$01 \square \mathrm{Sim}$

$02 \square$ Não implementação de estratégias?

05. Como que é o processo de implementação do planejamento estratégico da empresa?

06. O planejamento estratégico é
implementado através de uma série de
projetos ou iniciativas?
07. O quanto a visão é compreendida
dentro da organização?
08. Caso ela não seja compreendida e
internalizada por todos, por favor, qual(is)
é(são) a(s) principal(ais) razão(ões)?
(múltipla escolha)
$01 \square$ Não está atualizada

06. O planejamento estratégico é implementado através de uma série de 07. O quanto a visão é compreendida dentro da organização?

08. Caso ela não seja compreendida e internalizada por todos, por favor, qual(is) é(são) a(s) principal(ais) razão(ões)?

01 $\square$ Não está atualizada

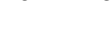




\begin{tabular}{|c|c|c|c|c|}
\hline $\begin{array}{l}\text { 10. Qual é a porcentagem das estratégias } \\
\text { formuladas em sua empresa são } \\
\text { efetivamente implementadas gerando } \\
\text { resultados aparentes }\end{array}$ & $01 \square$ Mais de $90 \%$ & $02 \square$ Entre 60 e $90 \%$ & $03 \square$ Entre 30 e $60 \%$ & $\begin{array}{l}04 \square \text { Menos de } \\
30 \%\end{array}$ \\
\hline
\end{tabular}

11. Quais razões de sucesso na implementação

12. Caso não seja mais do que $90 \%$, quais são as razões do não alcance do sucesso na implementação? (múltipla escolha)

$05 \square$ Houve mudanças no ambiente econômico externo que invalidou a estratégia

$08 \square$ Falta de entendimento da função da estrutura e do projeto organizacionais no processo de execução

$13 \square$ Incapacidade de gerenciar a mudança efetivamente ou separar a resistência interna à mudança

$18 \square$ Falta de sentimentos de pertencer de uma estratégia ou de planos de execução entre os principais funcionários

$23 \square$ Impaciência - as mudanças tem que acontecer o quanto antes. CEOs podem ser inflexíveis e quererem a mudança "para ontem".

$28 \square$ Compartilhamento deficiente ou inadequado de informações entre as pessoas ou unidades de negócios responsáveis pela execução da estratégia

13. Cada executivo tem clareza das suas responsabilidades na implementação da estratégia?
$01 \square$ Teve mudanças dentro da empresa que invalidaram a estratégia

$03 \square$ A responsabilidade pela implementação não estava clara

$06 \square$ Faltou uma maior cobrança das pessoas que eram responsáveis por implementar
$09 \square$ O tempo de implementação foi maior do que o planejado

$14 \square$ Fatores externos incontroláveis

$19 \square$ A alta direção não avalia realisticamente se a empresa consegue executar o plano

$24 \square$ Falta de celebração do sucesso, faltando reconhecimento e recompensa pelo progresso

$29 \square$ Tentar executar uma estratégia que entre em conflito com a estrutura existente de poder

\section{$01 \square$ Está totalmente}

claro os papéis e responsabilidade de implementação cada executivo na
$10 \square$ Os funcionários não tinham as competências necessárias $15 \square$ Liderança inadequada e falta de suporte

\section{$20 \square$ Os principais} formuladores das estratégias não participam ativamente da implementação $25 \square$ Crises e prioridades conflitantes, comprometendo a atenção necessária à implementação (falta disciplina de execução)

$30 \square$ Não ter orientações ou um modelo para orientar os esforços de execução da estratégia

$02 \square \mathrm{Sim}$, em sua maioria
$02 \square$ Não havia incentivos ou as pessoas não estavam motivadas para implementar $04 \square$ Falha na comunicação

$07 \square$ Faltou uma melhor habilidade em gerenciamento de projetos

$11 \square$ Os problemas enfrentados não foram previstos

$2 \square$ As metas não são tão bem compreendidas

$16 \square$ Falha na comunicação vertical

$17 \square$ Recursos financeiros insuficientes para executar a estratégia $22 \square$ O nível gerencial não trabalha em equipe

$26 \square$ Falta de suporte $27 \square$ Os para a execução da estratégia por parte da alta administração funcionários foram inadequados

$31 \square$ Comunicação confusa de responsabilidade e/ou obrigação para decisões ou ações de execução

$03 \square$ Está razoavelmente claro
$32 \square$ Estratégia vaga ou deficiente

$04 \square$ Não está claro as responsabilidades 


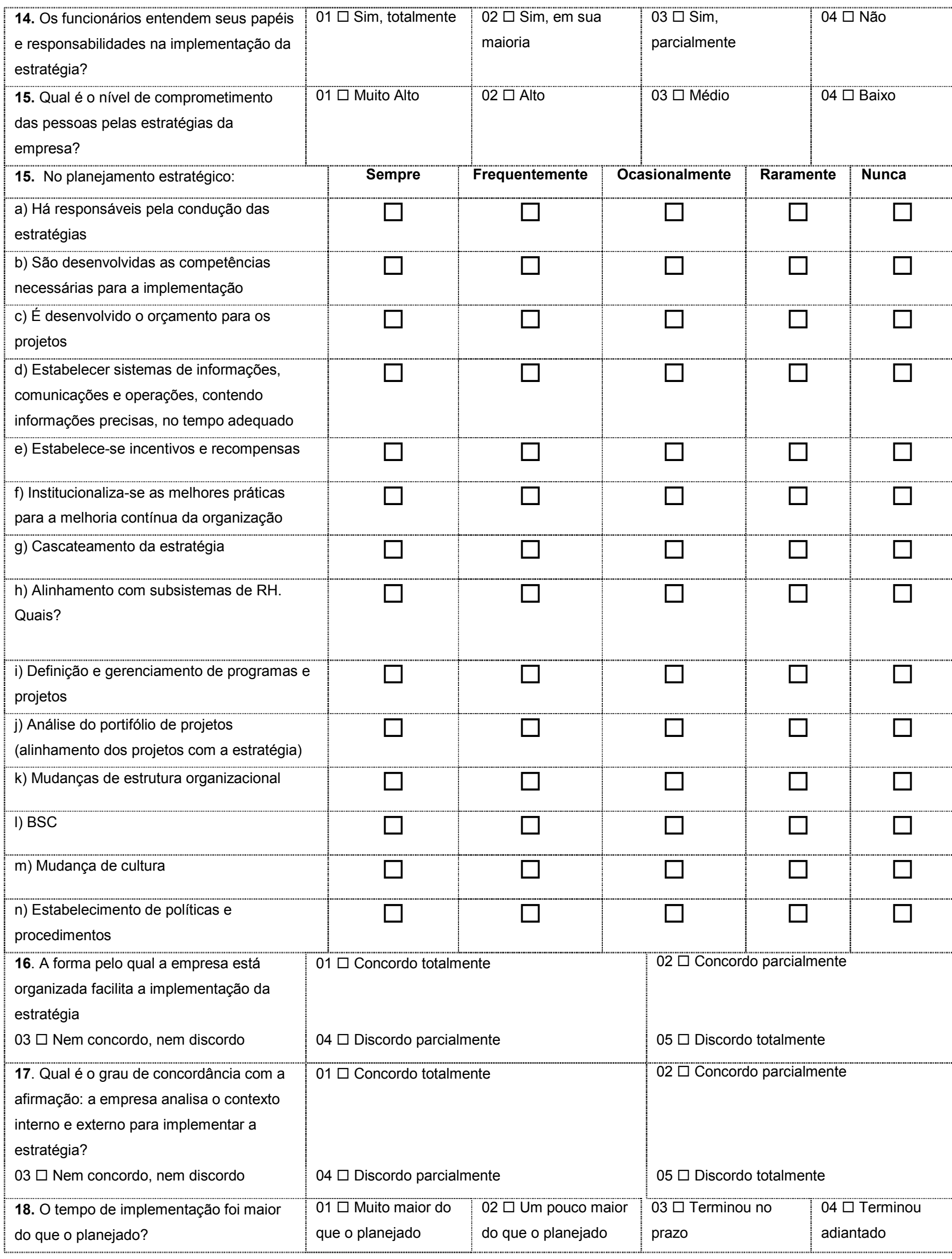


19. As atividades foram coordenadas de forma? Nota 1 (ineficaz) e 5 eficaz 20. Qual é a freqüência que a empresa mensura e acompanha o progresso na implementação da estratégia? $05 \square$ Todo mês

$01 \square$ A cada 2 meses

$03 \square$ A cada 3 meses

$06 \square$ A cada 6 meses
$02 \square$ Uma vez por ano

$04 \square$ Não acompanha

21. Qual é o seu grau de satisfação em relação ao processo de implementação de estratégias da empresa? (nota de 1 a 10) 


\section{QUESTIONÁRIO - PROJETOS}

\begin{tabular}{|c|c|}
\hline $\begin{array}{l}\text { I. } \\
\text { Empresa }\end{array}$ & II. Setor \\
\hline III. Email & IV. Ocupação \\
\hline
\end{tabular}

\begin{tabular}{|c|c|c|c|c|c|c|c|}
\hline $\begin{array}{l}\text { 01. A organização tem uma metodologia de } \\
\text { gestão de projetos formal? }\end{array}$ & $\begin{array}{l}01 \square \operatorname{Sim}, \mathrm{s} \\
\text { extremamen }\end{array}$ & $\begin{array}{l}02 \square \operatorname{Sin} \\
\text { parte for }\end{array}$ & nal sendo & & $\begin{array}{l}03 \square \operatorname{Sim}, n \\
\text { pouco form }\end{array}$ & & $04 \square$ Não tem \\
\hline $\begin{array}{l}\text { 02. Como se divide o trabalho entre projetos } \Theta \\
\text { atividades rotineiras na empresa }\end{array}$ & $\begin{array}{l}01 \square 100 \% \\
\text { rotina }\end{array}$ & $\begin{array}{l}02 \square 75 \% \text { rotina } \\
\text { e } 25 \% \text { projetos }\end{array}$ & $\begin{array}{l}03 \square 50 \\
\text { e } 50 \% p\end{array}$ & $\begin{array}{l}\% \text { rotina } \\
\text { rojetos }\end{array}$ & $\begin{array}{l}04 \square 25 \% \\
\text { e } 75 \% \text { pro }\end{array}$ & $\begin{array}{l}\text { otina } \\
\text { otos }\end{array}$ & $\begin{array}{l}04 \square 100 \% \\
\text { projetos }\end{array}$ \\
\hline $\begin{array}{l}\text { 03. O planejamento estratégico é } \\
\text { implementado através de um processo } \\
\text { formal de definição de projetos e iniciativas } \\
\text { estratégicas? }\end{array}$ & $\begin{array}{l}01 \square \mathrm{Sim}, \\
\text { absolutamente }\end{array}$ & $\begin{array}{l}02 \square \text { Sim, mas } 0 \\
\text { ser melhor integr } \\
\text { processo }\end{array}$ & $\begin{array}{l}\text { veria } \\
\text { do este }\end{array}$ & $03 \square \mathrm{Pc}$ & cialmente & $04 \square$ & Jão \\
\hline
\end{tabular}

04. Qual é o envolvimento da prática de gerenciamento de projetos no processo de implementação de estratégias

05. No planejamento estratégico são
considerados os projetos de:

11. Qual é a porcentagem dos projetos entregues dentro do prazo, custo e qualidade?

12. Quais atividades envolvem os grupos de subprocessos de Iniciação,

Planejamento, Execução e Controle dos

Projetos para a execução das estratégias?

13. Quais atividades de gerenciamento de projetos das áreas do conhecimento são utilizadas para a execução das estratégias? 


\begin{tabular}{|c|c|c|c|c|}
\hline $\begin{array}{l}\text { 14. Quais técnicas de gerenciamento de } \\
\text { projetos a empresa utiliza para a } \\
\text { implementação de estratégias? }\end{array}$ & $\begin{array}{l}01 \square \text { Pontuação de } \\
\text { projetos }\end{array}$ & $\begin{array}{l}02 \square \text { Fluxo de caixa de } \\
\text { projetos }\end{array}$ & $\begin{array}{l}03 \square \text { Abordagem de } \\
\text { opções reais }\end{array}$ & $04 \square$ Project charter \\
\hline $05 \square$ WBS & $\begin{array}{l}06 \square \text { Sequenciamento } \\
\text { de atividades }\end{array}$ & $07 \square$ Gráficos de Gantt & $\begin{array}{l}08 \square \text { Corrente } \\
\text { crítica }\end{array}$ & $09 \square$ Fluxograma \\
\hline $10 \square$ Análise de Monte Carlo & $\begin{array}{l}11 \square \text { Árvore de } \\
\text { decisão }\end{array}$ & $\begin{array}{l}12 \square \text { Matriz de } \\
\text { responsabilidades }\end{array}$ & $\begin{array}{l}13 \square \text { Matriz / } \\
\text { análise de } \\
\text { stakeholders }\end{array}$ & $\begin{array}{l}14 \text { Inventário de } \\
\text { habilidades }\end{array}$ \\
\hline $15 \square$ Gráfico de folgas & $16 \square E V A$ & $\begin{array}{l}17 \text { Mapa de melhoria } \\
\text { da qualidade }\end{array}$ & $\begin{array}{l}18 \square \text { Gráfico de } \\
\text { Pareto }\end{array}$ & $\begin{array}{l}19 \square \text { Diagrama de } \\
\text { causa-efeito }\end{array}$ \\
\hline $\begin{array}{l}\text { 15. O gerenciamento de custo, qualidade, } \\
\text { escopo e prazo estão atrelados as } \\
\text { estratégias genéricas da companhia? }\end{array}$ & $01 \square \mathrm{Sim}$ & $02 \square$ Sim, parcialmente & $03 \square$ Não & \\
\hline $\begin{array}{l}\text { 16. A empresa possui um PMO? Project } \\
\text { management office? }\end{array}$ & \multicolumn{2}{|l|}{$01 \square \mathrm{Sim}$} & \multicolumn{2}{|l|}{$02 \square$ Não } \\
\hline $\begin{array}{l}\text { 17. Quais atividades são realizadas pelo } \\
\text { PMO? }\end{array}$ & $01 \square$ Recrutamento & $\begin{array}{l}02 \square \text { Treinamento e } \\
\text { Desenvolvimento }\end{array}$ & $\begin{array}{l}03 \square \text { Auxiliar os } \\
\text { gerentes de projetos }\end{array}$ & $\begin{array}{l}04 \text { Alocação de gtes } \\
\text { de projeto nos projetos }\end{array}$ \\
\hline $\begin{array}{l}05 \square \text { Avaliação de gerentes } \\
\text { De projeto }\end{array}$ & $\begin{array}{l}06 \square \text { Garantia de } \\
\text { entrega dos produtos } \\
\text { do projeto }\end{array}$ & $\begin{array}{l}07 \text { Padronizar } \\
\text { metodologia de GP }\end{array}$ & $\begin{array}{l}08 \square \text { Centralização } \\
\text { informações e } \\
\text { comunicação }\end{array}$ & $\begin{array}{l}09 \text { Disseminar lições } \\
\text { aprendidas }\end{array}$ \\
\hline
\end{tabular}

\begin{tabular}{|c|c|c|c|c|c|}
\hline \multicolumn{3}{|l|}{ Avaliação da empresa } & \multirow[b]{2}{*}{$\begin{array}{l}\text { Nem concordo, } \\
\text { nem discordo }\end{array}$} & \multirow[b]{2}{*}{$\begin{array}{c}\text { Discordo } \\
\text { parcialmente }\end{array}$} & \multirow[b]{2}{*}{$\begin{array}{l}\text { Discordo } \\
\text { totalmente }\end{array}$} \\
\hline 18. Qual é a sua opinião sobre: & $\begin{array}{l}\text { Concordo } \\
\text { totalmente }\end{array}$ & $\begin{array}{l}\text { Concordo } \\
\text { parcialmente }\end{array}$ & & & \\
\hline $\begin{array}{l}\text { a) A maioria das pessoas sabe distinguir } \\
\text { projetos de atividades que não são projetos }\end{array}$ & & & & & \\
\hline $\begin{array}{l}\text { b) A organização sabe utilizar as técnicas de } \\
\text { gestão de projetos }\end{array}$ & & & 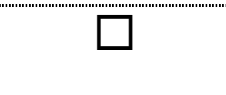 & & $\Gamma$ \\
\hline $\begin{array}{l}\text { c) Quando alguém quer preparar uma } \\
\text { proposta de projeto há um modelo } \\
\text { padronizado ou uma orientação que todos } \\
\text { conhecem }\end{array}$ & & & & & \\
\hline $\begin{array}{l}\text { d) Muitas pessoas sabem preparar um plano } \\
\text { de projeto na empresa }\end{array}$ & & & & & \\
\hline $\begin{array}{l}\text { e) Há procedimentos bem estabelecidos de } \\
\text { aprovação de planos e propostas de projetos }\end{array}$ & 7 & $\square$ & $\square$ & & \\
\hline $\begin{array}{l}\text { f) Nenhum projeto começa sem uma clara } \\
\text { definição das variáveis de desempenho - } \\
\text { escopo, qualidade, prazo e custo }\end{array}$ & & & & & \\
\hline $\begin{array}{l}\text { g) O executivo principal sabe dizer a qualquer } \\
\text { momento, em que situação se encontram os } \\
\text { projetos em andamento }\end{array}$ & 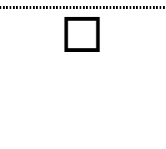 & 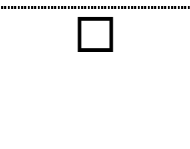 & $\square$ & $\square$ & $\square$ \\
\hline $\begin{array}{l}\text { h) Existe uma função bem definida de gerente } \\
\text { de projeto }\end{array}$ & 5 & $\square$ & $\square$ & 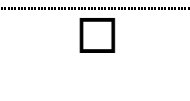 & $\square$ \\
\hline $\begin{array}{l}\text { i) Há um bom número de pessoas preparadas } \\
\text { para desempenhar a função de gerente de } \\
\text { projeto }\end{array}$ & 7 & $\square$ & $\square$ & $\square$ & $\square$ \\
\hline
\end{tabular}




\begin{tabular}{|c|c|c|c|c|c|}
\hline $\begin{array}{l}\text { j) Há uma sequêência bem definida de } \\
\text { procedimentos e pontos de decisão para lidar } \\
\text { com o ciclo de vida do projeto }\end{array}$ & $\square$ & $\square$ & $\square$ & $\square$ & $\square$ \\
\hline $\begin{array}{l}\text { k) As equipes de projetos reúnem-se } \\
\text { regularmente para planejar, executar e } \\
\text { controlar suas atividades }\end{array}$ & $\square$ & $\square$ & $\square$ & $\square$ & $\square$ \\
\hline $\begin{array}{l}\text { I) As responsabilidades dos executivos e } \\
\text { funcionários das áreas funcionais, em relação } \\
\text { ao gerenciamento de projetos, estão bem } \\
\text { definidos }\end{array}$ & $\square$ & $\square$ & $\square$ & $\square$ & $\square$ \\
\hline $\begin{array}{l}\text { m) Sabemos avaliar o desempenho de } \\
\text { projetos e aprender com erros e acertos na } \\
\text { gerencia de projetos }\end{array}$ & $\square$ & $\square$ & $\square$ & $\square$ & $\square$ \\
\hline $\begin{array}{l}\text { n) Há escolha e composição criteriosa da } \\
\text { equipe para execução dos projetos. }\end{array}$ & $\square$ & $\square$ & $\square$ & $\square$ & $\square$ \\
\hline $\begin{array}{l}\text { o) Há envolvimento e comprometimento da } \\
\text { equipe para o alcance dos resultados dos } \\
\text { projetos. }\end{array}$ & $\square$ & $\square$ & $\square$ & $\square$ & $\square$ \\
\hline $\begin{array}{l}\text { p) Há conhecimento, habilidades e atitudes } \\
\text { adequadas da equipe de projetos. }\end{array}$ & $\square$ & $\square$ & $\square$ & $\square$ & $\square$ \\
\hline $\begin{array}{l}\text { q) Há liderança efetiva do gerente de projetos } \\
\text { sobre a equipe. }\end{array}$ & $\square$ & $\square$ & $\square$ & $\square$ & $\square$ \\
\hline $\begin{array}{l}\text { r) Há conhecimento, habilidades e atitudes } \\
\text { adequadas do gerente de projetos. }\end{array}$ & $\square$ & $\square$ & $\square$ & $\square$ & $\square$ \\
\hline $\begin{array}{l}\text { s) Há certificaçôes em gerenciamento de } \\
\text { projetos compatíveis com as necessidades. }\end{array}$ & $\square$ & $\square$ & $\square$ & $\square$ & $\square$ \\
\hline $\begin{array}{l}\text { t) Estrutura organizacional que dê assistência } \\
\text { ao gerente de projetos e a sua equipe } \\
\text { (autoridade e poder necessários) }\end{array}$ & $\square$ & $\square$ & $\square$ & $\square$ & $\square$ \\
\hline $\begin{array}{l}\text { u) Os executivos proporcionam o patrocínio } \\
\text { efetivo durante todo o ciclo de vida do projeto }\end{array}$ & $\square$ & $\square$ & $\square$ & $\square$ & $\square$ \\
\hline $\begin{array}{l}\text { v) Procura-se desenvolver e utilizar } \\
\text { consistente as melhores práticas no } \\
\text { gerenciamento de projetos. }\end{array}$ & $\square$ & $\square$ & $\square$ & $\square$ & $\square$ \\
\hline $\begin{array}{l}\text { W) Há uso efetivo de indicadores de } \\
\text { desempenho de projetos, durante o ciclo de } \\
\text { vida }\end{array}$ & $\square$ & $\square$ & $\square$ & $\square$ & $\square$ \\
\hline $\begin{array}{l}\text { x) Há ferramentas e sistemas de informaçōes } \\
\text { orientadas ao gerenciamento de projetos }\end{array}$ & $\square$ & $\square$ & $\square$ & $\square$ & $\square$ \\
\hline $\begin{array}{l}\text { y) Há informaçôes de qualidade para o } \\
\text { planejamento, acompanhamento e controle } \\
\text { dos projetos }\end{array}$ & $\square$ & $\square$ & $\square$ & $\square$ & $\square$ \\
\hline $\begin{array}{l}\text { z) Ocorre monitoramento e gestão efetiva da } \\
\text { satisfação dos clientes,durante o ciclo de vida } \\
\text { do projeto, quanto aos resultados esperados }\end{array}$ & $\square$ & $\square$ & $\square$ & $\square$ & $\square$ \\
\hline
\end{tabular}




\begin{tabular}{|c|c|c|c|c|c|}
\hline $\begin{array}{l}\text { Áreas do } \\
\text { conhecimento - } \\
\text { gerenciamento de } \\
\text { projetos }\end{array}$ & $\begin{array}{l}\text { Processos iniciais / } \\
\text { Linguagem comum }\end{array}$ & Processos comuns & \begin{tabular}{|} 
Metodologia singular $/$ \\
Processos \\
Institucionalizados e \\
Padrões Organiz.
\end{tabular} & $\begin{array}{l}\text { Processos } \\
\text { Gerenciados / } \\
\text { Benchmarking }\end{array}$ & $\begin{array}{c}\text { Melhoria Contínua I } \\
\text { Processos de } \\
\text { Otimização }\end{array}$ \\
\hline $\begin{array}{l}\text { Gerenciamento } \\
\text { da integração }\end{array}$ & $\begin{array}{l}\square \text { Não há prática, } \\
\text { padrão ou PMO } \\
\text { estabelecido. O } \\
\text { trabalho é feito } \\
\text { pontualmente ou } \\
\text { conforme necessidade. }\end{array}$ & $\begin{array}{l}\square \text { Há documentação } \\
\text { básica dos processos } \\
\text { para o planejamento e } \\
\text { monitoramento do } \\
\text { projeto. A Alta Direção } \\
\text { é envolvida somente } \\
\text { em projetos de alta } \\
\text { visibilidade / grande } \\
\text { porte. }\end{array}$ & $\begin{array}{l}\square \text { As iniciativas de } \\
\text { integração do projeto } \\
\text { são institucionalizadas, } \\
\text { incluindo procedimentos } \\
\text { e padrões. O Project } \\
\text { Office começa a } \\
\text { integrar os dados dos } \\
\text { projetos. }\end{array}$ & $\begin{array}{l}\square \text { São utilizados } \\
\text { processos / padrões } \\
\text { para todos os projetos } \\
\text { e são integrados com } \\
\text { os processos e } \\
\text { sistemas corporativos. } \\
\text { Decisões são } \\
\text { baseadas em } \\
\text { métricas de } \\
\text { desempenho }\end{array}$ & $\begin{array}{l}\square \text { São utilizados } \\
\text { procedimentos para } \\
\text { melhoria da integração } \\
\text { do projeto. Lições } \\
\text { aprendidas são } \\
\text { regularmente } \\
\text { revisitadas e utilizadas } \\
\text { para melhorar os } \\
\text { processos } \\
\text { documentados }\end{array}$ \\
\hline $\begin{array}{l}\text { Gerenciamento } \\
\text { do escopo }\end{array}$ & $\begin{array}{l}\square \text { Há requerimentos } \\
\text { gerais de negócio. Não } \\
\text { há ou há em menor } \\
\text { escala a gestão do } \\
\text { escopo ou } \\
\text { documentação. A Alta } \\
\text { Direção está apar } \\
\text { somente dos principais } \\
\text { marcos do projeto. }\end{array}$ & $\begin{array}{l}\square \text { Há gerenciamento } \\
\text { básico do escopo. As } \\
\text { técnicas de } \\
\text { gerenciamento do } \\
\text { escopo são aplicadas } \\
\text { regularmente em } \\
\text { projetos de grande } \\
\text { porte ou de alta } \\
\text { visibilidade. }\end{array}$ & $\begin{array}{l}\square \text { Há processo de } \\
\text { gerenciamento } \\
\text { inteiramente } \\
\text { documentado e utilizado } \\
\text { na maioria dos projetos. } \\
\text { Os stakeholders } \\
\text { participam ativamente } \\
\text { nas decisões de } \\
\text { escopo. }\end{array}$ & $\begin{array}{l}\square \text { Os processos de } \\
\text { gerenciamento são } \\
\text { utilizados em todos os } \\
\text { projetos. Os projetos } \\
\text { gerenciados e } \\
\text { avaliados à luz de } \\
\text { outros projetos. }\end{array}$ & $\begin{array}{l}\square \text { Medidas de } \\
\text { efetividade e eficiência } \\
\text { guiam as decisões } \\
\text { relativas ao } \\
\text { gerenciamento do } \\
\text { escopo. Foco na alta } \\
\text { utilização do valor. }\end{array}$ \\
\hline $\begin{array}{l}\text { Gerenciamento } \\
\text { do tempo }\end{array}$ & $\begin{array}{l}\square \text { Não há } \\
\text { planejamento ou } \\
\text { padrão estabelecido } \\
\text { para o gerenciamento } \\
\text { do tempo. Falta } \\
\text { documentação cria } \\
\text { dificuldade para atingir } \\
\text { sucessos em projetos } \\
\text { repetitivos. }\end{array}$ & $\begin{array}{l}\square \text { Existe processos } \\
\text { básicos mas não o } \\
\text { necessário para o } \\
\text { planejamento do } \\
\text { tempo. Há padrões de } \\
\text { para projetos de } \\
\text { grande porte ou de } \\
\text { alta visibilidade. }\end{array}$ & $\begin{array}{l}\text { Os processos de } \\
\text { gerenciamento do } \\
\text { tempo são } \\
\text { documentados e } \\
\text { utilizados para a maioria } \\
\text { dos projetos. Há } \\
\text { integração do projeto } \\
\text { com a organização } \\
\text { incluindo a relação de } \\
\text { dependência entre } \\
\text { projetos. }\end{array}$ & $\begin{array}{l}\square \text { O gerenciamento } \\
\text { do tempo utilize } \\
\text { dados históricos para } \\
\text { prever o desempenho } \\
\text { (em projetos) futuros. } \\
\text { As decisões da alta } \\
\text { direção são baseadas } \\
\text { em métricas de } \\
\text { eficiência e eficácia. }\end{array}$ & $\begin{array}{l}\square \text { Há processo de } \\
\text { melhoria contínua dos } \\
\text { procedimentos } \\
\text { utilizados para o } \\
\text { gerenciamento do } \\
\text { tempo. Lições } \\
\text { aprendidas são } \\
\text { examinadas e utilizadas } \\
\text { para melhorar os } \\
\text { processos } \\
\text { documentados. }\end{array}$ \\
\hline $\begin{array}{l}\text { Gerenciamento } \\
\text { do custo }\end{array}$ & $\begin{array}{l}\square \text { Não há práticas ou } \\
\text { padrões estabelecidos. } \\
\text { A documentação dos } \\
\text { processos de custos é } \\
\text { pontual ou é realizado } \\
\text { conforme necessidade, } \\
\text { e as equipes do projeto } \\
\text { seguem práticas } \\
\text { informais. }\end{array}$ & $\begin{array}{l}\square \text { Existe processo } \\
\text { para estimar, controlar } \\
\text { e a gestão do } \\
\text { desempenho dos } \\
\text { custos. O } \\
\text { gerenciamento dos } \\
\text { processos de custos } \\
\text { são utilizados em } \\
\text { projetos de grande } \\
\text { porte ou de alta } \\
\text { visibilidade. }\end{array}$ & $\begin{array}{l}\square \text { Os processos de } \\
\text { gerenciamento de } \\
\text { custos são } \\
\text { padronizados e } \\
\text { utilizados na maioria } \\
\text { dos projetos. Os custos } \\
\text { são inteiramente } \\
\text { integrados com as } \\
\text { fontes de recursos do }\end{array}$ & $\begin{array}{l}\square \text { O planejamento e } \\
\text { acompanhamento dos } \\
\text { custos são integrados } \\
\text { com o PMO e os } \\
\text { sistemas de RH e } \\
\text { financeiros. Os } \\
\text { processos estão } \\
\text { integrados com os } \\
\text { processos } \\
\text { corporativos. }\end{array}$ & $\begin{array}{l}\square \text { As lições } \\
\text { aprendidas melhoram } \\
\text { os processos } \\
\text { documentados. A Alta } \\
\text { Direção ativamente } \\
\text { utilize métricas de } \\
\text { eficiência e eficácia } \\
\text { para a tomada de } \\
\text { decisão. }\end{array}$ \\
\hline
\end{tabular}




\begin{tabular}{|c|c|c|c|c|c|}
\hline $\begin{array}{l}\text { Gerenciamento } \\
\text { da qualidade }\end{array}$ & $\begin{array}{l}\square \text { Não há padrão ou } \\
\text { prática estabelecida do } \\
\text { gerenciamento da } \\
\text { qualidade. A Alta } \\
\text { Direção está } \\
\text { procurando definir o } \\
\text { que é qualidade. }\end{array}$ & $\begin{array}{l}\square \text { É adotado uma } \\
\text { política básica da } \\
\text { qualidade do projeto. } \\
\text { A Alta Direção } \\
\text { encoraja a aplicação } \\
\text { da política da } \\
\text { qualidade em grandes } \\
\text { projetos ou de alta } \\
\text { visibilidade. }\end{array}$ & $\begin{array}{l}\square \text { Os processos da } \\
\text { qualidade são } \\
\text { documentados e são } \\
\text { definidos como padrão } \\
\text { dentro da organização. } \\
\text { A Alta Direção é } \\
\text { envolvida na visão geral } \\
\text { da maioria dos projetos. }\end{array}$ & $\begin{array}{l}\square \text { Todos os } \\
\text { projetos requerem o } \\
\text { uso de uma } \\
\text { metodologia de } \\
\text { processos de } \\
\text { planejamento da } \\
\text { qualidade. O PMO } \\
\text { coordena e assegura } \\
\text { os padrões de } \\
\text { qualidade }\end{array}$ & $\begin{array}{l}\square \text { Os processos da } \\
\text { qualidade incluem os } \\
\text { guias para a coleta de } \\
\text { melhorias para o } \\
\text { processo. As métricas } \\
\text { são chaves para a } \\
\text { tomada de decisão da } \\
\text { qualidade do produto. }\end{array}$ \\
\hline $\begin{array}{l}\text { Gerenciamento } \\
\text { dos Recursos } \\
\text { Humanos }\end{array}$ & $\begin{array}{l}\square \text { Não há processos } \\
\text { repetitivos aplicados } \\
\text { para o planejamento de } \\
\text { recursos humanos. As } \\
\text { equipes de projetos são } \\
\text { pontuais e conforme } \\
\text { demanda. Os custos e } \\
\text { os tempos dos recursos } \\
\text { humanos não são } \\
\text { mensurados. }\end{array}$ & $\begin{array}{l}\square \text { Há processos } \\
\text { passíveis de repetição } \\
\text { que define como } \\
\text { planejar e gerenciar os } \\
\text { recursos humanos. Há } \\
\text { acompanhamento dos } \\
\text { recursos somente para } \\
\text { projetos de alta } \\
\text { visibilidade. }\end{array}$ & $\begin{array}{l}\square \text { A maioria do } \\
\text { projeto segue } \\
\text { processos } \\
\text { estabelecidos de } \\
\text { gerenciamento de } \\
\text { recursos humanos. Há } \\
\text { programas de } \\
\text { desenvolvimento } \\
\text { profissional } \\
\text { estabelecidos para a } \\
\text { carreira de gerente de } \\
\text { projetos. }\end{array}$ & $\begin{array}{l}\square \text { Há previsão de } \\
\text { recursos utilizados } \\
\text { para planejar e } \\
\text { priorizar projetos. O } \\
\text { desempenho da } \\
\text { equipe do projeto é } \\
\text { mensurado e } \\
\text { integrado com o } \\
\text { desenvolvimento de } \\
\text { carreira. }\end{array}$ & $\begin{array}{l}\square \text { O processo de } \\
\text { gerenciamento de } \\
\text { projetos engaja as } \\
\text { equipes de projetos } \\
\text { para realizarem a } \\
\text { documentação das } \\
\text { lições aprendidas. A } \\
\text { melhoria contínua é } \\
\text { incorporada no } \\
\text { processo de } \\
\text { gerenciamento do } \\
\text { recursos humanos. }\end{array}$ \\
\hline $\begin{array}{l}\text { Gerenciamento } \\
\text { da comunicação }\end{array}$ & $\begin{array}{l}\square \text { A comunicação é } \\
\text { feita pontualmente ou } \\
\text { conforme necessidade, } \\
\text { procurando oferecer } \\
\text { pelo menos o status } \\
\text { atual do projeto de } \\
\text { forma informal. }\end{array}$ & $\begin{array}{l}\square \text { São adotados } \\
\text { alguns processos } \\
\text { básicos. Projetos de } \\
\text { grande porte ou alta } \\
\text { visibilidade seguem os } \\
\text { processos de } \\
\text { comunicação e } \\
\text { oferece status do } \\
\text { progresso mostrando } \\
\text { inclusive as restrições } \\
\text { do projeto. }\end{array}$ & $\begin{array}{l}\square \text { A Alta Direção tem } \\
\text { um envolvimento ativo } \\
\text { no desempenho do } \\
\text { projeto. A maioria dos } \\
\text { projetos executa um } \\
\text { plano formal de } \\
\text { comunicação. }\end{array}$ & $\begin{array}{l}\square \text { O plano de } \\
\text { gerenciamento de } \\
\text { comunicação é } \\
\text { utilizado em todos os } \\
\text { projetos. O plano de } \\
\text { comunicação é } \\
\text { integrado com a } \\
\text { estrutura corporativa } \\
\text { de comunicação. }\end{array}$ & $\begin{array}{l}\square \text { Há um processo d } \\
\text { melhoria continua do } \\
\text { gerenciamento da } \\
\text { comunicação no } \\
\text { projetos. As lições } \\
\text { aprendidas são } \\
\text { capturadas e } \\
\text { incorporadas. }\end{array}$ \\
\hline $\begin{array}{l}\text { Gerenciamento } \\
\text { do risco }\end{array}$ & $\begin{array}{l}\square \text { Não há padrão ou } \\
\text { prática estabelecida do } \\
\text { gerenciamento do } \\
\text { risco. A documentação } \\
\text { dos riscos é mínima e } \\
\text { os resultados não são } \\
\text { compartilhados. A } \\
\text { resposta ao risco é } \\
\text { reativa. }\end{array}$ & $\begin{array}{l}\square \text { Os processos de } \\
\text { gerenciamento são } \\
\text { documentados e } \\
\text { utilizados em projetos } \\
\text { de grande porte. A } \\
\text { Alta Direção é } \\
\text { consistemente } \\
\text { envolvida com os } \\
\text { riscos de grandes } \\
\text { projetos ou de alta } \\
\text { visibilidade. }\end{array}$ & $\begin{array}{l}\square \text { o processo de } \\
\text { gerenciamento de } \\
\text { riscos é utilizado na } \\
\text { maioria dos projetos. } \\
\text { São utilizadas métricas } \\
\text { para suportar as } \\
\text { decisões de riscos no } \\
\text { nível do projeto e de } \\
\text { programa. }\end{array}$ & $\begin{array}{l}\square \text { A Alta Direção é } \\
\text { envolvida ativamente } \\
\text { na gestão dos riscos } \\
\text { da organização. Os } \\
\text { sistemas de risco são } \\
\text { integrados com os } \\
\text { sistemas de tempo, } \\
\text { custo e recursos. }\end{array}$ & $\begin{array}{l}\square \text { Os processos de } \\
\text { melhoria contínua são } \\
\text { utilizados para } \\
\text { assegurar que os } \\
\text { projetos são } \\
\text { continuamente } \\
\text { mensurados e } \\
\text { gerenciados com base } \\
\text { em métricas de } \\
\text { desempenho e valor } \\
\text { agregado. }\end{array}$ \\
\hline
\end{tabular}




\begin{tabular}{|c|c|c|c|c|c|}
\hline $\begin{array}{l}\text { Gerenciamento } \\
\text { das aquisições }\end{array}$ & $\begin{array}{l}\square \text { Não há processo } \\
\text { estabelecido de } \\
\text { aquisições. Os } \\
\text { métodos são pontuais e } \\
\text { conforme necessidade. } \\
\text { Os contratos são } \\
\text { gerenciados somente } \\
\text { após a entrega. }\end{array}$ & $\begin{array}{l}\square \text { Há processos } \\
\text { básicos documentados } \\
\text { para compras de } \\
\text { produtos e serviços. } \\
\text { Há processo de } \\
\text { aquisições somente } \\
\text { para grandes projetos } \\
\text { ou de alta visibilidade. }\end{array}$ & $\begin{array}{l}\square \text { Há processo } \\
\text { organizacional } \\
\text { padronizado e utilizado } \\
\text { pela maioria dos } \\
\text { projetos. A equipe do } \\
\text { projeto e o } \\
\text { departamento estão } \\
\text { integrados em um } \\
\text { processo de aquisições. }\end{array}$ & $\begin{array}{l}\square \text { As decisões de } \\
\text { fazer/comprar são } \\
\text { feitas na perspectiva } \\
\text { da organização. O } \\
\text { fornecedor está } \\
\text { integrada nos } \\
\text { mecanismos de } \\
\text { gerenciamento de } \\
\text { projetos da } \\
\text { organização. }\end{array}$ & $\begin{array}{l}\square \text { O processo de } \\
\text { aquisição é revisto } \\
\text { periodicamente. A } \\
\text { melhoria contínua foca } \\
\text { nas métricas de } \\
\text { eficiência e eficácia das } \\
\text { aquisições }\end{array}$ \\
\hline
\end{tabular}

